\title{
Molecular characterization of ion channel subunits in the normal and remodeled canine hear
}

Citation for published version (APA):

Ramakers, C. R. B. (2005). Molecular characterization of ion channel subunits in the normal and remodeled canine hear. [Doctoral Thesis, Maastricht University]. Maastricht University. https://doi.org/10.26481/dis.20050311cr

Document status and date:

Published: 01/01/2005

DOI:

$10.26481 /$ dis. $20050311 \mathrm{cr}$

Document Version:

Publisher's PDF, also known as Version of record

\section{Please check the document version of this publication:}

- A submitted manuscript is the version of the article upon submission and before peer-review. There can be important differences between the submitted version and the official published version of record.

People interested in the research are advised to contact the author for the final version of the publication, or visit the DOI to the publisher's website.

- The final author version and the galley proof are versions of the publication after peer review.

- The final published version features the final layout of the paper including the volume, issue and page numbers.

Link to publication

\footnotetext{
General rights rights.

- You may freely distribute the URL identifying the publication in the public portal. please follow below link for the End User Agreement:

www.umlib.nl/taverne-license

Take down policy

If you believe that this document breaches copyright please contact us at:

repository@maastrichtuniversity.nl

providing details and we will investigate your claim.
}

Copyright and moral rights for the publications made accessible in the public portal are retained by the authors and/or other copyright owners and it is a condition of accessing publications that users recognise and abide by the legal requirements associated with these

- Users may download and print one copy of any publication from the public portal for the purpose of private study or research.

- You may not further distribute the material or use it for any profit-making activity or commercial gain

If the publication is distributed under the terms of Article $25 \mathrm{fa}$ of the Dutch Copyright Act, indicated by the "Taverne" license above, 
Molecular characterisation of ion channel subunits in the normal and remodeled canine heart 
(C) Christian Ramakers, Maastricht 2005

ISBN 90-9018442-2

Cover: Stray dog, Misawa, Aomori (Daido Moriyama, 1971) 


\section{Molecular characterisation of ion channel subunits in the normal and remodeled canine heart}

\section{PROEFSCHRIFT}

ter verkrijging van de graad van doctor aan de Universiteit Maastricht, op gezag van de Rector Magnificus, Prof. mr. G.P.M.F. Mols, volgens het besluit van het College van Decanen, in het openbaar te verdedigen op vrijdag 11 maart 2005 om 12:00 uur

door

\section{Christian Ramakers}

geboren op 20 april 1973 in Maastricht 


\section{Promotores:}

Prof dr. M.A. Vos

Prof. dr. A.F.M. Moorman (Universiteit van Amsterdam)

\section{Beoordelingscommissie:}

Prof. dr. M.J.A.P. Daemen (voorzitter)

Prof. dr. M.A. Allessie

Prof. dr. J.M. de Bakker (Universiteit van Amsterdam)

Prof. dr. H.J.G.M. Crijns

Prof. dr. P.A.F.M. Doevendans (Universiteit Utrecht)

Financial support by the Netherlands Heart Foundation, J.E. Jurriaanse Stichting, Jacques $H$. de Jong Stichting and Stichting RESCAR Maastricht for the publication of this thesis is gratefully acknowledged.

Additional support was granted by St. Jude Medical Nederland B.V. and Roche Diagnistics B.V. 
The great tragedy of science: the slaying of a beautiful theory by an ugly fact. Thomas Hensy Huxtery

\section{Voor Eric}

(*) I nimei $1970-(+) 9$ fiebruari 1986 



\section{CONTENT}

9

\section{Chptr 1}

General Introduction

35

Chptr 2

Coordinated down-regulation of KCNQ1 and KCNE1 expression contributes to reduction of $I_{K s}$ in canine hypertrophied hearts

55

\section{Chptr 3}

Assumption free analysis of quantitative real-time PCR data

65

\section{Chptr 4}

Quantification of mRNA using inear regression of Log-linear PCR data-points as an alternative for the standard curve approach

$77 \quad$ Chptr 5

Asynchronous development of electrical remodelling and cardiac hypertrophy in the complete AV block dog

95

\section{Chptr 6}

Molecular and electrical characterization of the canine cardiac ventricular septum

$111 \quad$ Chptr 7

$I_{K s}$ downregulation and blunted $\beta$-adrenergic activation in canine ventricular remodeling confer the loss of $\beta$-adrenergic-induced shortening of repolarization, favoring proarrhythmia

$129 \quad$ Chptr 8

General Discussion

145 Summary

149 Samenvatting

153 Publications \& Abstracts

157 Curriculum vitae 



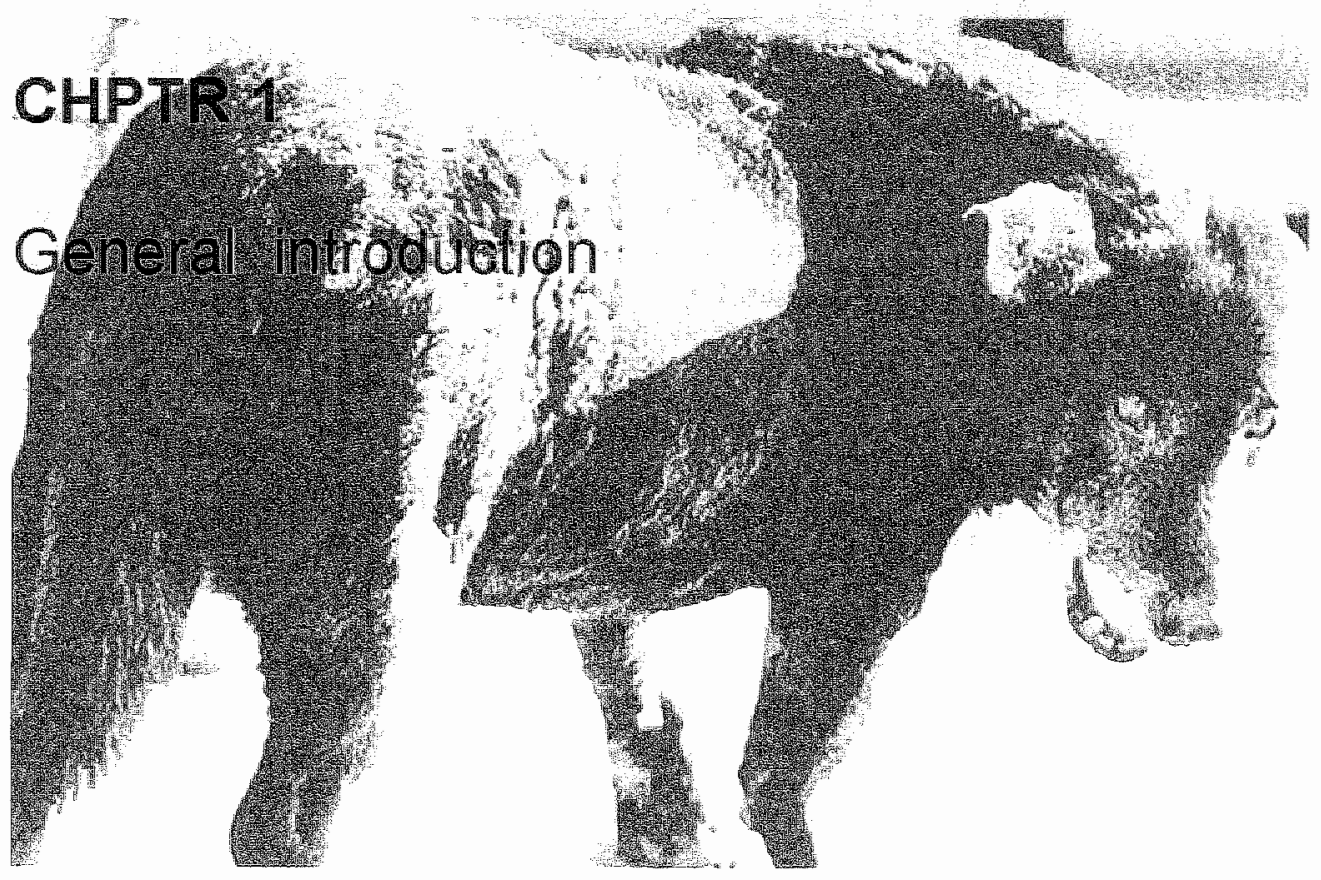




\section{Electrical properties of the heart}

Like all muscles, the heart is "born to contract". With a normal healthy frequency of 80 contractions per minute and an average human lifespan in The Netherlands of 78.4 years, the heart will contract $3,296,563,200(-3.3$ billion) times (1).

The synchronous contraction of the heart is initiated by electrical impulses that originate from distinct areas within the heart. These so-called nodes are populated mainly by pacemaker cells, which are under the regulation of the autonomic nervous system (vagal and sympathetic innervation). There are two distinct nodes in the heart. Located near the superior caval vein (vena cava superior) in the right atrium, the sino-atrial node (SA node) is responsible for generating an electrical impulse that is conveyed to all atrial myocytes, leading to a coordinated contraction of the atria. The second node, the so-called atrio-ventricular node ( $A V$ node) located near the top of the ventricular septum and the dorsal wall of the atrium, is responsible for delaying the electrical impulse coming from the atria and, via the Purkinje fibers, conveying it to all ventricular myocytes, leading to a coordinated contraction of the ventricles. Next to the dominant SA and AV node, other less dominant areas within the atria and ventricles exhibit automaticity. However due to the dominant nature of the SA and AV node (e.g. higher intrinsic rate) these areas do not have a physiological function and only come into play when either the SA or the AV node fail (e.g. SA or AV block). For instance, ablation of the AV node in the chronic atrio-ventricular block (CAVB) dog results in a lower ventricular rate that originates from an ectopic focus somewhere within the Purkinje system.

The complete electrical activity of one contraction cycle of the heart is represented in an electrocardiogram (ECG) (Figure 1, bottom). The ECG is build up out of 5 waves. The contraction of the atria (atrial depolarization) is recognized on an ECG as the P-wave. Ventricular contraction (ventricular depolarization) is the product of two temporally overlapping processes, i.e. endocardial and transmural activation, and results in the characteristic QRS complex (e.g. Q wave, R wave and S wave). Ventricular relaxation (repolarization) proceeds from the epicardial surface to the endocardium and is represented in the T wave.

While the ECG embodies the total electrical activity of the whole heart, the action potential (AP) represents the electrical activity of a single cardiomyocyte (Figure 1). The fundamental origin of the electrical excitability of cardiomyocytes lies in the fact that the hydrophobic lipid bi-layer, which constitutes the cell membrane, electrically separates the interior of a cardiomyocyte from its surrounding. Differences in ionic composition between the interior of a cell and its surrounding therefore result in a potential difference, which is commonly referred to as the membrane potential. The negative resting membrane potential of cardiomyocytes varies between -60 to $-90 \mathrm{mV}$, depending upon its location and function within the heart. A change in the membrane potential indicates that there is trafficking of ions over the hydrophobic lipid bi-layer. This trafficking is facilitated by ion channels. The meticulously orchestrated opening and closing of these ion channels results in the distinct AP profile.

Based on electrical function, there are roughly two types of cardiomyocytes: 1) pacemaker cells and 2) non-pacemaker cells. The non-pacemaker cells can be 
further subdivided in atrial, Purkinje and ventricular cardiomyocytes. These four types of cardiomyocytes (e.g pacemaker, atrial; Purkinje and ventricular) have distinct AP characteristics . A typical AP of a ventricular cardiomyocyte (non-pacemaker cell) shows a rapid initial depolarization (phase 0), a quick partial repolarization (phase 1) and then a "plateau" voltage near zero (phase 2) which is maintained for several hundred milliseconds. By contrast, the AP of neurons and skeletal muscle last only a few milliseconds. This plateau is then followed by a rapid repolarization phase (phase 3) which returns the membrane potential to its resting membrane potential (phase 4).

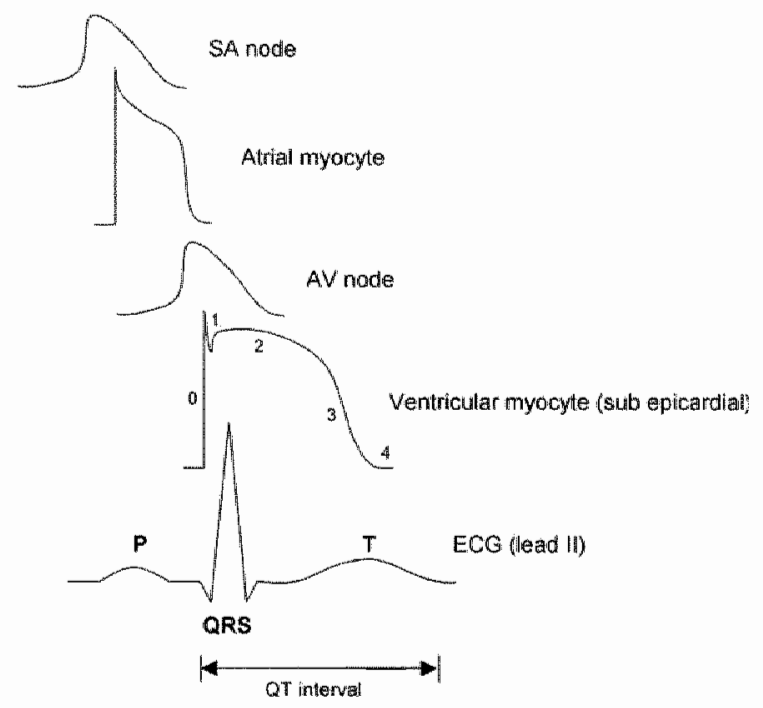

Figure 1 Action potential characteristics of the different cardiomyocytes (pacemaker and non-pacemakers cells) within the heart and an accompanying (schematic) ECG lead (II). For more details see the text.

Since the development in 1903 of the first practical device for recording cardiac potentials by Willem Einthoven (1860-1927), clinicians have used the ECG as a diagnostic tool to detect abnormalities in the impulse generation and conduction of the heart. These abnormalities are commonly referred to as arrhythmias. In general, arrhythmias can be divided in bradyarrhythmias (bradycardia), in which the heart rate is too low (adult heart: $<60$ beats/minute) and tachyarrhythmias (tachycardia), in which the heart rate is too high (adult heart: $>100$ beats/minute). In both severe cases, blood pressure cannot be maintained leading to loss of consciousness (syncope) and in the extreme case, sudden death.

The underlying mechanisms leading to arrhythmias are very diverse. An important risk factor in the generation of an arrhythmic event is the prolongation of the QT time. On a cellular level this QT time (Figure 1: ECG) can be translated into the duration of a ventricular AP. An increase in the AP duration (APD) can be dangerous in two ways: 1) a prolonged APD is often related to a prolonged plateau phase (phase 2) and therefore to a more labile repolarization, and can initiate a secondary depolarization (phase 0 ) prior to the completion of the primary AP. This so-called 
early-afterdepolarization (EAD) can generate an ectopic beat. The occurrence of multiple ectopic beats within a short period of time can result in an arrhythmia. 2) An intiomogeneous (e.g. region specific) prolongation of the APD (a.k.a. dispersion of repolarization) will disturb the natural balance of differences in APD between the various areas in the heart. This disturbance can have an influence on the normal impulse conduction, leading to EAD induced re-entrant beats, which can lead to an arrhythmia.

\section{The ventricular AP: ion channels \& molecular correlates}

Although the different ion channels are discussed within the context of the distinct AP phases, a certain amount of overlap in ion channel activity between the AP phases has to be considered. For an overview of the important ion channels and molecular correlates involved in the cardiac AP see table 1.

\subsection{AP depolarization}

The large depolarizing step from $-80 \mathrm{mV}$ to $+20 \mathrm{mV}$ (e.g. phase 0 , upstroke) is generated by a large influx of $\mathrm{Na}^{+}$ions through the voltage gated $\mathrm{Na}^{+}$channel ( $I_{\mathrm{N} \text { G }}$ ) (inward current). The human $\mathrm{Na}^{+}$channel $\left(\mathrm{Na}_{v} 1.5\right)$, which is encoded by the SCN5A gene, consists of an $\alpha$ subunit of approximately $227 \mathrm{kDa}$ and contains four homologous domains termed I-IV (Figure 2A). Within each domain, there are six transmembrane segments called S1-S6, and a hairpin-like $\mathrm{P}$ loop between $\mathrm{S} 5$ and S6 that comprises part of the channel pore. Voltage dependent gating is facilitated by a group of charged amino acids located in the $\mathrm{S} 4$ segment (voltage sensor) of each domain. The $\alpha$ subunit is associated with accessory subunits in the tissues of certain species, such as the $\beta$ subunits in mammals (2) and the tipE subunits in flies (3). In mammalian ventricular cardiomyocytes the preferential $\beta$ subunits are beta2 and beta4.

\subsection{Early repolarization}

Upon depolarization a short period of repolarization (phase 1) is initiated by the partial closure of $\mathrm{I}_{\mathrm{Na}}$ channels in combination with the opening of the transient outward $\mathrm{K}^{+}$channel $\left(\mathrm{I}_{\text {TO1 }}\right)$ allowing an efflux of $\mathrm{K}^{+}$ions (outward current). This $\sim 73$ kDa Kv4.3 channel protein (related to the Drosophila Shal-subfamily) is encoded by the KCND3 gene and is part of the class of $\mathrm{K}^{+}$channel subunits that consists of six transmembrane segments (S1-S6) (Figure 2C). Similar to the $\mathrm{Na}^{*}$ channel, the pore region of the channel is located between S5 and S6, while the voltage sensor is located in the $\mathrm{S} 4$ segment. In contrast to the $\mathrm{Na}^{+}$channel, a mature channel is formed by the assembly of four subunits of either Kv4.3 or the closely related Kv4.2 into a homo- or heterotetrameric channel. Where the Kv4.3 homomeric channels seem to represent the $\mathrm{I}_{\mathrm{TO} 1}$ current, heteromeric Kv4.3-Kv4.2 channels seem to underlie the $I_{\text {ro,fast }}$ current (4). Important for the functional characteristics of the transient outward $\mathrm{K}^{+}$channel is the co-assembly with its $\beta$ subunit KChIP2 $(\sim 31 \mathrm{kDa})$, encoded by 
the KCNIP2 gene. The importance of KChIP2 co-assembly was shown in a murine knock-out model in which the absence of KChIP2 lead to a complete loss of the $I_{\text {tot }}$ current, predisposing homozygous ( $\mathrm{KChIP} 2^{*}$ ) mice to ventricular arrhythmias (5). Based on electron microscopy experiments, a mature homomeric Kv4.2 channel consists of a 4:4 channel complex, in which each Kv4.2 $\alpha$ subunit assembles with a single KChIP2 $\beta$ subunit (6).

Adding to the complexity of co-assembly is the fact that already eight alternatively spliced isoforms of KChIP2 have been described on PubMed. Functionally, these different isoforms can change the characteristics of the transient outward $\mathrm{K}^{+}$channel in a way that they can reduce or increase the current amplitude of $\mathrm{I}_{\mathrm{TO} 1}$ and accelerate or slow the rate of inactivation or recovery of inactivation (7). However, whether or not all these isoforms are relevant for the in vivo function of the channel in the ventricles remains unclear.

\subsection{Plateau phase}

The characteristic ventricular plateau (phase 2) is largely caused by various ion channels that generate opposing currents (outward vs. inward). Two important inward current generating channels are the L-type $\mathrm{Ca}^{2+}$ channel and the $\mathrm{Na}^{+}-\mathrm{Ca}^{2+}$ exchanger NCX. The cardiac L-type $\mathrm{Ca}^{2+}$ channel is formed by the $\mathrm{Ca}_{\mathrm{v}} 1.2$ protein $(\sim 249 \mathrm{kDa})$ and is encoded by the CACNA1C gene. Of all the ion channels involved in shaping the $\mathrm{AP}$, the $\mathrm{Ca}^{2+}$ channels are structurally the most complex. The voltageactivated $\mathrm{Ca}^{2+}$ channels that have been characterized are complexes of a poreforming $\alpha_{4}$ subunit; a transmembrane, disulfide-linked complex of $\alpha_{2}$ and $\delta$ subunits $\left(\alpha_{2} \delta\right)$; an intracellular $\beta$ subunit and a transmembrane $\gamma$ subunit (8). Structurally, the $\alpha 1$ subunit resembles the pore forming $\alpha$ subunit of the $\mathrm{Na}_{\mathrm{v}} 1.5$ channel with 4 domains (I-IV) consisting of 6 transmembrane segments (Figure 2A). The $\alpha 1$ subunit is sufficient to produce functional $\mathrm{Ca}^{2+}$ channels, but with low expression levels and abnormal kinetics and voltage dependence (9). Co-expression of the $\alpha_{2} \delta$ subunit

A

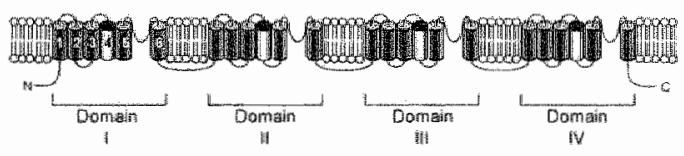

B

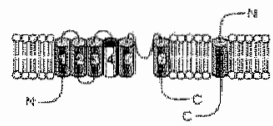

Figure 2. Schematic representation of sorne of the important ion charnel subunits Involved in shaping the ventricular action potential. For

C

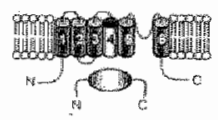

D

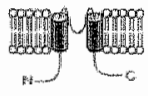

the potassilum channels $B$ and

C) a functionall chaninel is formed by four a-subunits (homomeric or heteromertic tetramers). For most potassium channels the interaction with subunits (e.g. Mink, MiRP. 1. KChIP2) is crudid for channe: function. 
and especially the $\beta$ subunit enhances the level of expression and confers more normal gating properties (10). There are four known $\beta$ subunit genes ( $\beta 1$ through B4), which give rise to a total of eighteen different isoforms. Co-localization studies with the $\alpha 1$ and $\beta 1-4$ isoform subunits suggest differential subcellular localization of L-type $\mathrm{Ca}^{2+}$ channels (11). For the $\gamma$ subunit, 8 different genes have been described. Whether or not all these subunit genes translate into proteins with a relevant function in cardiac tissue is unknown.

The second important inward current during the plateau is generated by the action of the $\mathrm{Na}^{+}-\mathrm{Ca}^{2+}$ exchanger $\mathrm{NCX}(\sim 109 \mathrm{kDa})$, which is encoded by the SLC8A1 gene. The mammalian $\mathrm{NCX}$ forms a multigene family of homologous proteins comprising 3 isoforms: $\mathrm{NCX} 1$ (12), $\mathrm{NCX} 2(13)$, and $\mathrm{NCX} 3$ (14). These isoforms share $-70 \%$ amino acid identity in the overall sequences and thus presumably have a very similar molecular structure. NCX1 is the first NCX cloned and is highly expressed in cardiac muscle and brain, and to a lesser extent in a variety of other tissues. NCX2 and NCX3 are not expressed in adult rat heart at the protein level, but a NCX2-specific transcript can be detected faintly by using reverse transcriptase-PCR (15). NCX2 and NCX3 are expressed in a few limited tissues, such as brain, and their molecular properties and functions remain unclear. Functionally, NCX catalyses the exchange of $3 \mathrm{Na}^{+}$for $1 \mathrm{Ca}^{2+}$ ion across the plasma membrane in either the $\mathrm{Ca}^{2+}$-efflux or $\mathrm{Ca}^{2+}$ influx (reverse) mode, depending on the electrochemical gradients of the substrate ions. Based on ion affinity studies it has been shown that the affinity for intracellular $\mathrm{Ca}^{2+}$ is hundred times higher than for extracellular $\mathrm{Ca}^{2+}(16)$, therefore the primary function of $\mathrm{NCX}$ in the heart is extrusion of $\mathrm{Ca}^{2+}$ from myocytes during relaxation and diastole, which generates an inward current and in addition balances $\mathrm{Ca}^{2+}$ entry via $\mathrm{Ca}_{\sqrt{ }} 1.2$ channels during cardiac excitation.

As already mentioned in the beginning of this paragraph, in the plateau the inward currents are counterbalanced by outward currents. These outward currents are generated mainly by the efflux of $\mathrm{K}^{+}$through opening of two voltage dependent potassium currents which will be discussed in detail in the next paragraph.

\subsection{Repolarization}

With the continuing efflux of $\mathrm{K}^{+}$and the closing of the inward current generating channels, the characteristic ventricular AP plateau comes to an end, thereby introducing the final repolarizing phase of the AP (phase 3 ) to its resting membrane potential (phase 4). Although first identified as a single potassium current (17), the delayed rectifier current $I_{K}$ is composed of two distinct components: the rapidly activating $I_{K_{r}}$ and more slowly developing $I_{K s}(18)$. Moleculary, the $I_{K r}$ and $I_{K s}$ currents are facilitated by the HERG (Human Ether A-Gogo, $127 \mathrm{kDa}$ ) and KvLQT1 ( 75 $\mathrm{kDa}$ ) channels, respectively, and are encoded by the KCNH2 (HERG) and KCNQ1 (KvLQT1) gene. Like the Kv4.3 protein, KVLQT1 and HERG are part of the class of $\mathrm{K}^{*}$ channel $\alpha$ subunits that consist of six transmembrane segments (S1-S6), assembling into tetramers to form a mature channel (Figure 2B). In addition, both KVLQT1 and HERG need to associate with $\beta$ subunits in order to fully exhibit the kinetic and functional properties of the native currents. Originally identified as the 
channel protein responsible for $I_{K s}(19,20)$, MinK (Minimal $K^{*}$ channel protein) is a $\sim 15 \mathrm{kDa}$ protein with a single transmembrane segment, encoded by the KCNE1 gene. However, with the cloning of the KCNQ1 gene (21-23), the true identity of MinK as a $\beta$ subunit was established. The $\beta$ subunit which has been suggested to associate with the HERG protein, the MinK-Related Protein 1 (MiRP-1, $\sim 15 \mathrm{KDa}$ ) (24) is encoded by the KCNE2 gene and with a physical distance of less than $100 \mathrm{~kb}$ is considered to be a close neighbor of the KCNE1 gene. However, the rather sparse and specifically localized expression of MiRP-1 $(25,26)$ has made the contribution of this $\beta$ subunit to native $I_{K_{r}}$ current controversial. Next to MiRP-1, three other MiRP's have been identified (MiRP-2, -3 and -4 ) exhibiting similar $\beta$ subunit functions for a variety of ion channels $(27-30)$.

Table 1. Overview of the important currents and their molecular correlates inwolved in shaping the ventricular action potential.

\begin{tabular}{|c|c|c|c|c|}
\hline eurrent & Invardioitward & Subunit & Geno r r & $\begin{array}{l}\text { Chromosomal tocation } \\
\text { numan) }\end{array}$ \\
\hline$I_{\text {Na }}$ & Inward & $\begin{array}{l}\alpha: \mathrm{Na}_{\mathrm{v}} 1.5 \\
\beta: \text { Beta-2/-4 }\end{array}$ & $\begin{array}{l}\alpha: \text { SCN5A } \\
\beta: S C N 2 B / 4 B\end{array}$ & $\begin{array}{l}\alpha: 3 p 21 \\
\beta: 11 q 23 / 23.3\end{array}$ \\
\hline & Sutward & 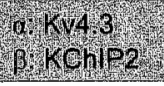 & 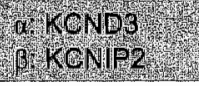 & 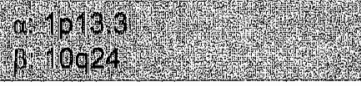 \\
\hline$I_{\mathrm{Na}}$ & Inward & NCX1 & SLC8A1 & $2 \mathrm{p} 22-23$ \\
\hline & pward & 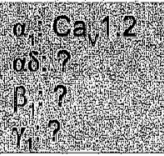 & 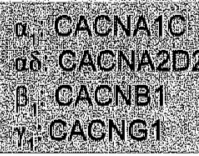 & 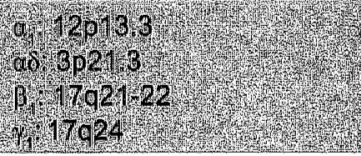 \\
\hline$I_{K s}$ & Outward & $\begin{array}{l}\alpha: \text { KvLQT1 } \\
\beta: \text { MinK }\end{array}$ & $\begin{array}{l}\alpha: \text { KCNQ1 } \\
\beta: \text { KCNE1 }\end{array}$ & $\begin{array}{l}\alpha: 11 \mathrm{p} 15.5 \\
\beta: 21 \mathrm{q} 22.12\end{array}$ \\
\hline & puturard & 1) HER & $\begin{array}{l}\text { Rojve? } \\
\text { Rave? }\end{array}$ & $\begin{array}{l}776356 \\
132492212\end{array}$ \\
\hline$I_{K 1}$ & Outward & Kir2.1 & $\mathrm{KCNJ} 2$ & $17 q 23.1-24.2$ \\
\hline
\end{tabular}

Promiscuity of the $\alpha$ and $\beta$ subunits of $\mathrm{I}_{\mathrm{Ks}}$ and $\mathrm{I}_{\mathrm{Kr}}$ has been given a lot of attention

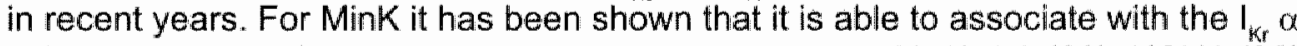
subunit HERG (31), while MiRP-1 is able to associate with Kv4.2 (32), HCN1 (26) and HCN4 (33). MiRP-2 (KCNE3) associates with Kv3.4 (27) and KvLQT1 (34), while MiRP-3 (KCNE4) (29) and MiRP-4 (KCNE5) (28) are able to associate with KVLQT1. Whereas such observations suggest that $\alpha$ subunits in native cells rarely function alone (35), these varied partnerships have not yet been demonstrated in vivo. The most recent and interesting interaction has been found between the a subunits of $I_{K s}$ and $I_{K r^{\prime}}$ KVLQT1 and HERG, respectively (36), probably forming functional ion channels analogous to the Kv4.2-Kv4.3 heteromeric channels (4). Interestingly, KVLQT1-HERG interaction increased HERG-protein membrane localization, enhanced $\mathrm{I}_{\mathrm{kr}}$ current density ${ }_{\text {, }}$ and altered the biophysical properties of 
the current closer to native $I_{\mathrm{Kr}}$ while, in contrast, $\mathrm{I}_{\mathrm{Ks}}$ current characteristics remained unchanged (36).

\subsection{Resting membrane potential}

With the progression of repolarization and a more negative membrane potential the delayed rectifier channels inactivate returning the membrane potential to its resting membrane potential. Under resting conditions the inside negative transmembrane potential difference is attributable primarily to the ionic gradient of the $\mathrm{K}^{+}$ions. On the ane hand there is a efflux of $\mathrm{K}^{+}$ions through the inward rectifier channels $\left(I_{K 1}\right.$ current). On the other hand there is an influx of $\mathrm{K}^{+}$ions through the action of the $\mathrm{Na}^{+}-$ $\mathrm{K}^{+}$pump, exchanging $3 \mathrm{Na}^{+}$ions (efflux) for $2 \mathrm{~K}^{+}$ions (influx).

The subunits of the inward rectifier channels (Kir2. $x, \sim 48 \mathrm{kDa}$ ) which facilitate the $I_{K 1}$ current are part of a family of Kir channels consisting of seven subfamilies (Kir1.x through Kir7. $x$ ) and consist of only two transmembrane segments (Figure 2D). Similar to the Kv channels, Kir channels need to associate in tetramers (homoor heteromeric) to form mature channels. The Kir2.x subfamily consists of four members (Kir2.1, Kir2.2, Kir2.3 and Kir2.4). Transgenic mice lacking the KCNJ2 gene encoding the Kir2.1 channel protein showed a complete absence of $\mathrm{I}_{\mathrm{K} 1}$ current in cardiomyocytes, whereas mice lacking the $\mathrm{KCNJ} 12$ gene encoding the Kir2.2 channel protein showed a $50 \% \mathrm{I}_{\mathrm{k} 1}$ current reduction (37). Although members of the Kir6. $x$ channel subfamily associate with the ATP-binding proteins of the sulfonylurea receptor family (SUR) (38), no $\beta$ subunits have been described to associate with the Kir2.1 channel protein. Formation of heteromeric Kir2.x channels has shown to be an important mechanism determining regional and species differences for the inward rectifier current $I_{K i}(39,40)$.

\section{Ion channelopathies: congenital and acquired long QT syndrome}

From the previous paragraph it is clear that the distinct morphology of an AP is orchestrated by a multitude of different ion channels. Different cardiomyocytes (i.e. nodal, atrial, ventricular and Purkinje cells) have different musicians. It is therefore not surprising that the dysfunction of one or more of these channels can result in a severe change in the morphology of the AP. If, for some reason, there is a lower density of outward generating-ion channels (e.g. potassium channels), there will be a prolongation of the plateau phase, which in turn will prolong the duration of the AP. On an ECG this can be recognized as a prolongation of the QT time. This so-called long QT syndrome (LQTS) can be congenital (e.g. inherited) or acquired (41).

\subsection{Congenita/ LQTS}

The first LQTS family was described in 1957 by Jervell and Lange-Nielsen who reported the autosomal recessive disease, including deafness, QT prolongation and sudden death in childhood (42). In 1963 and 1964, the much more common Romano-Ward variant was described $(43,44)$, characterized by autosomal dominant 
inheritance, and episodes of syncope and/or sudden death due to torsade de pointes (TdP) arrhythmias and ventricular fibrillation. Estimates suggest that the congenitall LQTS causes 3,000 to 4,000 sudden deaths in children and young adults each year in the United States (45). With the advent of genetic and molecular techniques (e.g. sequence analysis, PCR, linkage analysis, etc.) several genes have been associated with the LQTS. So far, seven genes have been identified with mutations linked to the congenital LQTS (LQT1 through LQT7) (Table 2). Not surprisingly, all but one of these genes encode for ion channel subunits involved in AP repolarization. Mutations in the KCNQ1 gene cause LQT1 (23). LQT2 is associated with the KCNH2 gene (46), while mutations in SCN5A are linked to LQT3. Interestingly, mutations in SCN5A are

Table 2. All sewen LQTS genes with known mutations that are linked to the congenital LQTS with their prevalence in a population of 262 urrelated individuals (8.1) (Note the reference did not include LQT4 and LQT7 because the population was not screened for those genes). Overwiew of the type of mulations and location of the mutations in proteins: for LQTS genes $(81)$.

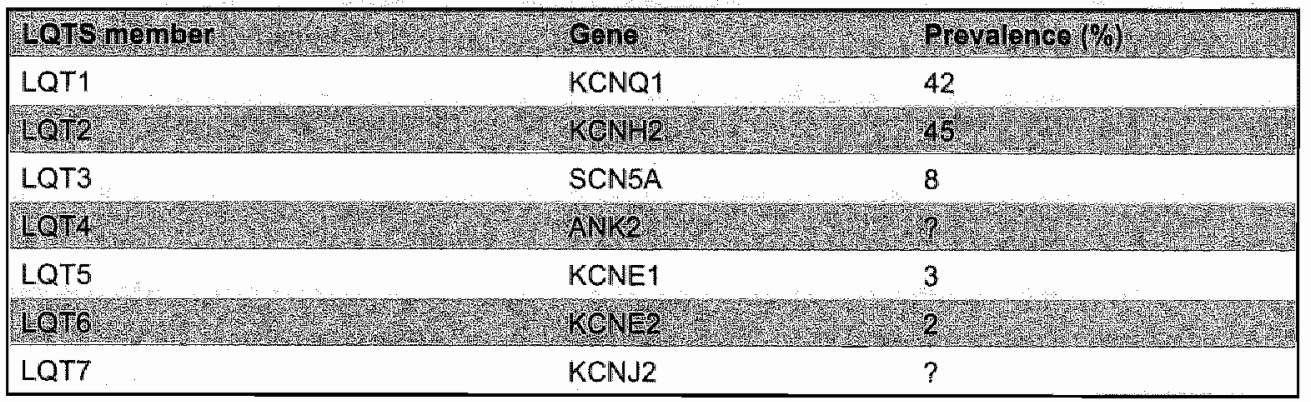

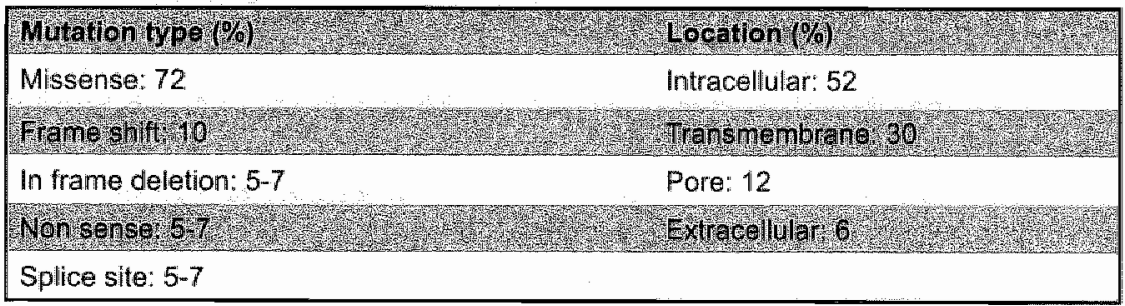

also linked to the Brugada (47) as well as the Lenegre-Lev syndrome (progressive cardiac conduction defect) (48). However, these mutations are loss-of-function type mutations, in contrast to the gain-of-function type mulations in LQT3.

Being the only gene encoding a non-ion channel protein in the LQTS list, ANK2 encodes for the ankyrin2 protein which is responsible for LQT4 (49). Ankyrin2 is part of a protein family believed to link the integral membrane proteins to the underlying cytoskelleton and play key roles in activities such as cell motility, activation, proliferation, contact and the maintenance of specialized membrane domains (50). LQT5 and LQT6 are linked to the $\beta$ subunits of $I_{K S}$ and $I_{K r^{t}}$ KCNE1 and KCNE2, 
respectively $(24,51)$. The latest gene added to the LQTS list is the KCNJ2 gene, which has been linked to the Andersen syndrome and the LQT7 form $(52,53)$. The described genes that have been linked to the LQTS account for $50 \%$ to $60 \%$ of clinically diagnosed cases, indicating that the LQTS list will almost definitely grow as more candidate genes will be identified. Especially the link between LQT4 and the ANK2 protein has opened the door for a whole new group of cytoskeletal proteins with a potential involvement in the long QT syndrome, emphasizing on electromechanical coupling and the occurrence of arrhythmias.

Although the screening of potential carriers for mutations related to the LQTS has proven to be of great diagnostic value, the clinical phenotype of the disease in these carriers is not always as clear as expected. The observed complexity of these socalled monogenic disorders (e.g. disorders caused by a single genetic defect that follow Mendelian inheritance) can be attributed to two important factors: penetrance and expressivity (54). The penetrance of a monogenic disease is defined as the percentage of individuals with a mutant allele who develop the phenotype of the related disease. This penetrance can vary between $10 \%$ and $100 \%$. The expressivity of a disease is defined as the different phenotypical manifestations that can be observed among carriers of the same genetic defect. Combining these two factors it is clear that the clinical phenotype of a monogenic disease can be very diverse, ranging from no phenotype at all to a completely unexpected phenotype.

\subsection{Acquired LQTS}

With the unraveling of the human genome, more and more genes are being characterized and screened for their involvement in disease, thereby increasing the insights in far more common, acquired diseases. Heart failure is one example. It is a well known fact that cardiomyocytes from failing hearts show a prolongation of the QT time, resulting in a more labile AP repolarization (55-57), Prolongation of the AP can be accomplished by a (transcriptional) downregulation of $\mathrm{K}^{+}$channels subunits, like $\operatorname{KCND3}(58,59)$, resulting in a lowered channel density in the cell membrane and thus a lower current density.

In heart failure patients this prolongation provides an initial adaptive response, with more time becoming available for excitation-contraction coupling, which in the short term mitigates the decrease in cardiac output (58). Nevertheless, this response may become maladaptive in the long term, predisposing patients to afterdepolarizations, inhomogeneous repolarization and arrhythmias. Besides transcriptional regulation, this (active) response of the cardiomyocyte to a chronic altered situation (e.g. hypertension, ischemia, brady-, tachycardia, etc.) harbors other numerous regulatory steps like DNA methylation, alternative splicing, RNA destabilization, protein maturation and protein phosphorylation (for a short overview see Table 3). 


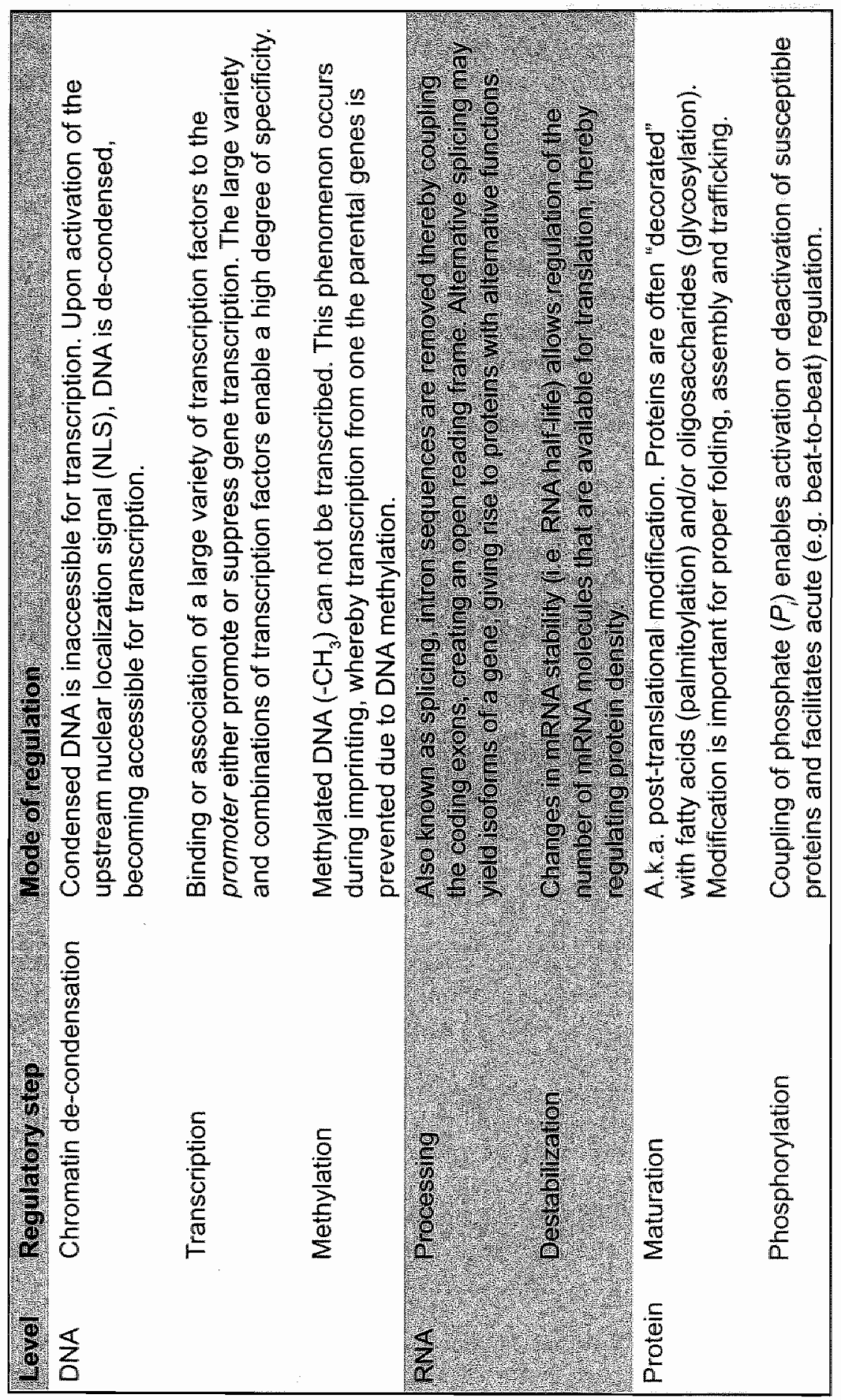


In addition to the obvious stimuli leading to heart failure (e.g. pressure and/or volume overload), the exposure to drugs that block ion channels, in most cases $\mathrm{K}^{+}$channels, in combination with these stimuli can worsen the acquired LQTS. Blockade of an ion channel can be intentionally, as in the case of class III anti-arrhythmic drugs (e.g. dofetilide, sotalol and amiodarone), or it can be unintentionally, with ion channel blockade being a harmful side-effect of the drug. Some of the medication with harmful side-effects include anesthetics, antihistamines, antibiotics, antifungal drugs, psychotropic drugs and diuretics (60). The $\mathrm{I}_{\mathrm{k} r}$ a subunit HERG is a common target for this unintentional blockade , believed to be attributed to the rather promiscuous inner vestibule of the HERG protein for small organic molecules (61). Ut is not yet known why a certain subpopulation is particularly prone to drug-induced LQTS. It might be that, like in the congenital LQTS, penetrance and expressivity are involved. One notion is that by virtue of $\mathrm{K}^{*}$ channels redundancy, the repolarization process harbors a certain "reserve". A reduction in this so-called repolarization reserve, for

Table 4. Sctiematic representation of the ventricular meterageneity in the undiseased heart (Base ws. Apex; RV vS. LV" LV trensmural). In the Base vS. Apex comparison, cardlomyocyles from the midmyocardial regions were used. Endo: subendocarelial, M: imidnyocardial, Epi: subepicardlial.

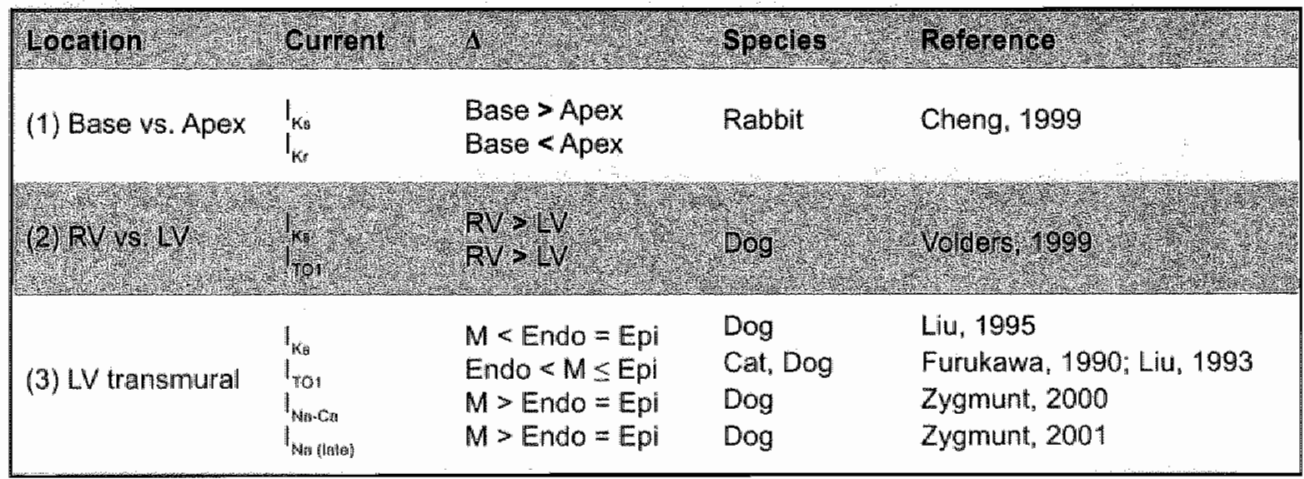

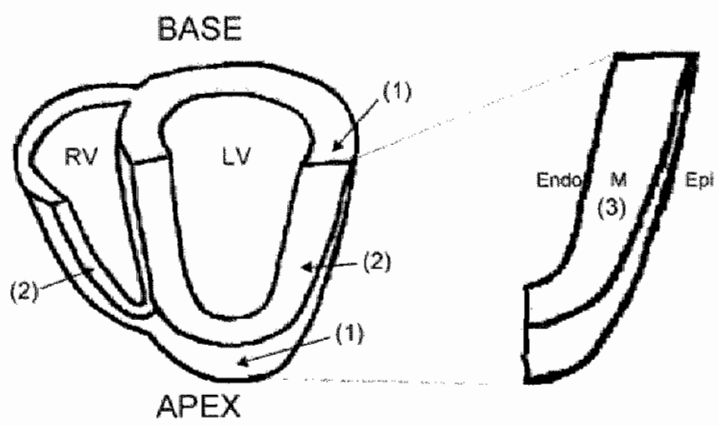


example due to a harmless ion channel mutation or polymorphism that on itself does not cause an arrhythmic event, may potentially lead to arrhythmias in the presence of certain drugs (62).

\section{The dog with chronic complete atrio-ventricular block}

In the field of cardiac electro-physiology the use of large animal models (goat, pig, dog) has been of great importance. The main reason for this being that there is a systematic decrease in theart rate with increasing body size. This correlation is accompanied by a corresponding increase in APD as well as changes in AP morphology. In particular the occurrence of a plateau phase and the presence of plateau phase-related ion channels (e.g. $I_{\mathrm{Ks}}$ and $I_{\mathrm{Kr}}$ ) distinguishes the larger animals from, for instance, rodents, bringing the physiology of the heart in large animals closer to that of humans.

Regional electrophysiological heterogeneity of AP morphology and duration due to differences in ionic currents is an intrinsic feature of normal, healthy (ventricular) myocardium in a number of large mammals, including dogs (Table 4). Changes in this heterogeneity due to (chronic) electrical remodeling are one of the major causes for the occurrence of ventricular arrhythmias and SCD (63). In light of that, large animal models exhibiting (chronic) ventricular remodeling have proven to be valuable in understanding the mechanisms underlying cardiac remodeling (64-67). The chronic complete atrio-ventricular block (CAVB) dog has been the center of attention for clinical and basic electrophysiological research in our group for the last two decades. In this model, ablation of the AV node (complete AV block) interrupts the normal impulse conduction between the atria and ventricles, resulting in a bradycardic idioventricular rhythm and chronic ventricular remodeling (Figure 4).

This process of ventricular remodeling is characterized by:

1) Structural remodeling (Figure 4A), manifested by a chronic eccentric biventricular hypertrophy (RV $>L V$ ) which compensates for the increased acute stretch on the ventricular walls due to the volume overload $(65,68)$.

2) Electrical remodeling (Figure $4 B$ ), in which the remodeling in the LV is more pronounced than in the $\mathrm{RV}$ resulting in an inhomogeneous prolongation of ventricular repolarization ( $\mathrm{LV}_{\mathrm{APD}}$ prolongs more than $\mathrm{RV}$ APD $)(69)$.

3) Contractile remodeling (Figure $4 \mathrm{C}$ ), as shown by the increased $\mathrm{Ca}^{2+}$ transients thereby improving the inotropic performance at the slow idioventricular rate and compensating for the drop in cardiac output $(70,71)$.

It is believed that this inhomogeneous electrical remodeling renders CAVB dogs more susceptible for EAD's and consequently more vulnerable to (drug-induced) 
A

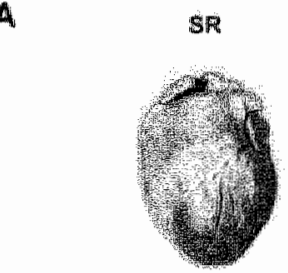

$\begin{array}{cc}\text { horat } & 7.6 \\ \text { body wotght } & \text { g/kg }\end{array}$

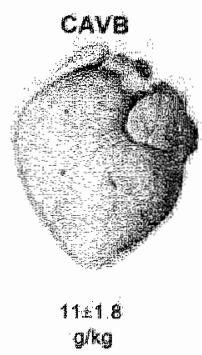

$\mathrm{g} / \mathrm{kg}$
B

SR

CAVB

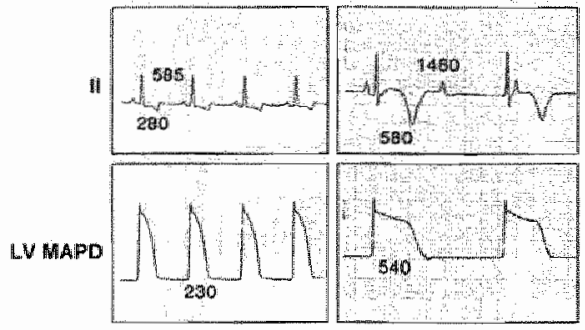

D

Sudden Cardiac Daath

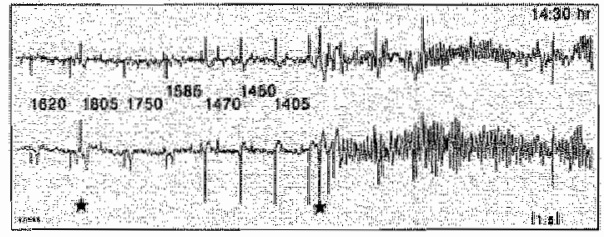

Figure 4. Overwiew of the wentricular remodeling process in CAVB dogs. (A) Structural remodeling is manifested by an eccentric compensated biventricular hypertrophy, in which the RV lyypertiophies more than the LV. (B) CAVB also results in electrical remodeling as shown by the increase in QT time (580 ws. $280 \mathrm{~ms}$ ) and the LV MAPD (540 ws. 230 ms). (C) Contractile remodeling is shown by an increase in LV dP/dT, thereby nomaizing the drop in cardiac output upon acute AVB. (D) Telemetry reconding showing beat-to-beat wariation preceding a TdP arrhytmia of a dog that died as a result of swdden cardiac death (SCD).

Torsade de Pointes (TdP) arrhythmias and $\operatorname{SCD}(65,72,73)$. An important step in better understanding of the mechanisms related to inhomogeneous electrical remodeling has been the downregulation of the $I_{K s}$ (LV -50\%; RV -55\%) and $I_{K r}$ current (RV $-45 \%)(73)$ and the increase in activity of the $I_{\text {Na-Ca }}$ exchanger (LV) (71), with the notion that other currents like $\mathrm{I}_{\mathrm{Na}}$ might also contribute (unpublished results). Within the population of CAVB dogs there exists a degree of heterogeneity. Most CAVB dogs show an expected increased vulnerability to (drug) inducible TdP arrhythmias. A small group remains un-inducible, while some CAVB dogs die suddenly (witnessed SCD: 16 of a total of 117 dogs). Telemetry recordings have shown that SCD in CAVB dogs is characterized by a spontaneous episode of TdP arrhythmia, which deteriorates in ventricular fibrillation resulting in SCD (74). It has been suggested that an increased short-term variability of repolarization (Figure 4D; beat-to-beat variation) might be a predicative parameter for the identification of SCD-prone CAVB dogs (75). The mechanism behind the occurrence of SCD is 
unknown but probably has to be sought in the genetic background of the individual dogs. Similar to a decreased repolarization reserve in the (acquired) drug-induced LQTS, the combination of electrical remodeling and polymorphisms might increase the probability of SCD in these dogs.

\section{Methodology: PCR based mRNA quantification}

With an initial focus on "hybridization" as a way for quantifying mRNA transcripts (e.g. Northern blotting and RNAse Protection Assay), reverse transcription-polymerase chain reaction (RT-PCR) based methods like the competitive multiplex RT-PCR (Chapter 2) and kinetic real-time RT-PCR (Chapters 3-7) are the methods of choice when dealing with small tissue samples (1-10 mg) and low abundant mRNA transcripts. Because it is impossible to use RNA as template in a PCR reaction, all PCR based mRNA quantification methods are based on a two-step principle: cDNA synthesis by reverse transcription of mRNA followed by a PCR reaction on the CDNA. Low abundant detection is possible due to the exponential nature of the amplification process (with each progressing cycle the number of transcripts from the previous cycle is doubled).

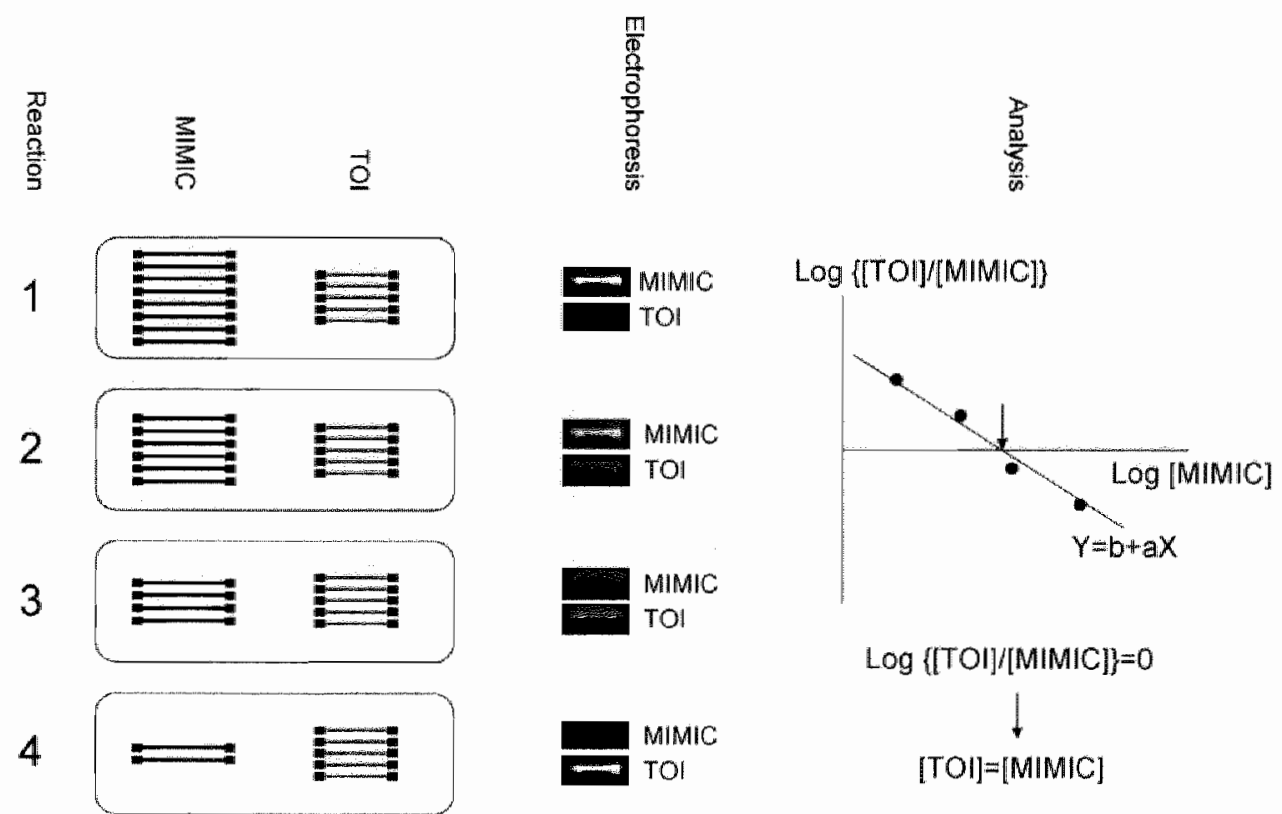

Figure 5. Schematic representation of the multiplex competitive RT-PCR method. Quantification is besed on competition for primer anmealing between the transcript of interest (TOI) and an exogenous DNA fragment (MIMIC). For more details see the text. 


\subsection{Multiplex competitive RT-PCR}

This method relies on the competition between an exogenous (e.g. viral DNA) amplicon (Figure 5: MIMIC), which is added with a known concentration to the PCR reaction, and the transcript of interest (Figure 5: TOl). The competition is accomplished by ligating the exact same primer binding sequence on both ends of MIMIC amplicon as of the transcript of interest. When the MIMIC amplicon is present in access (Figure 5: reaction 1), MIMIC amplification is dominant. With each MIMIC dilution step, preferential amplification slowly shift towards the transcript of interest (Figure 5: reaction 2 through 4). Upon gel electrophoresis and blotting of the MIMIC and TOI amplicons, the intensity of both bands is determined and plotted. Linear regression on the plotted points yields a simple first degree relation $(Y=b+a X)$, in which the $X$-axis intercept $(Y=0, \log 1=0)$ represents the concentration of the transcript of interest. Note that figure 5 represents a schematic flow-chart for the quantification of a single sample!

A

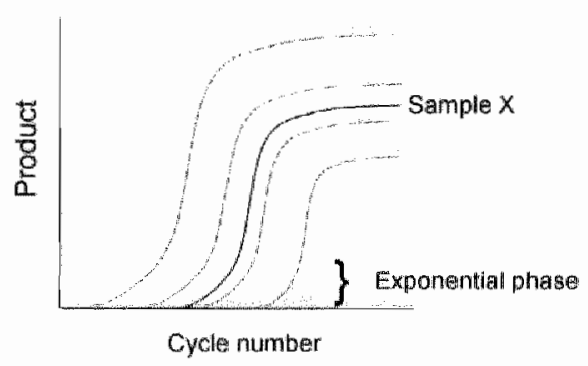

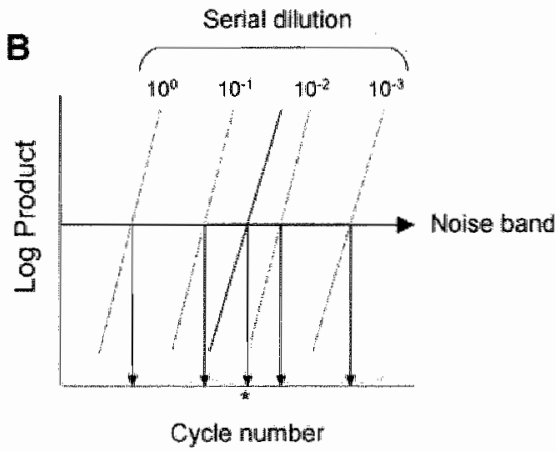

Cycte number

C

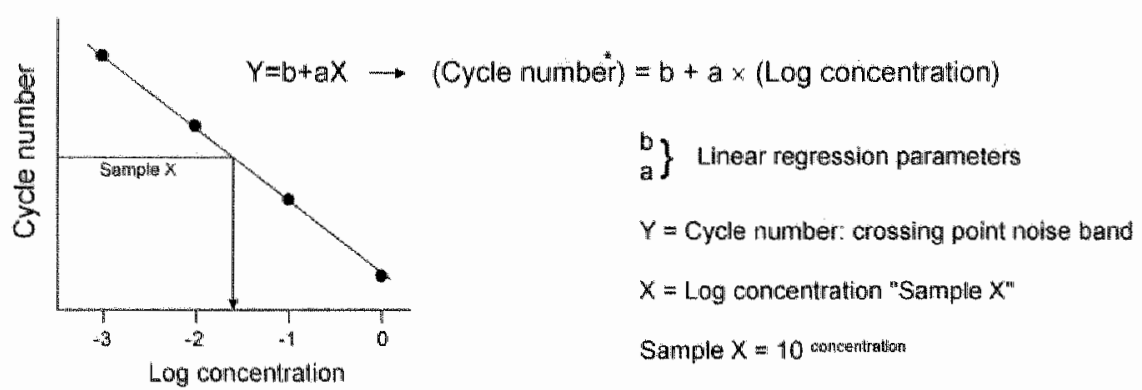

Figure 6. Quantification of MRMA wsing kinetic real-time PCR. Quantification is based on the continulaus monitoring of formed PCR product by using intercalating fluorescent dyes (e.g. SYBR Green I) or fluorescent probes. This continuous monitoring enables the identification of the exponential phase (4-7 cycles), in which there is a constamt increase in PCR product with each cycle number. For more details see text. 


\subsection{Kinetic real-time RT-PCR}

Recent advances in PCR combined with new fluorescent techniques have led to the introduction of kinetic real-time RT-PCR. With this technique it is possible to monitor, in real-time, the kinetics of a PCR by determining the amount of synthesized product with the progression of each PCR cycle. Several fluorescent detection formats are possible, two of which are PCR probes and intercalating fluorescent dyes. While PCR probe-based detection provides a higher specificity (i.e. each probe is designed for a specific transcript of interest), the intercalating fluorescent dyes like SYBR Green I allow for a more versatile quantification of multiple mRNAs. The strong point of this approach is that quantification is performed in the most reliable phase of the PCR, the so-called exponential phase (Figure $6 \mathrm{~A}$ ). In this phase the increase in product is constant over a number of cycles. The exponential phase is also referred to as the Log-linear phase because of the linear relation between Log product ( $Y$-axis) and cycle number ( $X$-axis) (Figure 6B). Quantification of cDNA according to the standard procedure involves the use of a standard curve. Such a standard curve can be made by a serial dilution of one of the cDNA samples under investigation. The standard curve is then generated by manually placing a noise band within the loglinear phase of the PCR reaction (Figure 6B). This noise band, a line representing an equal amount of formed product, is reached at different numbers of cycles per known cDNA dilution or total RNA input. With this, the measured number of cycles ( $Y$-axis) is plotted against the Log concentration ( $X$-axis). The best fitting regression line is then used as a standard curve (Figure $6 \mathrm{C}$ ) to quantify the starting concentration of a specific cDNA in all other unknown samples within that PCR run.

\section{Aims of the thesis}

It is a well known fact that spatial differences exist in the electrophysiologic build-up of the normal, healthy ventricular myocardium and that this heterogeneity is subject to change during ventricular remodeling, more specifically electrical remodeling. It is suggested that these changes in (spatial) heterogeneity (due to genetics and/or environment) are important predisposing factors for the accurrence of ventricular arrhythmias and in some cases sudden cardiac death. While the in vivo and in vitro characterization of the CAVB model has been the center of attention for the last couple of years, the molecular mechanisms underlying the remodeling processes have been neglected. Therefore, the focus of this thesis has been to elucidate some of the molecular characteristics of the spatial heterogeneity in remodeled canine hearts compared to normal hearts, and to assess the temporal behavior of these changes in the CAVB dog.

The first aim is to verify the import cellular findings of $\mathrm{I}_{\mathrm{Ks}}$ current downregulation in the LV and RV anterior free wall of CAVB dogs on a messenger RNA (mRNA) and protein level using a combination of Northern blotting, competitive multiplex PCR and Western blotting (Chapter 2).

Because of the relative insensitive Northern blot technique and the laborious nature 
of the competitive multiplex PCR method, kinetic real-time RT-PCR has become the standard for quantification of (low abundant) mRNA. Not satisfied with the reproducibility of the standard quantification technique used in kinetic real-time $R T$ $P C R$ we propose an alternative and more honest approach for quantifying mRNA. In that respect, the chapters 3 and 4 will deal with a methodological optimization of the kinetic real-time RT-PCR technique.

There is a strong link between cardiac hypertrophy, the prolongation of the QT time and an increased propensity for ventricular arrhythmias (76). Also in CAVB dogs, the structural (i.e. hypertrophy) and electrical remodeling seem to be associated. Chapter 5 investigates the coupling and time dependent nature of both processes. Attempting to dissociate both processes we will intervene in the Renin-Angiotensin System (RAS) by blocking the Angiotensin II-Type 1 (AT1) receptor with Irbesartan. Intervention in the RAS by AT1 blockade in stead of ACE inhibition circumvents an alternative pathway of Angiotensin II formation through Chymase, a serine-protease. In light of the observed heterogeneity in the ventricles, the ventricular septum is less well described. It has been proposed that the ventricular septum is an extension of the LV free wall (77). However, anatomically, the septum divides the LV from the RV and therefore is as much part of the LV wall as it is of the RV wall. Having said this, in combination with the interventricular differences (LV vs. RV) in control dogs (78), the ventricular septum is the obvious location within the ventricles where these differences are expected to be most prominent. Therefore, Chapter 6 will scrutinize the electrophysiological and molecular composition of the septum in canine ventricles and tries to answer whether or not the ventricular septum is a "true" septum.

There have been conflicting results on the contribution of $I_{K_{5}}$ to ventricular repolarization. While $\mathrm{I}_{\mathrm{Ks}} \alpha$ and $\beta$ subunits have been linked to the congenital LQTS, pharmacological block of the current under baseline conditions does not prolong the APD (79). This discrepancy was explained when it was shown that $I_{\mathrm{Ks}}$ function only becomes prominent during $\beta$-adrenergic receptor stimulation, promoting AP repolarization by increased activation (80). Chapter 7 will investigate the temporal behavior of molecular and functional $I_{K S}$ downregulation, in combination with the $\beta$ adrenergic responsiveness of $\mathrm{I}_{\mathrm{K} .}$. In order to do so, needle biopsies from the $L V$ apex are taken on specific time points upon AVB (SR, 3 days AVB, 8 days AVB and 30 days AVB), using each dog as his own control. 


\section{References}

1. Koek HL, van Leest LATM, Verschuren WMM, Bots ML. Hart-en vaatziekten in Nederland 2004. Nederlandse Hartstichting 2004.

2. Catterall WA. Structure and modulation of $\mathrm{Na}+$ and $\mathrm{Ca} 2+$ channels. Ann $\mathrm{N}$ Y Acad Sci 1993;707:1-19.

3. Feng G, Deak P, Chopra M, Hall LM. Cloning and functional analysis of TipE, a novel membrane protein that enhances Drosophila para sodium channel function. Cell 1995;82(6):1001-11.

4. Guo W, Li H, Aimond F, Johns DC, Rhodes KJ, Trimmer JS, et al. Role of heteromultimers in the generation of myocardial transient outward $\mathrm{K}+$ currents. Circ Res 2002;90(5):586-93.

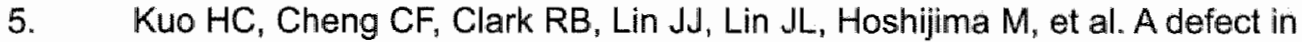
the Kv channel-interacting protein 2 (KChIP2) gene leads to a complete loss of I(to) and confers susceptibility to ventricular tachycardia. Cell 2001;107(6):801-13.

6. Kim LA, Furst J, Gutierrez D, Butler MH, Xu S, Goldstein SA, et al. Threedimensional structure of I(to); Kv4.2-KChIP2 ion channels by electron microscopy at 21 Angstrom resolution. Neuron 2004;41(4):513-9.

7. Decher N, Barth AS, Gonzalez T, Steinmeyer K, Sanguinetti MC. Novel KChIP2 isoforms increase functional diversity of transient outward potassium currents. J Physiol 2004;557(Pt 3):761-72.

8. Chang FC, Hosey MM. Dihydropyridine and phenylalkylamine receptors associated with cardiac and skeletal muscle calcium channels are structurally different. J Biol Chem 1988;263(35):18929-37.

9. Perez-Reyes E, Kim HS, Lacerda AE, Horne W, Wei XY, Rampe D, et al. Induction of calcium currents by the expression of the alpha 1-subunit of the dihydropyridine receptor from skeletal muscle. Nature 1989;340(6230):233-6.

10. Lacerda AE, Kim HS, Ruth P, Perez-Reyes E, Flockerzi V, Hofmann F, et al. Normalization of current kinetics by interaction between the alpha 1 and beta subunits of the skeletal muscle dihydropyridine-sensitive $\mathrm{Ca} 2+$ channel. Nature $1991 ; 352(6335): 527-30$.

11. Foell JD, Balijepalli RC, Delisle BP, Yunker AM, Robia SL, Walker JW, et al. Molecular heterogeneity of calcium channel beta-subunits in canine and human heart: evidence for differential subcellular localization. Physiol Genomics $2004 ; 17(2): 183-200$. 
12. Nicoll DA, Longoni S, Philipson KD. Molecular cloning and functional expression of the cardiac sarcolemmal $\mathrm{Na}(+)-\mathrm{Ca} 2+$ exchanger. Science $1990 ; 250(4980): 562-5$.

13. Li Z, Matsuoka $S$, Hryshko LV, Nicoll DA, Bersohn MM, Burke EP, et al. Cloning of the $\mathrm{NCX} 2$ isoform of the plasma membrane $\mathrm{Na}(+)-\mathrm{Ca} 2+$ exchanger. J Biol Chem 1994;269(26):17434-9.

14. Nicoll DA, Quednau BD, Qui Z, Xia YR, Lusis AJ, Philipson KD. Cloning of a third mammalian $\mathrm{Na}+\mathrm{Ca} 2+$ exchanger, $\mathrm{NCX}$. J Biol Chem 1996;271(40):2491421.

15. Quednau BD, Nicoll DA, Philipson KD. Tissue specificity and alternative splicing of the $\mathrm{Na}+/ \mathrm{Ca} 2+$ exchanger isoforms $\mathrm{NCX} 1, \mathrm{NCX} 2$, and $\mathrm{NCX} 3$ in rat. Am $J$ Physiol 1997;272(4 Pt 1):C1250-61.

16. Miura $Y$, Kimura J. Sodium-calcium exchange current. Dependence on internal $\mathrm{Ca}$ and $\mathrm{Na}$ and competitive binding of external $\mathrm{Na}$ and $\mathrm{Ca}$. J Gen Physiol $1989 ; 93(6): 1129-45$.

17. Noble D, Tsien RW. Outward membrane currents activated in the plateau range of potentials in cardiac Purkinje fibres. J Physiol 1969;200(1):205-31.

18. Sanguinetti MC, Jurkiewicz NK. Two components of cardiac delayed rectifier $\mathrm{K}+$ current. Differential sensitivity to block by class III antiarrhythmic agents. J Gen Physiol 1990;96(1):195-215.

19. Blumenthal EM, Kaczmarek LK. Structure and regulation of the MinK potassium channel. Neurochem Res 1992;17(9):869-76.

20. Freeman LC, Kass RS. Expression of a minimal $\mathrm{K}+$ channel protein in mammalian cells and immunolocalization in guinea pig heart. Circ Res 1993;73(5):968-73.

21. Barhanin J, Lesage $F$, Guillemare $E$, Fink $M$, Lazdunski $M$, Romey $G$. $\mathrm{K}(\mathrm{V}) \mathrm{LQT} 1$ and IsK (minK) proteins associate to form the I(Ks) cardiac potassium current. Nature 1996;384(6604):78-80.

22. Sanguinetti MC, Curran ME, Zou $A$, Shen J, Spector PS, Atkinson DL, et all. Coassembly of K(V)LQT1 and minK (IsK) proteins to form cardiac l(Ks) potassium channel. Nature 1996;384(6604):80-3.

23. Wang Q, Curran ME, Splawski I, Burn TC, Millholland JM, VanRaay TJ, et al. Positional cloning of a novel potassium channel gene: KVLQT 1 mutations cause cardiac arrhythmias. Nat Genet 1996;12(1):17-23. 
24. Abbott GW, Sesti F, Splawski I, Buck ME, Lehmann MH, Timothy KW, et al. MiRP1 forms $\mathrm{IKr}$ potassium channels with HERG and is associated with cardiac arrhythmia. Cell 1999;97(2):175-87.

25. Pourrier M, Zicha S, Ehrlich J, Han W, Nattel S. Canine ventricular KCNE2 expression resides predominantly in Purkinje fibers. Circ Res 2003;93(3):189-91.

26. Yu H, Wu J, Potapova I, Wymore RT, Holmes B, Zuckerman J, et al. MinKrelated peptide 1: A beta subunit for the $\mathrm{HCN}$ ion channel subunit family enhances expression and speeds activation. Circ Res 2001;88(12):E84-7.

27. Abbott GW, Butler MH, Bendahhou S, Dalakas MC, Ptacek LJ, Goldstein SA. MiRP2 forms potassium channels in skeletal muscle with Kv3.4 and is associated with periodic paralysis. Cell 2001;104(2):217-31.

28. Angelo $K$, Jespersen $T$, Grunnet $M$, Nielsen MS, Klaerke DA, Olesen SP. KCNE5 induces time- and voltage-dependent modulation of the KCNQ1 current. Biophys J 2002;83(4):1997-2006.

29. Grunnet $M$, Jespersen $T$, Rasmussen HB, Ljungstrom $T$, Jorgensen NK, Olesen SP, et al. KCNE4 is an inhibitory subunit to the KCNQ1 channel. J Physiol 2002;542(Pt 1):119-30.

30. Hofman-Bang J, Jespersen T, Grunnet M, Larsen LA, Andersen PS, Kanters JK, et al. Does KCNE5 play a role in long QT syndrome? Clin Chim Acta 2004;345(12):49-53.

31. McDonald TV, Yu Z, Ming Z, Palma $E$, Meyers MB, Wang KW, et all. A minK-HERG complex regulates the cardiac potassium current $\mid(K \mathrm{Kr})$. Nature $1997 ; 388(6639): 289-92$.

32. Zhang TT, Takimoto $K$, Stewart AF, Zhu $C$, Levitan ES. Independent regulation of cardiac Kv4.3 potassium channel expression by angiotensin II and phenylephrine. Circ Res 2001;88(5):476-82.

33. Decher N, Bundis F, Vajna R, Steinmeyer K. KCNE2 modulates current amplitudes and activation kinetics of $\mathrm{HCN} 4$ : influence of KCNE family members on HCN4 currents. Pflugers Arch 2003;446(6):633-40.

34. Melman YF, Domenech A, de la Luna S, McDonald TV. Structural determinants of KvLQT1 control by the KCNE family of proteins. J Biol Chem $2001 ; 276(9): 6439-44$.

35. Abbott GW, Goldstein SA, Sesti F. Do all voltage-gated potassium channels use MiRPs? Circ Res 2001;88(10):981-3. 
36. Ehrlich $J \mathbb{R}$, Pourrier M, Weerapura M, Ethier $N$, Marmabachi $A M$, Hebert TE, et al. KVLQT1 modulates the distribution and biophysical properties of HERG. A novel alpha-subunit interaction between delayed rectifier currents. I Biol Chem $2004: 279(2): 1233-41$.

37. Zaritsky JJ, Eckman DM, Wellman GC, Nelson MT, Schwarz TL. Targeted disruption of Kir2.1 and Kir2.2 genes reveals the essentiall role of the inwardly rectifying $\mathrm{K}(+)$ current in $\mathrm{K}(+)$-mediated vasodilation. Circ Res $2000 ; 87(2): 160-6$.

38. Fujita A, Kurachi $Y$. Molecular aspects of ATP-sensitive $K+$ channels in the cardiovascular system and $\mathrm{K}+$ channel openers. Pharmacol Ther $2000,85(1): 39-53$.

39. Dhamoon AS, Pandit SV, Sarmast F, Parisian KR, Guha P, Li $Y$, et al. Unique Kir2.x properties determine regional and species differences in the cardiac inward rectifier K+ current. Circ Res 2004;94(10):1332-9.

40. Schram G, Melnyk P, Pourrier M, Wang Z, Nattel S. Kir2.4 and Kir2.1 K(+) channel subunits co-assemble: a potential new contributor to inward rectifier current heterogeneity. J Physiol 2002;544(Pt 2):337-49.

41. Belardinelli L, Antzelevitch C, Vos MA. Assessing predictors of drug-induced torsade de pointes. Trends Pharmaco| Sci 2003;24(12):619-25.

42. Jervell A, Lange-Nielsen F. Congenital deaf-mutism, functional heart disease with prolongation of the Q-T interval and sudden death. Am Heart J 1957;54(1):5968.

43. Romano $C$, Gemme G, Pongiglione R. [Rare Cardiac Arrythmias of the Pediatric Age. li. Syncopal Attacks Due to Paroxysmal Ventricular Fibrillation. (Presentation of 1st Case in Italian Pediatric Literature)]. Clin Pediatr (Bologna) $1963 ; 45: 656-83$.

44. Ward OC. A New Familial Cardiac Syndrome in Children. J Ir Med Assoc $1964 ; 54: 103-6$.

45. Vincent GM. The molecular genetics of the long QT syndrome: gemes causing fainting and sudden death. Annu Rev Med 1998;49:263-74.

46. Curran ME, Splawski I, Timothy KW, Vincent GM, Green ED, Keating MT. A molecular basis for cardiac arrhythmia: HERG mutations cause long QT syndrome. Cell 1995;80(5):795-803.

47. Bezzina $C$, Veldkamp MW, van Den Berg MP. Postma AV, Rook MB, Viersma JW, et al. A single $\mathbb{N a ( + )}$ channel mutation causing both long-QT and Brugada syndromes. Circ Res 1999;85(12):1206-13. 
48. Schott $\mathrm{JJ}$, Alshinawi $C$, Kyndt $F$, Probst $V$, Hoorntje $T M$, Hulsbeek $M$, et al. Cardiac conduction defects associate with mutations in SCN5A. Nat Genet 1999;23(1):20-1.

49. Mohler PJ, Schott $J J$, Gramolini AO, Dilly KW, Guatimosim $S$, duBell $W H_{1}$ et al. Ankyrin-B mutation causes type 4 long-QT cardiac arrhythmia and sudden cardiac death. Nature 2003;421(6923):634-9.

50. Bennett PB. Anchors Aweigh! ion channels, cytoskeletal proteins, and cellular excitability. Circ Res $2000 ; 86(4): 367-8$.

51. Splawski I, Tristani-Firouzi M, Lehmann MH, Sanguinetti MC, Keating MT. Mutations in the hminK gene cause long QT syndrome and suppress IKs function. Nat Genet 1997;17(3):338-40.

52. Bendahhou $\mathrm{S}$, Donaldson MR, Plaster NM, Tristani-Firouzi M, Fu YH, Ptacek LJ. Defective potassium channel Kir2.1 trafficking underlies Andersen-Tawil syndrome. J Biol Chem 2003;278(51):51779-85.

53. Tristani-Firouzi M, Jensen $\mathrm{JL}$, Donaldson MR, Sansone V, Meola G, Hahn $A$, et al. Functional and clinicall characterization of $\mathrm{KCNJ} 2$ mutations associated with LQT7 (Andersen syndrome). J Clin Invest 2002;110(3):381-8.

54. Priori SG. Inherited arrhythmogenic diseases: the complexity beyond monogenic disorders. Circ Res 2004;94(2):140-5.

55. Berger RD, Kasper EK, Baughman KL, Marban E, Calkins $H$, Tomaselli GF. Beat-to-beat QT interval variability: novel evidence for repolarization lability in ischemic and nonischemic dilated cardiomyopathy. Circulation 1997;96(5):1557-65.

56. Beuckelmann DJ, Nabauer M, Erdmann E. Alterations of $K+$ currents in isolated human ventricular myocytes from patients with terminal heart failure. Circ Res 1993;73(2):379-85.

57. Kaab S, Nuss HB, Chiamvimonvat N, O'Rourke B, Pak PH, Kass DA, et al. lonic mechanism of action potential prolongation in ventricular myocytes from dogs with pacing-induced heart failure. Circ Res 1996;78(2):262-73.

58. Kaab S, Dixon J, Duc J, Ashen D, Nabauer M, Beuckelmann DJ, et al. Molecular basis of transient outward potassium current downregulation in human heart failure: a decrease in Kv4.3 mRNA correlates with a reduction in current density. Circulation 1998;98(14):1383-93.

59. Patberg KW, Plotnikov AN, Quamina A, Gainullin RZ, Rybin A, Danilo P. $\mathrm{Jr}$., et al. Cardiac memory is associated with decreased levels of the transcriptional factor CREB modulated by angiotensin II and calcium. Circ Res 2003;93(5):472-8. 
60. Camm AJ, Janse MJ, Roden DM, Rosen MR, Cinca $J_{*}$ Cobbe SM. Congenital and acquired long QT syndrome. Eur Heart J 2000;21(15):1232-7.

61. Mitcheson JS, Chen J, Lin M, Culberson C, Sanguinetti MC. A structural basis for drug-induced long QT syndrome. Proc Natl Acad Sci U S A 2000;97(22):1232933.

62. Walker BD, Krahn AD, Klein GJ, Skanes AC, Yee R. Drug induced QT prolongation: lessons from congenital and acquired long QT syndromes. Curr Drug Targets Cardiovasc Haematol Disord 2003;3(4):327-35.

63. Tomaselli GF, Beuckelmann DJ, Calkins HG, Berger RD, Kessler PD, Lawrence $\mathrm{JH}$, et al. Sudden cardiac death in heart failure. The role of abnormal repolarization. Circulation 1994;90(5):2534-9.

64. Herweg B, Chang F, Chandra P, Danilo P, Jr., Rosen MR. Cardiac memory in canine atrium: identification and implications. Circulation 2001;103(3):455-61.

65. Vos MA, de Groot SH, Verduyn SC, van der Zande J, Leunissen HD, Cleutjens $\mathrm{JP}$, et al. Enhanced susceptibility for acquired torsade de pointes arrhythmias in the dog with chronic, complete AV block is related to cardiac hypertrophy and electrical remodeling. Circulation 1998;98(11):1125-35.

66. Wijfels MC, Kirchhof CJ, Dorland R, Power J, Allessie MA. Electrical remodeling due to atrial fibrillation in chronically instrumented conscious goats: roles of neurohumoral changes, ischemia, atrial stretch, and high rate of electrical activation. Circulation 1997;96(10):3710-20.

67. Yue L, Feng J, Gaspo R, Li GR, Wang Z, Nattel S. Ionic remodeling underlying action potential changes in a canine model of atrial fibrillation. Circ Res $1997 ; 81(4): 512-25$

68. Verduyn SC, Ramakers C, Snoep G, Leunissen JD, Wellens HJ, Vos MA. Time course of structural adaptations in chronic AV block dogs: evidence for differential ventricular remodeling. Am J Physiol Heart Circ Physiol 2001;280(6):H2882-90.

69. Verduyn SC, Vos MA, van der Zande J, van der Hulst FF, Wellens HJ. Role of interventricular dispersion of repolarization in acquired torsade-de-pointes arrhythmias: reversal by magnesium. Cardiovasc Res 1997;34(3):453-63.

70. de Groot SH, Schoenmakers M, Molenschot MM, Leunissen JD, Wellens $\mathrm{HJ}$, Vos MA. Contractile adaptations preserving cardiac output predispose the hypertrophied canine heart to delayed afterdepolarization-dependent ventricular arrhythmias. Circulation 2000;102(17):2145-51. 
71. Sipido KR, Volders $P G$, de Groot SH, Verdonck F, Van de Werf F, Wellens $\mathrm{HJ}_{3}$ et al. Enhanced $\mathrm{Ca}(2+)$ release and $\mathrm{Na} / \mathrm{Ca}$ exchange activity in hypertrophied canine ventricular myocytes: potential link between contractile adaptation and arrhythmogenesis. Circulation 2000;102(17):2137-44.

72. Schoenmakers M, Ramakers C, van Opstal JM, Leunissen JD, Londono C, Vos MA. Asynchronous development of electrical remodeling and cardiac hypertrophy in the complete AV block dog. Cardiovasc Res 2003;59(2):351-9.

73. Volders PG, Sipido KR, Vos MA, Spatjens RL, Leunissen JD, Carmeliet $E$, et al. Downregulation of delayed rectifier $K(+)$ currents in dogs with chronic complete atrioventricular block and acquired torsades de pointes. Circulation $1999 ; 100(24): 2455-61$.

74. van Opstal JM, Verduyn SC, Leunissen HD, de Groot SH, Wellens HJ, Vos MA. Electrophysiological parameters indicative of sudden cardiac death in the dog with chronic complete AV-block. Cardiovasc Res 2001;50(2):354-61.

75. Thomsen MB, Truin M, Beekman J, Stengl M, Vos MA. Beat-to-beat variability of repolarisation is increased before sudden arrhythmogenic death in dogs with remodelled hearts. European Heart Journal 2004;25:29.

76. Tomaselli GF, Marban E. Electrophysiological remodeling in hypertrophy and heart failure. Cardiovasc. Res 1999;42(2):270-83.

77. Konarzewska H, Peeters GA, Sanguinetti MC. Repolarizing K+ currents in nonfailing human hearts. Similarities between right septal subendocardial and left subepicardial ventricular myocytes. Circulation 1995;92(5):1179-87.

78. Volders $P G$, Sipido KR, Carmeliet E, Spatjens RL, Wellens HJ, Vos MA. Repolarizing $\mathrm{K}+$ currents ITO1 and $\mathrm{K}$ s are larger in right than left canine ventricular midmyocardium. Circulation 1999;99(2):206-10.

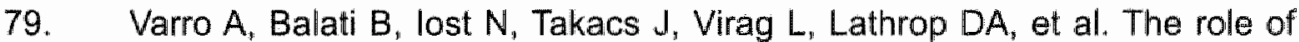
the dellayed rectifier component IKs in dog ventricular muscle and Purkinje fibre repolarization. J Physiol 2000;523 Pt 1:67-81.

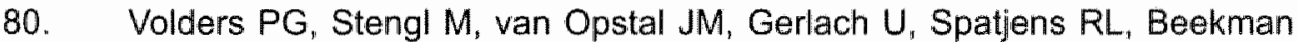
$\mathrm{JD}$, et al. Probing the contribution of $\mathrm{IKs}$ to canine ventricular repolarization: key role for beta-adrenergic receptor stimulation. Circulation 2003;107(21):2753-60.

81. Splawski I, Shen J, Timothy KW, Lehmann MH, Priori S, Robinson JL, et al. Spectrum of mutations in long-QT syndrome genes. KVLQT1, HERG, SCN5A, KCNE1, and KCNE2. Circulation 2000;102(10):1178-85. 


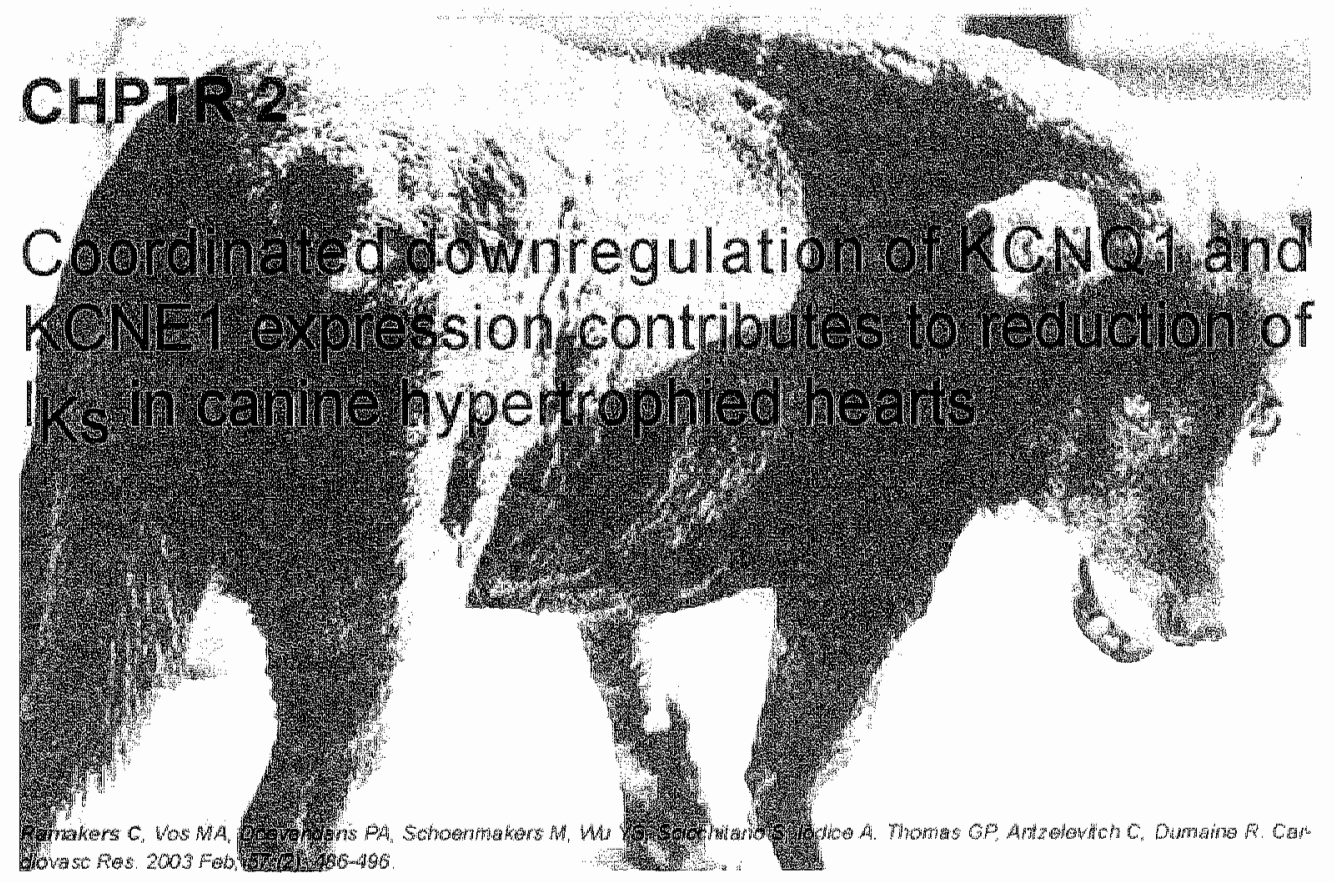




\section{SUMMARY}

Objective: In animal models of hypertrophy, electrical remodeling giving rise to QT prolongation occurs rapidly and is associated with the development of Torsade de Pointes (TdP) arrhythmias and sudden death. Chronic AV block (CAVB)-induced hypertrophy in dogs has been associated with a reduction in the slow component $\left(1_{K_{s}}\right)$ of the delayed rectifier potassium current $\left(I_{k}\right)$, which contributes to a prolongation of ventricular repolarization, the development of an acquired form of long QT, and the substrate for triggered activity and TdP. The present study was designed to probe the molecular basis for the decrease in $\mathrm{I}_{\mathrm{Ks}}$ by studying the characteristics of KCNE1 and/or KCNQ1, the putative genes responsible for formation of the channel.

Methods and Results: Using a combination of Northern blot, competitive multiplex PCR and immunoblot assays, we found that CAVB reduces KCNE1 and KCNQ1 mRNAin the canine ventricles by $70 \%$ and $80 \%$, respectively. Protein levels of KCNE1 and KCNQ1 were reduced by $60 \%$ and $50 \%$, respectively. We also demonstrate at the molecular level the basis for inter-ventricular difference in $\mathrm{I}_{\mathrm{Ks}}$ density previously reported in hearts of normal dogs and show the basis for reduction of this difference in the CAVB dog.

Conclusions: Our results indicate that the CAVB-induced reduction in $I_{K s}$ is due to a down-regulation of KCNE1 and KCNQ1 transcription. The data suggest that electrical remodeling of the cardiac ventricle during hypertrophy involves regulation of the gene expression through modulation of transcriptional and translational regulatory pathways. The reduction in KCNE1 and KCNQ1 expression increases the dependence of ventricular repolarization on the rapid component of $I_{K}$ and may potentiate the action of Class III antiarrhythmic agents. 


\section{INTRODUCTION}

Cardiac hypertrophy secondary to hypertension is associated with a 6-fold increase in the risk of sudden death. Prolongation of the repolarization time has been a consistent finding in hypertrophied hearts. This electrical remodeling has often been observed before fibrosis or clinical signs of heart failure become evident in animal models $(1,2)$.

In the canine chronic atrio-ventricular block (CAVB) model, biventricular hypertrophy results from adaptation to volume overload induced by long term bradycardia and AV asynchrony $(2,3)$ and develops before observable changes in the tissue collagen content or capillary/fiber ratio (2). Electrical remodeling is accompanied by the development of cellular hypertrophy (4) and predisposes the heart to the development of Torsade de Pointes arrhythmias (5-7). CAVB significantly increases ventricular action potential duration (APD), more so in the left ventricle (LV) than in the right (RV), and steepens the APD-rate relationship (2). CAVB-induced changes in repolarization are due in part to a decrease in the amplitude of the slow component of the voltage-gated delayed rectifier potassium current $\left(\mathrm{I}_{\mathrm{Ks}}\right)(8)$. In dogs with normal sinus rhythm (SR), $I_{K s}$ is normally larger in RV (9-12). Reduction of $I_{K s}$ density during CAVB (13) may contribute to an increase in inter-ventricular and transmural dispersion of repolarization, potential indices (14) for the development of Torsade de Pointes (5).

The $I_{K s}$ channel is formed by the association of the KCNQ1 and KCNE1 gene products $(15,16)$; one or both are involved in LQT1, LQT5 and Jervell-LangeNielsen forms of congenital long QT sydrome (LQTS) (17). The molecular basis for the inter-ventricular distribution of $\mathrm{I}_{\mathrm{ks}}$ and its reduction during CAVB is unknown. In this study we examine the hypothesis that the inter-ventricular distribution of $\mathrm{I}_{\mathrm{Ks}}$ in sinus rhythm dogs and its reduction in density during CAVB are linked to altered expression of KCNQ1, KCNE1 or both genes.

\section{METHODS}

At three time points (sinus rate, and at the idioventricular rhythm at acute and 4-6 weeks chronic AV-block), a six lead surface ECG was serially recorded together with two endocardially placed monophasic action potential catheters. To correct for the slowing of the heart rate, the anaesthetised, adult mongrel dogs $(20-40 \mathrm{~kg})$ were paced at AAVB and CAVB at a cycle length, which was comparable to the cycle length of the previous sinus rhythm. For details about placement of the MAP catheters and the analysis of the signals, we refer to previous publications $(2,5)$.

The average area of the cardiac myocytes was obtained under brightfield microscopy by measuring the width and the length of rod shape myocytes.

Complete AV block was produced by injection of $37 \%$ formaldehyde into the AV groove. Details of the procedure were previously described $(2,5)$. All animals were euthanized by pentobarbital injection and the hearts were rapidly excised and placed in a cold cardioplegic solution (18). Dogs had AV block for $102 \pm 40$ days before 
euthanasia. Tissue or biopsies were snap frozen in liquid nitrogen and stored at $-70^{\circ} \mathrm{C}$ if RNA extraction or protein isolation was not immediately performed.

All procedures were performed in accordance with the Guiding Principles in the care and Use of Animals as approved by the American Physiological Society (NIH pub. 85-23 revised 1996) with the approval of the Committee for Experiments on Animals of Maastricht and the Masonic Medical Research Institutional Animal Care and Use Committee.

\subsection{Northern blotting}

Transmural RV and LV biopsies from CAVB and control dogs were taken from the middle portion of each ventricle. DNA templates for the KCNQ1 (517 bp) and KCNE1 (99 bp) probes were generated from a dog CDNA library by PCR using primers with homologous sequences in Human, Xenopus Laevis, mouse and rat. Each amplicon was sequenced and ligated into the PCR-Script AMP SK(+) expression vector (Stratagene, Menasha, WI). The cDNA probes were then amplified by $P C R$ and radioactively labeled by incorporation of trace amounts of $\left[\alpha^{32} P\right] d C T P$. Total RNA was extracted using the TRIZOL Total RNA extraction kit (Gibco BRL Life Technologies, MD) according to the manufacturer's protocol. The quality and quantity of RNA were respectively assessed by visual inspection on denaturing gels and measured by optical density (OD) reading at 260 and $280 \mathrm{~nm}$. Total RNA (20 $\mu \mathrm{g} /$ /ane) was fractionated on a $1 \%$ denaturing agarose gel and transferred to a nitrocellulose membrane (Hybond $\mathrm{NX}^{+}$, Amersham, Piscataway $\mathrm{NJ}$ ) for hybridization with the KCNQ1 and KCNE1 probes respectively. Radiolabeled 18S rRNA ( $\left[\alpha^{32} P\right]$ dCTP) was used as loading control. Blots were pre-hybridized (blocked) with salmon sperm ssDNA. Probes were diluted to an activity of $10^{7} \mathrm{cpm} / \mathrm{ml}$ and let to hybridize on the membrane at $57-60^{\circ} \mathrm{C}$ overnight. Blots were exposed to a phosphor screen for 3-4 days and analyzed on a phosphor imager (Kodak, $\mathrm{N} J$ ). Following analysis of the first hybridization (KCNQ1), blots were stripped and re-probed for KCNE1 RNA.

\subsection{Competitive Multiplex RT-PCR}

Two milligrams of cardiac tissue were dissected from the base of the anterior wall of each ventricle. Total RNA was extracted as described above and reverse transcribed (RT) using Superscript II (Gibco BRL, Gaithesburg, MD) according to the manufacturer's protocol. Yields were quantified by $\mathrm{OD}_{260 / 280}$ and gel densitometry. A fragment of v-erB (viral erB) was amplified with composite primers having short segments of the $-\mathrm{NH}_{2}$ and $-\mathrm{COOH}$ termini of $\mathrm{KCNE} 1$ or $\mathrm{KCNQ} 1$ to yield a competitive DNA fragment (MIMIC) with terminal sequences identical to their respective target genes. MIMIC was used as an exogenous non-homologue internal standard to compete with the target genes KCNQ1 and KCNE1. MIMIC and target genes were amplified using $2 \mu \mathrm{g}$ of RT-DNA mixed with $5 \mu \mathrm{l}$ of MIMIC dilutions in 10-fold increments from 100 attomoles, Pfu DNA polymerase and dNTP's containing $0.01 \%$ of digoxigenin (DIG) labeled dTTP's. PCR products were transferred to a positively charged nylon membrane for quantitative assay. The signal was detected using FAB fragments from sheep anti-digoxigenin antibodies conjugated with alkaline 
phosphatase (AP) and the chemiluminescent AP substrate CDP-star (BoehringerMannheim, Germany). Membranes were exposed to X-ray films and the density of each band was measured using an EDC scanning densitometer (Helena Labs, Fort Worth TX).

\subsection{Electrophysiological recordings}

Cardiac myocytes were dissociated from the left ventricles of adult mongrel dogs as previously described (18). Following dissociation, the cells were resuspended in a cardioplegic solution containing (in $\mathrm{mM}$ ): $132 \mathrm{NaCl}, 20 \mathrm{HEPES} / \mathrm{NaOH}, 3.3$ $\mathrm{MgSO}_{4} \times 7 \mathrm{H}_{2} \mathrm{O}, 11.1 \mathrm{D}$-Glucose, $5 \mathrm{KCl}, 0.5 \mathrm{CaCl}_{2}, 1.5 \% \mathrm{BSA}$ and stored at $4^{\circ} \mathrm{C}$ for 1 to 3 hours. In instances where the yield of viable cells was low, the fraction was enriched by purification on a Percoll gradient as previously described (19).

For patch clamp recordings in whole cell configuration, cells were placed in the perfusion chamber of an inverted microscope and superfused with Tyrode solution containing $E-4031(5 \mathrm{mM})$, a specific $I_{K r}$ blocker $(20,21)$ and nifedipine $(5 \mathrm{mM})$, a calcium channel blocker. Pipette solutions contained the following (in $\mathrm{mM}$ ): $125 \mathrm{~K}$ aspartate, $20 \mathrm{KCl}, 1 \mathrm{MgCl}_{2}, 5 \mathrm{MgATP}, 5 \mathrm{HEPES}, 10 \mathrm{EGTA}\left(\mathrm{pH} 7.1(\mathrm{KOH})\right.$. I $\mathrm{Ks}_{\mathrm{s}}$ was recorded by a depolarization step to $30 \mathrm{mV}$ for $3 \mathrm{sec}$ from a holding membrane potential of $-50 \mathrm{mV}$, followed by repolarization to $0 \mathrm{mV}$ (repeated 5 times every 10 seconds). Ito was not blocked, but it had little influence on our measurement of $I_{k}$ because of its fast and complete inactivation in this species (22). Currents were
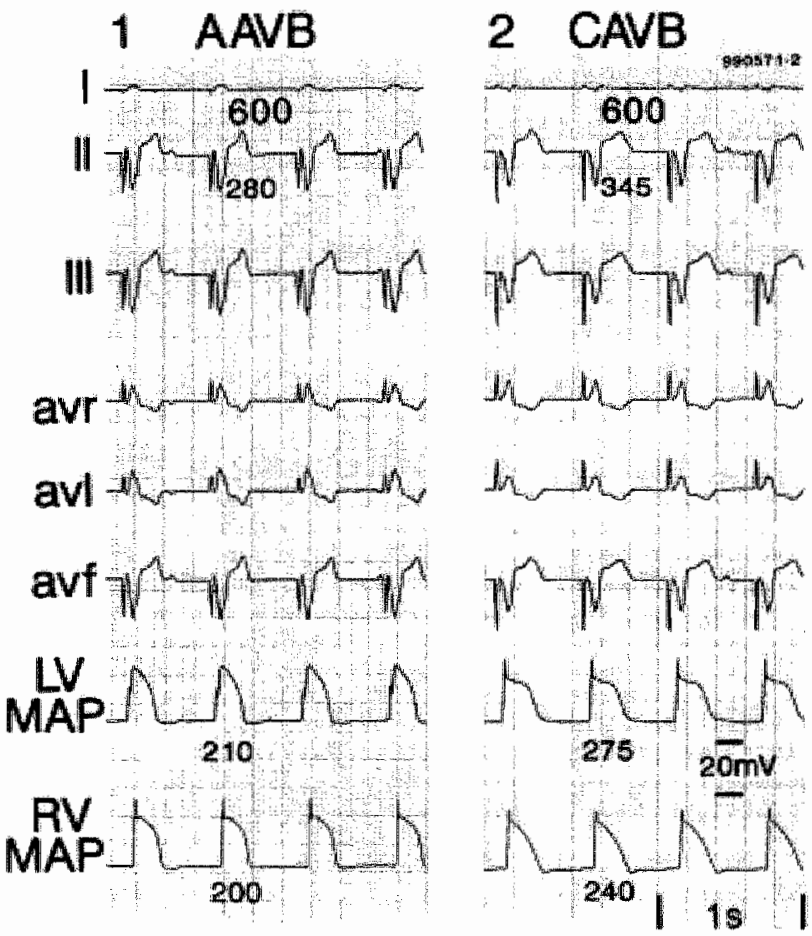

Figure 1. Eloctrophysiological remodeling of canine hearts during AV block. Representative ECG from standard leads logether with two monophasic action potential (MAP) recordings from the loft (LV) and tight (RV) wentricles (25 mm/sec) in the same $\mathrm{dog}$ to show the progression of the electrophysiological parameters from the initial acute AV black (AAVB) to the chronic AV block conditions (CAVB) after 32 days. Hearts were paced at a basic cycle length of 600 msec via an apical alectrade. ECG, QT-time and action potential recordings showed significant prolongation from 280 $10345 \mathrm{~ms}$ (lead ll), 210 to $275 \mathrm{~ms}$ (LV MAP) and 20010240 ms (RV MAP) respectiwely. 
amplified with an axopatch $2 \mathrm{~A}$, recorded and analyzed using the Axon Pclamp v. 8 suite of software (Axon Instrument, Carlsbad CA).

\subsection{Cryosectioning}

Thin slices from the heart ventricles were dissected out and immediately placed for 10 minutes in a relaxing $\mathrm{Ca}^{2+}$-free Tyrode solution at $4^{\circ} \mathrm{C}$ containing (in $\mathrm{mM}$ ): $130 \mathrm{NaCl}, 10 \mathrm{KCl}, 0.2 \mathrm{CaCl}, 2 \mathrm{MgCl}, 10$ HEPES. The bathing solution was then supplemented with Caffeine, $5 \mathrm{mM}$ and the tissue was let to relax for another 15 minutes. Tissues were then cryoprotected by incubating the slices 4 to 8 hours in the relaxing solution supplemented by $25 \%(\mathrm{w} / \mathrm{v})$ sucrose. The slices were then quickly rinsed in $\mathrm{Ca}^{2 *}$-free Tyrode, placed in cryogenic cassettes, dipped in liquid nitrogen for 2 to 4 minutes and stored at $-80^{\circ} \mathrm{C}$. Sectioning $(15 \mathrm{~mm})$ of the tissue block was performed on a Leitz 1720 Digital Kryostat (Leica Microsystems, NJ) according to the manufacturer's instructions. Hematoxylin-Eosin staining followed standard clinical procedures.

\subsection{Immunoblots}

Polyclonal antibodies (Ab) against the epitopes SVSEKSKDRGSNTIG and YIRSKKLEHSHDPFN in the -COOH termini of KCNQ1 in KCNE1 respectively, were raised in rabbits by intramuscular injection of a 50:50 mixture of 8 branch multiple antigenic peptides (MAP) and keyhole limpet hemocyanin (KLH) conjugated linear peptides. Abs were affinity purified on antigen sephadex columns and their titer was determined by ELISA. Total cell and tissue proteins were isolated out of the organic phase obtained from the totall RNA isolation procedure (AMBION, Austin, TX) by sequential overnight dialysis against $0.1 \%$ SDS at $4^{\circ} \mathrm{C}$. Membrane proteins were obtained by standard sucrose gradient centrifugation. Briefly, tissues were snap frozen in liquid $\mathrm{N}_{2}$ and pulverized using a mortar and pestle. One gram of tissue powder was homogenized in buffer containing: 4 mM HEPES, pH7.0; $320 \mathrm{mM}$ Sucrose; $0.2 \mathrm{mM}$ PefablocSC; Pepstatin A (1 mg/ml); Leupeptin (1 $\mathrm{mg} / \mathrm{ml})$; Aprotinin (1 $\mathrm{mg} / \mathrm{ml})$; Benzamidine $(100 \mathrm{mg} / \mathrm{ml})$ and Calpain inhibitors 1 and $111(8 \mathrm{mg} / \mathrm{ml}$ each) and centrifuged at $2000 \mathrm{~g}$ for 10 minutes to remove debris. The supernatant was set aside and the pellet was resuspended in fresh buffer, re-homogenized and spun a second time at $200 \mathrm{~g}$ for $10 \mathrm{~min}$. Both supernatants were pooled and centrifuged at $10^{4} \mathrm{~g}$ for $1 \mathrm{hr}$ and the membrane protein pellet was resuspended in $1 \mathrm{ml}$ buffer.

Table 1. Electrophysiological parameters during sinus rhythm (SR) and chronic AV block (CAVB). Paired electrophysiological parameters were obtained from the same dogs in SR just before AV block and after $37 \pm 8$ days of CAVB $(n=10)$. Each dog served as its own control. QT and IT intervals were corrected (QT, and JT) using the van de Water method (40). APD: action polential duration at $100 \%$ repolarization from MAP recondings (Figure 1). $\triangle A P D$ : difference between LV and RV APD. RR and OT intervals have their standard clinical meaning. All Data: ( \pm SD) are expressed in milliseconds and were significantly increased $(p<0.05$ ) after CAVB (umpaired t-test).

\begin{tabular}{|c|c|c|c|c|c|c|c|c|}
\hline & 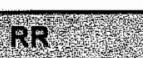 & ARs & QT & 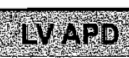 & RWAPD & AP & 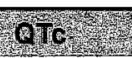 & $4 \operatorname{lin}^{2}$ \\
\hline SR & $601 \pm 114$ & $67 \pm 5$ & $250 \pm 40$ & & $210 \pm 34$ & $20 \pm 15$ & $285 \pm 33$ & $218 \pm 35$ \\
\hline CAVE & 3891263 & 8601 & $396 \times 59$ & 359657 & 8 3134 & 4628 & 36655 & $280=35$ \\
\hline
\end{tabular}


Protein concentration was determined by optical density $O D_{268: 280}$ readings and bicinchonic acid assay (SIGMA, St. Louis,MO). Proteins (20-70 $\mu \mathrm{g} / \mathrm{lane}$ ) were run on SDS-polyacrylamide (PAA) gels (12\% PAA for KCNQ1; 20\% PAA for KCNE1), and transferred on PVDF membranes (BIORAD, Hercules, $C A$,). The blots were incubated overnight with our polyclonal antibodies (anti-KCNQ1; 1:5000) and KCNE1 (Anti-IsK; 1:500). Loading errors were controlled by comparison of the coomassie blue or Ponceau staining of the PVDF membrane following semi-dry transfer.

The proteins of interest were detected by a secondary goat anti-rabbit Ab conjugated to alkaline phosphatase (AP) and enzymatic reaction with the chemiluminescent AP substrate CDP-Star (NEN, Boston, MA). Blots were exposed to $X$-ray films and each band intensity was measured using an EDC scanning densitometer (Helena Labs., Fort Worth, TX).

\subsection{Statistics}

Statistical significance was assessed with the Kruskal-Wallis test for nonparametric ANOVA. A level of $P<0.05$ was considered significant.

\section{RESULTS}

We initially monitored electrophysiological parameters in-vivo during the adaptation of the canine heart to AV block. Figure 1 shows that when paced at a cycle length of $600 \mathrm{~ms}_{n}$ the QT interval significantly prolonged as the heart adapted (32 days of CAVB). Monophasic action potential recordings showed concomitant prolongation of LV and RV APD and revealed an average increase in inter-ventricular dispersion of repolarization from $20 \pm 15$ to $45 \pm 30 \mathrm{~ms}$ (Table 1). With each dog serving as its own control, chronic AV block significantly increased $\mathrm{QT}_{\mathrm{c}}$ interval (limb leads) from $285 \pm 33 \mathrm{~ms}$ in sinus rhythm (SR) to $366 \pm 57 \mathrm{~ms}$ (Table 1). Structurally, the heart to body weight ratio $(\mathrm{g} / \mathrm{Kg})$ increased (data $\pm \mathrm{SD}$ ) from $7.7 \pm 1.2(\mathrm{n}=15)$ in $\mathrm{SR}(2)$ to $11.5 \pm 1.4(n=10)$ after CAVB. Hypertrophy was also evidenced by a thickening of the

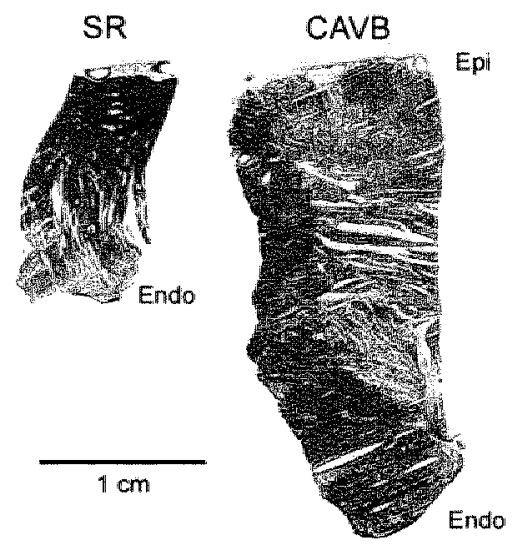

Flgure 2. Volume induced cardiac hypertrophy. Chronic AW block induced a thickering of the lleft ventricular wall as: shown by hematoxylin-eosin staining of a cryosection obtained immediately after dissection of the ventricles as described in Mekhods. 
left ventricle (Figure 2), resulting from an increase in the average size of myocardial myocytes from $3381 \pm 81 \mathrm{~mm}^{2}$ ( $n=1166$ ) to $4753 \pm 155 \mathrm{~mm}^{2}$ ( $\mathrm{n}=387, p<0.001$ ). Previous studies (13) have shown CAVB to be associated with a reduction in $\mathrm{I}_{\mathrm{Ks}}$ density in both ventricles. A similar reduction in $I_{K .}$ density was also abserved in myocytes of our CAVB dogs (Figure 3 ).

To link the decrease in $\mathrm{I}_{\mathrm{ks}}$ to changes in KCNQ1 and KCNE1 mRNA, we performed Northern blot assays. Figure 4A shows that our probes detected a 3.2 and 0.4 $\mathrm{kb}$ band corresponding to the size expected for KCNQ1 (3.2kb) (15) and KCNE1 $(0.39 \mathrm{~kb})(23,24)$ RNA, respectively. In biopsies from three SR dogs, the relative

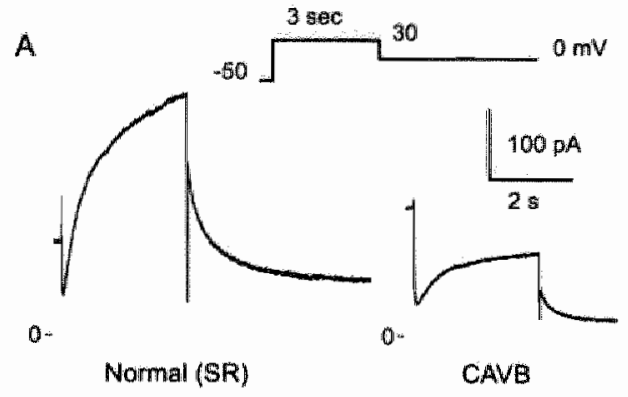

B

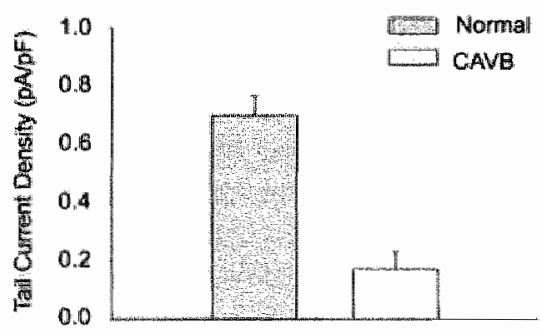

Figure 3, $I_{\text {wis }}$ density is significantly reduced during Chronic AVB black. The slowly activating component of the delayed rectifer current $\left(0_{\text {xis }}\right)$ is significantly smaller in CAVB dog epicardial myocytes compared to those of nomal diogs. I was recorded in the presence of $5 \mathrm{~m} M$ nifedipine

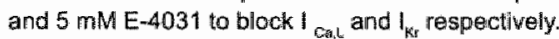
A) Current traces elicited by step depolarizations from a holding potential of $-50 \mathrm{mV}$ to $30 \mathrm{mV}$ for 3 $\mathrm{sec}$ and repotarization to $\mathrm{O} \mathrm{mV}$ in a nomal myocyte (Cm: $170 \mathrm{pF}$ ) and a CAVB myocyte (Cm: $255 \mathrm{pF}$ ). Voltage protocol is shown on the top. B) in CAVB imyocytes, $I_{R^{2}}$ tall current density was signilicantly lower $(0.17 \pm 0.07 \mathrm{pA} / \mathrm{pF})$ compared to normal myocytes $(0.70 \pm 0.07 \mathrm{pApF}) \mathrm{I}_{\mathrm{ks}}$ was measured as the tail current on relurn of membranie potential to $0 \mathrm{mV}$ from $30 \mathrm{mV}$. Data shown are mean \pm S.E.M $(n=4-6)$. " P<0.05 compared to nommal myocytes (Student's "t"test).

intensity of the bands for KCNQ1 and KCNE1 was similar in RV and LV. CAVB decreased the KCNQ1 RNA signal by $35 \pm 10 \%$ (vs. SR) in RV and by $38 \pm 20 \%$ in LV (Fig $4 B$ ). KCNE1 RNA was reduced by $63 \pm 8 \%$ and $46 \pm 27 \%$ (vs. SR) in LV and RV respectively following CAVB (Figure $4 \mathrm{C}$ ). We observed large inter-sample variations in the amount of transcripts within the small number of biopsies performed $(n=3)$. We attributed part of the variation to the low sensitivity of the Northern blot assay, the inherent normalization process needed to obtain semi-quantitative data and anatomical variations linked to the location of the biopsies.

To more accurately determine differences in $\mathrm{mRNA}$, we performed multiplex RTPCR (Figure 5). This method was favored over RNAse protection assay because of its better reproducibility, its higher sensitivity and ability to avoid the artifactual variations inherent to comparison with housekeeping genes whose abundance may 
also vary during CAVB. Figure 5D, E shows that CAVB reduced KCNE reverse transcribed cDNA by $72 \pm 25 \%$ and $76 \pm 29 \%$ and $K C N Q 1$ by $82 \pm 20 \%$ and $93 \pm 7 \%$ in LV and RV respectively (Figure 5D,E). Multiplex RT-PCR also revealed that KCNQ1 cDNA was $355 \pm 30 \%$ more abundant in RV than in LV in SR dogs. CAVB abolished the inter-ventricular difference. In control experiments (Figure 5B), no genomic DNA was amplified from the RNA templates.

A

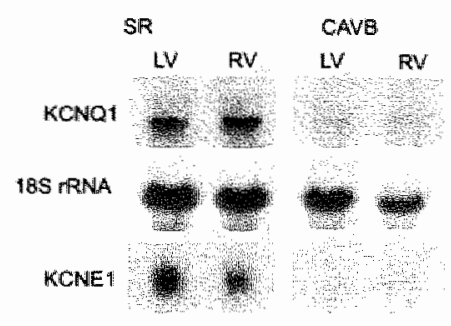

B

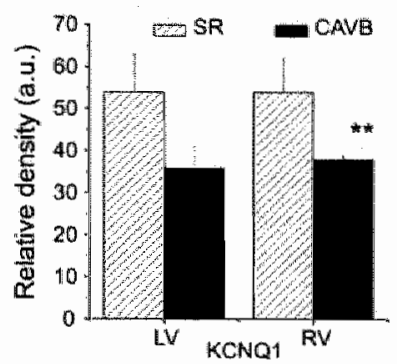

C

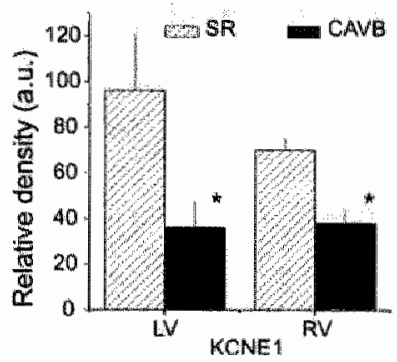

Figure 4. Chronic AV block (CAVB) reduces KCNQ1 and KCNE1 RNA levels in canine left (LV) and right ventricle (RV). A) Representative Northern blots from sinus rhythm (SR) and CAVB dogs. CDNA tragments from KCNQ1 and KCNE1 were obtained by PCR amplification, radiolabelled and hybridized to RNA extracted from tissues of cardiac biopsles taken from the mid region of the leit and right wentricular wall (see methods). Commercially avaitable cDNA probes for 18 s ribosomal RNA were used as loading control and reference standards (house keeping gene). B, C) The density of the KCNQ1 and KCNE1 bands in arbitrary units (a.u.) was normailized to the density of their respective 18S ribosomal RNA band (Relative density). Significance lewels: * $P<0.05,{ }^{* *} P<0.01,(n=3)$ SR vs. CAVB (Krustal-Wallis test "or nonparametric ANOVA).

To assess changes in protein expression, we performed immunoblots on proteins isolated from tissues. Figure 6 shows that our KCNE1 antibody recognized a protein of $35 \mathrm{kDa}$ and in some samples a lower molecular weight protein around $20 \mathrm{kDa}$ (Figure $6 \mathrm{~A}$ ). The density of the $35 \mathrm{kDa}$ band was $23 \pm 10 \%$ higher in RV vs. LV $(p=0.048$ ) of control dogs (Figure 6B). CAVB reduced the expression of KCNE1 by $58 \pm 14 \%$ and $70 \pm 15 \%$ in LV and RV respectively and abolished the small interventricular difference (Figure 6B).

Because CAVB-induced hypertrophy may induce changes in the cellular composition of the cardiac ventricles and reduce the relative contribution of KCNQ1 and KCNE1 to the tissue protein pool, we compared the banding patterns from tissue and acutely dissociated myocyte proteins. Figure $6 \mathrm{C}$ shows that a similar reduction in band intensity was observed in myocytes protein. The same observations were made in three different batches of cells from the left ventricle with an average reduction of $47 \pm 25 \%$. In control experiments (Figure 6D), antibodies pre-absorbed against the KCNE1 antigen failed to detect the strong $32 \mathrm{kDa}$ band observed in control.

In SR dogs, our KCNQ1 Ab recognized two bands of $\sim 72 \mathrm{kDa}$ and $\sim 120 \mathrm{kDa}$. Figure 7A shows that the intensity of both bands was strongly reduced by CAVB. To quantitate the change in expression, we measured the density of each band from 


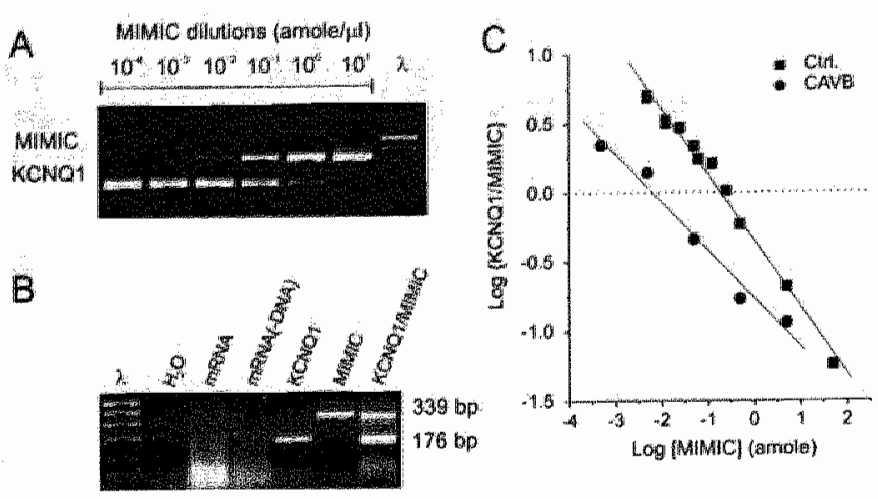

Figure 5. Competitiwe muttiplex RT-PCR shows CAVB-induced reduction of KCNEY and KCNOH CONA reverse transcribed (RT) from messenger RNA and reveals inter-ventricular helerogeneities in MRNA distribution. A) Representalive competitive $\mathrm{PCR}$ experintent. An exogenous MIMIC fragment was engineered to have identical primer sequence as the target gene (KCNQI) and used as internal standaric (MIMIC). The same set of primers amplified both the target gene and MMMlC thus eliminating non-linearity in the amplification of the two products. Ten fold dilutions of MIMIC and $2 \mu \mathrm{g}$ of RT-CDNA were used for each competitive PCR between MIMIC and KCNQH. The high intensity band in the DNA ladder (1) corresponds to $1 \mathrm{~kb}$. Size of fragments: MIMIC $332 \mathrm{bp}$. KCNQ1: 176 bp. B) Contral experiment showing that the $P C R$ product is not due to amplification of genomic DNA. When sterile water, total RNA or DNAse treated RNA IRNAL-

DNA.y were used as template for amplification, no amplicons were observed. C) Representative results from normal (Cth.) and CAVM dogss. The density of the KCNQ1 band was nomalized to that of MIMIC (Log $\{K C N Q 1 / M M M I C\})$ and

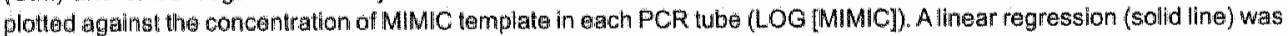
fitted to each set of data. $D, E)$ The concentration of targot gene cDNA in attomoles was determined by the intersection of the linear regression with the abscissa and normalized to the amount of RT-CDNA lemplate (mg) Used in each PCR reaction. Na 6 KCNE1 control dogs (Ctrl.), 4 KCNOU RV CAtr., 4 CAVB dogs. Statistical signiflcance (ANOVA): P P $<0.05$,

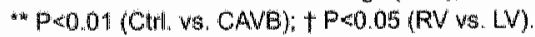

the RV and LV of CAVB dogs and normalized them to their respective values in SR dogs. Figure $7 \mathrm{~B}$ shows that CAVB similarly reduced the density of the $72 \mathrm{kDa}$ and $120 \mathrm{kDa}$ in LV and RV respectively. When the intensity of both bands was averaged, protein expression was reduced by $45 \pm 10 \%$ (RV) and $60 \pm 14 \%$ (LV). To assess whether the RNA distribution observed with RT-PCR translated into inter-ventricular differences in protein expression, we normalized the density of each immunoblot band from RV to their respective intensity in LV. Figure 7C shows that significantly more KCNQ1 protein was present in the right ventricle. The RVILV density ratio of both $72 \mathrm{kDa}$ and $120 \mathrm{kDa}$ bands were greater than 1 in sinus rhythm dogs. In CAVB dogs, the RV/LV ratio of the $72 \mathrm{kDa}$ band was slightly smaller but when the density of the $120 \mathrm{kDa}$ and the $72 \mathrm{kDa}$ were summed the difference was not significant. Thus, CAVB significantly reduced the inter-ventricular difference in protein and RNA 
A

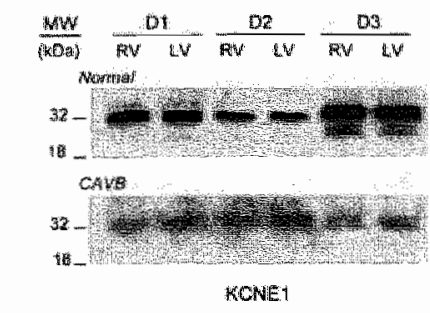

C

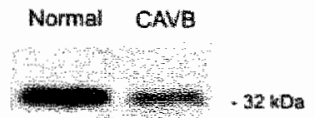

B

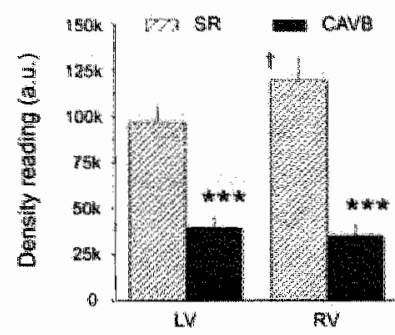

D)

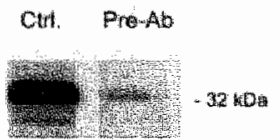

Figure 6. Expression of KCNE1 proteins is significantly reduced by CAVB. A Rapresentative Westem blot of tissue proteins $(20 \mathrm{Hg})$ extracted from the left ( $(\mathrm{V})$ ) and right ventricle (RV) of three nomal and three CAVB dogs (DH D3) and probed with affinity purified KCNE1 polyclonal antibody (PAb). The KCNE1 pAb recognized a band around $-35 \mathrm{KDa}$ and $\mathrm{a}$ very faint band around $-20 \mathrm{kDa}$ in control dogs. CAVB signiflcantly reduced the amount of protein recognized $\mathrm{Dy}$ the KCNE $1 \mathrm{pAb}$. B) Intensity of each band, in arbitrary units (a.u.), was measured by densitometry to assess the total protein expression in LV and RV of normal $(n=8)$ and CAVB dogs (n=9). Given the iow intensity of the $20 \mathrm{kDa}$ band, only the densily of the $35 \mathrm{kDa}$ band was measured in each experiment. C) Experiment described in $\mathrm{A}$ was repeated on proteins isolated from cardiac myocytes aculely dissociated from the endocardium of the left ventricle. D) Control Western blots using proteins extracted under low denaturing conditions and probed with anti-KCNE 1 antibodies (CHA) or with antibodies pre-absorbed against the KCNE antigen (Pre-Abs). Statistical significance (ANOVA): $p<0.001$ (CHr). Vs. CAVB); $0<0.05$ (RV vs. LV).

distribution. A $72 \mathrm{kDa}$ band is predicted based on the KCNQ1 protein sequence. Figure $7 \mathrm{D}$ shows that both the $72 \mathrm{kDa}$ and $120 \mathrm{kDa}$ bands were recognized in the total protein preparation but only the $120 \mathrm{kDa}$ band was predominant in proteins isolated from the membrane fraction. Thus, the $120 \mathrm{kDa}$ band is linked to the cytoplasmic (mature) form of the protein while the $72 \mathrm{kDa}$ band is likely to be related to cytosolic proteins. To verify that both bands were linked to KCNQ1, we performed immunoblots using pre-absorbed KCNQ1 antibodies. Figure 7D (right panel) shows that the intensity of both bands was strongly reduced when the KCNQ1 antibody was pre-absorbed against the control antigen. A search for homologies in the $\mathrm{NIH}$ GenBank and SWISS-PROT databases revealed that the epitope recognized by the $\mathrm{pAb}$ is specific to KCNQ1. Our results show that the $72 \mathrm{kDa}$ and $120 \mathrm{kDa}$ antigens contained the KCNQ1 specific epitope.

\section{DISCUSSION}

We show that chronic AV block induces a significant reduction in the expression of $\mathrm{KCNE} 1$ and KCNQ1, the putative genes responsible for $\mathrm{I}_{\mathrm{Ks}}$. The reduction in $\mathrm{KCNE1}$ and KCNQ1 proteins that we report is in close agreement with the previous (13) demonstration of a $50 \%$ and $55 \%$ reduction in $I_{K S}$ density in the LV and RV of CAVB dogs. KCNQ1 mRNA was $300 \%$ more abundant in RV vs. LV. That inter-ventricular 
A
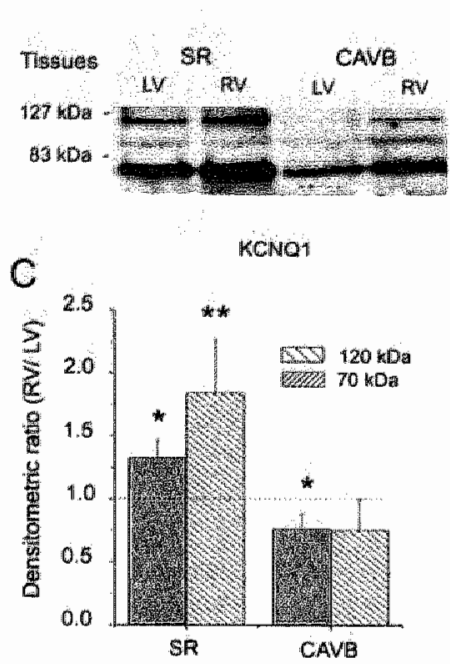

B

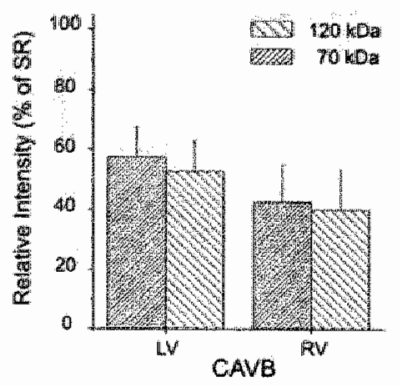

D

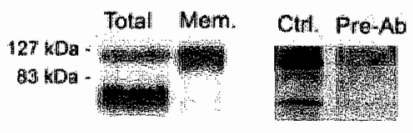

Figure 7. Expression of KCNQ1 proteins is significantly reduced by CAVB. A) Representative Western blot of tissue proteins $(20 \mu \mathrm{g})$ extracted from the left (LV) and right ventricle (RV) of a normal sinus rhythm dog (SR) and a CAVB dog and probed with affinity puriffed KCNQ1 polyclonal antibody (pAB). The $\mathrm{pAB}$ recognized twa bands with molecular weights (MW) of $\sim 72 \mathrm{kDa}$ and $\sim 120 \mathrm{kDa}$ respectively in normal dogs. Interssity of each band was measured by densitometry. B) To quantititate the CAVB-induced reduction in KCNQ1 expression, the average density of the bands from the left and right ventricles of CAVB dogs were normalized to the intensities obtained in SR dogs. All measurements showed a significant reduction in intensity during CAVB $(p<0.001)$. C) To measure inter-ventricular differences in the expression of KCNQ1, a density ratio light vs. left ventricle was calculated for the $72 \mathrm{KDa}$ and $120 \mathrm{kDa}$ band obtained from the normal " $S R_{n} n=8$ ) and CAVB dogs ( $n=9$ ). Statistical significance: " $p<0.05{ }^{*}$ *" $p<0.01$ (Ratio against 1). D) Left Panel: Experiments as described in A were repeated on total proteins (Total) and membrane proteins (Membr.) isolated from cardiac myocytes acutely dissociated from the endocardium of the left ventricle of SR. Right panel: Control immuncblot of proteins extracted under low denaturing conditions and probed with anti-KCNQ1 antibodies (Ctrl.) or with antibodles pre-absorbed against the KCNQN1 antigen (Pre-Ab).

mRNA distribution was abolished during CAVB. Thus, our data suggest that a common transcriptional factor, possibly stabilizing mRNA, may be responsible for the inter-ventricular difference in the expression of KCNQ1 and KCNE1 and that CAVB reduces the activity of this factor.

We observed a disproportionate CAVB-induced downregulation in KCNQ1 mRNA $(82-93 \%)$ when compared to protein levels $(45-60 \%)$ and $I_{K_{s}}$ current $(50-55 \%)$. In view of its proposed role as a chaperone protein $(15,16)$, KCNE1 may play a determining role in the expression of KCNQ1 at the level of the plasma membrane. This hypothesis is supported by our observation of a proportional reduction of KCNE1 protein, $\mathrm{mRNA}$ and $\mathrm{I}_{\mathrm{Ks}}$ and may explain the lack of corellation with the reduction of KCNQ1 mRNA in the CAVB dog.

Our findings of a proportionate reductions in the density of KCNQ1 membrane protein and cytosolic proteins, $120 \mathrm{kDa}$ and $72 \mathrm{kDa}$ bands respectively (Figure 7B, $D$ ), also raise the interesting possibility that KCNE1 regulates the expression of KCNQ1 through a feedback mechanism coordinating the translation of KCNQ1 with 
the formation/recycling of the KCNQ1/KCNE1 protein complex. Although the identity of the $120 \mathrm{kDA}$ band remains unclear, it is likely to be associated with a glycosilated protein complex formed by KNCQ1 and KCNE1 or another ancillary sub-unit. Our experiments with different glycosidase gave mixed results and remaining unspecific IgG's in our affinity purified polyclonal antibodies prevented efficient immunoprecipition of KCNQ1. Commercially available KCNQ1 antibodies failed to recognize the dog epitope. Further experiments are therefore needed to fully identify the components of the $120 \mathrm{kDa}$ band and validate the hypothesis of a feedback mechanism. Previous studies have shown an up-regulation of $\mathrm{Na}^{+}-\mathrm{Ca}^{2+}$ exchange (NCX1) current during CAVB (25). An increase in NCX1 mRNA in models of pressure overload hypertrophy (26) was also reported. But no significant changes in the density of the transient outward current $I_{10}$, the inward rectifier current $I_{k 1}$ and the slow inward calcium current were observed in our model $(13,25)$. Down-regulation of KCNE1 and KCNQ1 expression therefore contributes importantly to the electrical remodeling of the ventricular myocardium following volume overload hypertrophy. Our results also provide insight into the molecular basis for the inter-ventricular difference in $\mathrm{I}_{\mathrm{Ks}}$ previously shown to exist in normal hearts. We found interventricular ratios of 1.32 and 1.84 for KCNQ1 low and high molecular weight antigens respectively. These results are in good agreement with the data of Volders et al. (12) who reported $\mathrm{I}_{\mathrm{ks}}$ densities of $0.72 \pm 0.12 \mathrm{pA} / \mathrm{pF}$ and $0.38 \pm 0.13 \mathrm{pA} / \mathrm{pF}$ for the right and left ventricle respectively (RVILV ratio: 1.89 ). This concordance between the eletrophysiological and the biochemical data strengthens the notion that a KCNE1/ KCNQ1 protein complex is responsible for $\mathrm{I}_{\mathrm{Ks}}$.

Recent evidence suggests that other ancillary sub-units from the KCNE family may modulate KCNQ1 expression $(27,28)$. However the kinetics of currents described for KCNE2/KCNQ1 or KCNE3/KCNQ1 (in heterologous systems) differ from those normally present in dog cardiomyocytes. Moreover, our data strongly suggest that the association of KCNQ1 with KCNE1 is primarily responsible for $I_{K s}$ and that CAVBinduced reduction of KCNE1 and KCNQ1 expression is a sufficient, but not necessarily exclusive, mechanism to account for the reduction in $I_{\mathrm{Ks}}$ density. Recent evidences also indicated that $\mathrm{KCNE} 1$ may interact with $\mathrm{KCNH} 2$ (HERG), the gene coding for the alpha sub-unit generating $I_{k r}(29)$. Co-expression studies however demonstrated a competitive interaction between KCNE1 and KCNE2 for co-assembly with HERG largely favoring KCNE2 (29). This abservation notwithstanding, it is possible that the reduction of $\mathrm{KCNE} 1$ demonstrated in this study may also contribute to the marked reduction in $\mathrm{I}_{\mathrm{Kr}}$ known to be associated with CAVB.

We found a molecular a weight between 28 and $35 \mathrm{kDa}$ for KCNE1, slightly higher than what was previously reported (25 to $30 \mathrm{kDa}$ ). We attributed the discrepancy to technical differences. The molecular weight of KCNE1 was strongly dependent on the gel temperature and density and the protein standard used. The BioRad Kaleidoscope marker, used for most of our experiments indicated a $\mathrm{mW}$ around 30$35 \mathrm{kDa}$. Other markers (Promega) indicated a band closer to $29 \mathrm{kDa}$ on the same gel (not shown). 
Clinical implications

Prolongation of the QT interval has been a consistent finding in our model and in several other models of hypertension as well as humans, Our observations support the hypothesis that the electrical remodeling attending cardiac hypertrophy is akin to acquired long QT syndrome. The reduction of KCNQ1 and KCNE1 expression results in electrophysiology similar to the most severe form of LQTS in which $I_{K S}$ is drastically reduced due to dominant negative mutations in KCNQ1 or KCNE1 genes (30-33).

Torsade de Pointes (TdP) commonly develops in the setting of LQTS due in part to an increased dispersion of repolarization across the ventricular wall and septum of the heart, which creates the substrate for reentry $(2,14,34-36)$. In the canine and human heart, $M$ cells normally display low levels of $I_{\mathrm{Ks}}$. $M$ cells have been identified as the main culprits in LQTS-related arrhythmias because their action potentials prolong out of proportion in the presence of agents with Class III actions, thus augmenting transmural dispersion of repolarization. $M$ cells are also prone to develop EADs as well as delayed afterdepolarizations under these same conditions (36). The reduction in KCNE1 and KCNQ1 expression may confer to all ventricular cells arrhythmogenic properties similar to those normally found in the $M$ region. By drastically reducing $I_{\mathrm{Ks}}$, CAVB-induced hypertrophy may increase the dependence of late repolarization on $I_{K r}$ and, as a consequence, its sensitivity to Class III antiarrhythmic agents.

\section{Limitations}

The degree to which CAVB caused a reduction in KCNQ1 and KCNE1 RNA was smaller when assessed using Northern blot vs. quantitative PCR assay. Moreover, the differences in message between RV and LV in SR dogs were less apparent using the Northern blot assay. We attribute this largely to the superior sensitivity and accuracy of the quantitative PCR vs. Northern blot analysis, which relies on ratiometric measurements against an endogenous "housekeeping" gene RNA. These discrepancies may also be due in part to differences in the origin of the tissues along the apico-basal axis of the ventricle

A dominant negative N-terminal truncated KVLQT1 isoform (isoform 2) lacking 129 amino acids is expressed in the human heart (37). In immunoblots, Demolombe et al. (37) observed a small difference in the migration of the two isoforms and associated part of the weaker $I_{\mathrm{Ks}}$ current recorded in the left mid-myocardium to enhanced expression of the truncated isoform (38). Our Ab against KCNQ1 could not detect bands other than the ones previously attributed to the long isoform of KCNQ1 (37). The epitope recognized by our polyclonal antibody is found in human and $\operatorname{dog} \mathrm{KCNQ} 1$ and is located in that part of the $\mathrm{COOH}$ terminal region common to both isofoms. Our immunoassays suggest that llower molecular weight isoform 2 is not present in the ventricles of the dog. In other studies (not shown), we were not able to detect RNA corresponding to the truncated isoform 2 by RT-PCR or by RACE PCR (Rapid Amplification of Cohesive Ends) on our dog CDNA library. Since isoform 2 expression is cardiac-specific through genomic imprinting (39), chromosomal 
variations between species may limit its expression in dog ventricles. Comparisons between species should always be made cautiously; nonetheless, our results show that isoform 1 expression is reduced during CAVB. In human, the dominant negative effect of KCNQ1 isoform 2 may add to the downregulation of KCNQ1 (isoform 1) and $K C N E 1$ and potentiate the reduction in $\|_{K s}$. Thus, our model may underestimate the reduction in $I_{K s}$ linked to reduced expression of KCNQ1 and KCNE1 in human.

\section{ACKNOWLEDGEMENTS}

This work was supported by: Netherlands Heart Foundation NHS \#98042 (MAV), NHS pre-doctoral (CR), US National Institutes of Health: HL-47678 (CA) and HL59449 (RD), American Heart Association, NYS Affiliate (CA).

\section{REFERENCES}

1. Kaab S, Nuss HB, Chiamvimonvat N, O'Rourke B, Pak PH, Kass DA, et al. lonic mechanism of action potential prolongation in ventricular myocytes from dogs with pacing-induced heart failure. Circ Res 1996;78(2):262-73.

2. Vos MA, de Groot SH, Verduyn SC, van der Zande J, Leunissen HD, Cleutjens $\mathrm{JP}$, et al. Enhanced susceptibility for acquired torsade de pointes arrhythmias in the dog with chronic, complete AV block is related to cardiac hypertrophy and electrical remodeling. Circulation 1998;98(11):1125-35.

3. Wusten $B$, Flameng $W$, Schaper $W$. Cardiac function in the chronically volume-overloaded canine heart. Basic Res Cardiol 1977;72(2-3):172-7.

4. Verduyn SC, Ramakers C, Snoep G, Leunissen ID, Wellens HJ, Vos MA. Time course of structural adaptations in chronic AV block dogs: evidence for differential ventricular remodeling. Am J Physiol Heart Circ Physiol 2001;280(6):H2882-90.

5. Verduyn SC, Vos MA, van der Zande $J$, van der Hulst FF, Wellens $H J$. Role of interventricular dispersion of repolarization in acquired torsade-de-pointes arrhythmias: reversal by magnesium. Cardiovasc Res 1997;34(3):453-63.

6. Volders PG, Sipido KR, Vos MA, Kulcsar A, Verduyn SC, Wellens HJ. Cellular basis of biventricular hypertrophy and arrhythmogenesis in dogs with chronic complete atrioventricular block and acquired torsade de pointes. Circulation 1998;98(11): $1136-47$.

7. Verduyn SC, Vos MA, van der Zande J, Kulcsar A, Wellens HJ. Further observations to elucidate the role of interventricular dispersion of repolarization and 
early afterdepolarizations in the genesis of acquired torsade de pointes arrhythmias: a comparison between almokalant and d-sotalol using the dog as its own control. J Am Coll Cardiol 1997;30(6):1575-84.

8. Sanguinetti MC, Jurkíewicz NK. Lanthanum blocks a specific component of $\mathbb{I K}$ and screens membrane surface change in cardiac cells. Am J Physiol 1990;259(6 Pt 2):H1881-9.

9. Liu DW, Antzelevitch C. Characteristics of the delayed rectifier current (IKr and IKs) in canine ventricular epicardial, midmyocardial, and endocardial myocytes. A weaker IKs contributes to the longer action potential of the $M$ cell. Circ Res 1995;76(3):351-65.

10. Salata JJ, Jurkiewicz NK, Jow B, Folander K, Guinosso PJ, Jr., Raynor B, et al. IK of rabbit ventricle is composed of two currents: evidence for IKs. Am J Physiol 1996;271(6 Pt 2):H2477-89.

11. Li GR, Feng J, Yue L, Carrier M, Nattel S. Evidence for two components of delayed rectifier $K+$ current in human ventricular myocytes. Circ Res 1996;78(4):68996.

12. Volders $P G$, Sipido KR, Carmeliet E, Spatjens RL, Wellens HJ, Vos MA. Repolarizing $\mathrm{K}+$ currents ITO1 and IKs are larger in right than left canine ventricular midmyocardium. Circulation 1999;99(2):206-10.

13. Volders $P G$, Sipido KR, Vos MA, Spatjens RL, Leunissen JD, Carmeliet $E$, et al. Downregulation of delayed rectifier $\mathrm{K}(+)$ currents in dogs with chronic complete atrioventricular block and acquired torsades de pointes. Circulation 1999;100(24):2455-61.

14. Antzelevitch $C$, Dumaine R. Electrical heterogeneity in the heart: Physiological, pharmacological and clinical implications. New York: Oxford University Press; 2002.

15. Sanguinetti MC, Curran ME, Zou A, Shen J, Spector PS, Atkinson DL, et al, Coassembly of K(V)LQT1 and minK (IsK) proteins to form cardiac I(Ks) potassium channel. Nature 1996;384(6604):80-3.

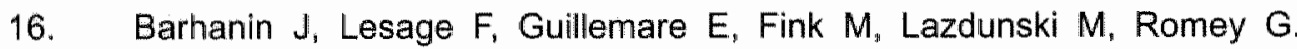
K(V)LQT1 and IsK (minK) proteins associate to form the I(Ks) cardiac potassium current. Nature 1996;384(6604):78-80.

17. Splawski I, Shen J, Timothy KW, Lehmann MH, Priori S, Robinson JL, et al. Spectrum of mutations in long-QT syndrome genes. KVLQT1, HERG, SCN5A, KCNE1, and KCNE2. Circulation 2000;102(10):1178-85. 
18. Zygmunt AC, Goodrow RJ, Weigel $\mathrm{CM}$. $\mathrm{INaCa}$ and $I \mathrm{Cl}(\mathrm{Ca})$ contribute to isoproterenol-induced delayed after depolarizations in midmyocardial cells. Am J Physiol 1998;275(6 Pt 2):H1979-92.

19. Heathers GP, Yamada KA, Kanter EM, Corr PB. Long-chain acylcarnitines mediate the hypoxia-induced increase in alpha 1-adrenergic receptors on adult canine myocytes. Circ Res 1987;61(5):735-46.

20. Sanguinetti MC, Jurkiewicz NK. Two components of cardiac delayed rectifier $\mathrm{K}+$ current. Differential sensitivity to block by class III antiarrhythmic agents. J Gen Physiol 1990;96(1):195-215.

21. Sanguinetti MC, Jurkiewicz NK. Delayed rectifier outward K+ current is composed of two currents in guinea pig atrial cells. Am J Physiol 1991;260(2 Pt 2): $\mathrm{H} 393-9$.

22. Liu DW, Gintant GA, Antzelevitch C. Ionic bases for electrophysiological distinctions among epicardial, midmyocardial, and endocardial myocytes from the free wall of the canine left ventricle. Circ Res 1993;72(3):671-87.

23. Murai T, Kakizuka A, Takumi T, Ohkubo H, Nakanishi S. Molecular cloning and sequence analysis of human genomic DNA encoding a novel membrane protein which exhibits a slowly activating potassium channel activity. Biochem Biophys Res Commun 1989;161(1):176-81.

24. Takumi $\mathrm{T}$, Ohkubo $\mathrm{H}$, Nakanishi $\mathrm{S}$. Cloning of a membrane protein that induces a slow voltage-gated potassium current. Science 1988;242(4881):1042-5.

25. Sipido KR, Volders $P G$, de Groot $S_{H}$, Verdonck $F$, Van de Werf $F$, Wellens $\mathrm{HJ}$, et al. Enhanced $\mathrm{Ca}(2+)$ release and $\mathrm{Na} / \mathrm{Ca}$ exchange activity in hypertrophied canine ventricular myocytes: potential link between contractile adaptation and arrhythmogenesis. Circulation 2000;102(17):2137-44.

26. Wang Z, Nolan B, Kutschke W, Hill JA. Na+-Ca2+ exchanger remodeling in pressure overload cardiac hypertrophy. J Biol Chem 2001;276(21):17706-11.

27. Tinel N, Diochot S, Borsotto M, Lazdunski M, Barhanin J. KCNE2 confers background current characteristics to the cardiac KCNQ1 potassium channel. Embo J 2000;19(23):6326-30.

28. Schroeder BC, Waldegger S, Fehr S, Bleich M, Warth R, Greger R, et al. A constitutively open potassium channel formed by KCNQ1 and KCNE3. Nature 2000;403(6766):196-9. 
29. Chen J, Zou A, Splawski I, Keating MT, Sanguinetti MC. Long QT syndromeassociated mutations in the Per-Arnt-Sim (PAS) domain of HERG potassium channels accelerate channel deactivation. J Biol Chem 1999;274(15):10113-8.

30. Chen $Q$, Zhang D, Gingell RL, Moss AJ, Napolitano C, Priori SG, et al. Homozygous deletion in KVLQT1 associated with Jervell and Lange-Nielsen syndrome. Circulation 1999;99(10):1344-7.

31. Schulze-Bahr $E$, Wang $Q$, Wedekind $H$, Haverkamp $W$, Chen $Q$, Sun $Y$, et al. KCNE1 mutations cause jervell and Lange-Nielsen syndrome. Nat Genet 1997;17(3):267-8.

32. Neyroud N, Tesson F, Denjoy I, Leibovici $M$, Donger C, Barhanin J, et al. A novel mutation in the potassium channel gene KVLQT1 causes the Jervell and Lange-Nielsen cardioauditory syndrome. Nat Genet 1997;15(2):186-9.

33. Geelen JL, Doevendans PA, Jongbloed RJ, Wellens HJ, Geraedts JP. Molecular genetics of inherited long QT syndromes. Eur Heart J 1998;19(10):14271433.

34. Antzelevitch C. Basic mechanisms of reentrant arrhythmias. Curr Opin Cardiol 2001;16(1):1-7.

35. Dumaine R, Antzelevitch C. Molecular mechanisms underlying the long QT syndrome. Curr Opin Cardiol 2002;17(1):36-42.

36. Antzelevitch $C_{n}$ Shimizu W, Yan GX, Sicouri S, Weissenburger J, Nesterenko V'vi et ad. The MP cell: its contribution to the ECS and to hormal and abnomal electitical function of the heart. J Cardiovasc Electrophysiol 1999;10(8):1124-52.

37. Demolombe $S$, Baro I, Pereon $Y$, Bliek J, Mohammad-Panah R, Pollard $H$, et al. A dominant negative isoform of the long QT syndrome 1 gene product. J Biol Chem 1998;273(12):6837-43.

38. Pereon $Y$, Demolombe $S$, Baro $I$, Drouin $E$, Charpentier $F$, Escande $D$. Differential expression of KVLQT1 isoforms across the human ventricular wall. Am J Physiol Heart Circ Physiol 2000;278(6):H1908-15.

39. Lee MP, Hu RJ, Johnson LA, Feinberg AP. Human KVLQT1 gene shows tissue-specific imprinting and encompasses Beckwith-Wiedemann syndrome chromosomal rearrangements. Nat Genet 1997;15(2):181-5.

40. Van de Water A, Verheyen $\downarrow$, Xhonneux R, Reneman RS. An improved method to correct the QT interval of the electrocardiogram for changes in heart rate. J Pharmacol Methods 1989;22(3)207-17. 




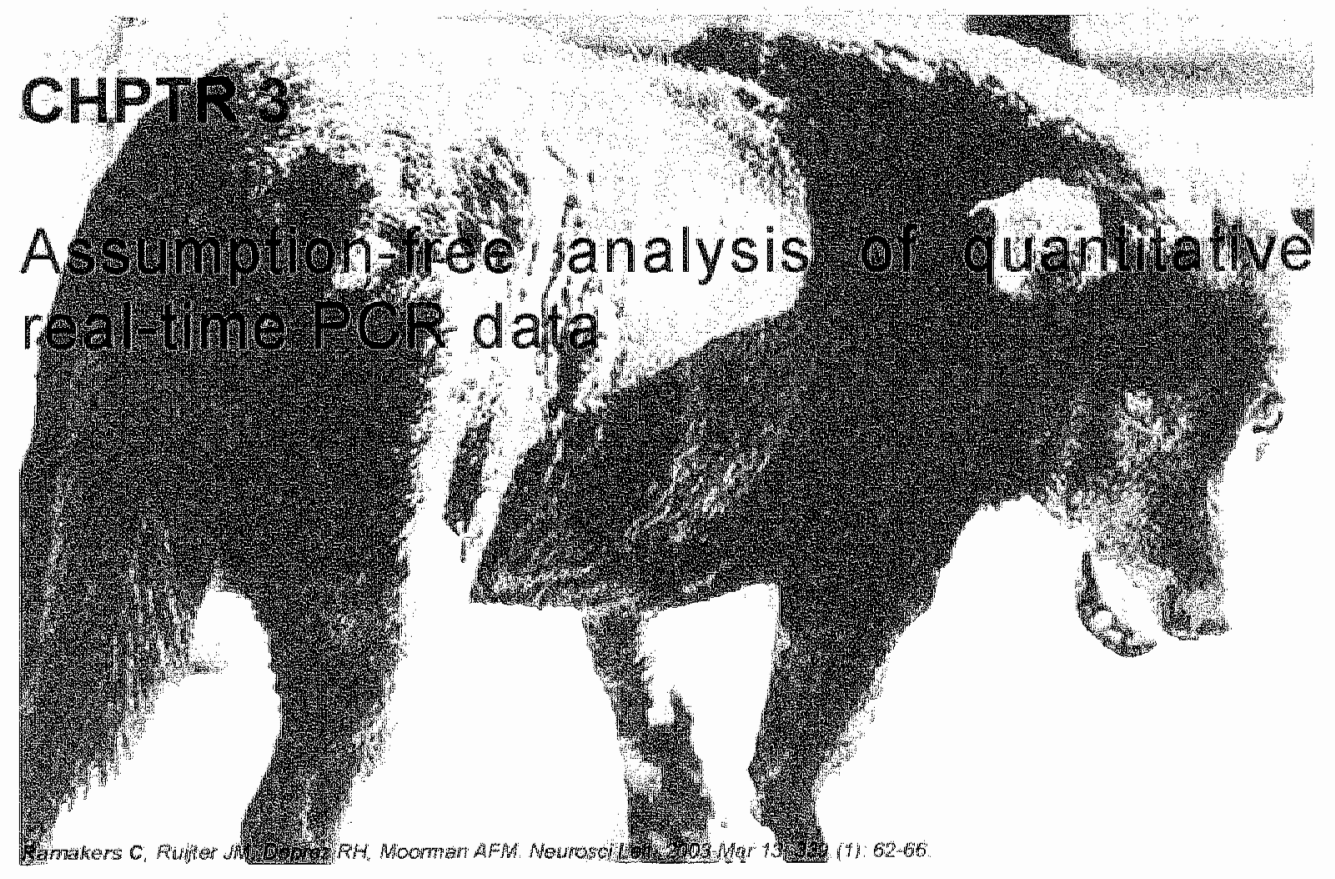




\section{SUMMARY}

Quantification of mRNAs using real-time PCR by monitoring with the fluorescent dye SYBR Green 1 is being extensively used in neurosciences, developmental biology, and medical diagnostics. Most PCR data analysis procedures assume that the PCR efficiency for the amplicon of interest is constant or even, in the case of the comparative $C_{1}$ method, equal to 2 . The latter method already leads to a 4 -fold error when the PCR efficiencies vary over just a 0.04 range. PCR efficiencies of amplicons are usually calculated from standard curves based on either known RNA inputs or on dilution series of a reference cDNA sample. In this paper we show that the first approach can lead to PCR efficiencies that vary over a 0.2 range, whereas the second approach may be off by 0.26 . Therefore, we propose linear regression on the Log(fiuorescence) per cycle number data as an assumption-free method to calculate starting concentrations of mRNAs and PCR efficiencies for each sample. A computer program to perform this calculation is available on request (e-mail: bioinfo@amc.uva.nl; subject: LinRegPCR). 
Recent developments in PCR combined with new fluorescent techniques have led to the introduction of quantitative or real-time $\operatorname{PCR}(1,2)$. This technique is extensively used in neurosciences, developmental biology and medical diagnostics and is preferred over other quantitative PCR methods because it does not rely on endpoint analyses, which can be misleading due to product inhibition, enzyme instability and a decrease of reaction components in time (3). Quantification of CDNA in realtime PCR in combination with the double stranded DNA specific dye SYBR ${ }^{\circledast}$ Green $I$ is based on the monitoring of the increasing fluorescence intensity after each PCR cycle. This SYBR green \| monitoring is available in all quantitative PCR systems. All currently used data analysis methods are based on determining the threshold cycle $\left(C_{t}\right)$, which is the fractional cycle number at which a fixed amount of DNA is formed. All calculations assume that the PCR efficiency of the amplicon of interest is constant over time and has the same value in all studied samples.

The comparative $C_{t}$ method even assumes this constant efficiency to be equal to 2 for the target and the reference amplicon (4). With this method, the amount of target amplicon $X$ in sample $S$, normalized to an endogenous reference $R$ and related to a control sample $C$ is calculated as shown in:

$$
2^{-\left\{\left(C_{t}^{X, s}-C_{t}^{R, s}\right)-\left(C_{t}^{X, C}-C_{t}^{R, c}\right)\right\}}
$$

Equation 1

resulting in the fold difference between sample and control. However, it has been reported that PCR efficiencies of target and reference amplicons can vary over a range of 1.8 to 2.0 (5). When this variation in PCR efficiency is taken into account, it can easily be calculated that a real 10 -fold difference can turn up as any value between 0.7 and 210 (Table 1). Even with a 0.04 range in PCR efficiencies (from 1.78 to 1.82 ) already a 4 -fold error in fold-difference will occur. This shows that the comparative $C_{t}$ method is very sensitive to variations in PCR efficiency. Alternatives, that include separate PCR efficiencies for target and reference amplicons but still

Table 1. Illustration of the effect of unequal PCR efficiencies on the result of the comparative Ct method. With this method, the fold difference defined as the amount of target amplicon $X$ in sample $S_{\text {" }}$ narmalized to an endogenous reference $R$ and related to a control sample $C$ can be calculated as shown in equation 1 . With an input 10 fold difference $\left(N_{0}\right.$ line) and PCR efficiencies ranging from 1.8 to 2.0 (E lines) the fractional number of cycles neaded to reach a thireshold of $50\left(N_{4}\right)$ can be calculated as $C_{t}=\left(\log \left(N_{t}\right)-\log (N o) / / \log (E)\right.$. From these threshold dycles the observed fold difference can be calculated ( 6 ).

\begin{tabular}{|c|c|c|c|c|c|}
\hline & Samplar & ris & Oonirol & Why & fold diforonge \\
\hline & Amplicon X & Reference & Amplicon $X$ & Reference & \\
\hline 10 & OMf & S0104 & 28. & and & te \\
\hline $\begin{array}{l}E \\
c_{t}\end{array}$ & $\begin{array}{l}2 \\
8.97\end{array}$ & $\begin{array}{l}1.8 \\
14.49\end{array}$ & $\begin{array}{l}1.8 \\
14.49\end{array}$ & $\begin{array}{l}2 \\
12.29\end{array}$ & Observed: 212 \\
\hline (6) & 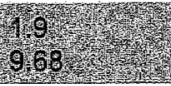 & $13^{2}$ & 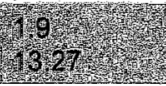 & 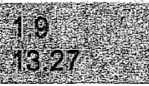 & 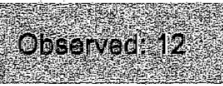 \\
\hline $\begin{array}{l}E \\
C_{t}\end{array}$ & $\begin{array}{l}1.8 \\
10.57\end{array}$ & $\begin{array}{l}2 \\
12.29 \\
\end{array}$ & $\begin{array}{l}2 \\
12.29 \\
\end{array}$ & $\begin{array}{l}1.8 \\
14.49\end{array}$ & Observed: 0.7 \\
\hline
\end{tabular}


assume constant efficiencies in all samples, have been published $(5,6)$. These alternatives rely on standard curves for the estimation of these PCR efficiencies.

The standard curve method is usually based on the $C_{i}$ values of either an input series of known RNA concentrations in the reverse transcription or a dilution series of a reference CDNA sample (4). The equation for PCR kinetics $\left(N_{C}=N_{0}{ }^{*} E f f{ }^{C}\right)$ states that the amount of product after $C$ cycles $\left(N_{c}\right)$ is equal to the starting concentration $\left(N_{0}\right)$ times the efficiency ( $E f f$ ) to the power $C$. This equation can be converted into the form (equation 2):

$$
C_{t}=\log \left(N_{\partial}\right) / \log (E f f)-\{1 / \log (E f f)\} \times \log \left(N_{\alpha}\right),
$$

Equation 2

which is a linear relation between $C_{t}$ and $\log \left(N_{d}\right)$ when $N_{c}$ is fixed and only when the efficiency is constant. The standard curve is constructed by fitting this equation to the $\log \left(N_{0}\right)$ and $C_{t}$ values for a known series of $N_{0}$. The PCR efficiency is then calculated from the slope of the standard curve $\left(E f f=10^{-1 / \text { slope }}\right)$. However, in most applications of real-time PCR the standard curve-derived PCR efficiencies are not used. The standard curve is only used as a calibration curve to estimate the starting concentrations of unknown samples.

We scrutinized the use of standard curves for estimating PCR efficiencies by reviewing the two approaches for creating standard curves: 1) the use of (duplicate) serial dilutions of one of the cDNA samples under investigation and 2) the use of

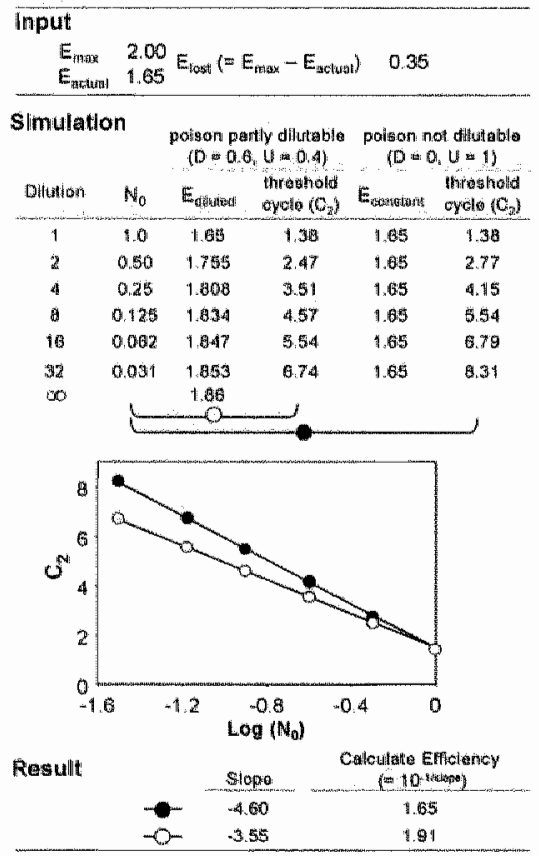

Figure 1. Computer simulation showing the influence of a poison in the cDNA sample that is serially dillted to construct a standard curve. Input gives the parameters used in the simulation. $E_{\text {sian }}$ represents the maximum PCR officiency and $E_{\text {acitit }}$ the actual PCR efficiency due to at loss in PCR efficiency ( $E$ ). A fraction $D$ of this loss is due to a poisom that cam be diluted, leaving a fraction $U$ that carnot be diluted $(U=1-D)$. Simulation shows the dillutions with the resulting $N_{0}$ values. The effect of the dilution on the PCR efficiency can be calculated with: $E=E_{\max }-U x$ $E_{\text {iost }}-$ (D/dflution) $\times E_{\text {abl. }}$. This calculation is carried out for a situation in which part of the loss is due to a poison that can be diluted (collumn $3_{4} E_{\text {ofinted }}$ ) and for a sifuation in which the loss in efficiency is due to factors, which cannot be diluted (columm 5. $E_{\text {ranstasts }}$ ). For both, the fractional number of cycles needed in each sample to reach the crossing line level of 2 $\left(C_{2}=\{\log (2)-\log (N)) / \log (E)\right)$ is calculated in columns 4 and 6 , respectively. The resulting threshold cycles $\left(C_{2}\right)$ are plotted against the $\log \left(N_{o}\right)$. Linear regression analysis of the "poisoned" standard curve (open circles) shows perfect linearity $\left(R^{2}=1\right)$. Result shows that the different slopes of the standard curves translate into significantly different calculated PCR efficiencies. Note that ultimate dilution of the poisoned sample would give an $E_{\text {diuted }}$ of 1.86 . 
a (duplicate) series of increasing amounts of total RNA as input in the reverse transcription (4). When the standard curve is based on the serial dilution of a single cDNA sample the chance exists that the sample used to generate this standard curve is contaminated with for example salt, phenol, chloroform and/or ethanol resulting in a lower-than-expected PCR efficiency. However, dilution of this sample will also dilute the "poison" and decrease its effect on the PCR reaction, thereby increasing the PCR efficiency with each dilution step. A computer calculation of this dilution effect (Figure 1) clearly shows that there is no direct relation between the individual PCR efficiencies ( $\left.E_{\text {dituted" }} 1.65-1.86\right)$ and the standard-curve-derived PCR efficiency (1.91). In this example the latter efficiency deviates 0.26 from the PCR efficiency of the undiluted reference sample and probably from all other samples prepared in the same way. Only when the individual PCR efficiencies of the standard curve samples are checked, a poisoned standard curve can be unmasked.

In the second approach, the standard curve is based on a series of increasing amounts of total RNA as input in the reverse transcription. To this end, six different concentrations of left ventricular total RNA of a mongrel dog were measured in triplicate. This experimental set-up enabled us to do a sub-sampling experiment and to construct two series of $3^{6}(=729)$ standard curves: one series based on 6 single data points per curve and another series based on 6 duplicate data points per curve. The frequency distributions of all slopes and calculated PCR efficiencies of these two series of standard curves are shown in Figure 2. The calculated PCR efficiencies for standard curves based on single data points vary between 1.81 and 2.02 ; the use of duplicates halves this range (Figure 2).

In summary, the comparative $C_{t}$ method and the standard curve rely heavily on the assumption that in all samples the PCR efficiency of each amplicon is constant. To by-pass this assumption in the analysis of quantitative PCR data, the fluorescence measured per cycle of each sample can be used. This alternative approach is based on linearization of the basic formula for exponential PCR amplification by taking the logarithm on both sides of the equation resulting in equation 3 :

$$
\log \left(N_{0}\right)=\log \left(N_{0}\right)+\log (E f f) \times C
$$

Equation :

The $N_{C}$ and $C$ are measured fluorescence data and cycle number, respectively. The log-linear part of the PCR data can be determined for each sample by selecting a lower and an upper limit of a "window-of-linearity" (Figure 3). Linear regression analysis is then used to calculate the intercept and the slope, $\log \left(N_{0}\right)$ and $\log ^{\prime}(E f f)$, respectively, from the straight line that fits best to the included data points. The starting concentration follows directly from the intercept of this linear regression line $\left(N_{0}=10^{\text {intercept }}\right)$, and is expressed in terms of SYBR Green I fluorescence. The individual PCR efficiency follows from the slope of the linear regression line (10 $\left.0^{\text {stope }}\right)$ and can be used as a quality check to exclude possible contaminated samples. To ensure unambiguous selection of data points within the window-of-linearity, an iterative algorithm is formulated to search for lines consisting of at least 4 and no more than 6 data points with the highest $R^{2}$ value and a slope close to the maximum 


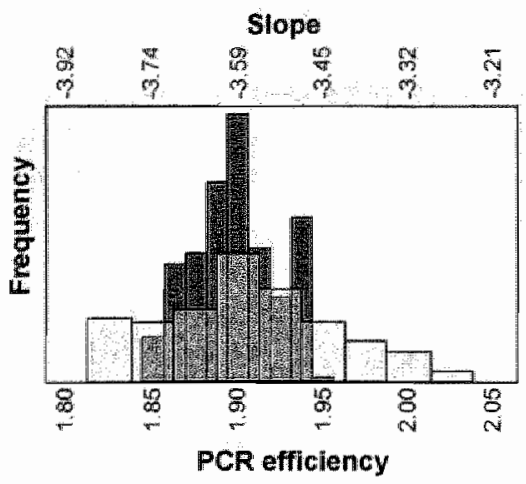

Figure 2. Sub-sampling experiment to estimate the variability of the PCR efficiencies calculated from the slope of the standaird curve. Six different concentrations of left ventricular total RWA of a mangrel dog $(0,065,0,13,0.26,0.65,1,3$, and $2.6 \mu \mathrm{g} / 50 \mathrm{wil}$ ) were reverse transcribed. In the real-time PCR $1.3 \mu$ of $\mathrm{CDNA}$ was used to amplify a $273 \mathrm{bP}$ GAPDH amplicon using dog specific primers (8). Details regarding reverse transcription and real-time PCR protocols have been previously published (4). Based on samples in which reverse transcriptase enzyme was omitted during reverse transcription, genomic DNA contamination of the samples was estimated to be $15000 \times$ less than the quantified cDNA levels and was therefore consldered to be negligible. All cDNAs were quantífed in triplicate. The graph shows the frequency distritbution of PCR efficiencies that can be calculated from the slopes $\left(E f f=10^{-1 / \text { tisher }}\right)$ of 729 standard curves constructed from all posistble permutations of the 6 times 3 RNA inputs (light bars). These PCR efficiencies range from 1.81 to 2.02. When the three possible duplicate observations per triplicate are used, the range of the distribution is recluced to 1.86 to 1.94 (dark barsi). The correlation coefficient squared $\left(\mathbb{R}^{2}\right)$ in both sets of calibration curves ranged from 0.98 to 1.00 indicating almost perfect linearity of all curves.

slope. The above algorithm gives the best correlation between the "known" input and the observed $N_{0}$ value as was tested in a large number of dilution series. Using lines with only 3 data points gives inconsistent $N_{0}$ values whereas longer lines may be biased by inclusion of below=detection=limit and/or plateau phase points. The slope criterion is included in the algorithm to avoid fitting in the plateau phase. Note that this algorithm provides an adequate "window-of-linearity" for most if not all of the samples. However, visual inspection of all amplification curves remains necessary to identify deviating samples that require an individual window or may have to be excluded. A computer program that implements the linear regression analysis of real-time PCR data and the described algorithm, as well as the possibility to interactively draw a window-of-linearity, is available by automatic request (email: bioinfo@amc.uva.nl; subject: LinRegPCR). This program is compatible with exported data from the LightCycler ${ }^{\mathrm{TM}}$ system (Roche) as well as the ABI Prism ${ }^{\text {B }}$ systems (Applied Biosystems).

It has been proposed recently (7) to determine the PCR efficiency of each sample from the amount of fluorescence $\left(N_{A}\right.$ and $\left.N_{B}\right)$ and the number of cycles $\left(C_{A}\right.$ and $\left.C_{B}\right)$ at two arbitrary thresholds $A$ and $B$ along the exponential phase using the equation:

$$
E=\left(N_{A} / N_{B}\right)^{1 /\left(C_{A}-C_{B}\right)}
$$

(Note that the symbols are adapted to the ones used in this letter and that a mistake in the exponent of the equation which appears in the original paper (reference 7 ) is corrected). 
There are several advantages of our proposed linear regression approach over this non-linear curve fit. The use of the Log(fluorescence) vs. cycle number plot in the linear regression approach enables more reliable identification of below-detectionlimit noise points and of data points that are no longer in the straight log-linear phase of the PCR reaction, both of which can not easily be identified in a non-logarithmic graph (Figure 3: Fiuorescence vs. Cycle number graphs). Furthermore, the use of all points in the log-linear phase with linear regression not only gives a more reliable measure for the slope of the regression line and thus for the PCR efficiency, but also provides the correlation coefficient as a measure for the goodness of fit. The main advantage of the linear regression approach is that an estimate of the $\mathrm{N}_{0}$, the initial number of molecules, can directly be calculated from the intercept parameter of the regression line.

In conclusion, the "poison" simulation as well as the sub-sampling experiment demonstrates that systematic and random differences in PCR efficiencies of individual samples make the standard curve an unreliable tool for quantification of mRNA levels. On the other hand, the linear regression approach enables the straightforward estimation and direct comparison of $\mathrm{N}_{0}$ values between samples and between target and reference amplicons without the need to assume equal PCR efficiencies. This greatly simplifies the calculation involved in real time PCR analyses and enables an independent estimation of mRNA contents in single samples. This may be of special importance when low quantities have to be reliably measured in small tissue samples as in fields of neuroscience and medical diagnostics.

\footnotetext{
Figure $3(\rightarrow$ page 62$)$. Ilustration of the linear regression caliculations implemented in a Microsof Excel spreadsheet for determining starting concentrations and PCR efficiencies per sample. The cycle number - fluorescence data pairs are imported at starting position A2. Only data of one sample are shown with cycle number and fluorescence in columns A and $B_{1}$ rows 4 till 43 . The IF-statements in rows 48 till 87 filter those data points thal fall in the so-called window-of-linearity. determined by setting the values in the anchored cells $B \$ 45$ and $B \$ 46$. These walues can be changed interactively. Once the window-of-linearity is established a regression line is fitted to the included data points. The functions in cells $B 89$, B90 and $B 91$ calculate the $R^{2}$, slope and the intercept, respectively. Finally, in cells B93 and B94 the PCR efficiency ( $=10^{\text {thispe }}$ ) and $N_{0}\left(=10^{\text {ormerefin }}\right)$ are calculated. A Microsoft Windows program to perform these calculations is awailable by automatic request (e-mail: bioinfo@amc.uva nl: subject; LinRegPCR).
} 


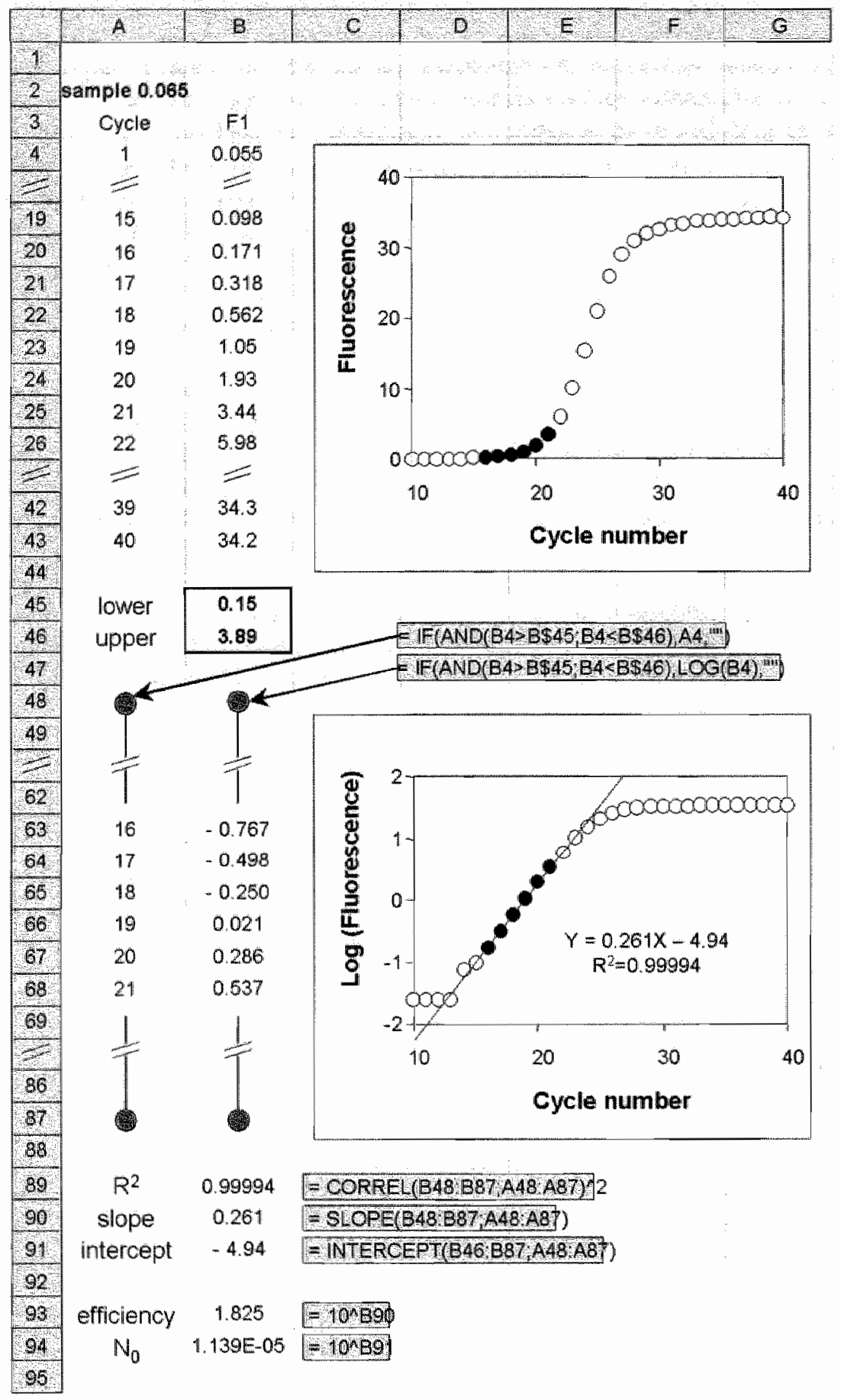




\section{ACKNOWLEDGEMENTS}

We would like to thank Dr. Marc Vos, Department of Cardiology, Academic Hospital Maastricht, and Dr. Onno Bakker, Department of Endocrinology and Metabolism, Academic Medical Center, Amsterdam for their constructive support. This research is partly supported by the Netherlands Heart Foundation, grant NHS 98.042 (CR) and NHS 96.002 (RHLD) (AFMM).

\section{REFERENCES}

1. Gibson UE, Heid CA, Williams PM. A novel method for real time quantitative RT-PCR. Genome Res 1996;6(10):995-1001.

2. Wittwer CT, Ririe KM, Andrew RV, David DA, Gundry RA, Balis UJ. The LightCycler: a microvolume multisample fluorimeter with rapid temperature control. Biotechniques 1997;22(1):176-81.

3. Kains P. The PCR plateua phase - towards an understanding of its limitations. Biochim. Biophys. Acta 2000;1494:23-27.

4. Livak KJ, Schmittgen TD. Analysis of relative gene expression data using real-time quantitative PCR and the 2(-Delta Delta $C(T))$ Method. Methods $2001 ; 25(4): 402-8$.

5. Kamphuis W, Schneemann A, van Beek LM, Smit AB, Hoyng PF, Koya E. Prostanoid receptor gene expression profile in human trabecular meshwork: a quantitative real-time PCR approach. Invest Ophthalmol Vis Sci 2001;42(13):320915.

6. Meijerink $J$, Mandigers $C$, van de Locht $L$, Tonnissen $E$, Goodsaid $F$, Raemaekers J. A novel method to compensate for different amplification efficiencies between patient DNA samples in quantitative real-time PCR. J Mol Diagn 2001;3(2):55-61.

7. Liu W, Saint DA. A new quantitative method of real time reverse transcription polymerase chain reaction assay based on simulation of polymerase chain reaction kinetics. Anal Biochem 2002;302(1):52-9. 



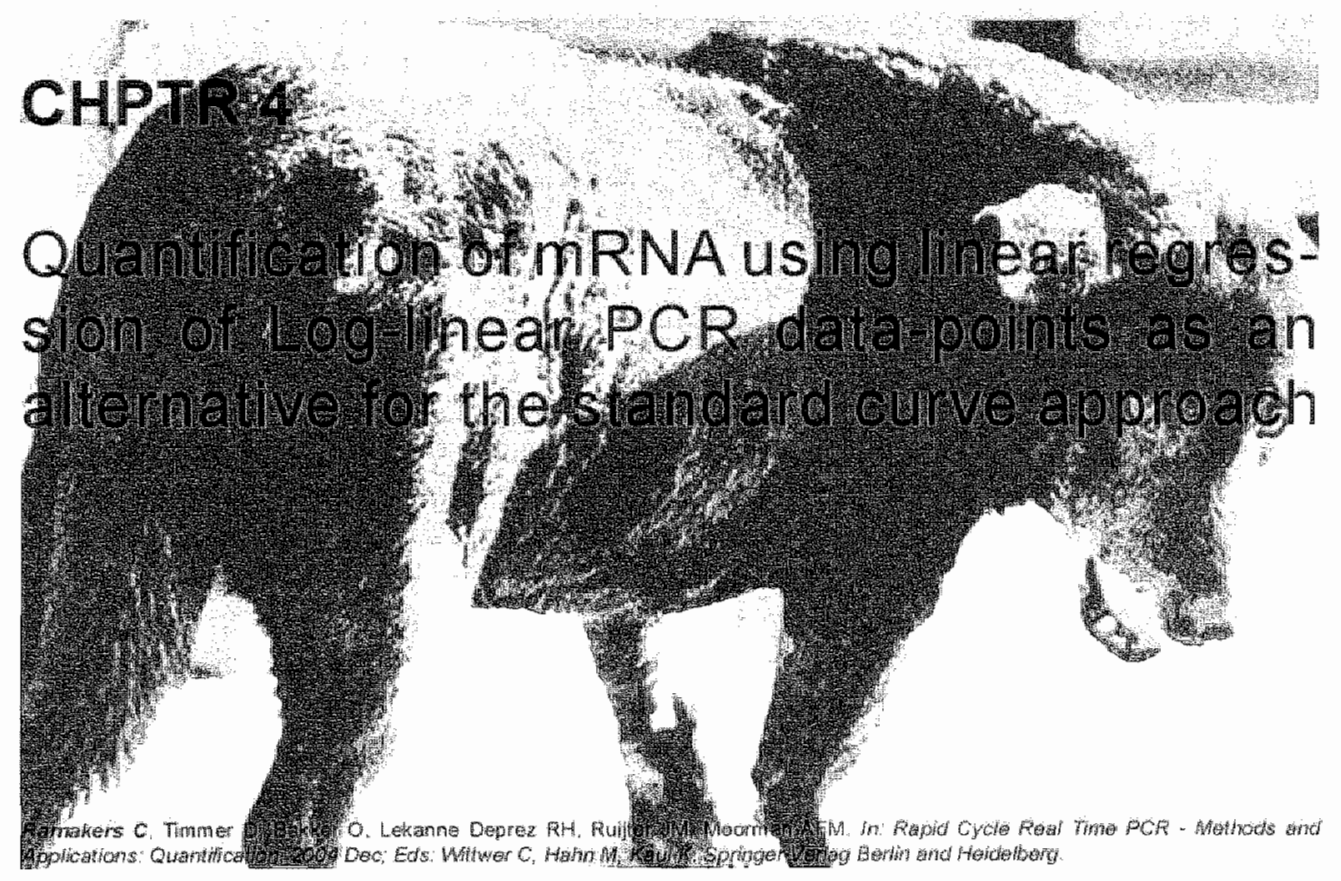




\section{INTRODUCTION}

The real-time PCR technique is increasingly becoming the standard for quantification of messenger RNA (mRNA) levels in biomedical sciences $(1,2)$. This technique is preferred over other quantitative PCR methods because it allows high-throughput screening and, more importantly, does not rely on end-point analysis. The latter can be misleading due to product inhibition, increasing enzyme instability, and a depletion of reaction components with increasing cycle number (3).

A widely used analysis method for real time PCR data relies on the construction of a standard curve. This method is based on determining the threshold cycle $(\mathrm{Ct})$, which is the cycle number at which a fixed amount of DNA is formed for a series of samples with a known input. Standard curves are usually based on the $C t$ values of either an input series of known RNA concentrations in the reverse transcription or a dilution series of a reference cDNA sample. The method uses the equation for PCR kinetics $N_{C l}=N_{0} \times(E f f)^{C l}$ in which $N_{C t}$ is the fixed amount of product at threshold cycle $C t, N_{0}$ is the starting concentration and Eff is the efficiency of the PCR. This exponential equation is converted into a linear relation between $\log \left(N_{0}\right)$ and $C t$ :

$$
C t=\log \left(N_{C}\right) / \log (E f f)-1 / \log (E f f) \times \log \left(N_{\alpha}\right)
$$

in which $-1 / \log (E f f)$ is the slope. Therefore a standard curve can be constructed by fitting a straight line to the $\log \left(N_{0}\right)$ and $C t$ values for a known series of $N_{0}$. An important assumption in this standard curve method is that the PCR efficiency of the amplicon of interest is constant and has the same value in all standard curve and unknown samples. This assumption is, however, not always fulfilled.

In a recent publication we have shown that standard-curve-derived efficiencies for a GAPDH primer set can vary up to $20 \%$ due to random variations. To circumvent $N_{0}$ quantification using a standard curve, we proposed an alternative method that uses linear regression in the Log-linear phase of individual samples (4). In short, the exponential function $N_{C}=N_{0} \times(E f f)^{C}$ is linearised by taking the logarithm on both sides of the equation:

$$
\log \left(N_{\partial}\right)=\log \left(N_{0}\right)+\log (E f f) \times C
$$

Equation 2

In this linear function, the slope term is represented by $\log (E f f)$ and the $Y$-axis intercept term by $\log \left(N_{0}\right)$. Note that this function is not valid in the plateau phase of the reaction. Using linear regression this equation can be fitted to the data points in the log-linear phase of each individual sample. The advantage of this approach is that it enables reliable quantification of $N_{0}$ values without using a standard curve, thereby avoiding the assumption of equal PCR efficiencies for all samples.

In this paper we demonstrate that when the PCR efficiencies of individual samples are more or less equal, both the linear regression and standard curve method can be used for quantifying $N_{0}$ values. However, when individual PCR efficiencies vary considerably, the standard curve method becomes unreliable, resulting in 
misinterpretation of starting concentrations, and in which case the linear regression method is the method of choice for accurate quantification.

\section{METHODS}

\subsection{Equipment}

- LightCycler Instrument (Roche Diagnostics, Almere, The Netherlands)

- LightCycler data analysis software version 3.532 (Roche Diagnostics)

- LightCycler Capillary Tubes (Roche Diagnostics)

- LinRegPCR software version 7.4 ([4]; bioinfo@amc.uva.nl, subject: LinRegPCR)

\subsection{Reagents}

- High Pure RNA tissue Kit (Roche Diagnostics)

- RiboGreen RNA Quantitation Kit (Molecular Probes, Leiden, The Netherlands)

- First Strand cDNA synthesis kit with random primers (Roche Diagnostics)

- DNA Master SY'BR green I kit (Roche Diagnostics)

\subsection{Procedures}

\subsubsection{Total RNA isolation / First strand synthesis}

Total RNA was isolated from human liver samples using the High Pure RNA Tissue Kit (Roche Diagnostics) according to the manufacturer's protocol. With the RiboGreen RNA Quantitation Kit (Molecular Probes) the total RNA concentration in each sample was determined and subsequently all samples were diluted to $0.1 \mathrm{\mu g} /$ $\mu \mathrm{l}$. Single-stranded cDNA was obtained using $1 \mu \mathrm{g}$ of total RNA and the First Strand CDNA synthesis kit with random primers (Roche Diagnostics).

\subsubsection{Oligonucleotides}

Table 1. Human GAPDH (5) and EF-10 primers.

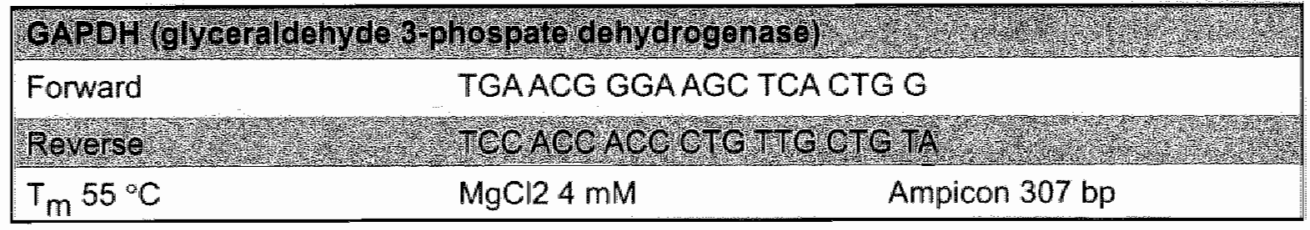

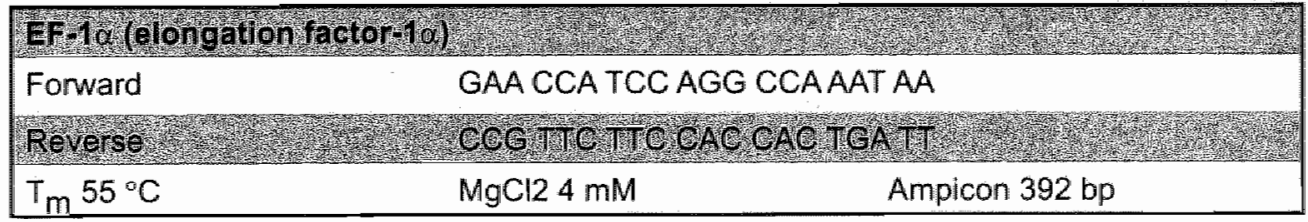




\subsubsection{Kinetic real-time $P C R$}

Table 2. Lighteycler reaction mix.

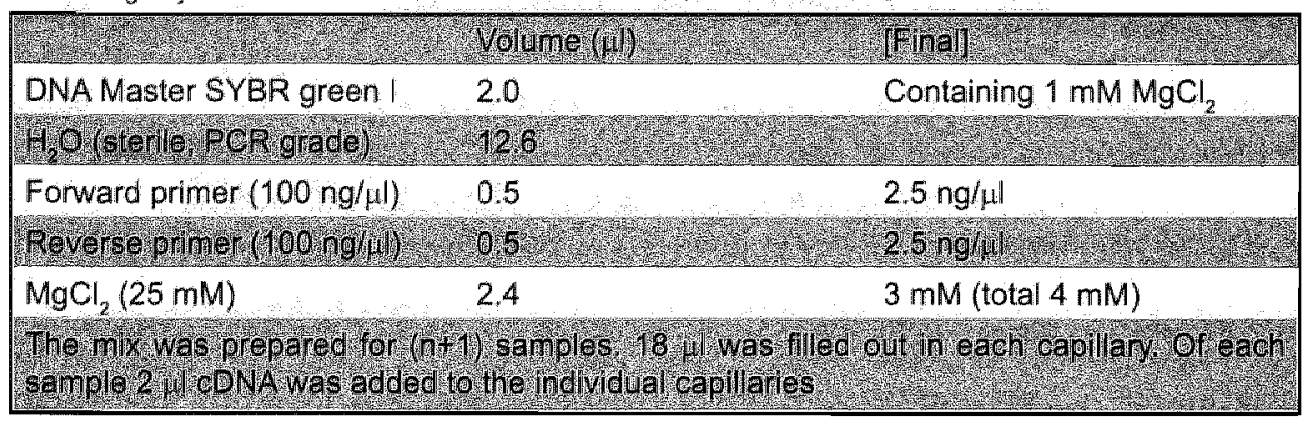

\section{RESULTS}

Specific amplification of the constitutively active genes EF-1 $\alpha$ (elongation factor1a), a protein involved in the translation of mRNA, and GAPDH (glyceraldehyde 3-phosphate dehydrogenase), an important enzyme in the glycolysis pathway, was confirmed by melting curve analysis revealing single melting peaks and polyacrylamide gel electrophoresis showing single bands of the expected size for both amplicons (data not shown). The $N_{0}$ values were determined using the standard curve and linear regression methods for both amplicons and are given in table 4. Figure 1 shows the correlation between the $N_{0}$ values of both methods (linear regression vs. standard curve). We found a high degree of correlation for the $N_{0}$ 's in the GAPDH data set (figure $1 \mathrm{~A}, \mathrm{R}^{2}=0.92$ ), while the $N_{0}$ 's in the $E F-1 \alpha$ data set (figure $1 B)$ did not show any correlation $\left(R^{2}=0.0025\right)$.

In order to check the standard curves of GAPDH and EF-1 $\alpha$, the data were exported to Microsoft Excel ${ }^{\mathrm{TM}}$. The parameters of both standard curves are listed in figure $2 A$ and $B$. The high correlation coefficient $\left(R^{2}=1.00\right)$ of both curves showed a high degree of linearity between the $C t$ and $\log \left(N_{\alpha}\right)$ values. The standard-curve-derived efficiency was calculated as 10-1/s/ope. This resulted in efficiencies of 1.89 and 1.92 for EF-1 $\alpha$ and GAPDH, respectively. The high degree of linearity and the observation that the standard-curve-derived PCR efficiencies had values lower than 2 (slope < -3.32) suggested that both standard curves were applicable for quantifying EF-1 $\alpha$ and GAPDH levels in "unknown" samples (6).

Inspecting the individual PCR efficiencies of all samples $(n=18)$ we found considerable variation in EF-1 $\alpha$ efficiency $(1.50 \pm 0.10$, mean $\pm \mathrm{sd}$ ) as shown in figure $3 \mathrm{~B}$ and listed in table 4 . The variation in the GAPDH data set was far less (figure $3 A$, table 4 ) with an average PCR efficiency of $1.73 \pm 0.04$. This indicates that the assumption of equal PCR efficiency of the standard curve method is not fulfilled for the EF-1 $\alpha$ amplicon, which may explain the lack of correlation between the linear regression and standard curve $N_{0}$ 's (figure 1B). 


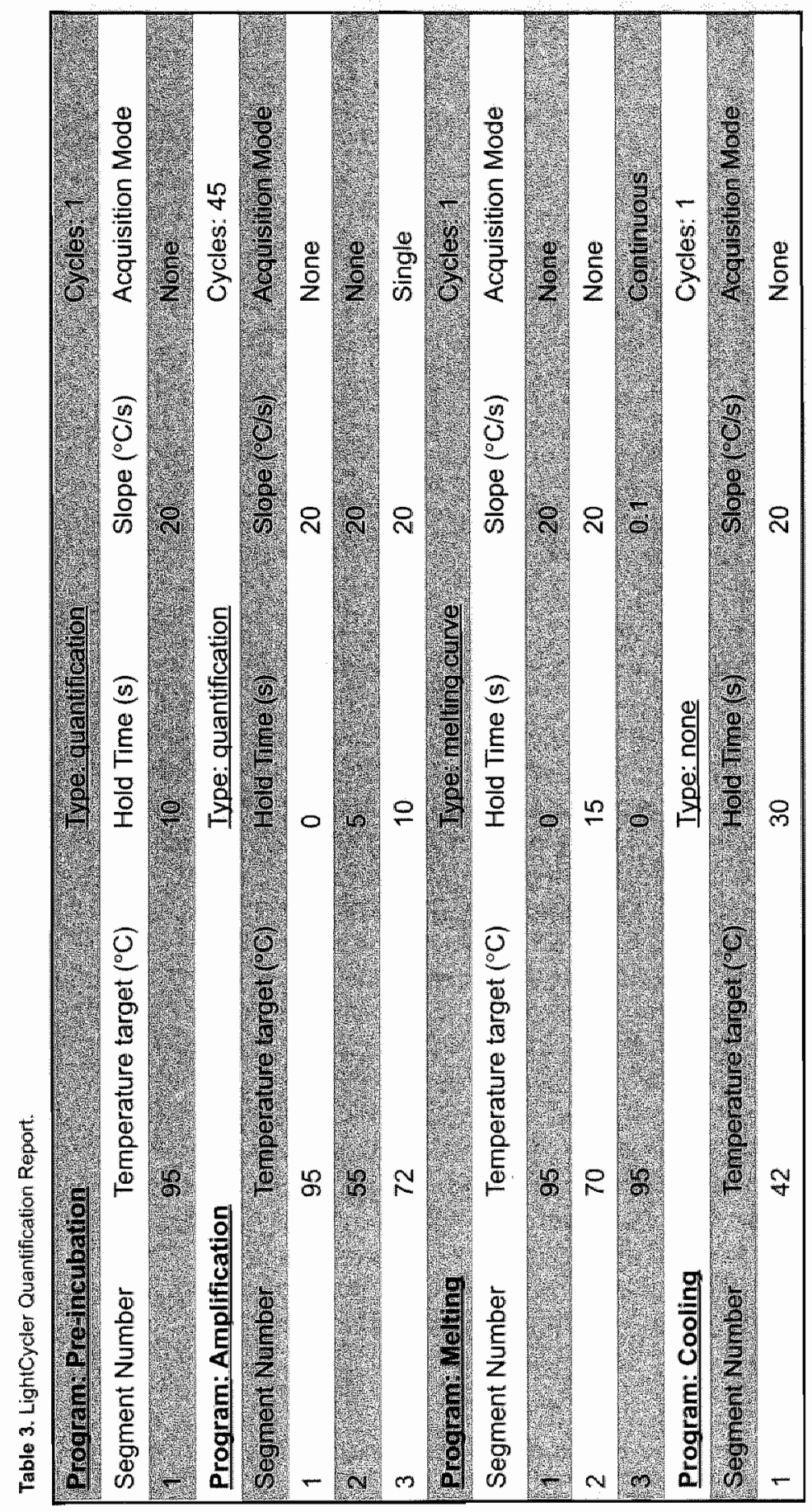


A

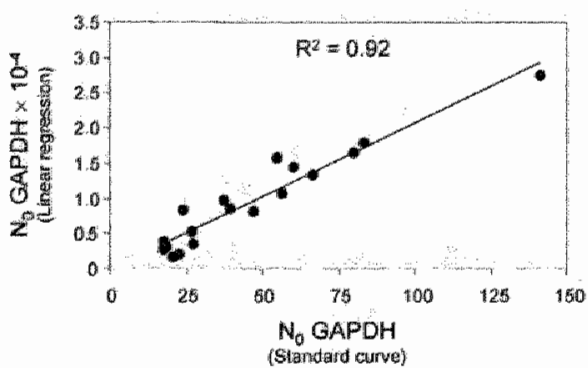

B

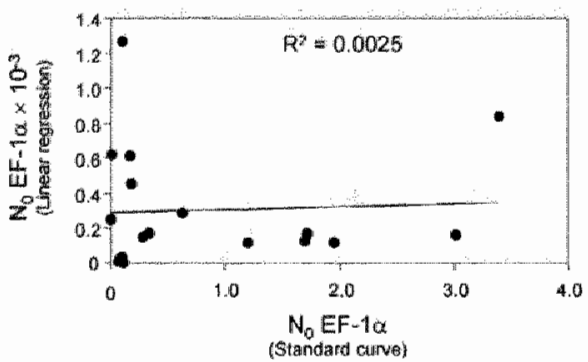

Figure 1. Correlation between starting concentrations $\left(N_{0}\right)$ obtained with linear regression ( $Y$-axis; expressed as fluorescence units) and standard curve derived $N_{0}$ values (X-axis) for GAPDH (A) and EF-1a (B).

Within the EF-1 $\alpha$ data set there were a couple of salient examples that show how quantification of samples with an aberrant PCR efficiency using a standard curve in combination with $C t$ values can go wrong (figure 4). Figure 4A shows the EF-1a amplification curves of two samples (samples 1 and 13 from table 4). In the standard curve method, the crossing point of the noise band for sample 13 was reached after 31.01 cycles. Compared to most of the other $C t$ values in table 4 this would indicate a very low expression level of EF-1 $\alpha$ in this particular sample $\left(N_{0}=0.004\right)$. Indeed, taking sample 1 as an arbitrary reference, the expression of EF-1 $\alpha$ in sample 13 is $-500 \times$ less than in sample 1. However, this large fold-difference only occurs when the assumption is made that both PCR efficiencies are equal. Calculating the individual PCR efficiency of sample 13 showed a very low efficiency of 1.30 compared to 1.60 for sample 1. This low PCR efficiency of sample 13 explains why the crossing point of this sample was found at 31.01 cycles. In fact, when using the linear regression method for $N_{0}$ calculation, thereby taking the differences in individual PCR efficiency into account, the $N_{0}$ values showed $-5 \times$ more EF-1 2 transcript in sample 13 compared to sample 1. Comparing the same samples in the GAPDH data set (table 4 , figure $4 \mathrm{~B}$ ) we found roughly the same number of fold-difference between samples 1 and 13 (standard curve: $\sim 2 \times$ more; linear regression: $-3.5 \times$ more).

Table 4. Individual PCR efficiencies for EF-1a and GAPDH in a sample population and a comparison of $N_{0}$ values from standard curve and linear regression methods. For standand curve quantification crossing paints were defermined with noise bands at 0.40 and 0.18 for EF- 1 or and GAPDH, respectively. Samples 1 and 13 (itallic-bold) are used as examples in the text and are shown in figure $4 .(\rightarrow$ page 71$)$ 


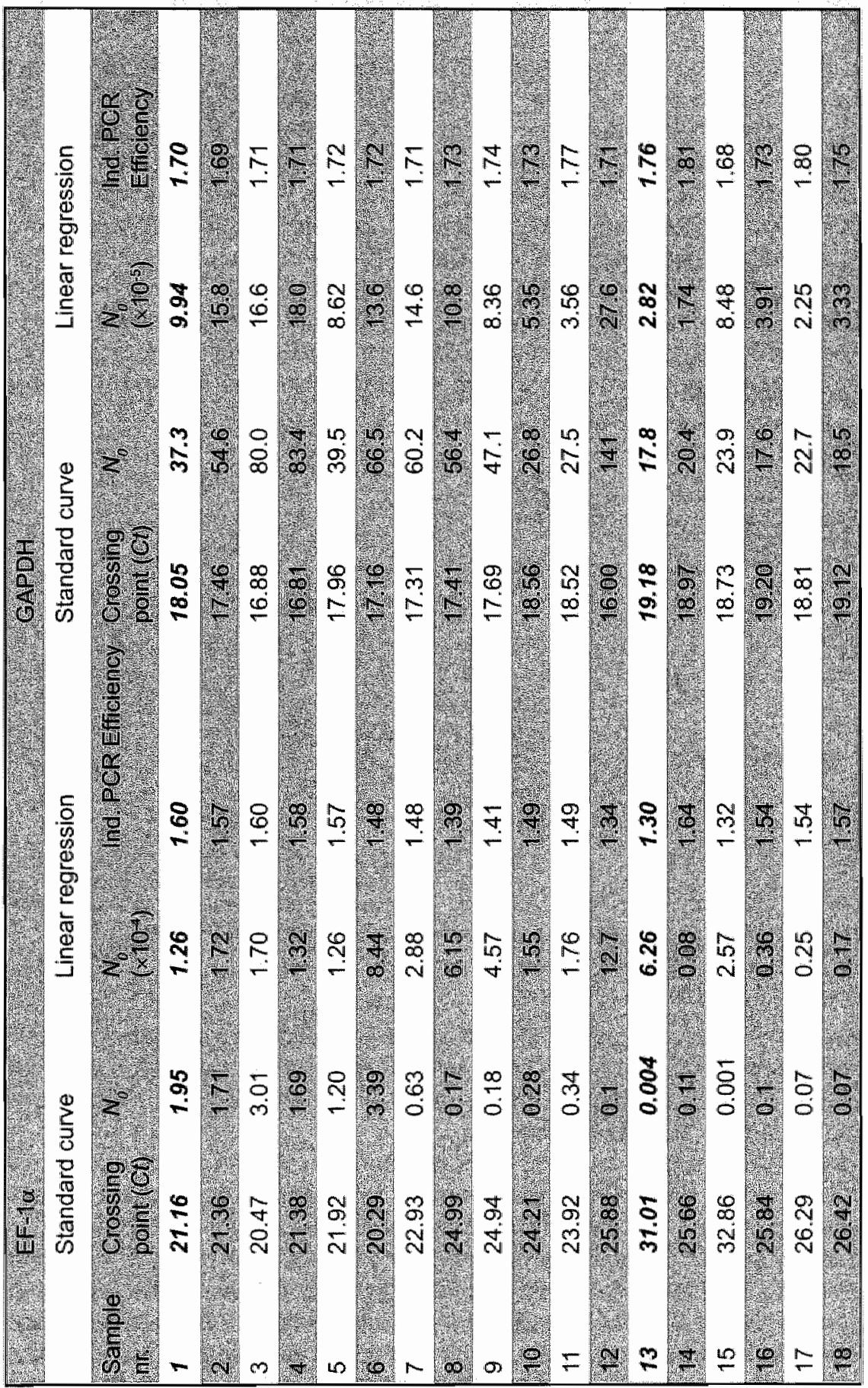




\section{COMMENTS}

Based on the parameters of the standard curves of both EF-1 $\alpha$ and GAPDH one would assume that both amplicons can be reliably measured. However, the $N_{0}$ values estimated with individual linear regression analysis of the EF-1 $\alpha$ amplification curves do not correlate with those derived from the standard curve. This exemplifies the importance of taking the individual PCR efficiencies into account in quantitative PCR data analysis. When the PCR efficiencies are more or less equal (GAPDH, figure $3 \mathrm{~A}$ ), there is a high degree of correlation between the two $N_{0}$ values (figure $1 \mathrm{~A})$, suggesting that both methods can be reliably used for quantifying starting concentrations. In contrast, large variations in individual PCR efficiencies (EF-1a, figure $3 \mathrm{~B}$ ) result in a loss of correlation between the two $N_{0}$ values (figure $1 \mathrm{~B}$ ). We attribute this discrepancy to the inability of the standard curve method to deal with

A

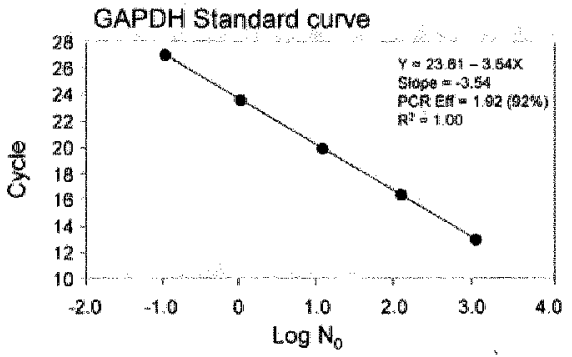

B

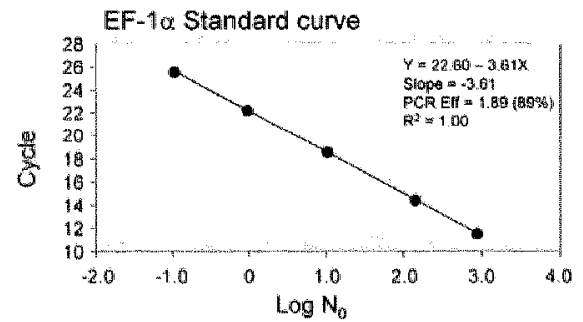

Figure 2. GAPDH (A) and EF-1 $\alpha$ (B) standard curves with standard curve parameters. Both standard cunves ane based on serial dilution of the same purifted cDNA sample.

differences in individual sample PCR efficiencies, resulting in a misinterpretation of starting concentrations derived from this curve. Consequently, when the variation in individual PCR efficiencies is large, the $N_{0}$ values obtained with linear regression are more reliable than the standard curve $N_{0}$ 's.

Different samples can have different PCR efficiencies. The cause of variation can be many, depending on for instance variation in reverse transcription efficiency, primer selection, (pharmacological) treatment of a patient prior to RNA isolation or leftover contaminants from tissue processing (e.g. ethanol, phenol). Unless a strict protocol for visual inspection of the log-linear amplification curves differences within and between LightCycler runs is employed in the laboratory, quantification of these samples using a standard curve can result in a gross misinterpretation of starting concentrations. Calculation of individual PCR efficiencies with the linear regression 


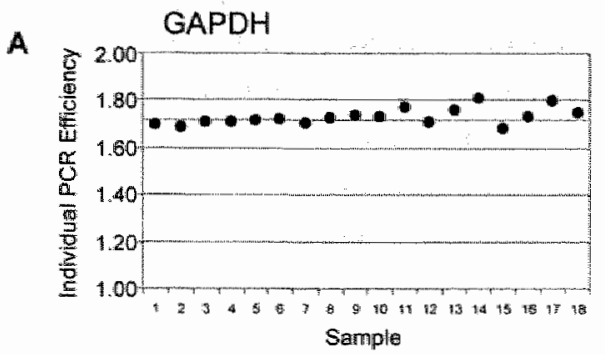

B

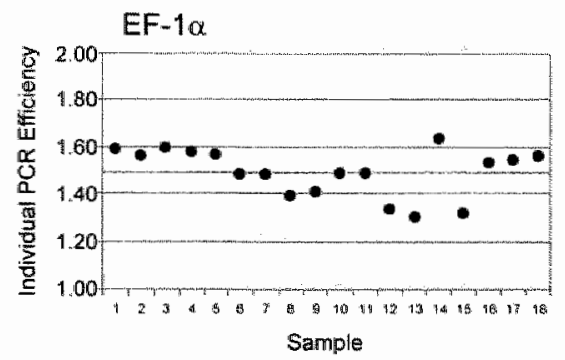

A

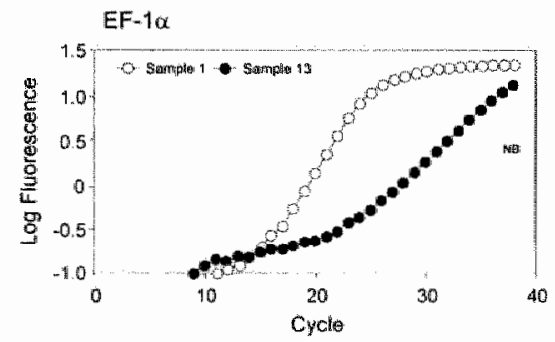

B

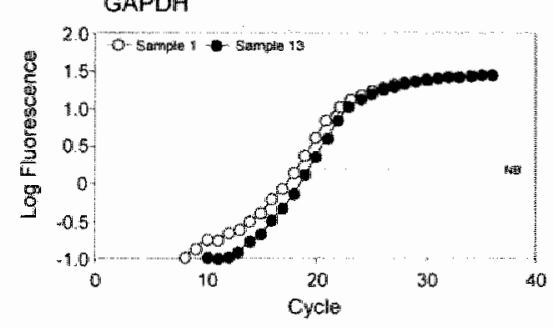

Figure 3. Individual PCR efficiencies of GAPDH (A) and EF-1a (B) calculated using linear regression analysis of the log-linear data points of each amplification curve. The average PCR efficiencies (dotted lines) were $1.73 \pm 0.04$ (mean $\pm \mathrm{sd}$ ) and 1.50 \pm 0.10 for GAPDH and EF-1a, respectively.
Figure 4. Example showing the influence of individual $P C R$ efficiencies on determining the $N_{p}$ values. The standard curve method uses a noise barid (NB) to determine crossing points ( $\mathrm{C}$ ( values), which in turn are used to calculate the $N_{0}$ values from the standard curve. For EF-1a (A) the noise band was sel at 0.40 . The noise band for GAPDH (B) was set at 0.18 . The quantification paramelers for the two samples are listed in tabte 4 .

method allows the identification of samples with aberrant PCR efficiencies. Since all quantitative PCR data analyses assume that the PCR efficiency of a sample is constant for all cycles up to the end of the log-linear phase, the intercept of the regression line is a valid estimate of the $N_{0}$. Although this comparison of methods 
shows that $N_{0}$ calculations based on individual PCR efficiencies are more accurate when the variation in individual sample PCR efficiency is high, the question remains whether very low PCR efficiencies will give accurate quantification results. It may very well be that an efficiency of $30 \%$ for EF- $1 \alpha$ sample 13 is too low for accurate quantification using either method. However, this example demonstrates rather dramatically how important individual PCR efficiencies are.

The fact that for the GAPDH experiment both methods give correlating results (figure $1 A$ ) indicates that the PCR efficiency variation for this amplicon does not violate the equal-PCR-efficiency assumption of the standard curve method. Nonetheless, we have previously shown that the slope of the standard curve is very dependent on small variations is PCR efficiencies of the samples used to construct the curve (4). Whereas this would not greatly influence the relative differences of $N_{0}$ values of samples derived from one curve, its effect on $N_{0}$ results derived from different standard curves should not be neglected.

It is clear that differences in individual PCR efficiencies influence the $N_{0}$ values. With the standard curve method there is no possibility to correct for these differences. As mentioned before, linearization of $N_{C}=N_{0} \times(E f f)^{c}$ not only yields an individual PCR efficiency, it also provides you with an $Y$-axis intercept, which is a direct measure of the $N_{0}$ value, thereby circumventing quantification with the standard curve assumption of equal PCR efficiencies. To facilitate this alternative quantification method we have developed a computer program that implements the linear regression analysis of real-time PCR using an automated algorithm (4). This program is compatible with exported data from the LightCycler system (Roche), the ABI Prism systems (Applied Biosystems), the Opticon system (MJ Research) as well as the iCycler system (Biorad) and is available on request (e-mail: bioinfo@amc.uva.nl; subject: LinRegPCR). 


\section{REFERENCES}

1. Gibson UE, Heid CA, Williams PM. A novel method for real time quantitative RT-PCR. Genome Res 1996;6(10):995-1001.

2. Wittwer CT, Ririe KM, Andrew RV, David DA, Gundry RA, Balis UJ. The LightCycler: a microvolume multisample fluorimeter with rapid temperature control. Biotechniques 1997;22(1):176-81.

3. Kains P. The PCR plateau phase - towards an understanding of its limitations. Biochimica et Biophysica Acta 2000;1494:23-27.

4. Ramakers C, Ruijter JM, Deprez RH, Moorman AF. Assumption-free analysis of quantitative real-time polymerase chain reaction (PCR) data. Neurosci Lett 2003;339(1):62-6.

5. Kimura Y, Suzuki T, Kaneko C, Darnel AD, Moriya T, Suzuki S, et al. Retinoid receptors in the developing human lung. Clin Sci (Lond) 2002;103(6):613-21.

6. Lekanne Deprez RH, Fijnvandraat AC, Ruijter JM, Moorman AF. Sensitivity and accuracy of quantitative real-time polymerase chain reaction using SYBR green I depends on cDNA synthesis conditions. Anal Biochem 2002;307(1):63-9. 



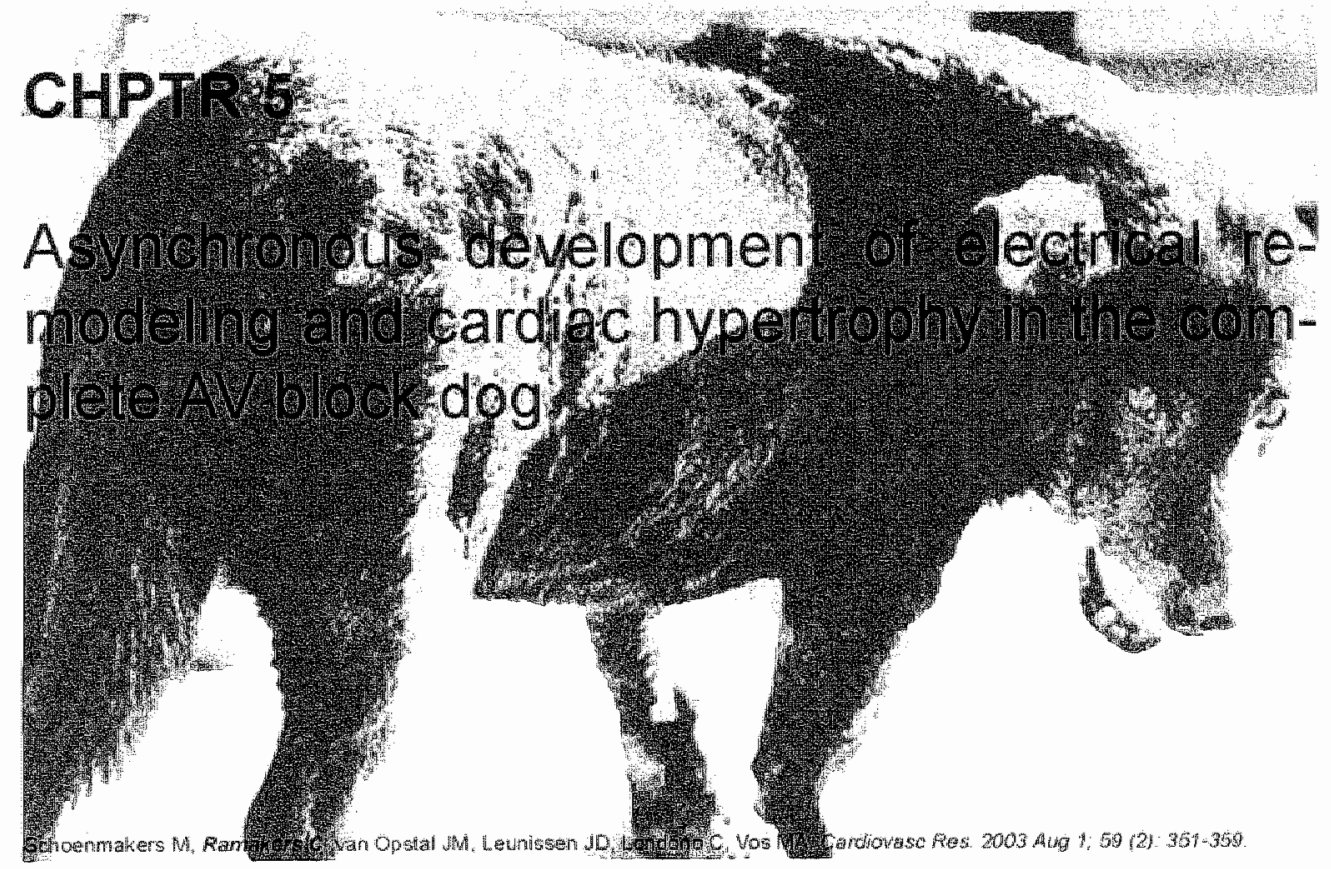




\section{SUMMARY}

Objective: Left ventricular hypertrophy has been associated with the prolongation of QT-time, and an increased risk of ventricular arrhythmias. The renin angiotensin system has been implicated in the development of ventricular hypertrophy. At 5 weeks complete AV block (CAVB) in the dog, there is: 1) biventricular hypertrophy associated with a transient activation of components of the renin angiotensin system, and 2) increased action potential duration, more pronounced in the left than in the right ventricle leading to spatial dispersion of repolarization, and 3) enhanced susceptibility to drug-induced torsade de pointes-arrhythmias. To investigate whether these remodeling processes develop in parallel, time dependency was assessed in absence or presence of the AT1 receptor-blocker Irbesartan.

Methods and Results: Dogs in sinus rhythm, 2 and 5 weeks CAVB were compared to dogs chronically treated with Irbesartan ( $30 \mathrm{mg} / \mathrm{kg}$ b.i.d). Endocardial monophasic APD of left and right ventricle was measured and susceptibility to torsade de pointes was tested by infusing dofetilide $\left(0.025 \mathrm{mg} / \mathrm{kg} / 5^{\prime}\right)$. Hypertrophy was determined by relating heart-to-body weight at sacrifice. Left ventricular APD had increased more than right ventricular APD at 2 and 5 weeks CAVB, leading to an increase in spatial dispersion. At that time torsade de pointes were evocable in the majority of the dogs. Hypertrophy had only developed completely at 5 weeks CAVB. Irbesartan had no effect on electrical and structural parameters or on arrhythmogenicity.

Conclusions: In the CAVB dog ventricular hypertrophy is not a prerequisite for electrical remodeling or drug-induced torsade de pointes, and the AT1-receptor has no dominant role in the completion of these remodeling processes. 


\section{INTRODUCTION}

Left ventricular hypertrophy is a common finding in the adult population and associated with an increased QT-time and enhanced risk of ventricular arrhythmias and sudden cardiac death $(1,2)$. In numerous animal models the relation between ventricular hypertrophy and the occurrence of electrophysiological changes, like the prolongation of ventricular repolarization, has been confirmed (3). In the chronic complete AV block (CAVB) dog, electrical remodeling is further characterized by an increase in spatial dispersion and a higher propensity to (drug induced) early afterdepolarizations, ectopic beats and torsade de pointes arrhythmias (TdP) $(4,5)$. Although the association between the presence of ventricular hypertrophy and the related electrical remodeling and arrhythmogenicity seems firm, the synchronicity in their course of development has never been studied. Therefore we determined the temporall behaviour of these processes after creation of AV-block.

Secondly, we attempted to dissociate these remodeling processes pharmacologically using Irbesartan (I), an angiotensin II type-1 receptor (AT1)-blocker. This approach was selected since in the CAVB dog-model the renin angiotensin system (RAS) is transiently activated (4), and AT1 mRNA expression levels relate to the degree of ventricular hypertrophy (6).

\section{METHODS}

\subsection{General}

Thirty mongrel dogs (body weight $21-33 \mathrm{~kg}, 15$ females) underwent experimental testing. Irbesartan (Sanofi-Synthélabo, Montpellier, France) was administered orally at a dose of $30 \mathrm{mg} / \mathrm{kg}$ b.i.d. 7 to 10 dogs, starting one week prior to AV block creation. Serial measurements were performed under premedication (ECG) or during complete anesthesia. Surface ECGs were recorded during regular sinus rhythm (SR) before and during Irbesartan (I), and repetitively after creation of AV-block until 2 weeks AV-block. Invasive measurements were performed at different time points: SR, acute AV-block (AAVB), CAVB2, and/or CAVB5. In which 2 and 5 indicates 2 or 5 weeks CAVB respectively. At the moment of sacrifice, dogs belonged to the following groups: SR $(n=5)$, CAVB2 $(n=8)$, CAVB5 $(n=7)$, CAVB2I $(n=5)$, and CAVB5I $(n=5)$. Since dogs were tested serially the numbers depicted in the tables often exceed the group size.

Animal handling was in accordance with the Guide for the Care and Use of Laboratory Animals published by the US National Institutes of Health (NIH Publication No. 85-23, revised 1996). The 'Committee for Experiments on Animals (DEC)' of the University of Maastricht, Netherlands approved the experiments.

\section{2 Experimental design of the studies}

After overnight fasting premedication consisted of acepromazine $(0.6 \mathrm{mg} / \mathrm{kg} \mathrm{i.m}$.) and buprenorfine $(0.009 \mathrm{mg} / \mathrm{kg}$ i.m.). The anesthesia, ventilation, preoperative, 
and postoperative care have been described in previous articles $(4,8)$. In 25 dogs complete AV-block was induced by radiofrequency ablation. A 7 French steerable catheter with a $4 \mathrm{~mm}$ tip (RF MarinrTM, Medtronic CardioRhythm, San Jose, CA, USA) was positioned across the tricuspid valve to record a large low atrial and a small His bundle potential, guided by fluoroscopic views from the right and left anterior oblique angles. The temperature controlled radiofrequency energy, with a power limit of $35-50 \mathrm{~W}$ and a target temperature of $70^{\circ} \mathrm{C}$ was delivered from a $500 \mathrm{~Hz}$ generator (AtakrTM, Medtronic CardioRhythm, San Jose, CA, USA) for 2 min, between the large tip thermocouple electrode of the ablation catheter and an adhesive pad applied on the back of the dog. For electrophysiological parameters (EP), the regular 6-lead surface ECG was accompanied by 2 monophasic action potentials (MAPs, EP Technologies Inc) placed at the endocardium of the left and right ventricle (LV and RV respectively). The EP measurements at AAVB and CAVB were performed at two basic rates: 1) the idioventricular rate (IVR), and 2) a fixed pacing rate (FRP) with an interstimulus interval of $500 \mathrm{~ms}$.

During FRP, which was performed for 2 min from the RV MAP, the ventricular effective refractory period (VERP) was determined incrementally (steps of $5 \mathrm{~ms}$ ) at twice diastolic threshold. For hemodynamics, pressure $(P)$ signals were recorded with a Sentron catheter (Sentron Europe Inc), which was positioned in the abdominal aorta for a short period (only during SR) and advanced to the LV cavity where it remained thereafter. All hemodynamic data were gathered during IVR. In the CAVB5 group, no hemodynamic data were collected since an extensive data set already existed. 9 Definitions, amplifications and filter settings were described in previous publications $(4,8,10)$.

An arrhythmogenic challenge was performed at CAVB by applying $0.025 \mathrm{mg} / \mathrm{kg}$ dofetilide intravenous for $5 \mathrm{~min}$. 8 The occurrence of TdP was scored for $20 \mathrm{~min}$. When TdP was seen $\geq 3$ times, the dog was considered susceptible.

At sacrifice, the heart was excised and weighed. The ventricles were isolated from the atria, RV was removed, and the septum was taken as part of the LV.

\subsection{Data analysis}

The signals of EP and hemodynamics were sampled at $1 \mathrm{kHz}$ and stored on hard disk. With a custom made computer program (ECG View) with a resolution of 2 $\mathrm{ms}$ and adjustable gain and time scale, the following parameters were measured offline: PP-time, RR-time, QRS-duration, QT-time, duration of the MAP (MAPD) at $100 \%$ repolarization, aortic $P, L V$ end diastolic pressure (EDP), LV systolic pressure (SP), and LV peak rate of pressure rise ( $+\mathrm{dP} / \mathrm{dtmax}$ ). Corrected (c) QT-time (11) was calculated, and spatial dispersion ( $\triangle M A P D)$ was defined as the difference between LV MAPD and RV MAPD. All data presented are the mean of 5 consecutive beats. An independent observer $(\mathrm{CL})$ checked all measurements.

\subsection{Analysis of ACE and chymase mRNA}

At sacrifice $L V$ and RV tissue of untreated $S R$ and CAVB dogs was immediately frozen in liquid nitrogen and stored at $-80^{\circ} \mathrm{C}$ until mRNA analysis. ACE and chymase 
mRNA levels were assessed at SR, CAVB2, and CAVB5 using quantitative real-time PCR (LightCycler, Roche Diagnostics, Almere; The Netherlands). Total RNA was isolated using the Qiagen RNeasy kit according to the manufacturers protocol.

Contamination of genomic DNA was further eliminated by digestion with DNAsel (Promega Benelux, Leiden "The Netherlands). First strand cDNA was synthesized using an optimized reverse transcription protocol (12). Real time PCR was performed using the FastStart DNA Master Sybr Green 1 kit (Roche Diagnostics Nederland, Almere, the Netherlands) and dog specific ACE, chymase (13) and GAPDH primers. Data of both ventricles were combined to increase sample size.

\subsection{Angiotensin II dose-response study}

During SR the pharmacologic activity of Irbesartan was characterized in preliminary experiments. The response of the aortic systolic pressure to intravenous incremental boluses of angiotensin II was measured in 3 dogs before and one week after the administration of Irbesartan.

\subsection{Statistics}

Pooled data are expressed as mean $\pm S D$. Serial comparisons were performed by paired student's t test and single parameters between independent groups by a 2-way ANOVA with a post-hoc Bonferroni $t$ test. Temporal measurements were tested using ANOVA for repeated measures. Values of $P<0.05$ were considered significant.

\section{RESULTS}

\subsection{Ventricular remodeling in the CAVB dog (control)}

\subsubsection{Time course of electrical remodeling}

In this study, the focus was on the electrophysiological changes taking place in the first 2 weeks after creation of AV-block. In the left panel of figure 1 changes in PP, RR, and QT-time are depicted at different time points under sedation. Acute AV-block resulted in a significant atrial cycle length decrease, while RR and QT did not significantly increase (left panels). Initially this lack of severe ventricular bradycardia came as a surprise. From personal observations we learned that this was only the case during the first 24 hours after creation of AV-block, thereafter the RR-time increased significantly. This lack of bradycardia could well be related to the severe decrease in PP-time (increased adrenergic state). In time (1 week complete AV block: CAVB1) the evolving ventricular bradycardia led to a further lengthening of QT-time, while the PP-time was returning to normal. At CAVB2 there was a further increase in QT-time while the RR remained stable (electrical remodeling). The presence of electrical remodeling was confirmed at CAVB2 when the heart rate was controlled at $500 \mathrm{~ms}$ fixed rate pacing (FRP) under complete anesthesia (right panel figure 1). The QT-time, LV MAPD, RV MAPD, and VERP were significantly increased 
at CAVB2. Moreover, the increase of MAPD was more pronounced in LV than in RV, leading to an increase in spatial dispersion of repolarization ( $\triangle M A P D: 14 \pm 10 \mathrm{~ms}$ at AAVB and $26 \pm 23 \mathrm{~ms}$ at CAVB2).

From 2 to 5 weeks CAVB, all electrophysiological parameters remained stable (table 1). Dofetilide administration resulted in the induction of reproducible TdP in the majority of the dogs at both times: 5 out of 6 dogs at CAVB2 and 5 out of 7 at CAVB5.

Table 1. Electrophysiological parameters in control groups.

\begin{tabular}{|c|c|c|}
\hline$M P$ P & $C A y B 2(n=B)$ & CAYSS III \\
\hline RR-time & $1144 \pm 419$ & $1271 \pm 275$ \\
\hline AThe & 8044-144 & 1418975 \\
\hline$Q T_{-}$-time & $372 \pm 26$ & $389 \pm 66$ \\
\hline HNAP & 336.90 & 368 78 \\
\hline RV MAPD & $296 \pm 40$ & $307 \pm 52$ \\
\hline M MPD & $40=22$ & 1615 \\
\hline
\end{tabular}
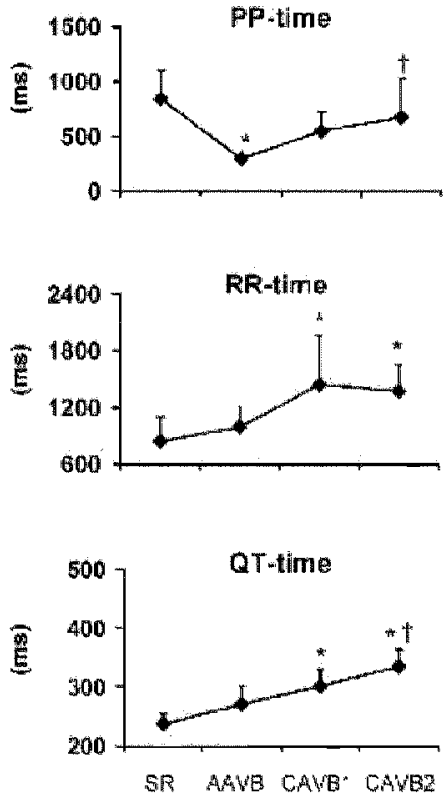

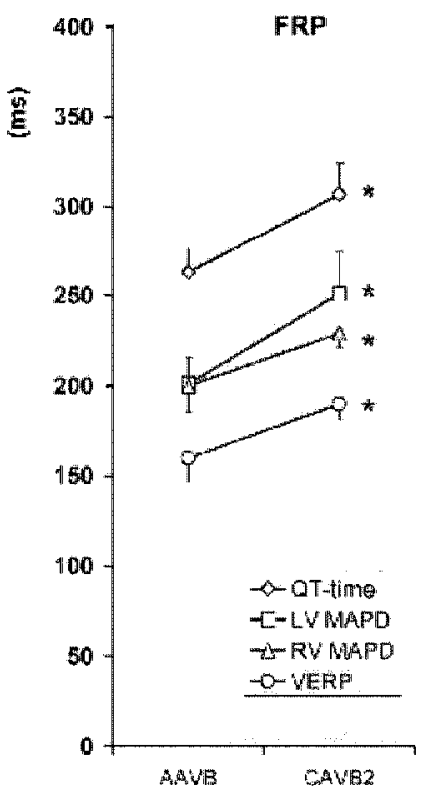

Figure 1. Temporal (x-axis) behavlour of PP-time (top), RR-time (middle), and QT-time (bottom) in 8 control dogs (left panel). In the right panel QT-time, LV MAPD, RV MAPD, and VERP during fixed rate pacing with an interstimulus interval of $500 \mathrm{~ms}$ at AAVB and CAVB2 in 6 serially tested dogs are shown. ("p<0.05 vs SR; 500.05 vs AAVB).PP-time initially decreases and returned to SR wallues at 2 weeks AV-black. After AV-block RR-time and ventricular repolarization significantly increase. This increase in efectrophysiological parameters was independent of rate (electrical remodeling). 


\subsubsection{Development of cardiac hypertrophy}

The presence of cardiac hypertrophy at CAVB5 was demonstrated by a significant increase in heart weight-to-body weight ratio $(\mathrm{H} / \mathrm{Bw})$ as compared to $\mathrm{SR}, 11.6 \pm 1.1$ g/ $/ \mathrm{kg}$ vs $7.9 \pm 0.7 \mathrm{~g} / \mathrm{kg}$ (figure 2). In contrast, the CAVB2 group did not show cardiac hypertrophy ( $\mathrm{H} / \mathrm{Bw}: 8.8 \pm 0.9 \mathrm{~g} / \mathrm{kg}$ ). When comparing the individual $\mathrm{H} / \mathrm{Bw}$ ratios, one appreciates that the $\mathrm{H} / \mathrm{B} w$ ratios of 3 dogs in the CAVB2 group is outwith the range observed in the SR group but within the range of the CAVB5 group. This indicates the presence of cardiac hypertrophy in these dogs.

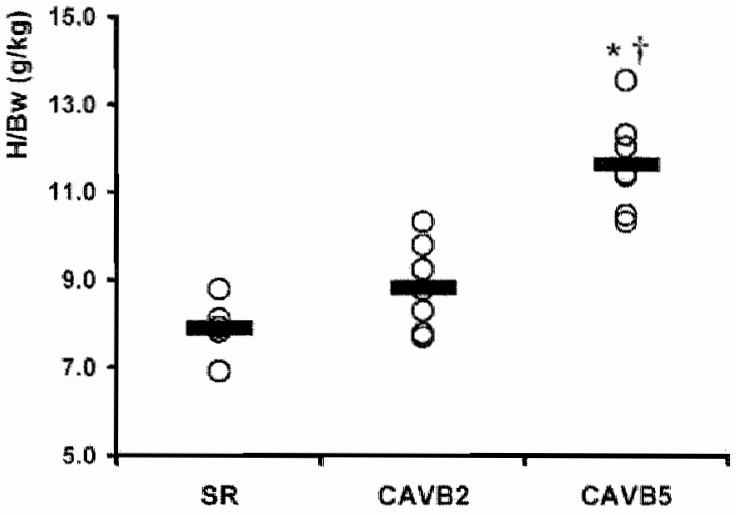

\subsubsection{Hemodynamic parameters}

The LVSP and LVEDP showed comparable values at SR and CAVB2: LVSP $110 \pm 23$ $\mathrm{mmHg}$ and $103 \pm 20 \mathrm{mmHg}$ respectively, and LVEDP $8 \pm 5 \mathrm{mmHg}$ and $8 \pm 1 \mathrm{mmHg}$ respectively. Contractility of the LV however was significantly higher at CAVB2 as seen by an increased $+\mathrm{dP} / \mathrm{dtmax}$ as compared to $S R(2543 \pm 1054 \mathrm{mmHg} / \mathrm{s}$ vs. $1447 \pm 396 \mathrm{mmHg} / \mathrm{s}$ respectively). None of the dogs showed physical signs of congestive heart failure either during the experimental period or at autopsy.

\subsubsection{Time dependent changes in mRNA expression levels of ACE and chymase} The two components of the cardiac tissue RAS showed a change in mRNAexpression after creation of AV-block. Ventricular ACE mRNA expression was unchanged at CAVB2 as compared to SR, and decreased at CAVB5. The mRNA expression of chymase however was increased at both CAVB2 and CAVB5 (figure 3).

\subsection{Effect of Irbesartan on ventricular remodeling}

\subsubsection{Effectiveness of AT1-blockade}

During SR the pharmacologic activity of Irbesartan was characterized in preliminary experiments. Daily administration of Irbesartan resulted in 1) a similar mean aortic $P(96 \pm 9$ before vs. $92 \pm 13 \mathrm{mmHg}$ during Irbesartan), and 2) a downward shift of the dose-response curve (figure 4). At a subdepressor dosage regimen, effective blockade of angiotensin II was reached. 
3.2.2 Effect of Irbesartan on electrophysiological parameters during SR

Daily adminstration of Irbesartan during SR did not alter EP. Serially $(n=10)$ the heart rhythm (PP-time: $726 \pm 198 \mathrm{~ms}$ before and $722 \pm 213 \mathrm{~ms}$ during Irbesartan), conduction (QRS-width: $59 \pm 9$ ms versus $64 \pm 12 \mathrm{~ms}$ ) and ventricular repolarization (QT-time: $234 \pm 16 \mathrm{~ms}$ versus $227 \pm 28 \mathrm{~ms}$ ) were not influenced after one week of treatment. In the EP group comparison, in which control $(n=12)$ and Irbesartan $(n=10)$ were compared, this lack of effect was confirmed by determination of LV MAPD ( $213 \pm 16$ ms versus $204 \pm 22$ ms respectively), RV MAPD ( $203 \pm 14$ ms versus $196 \pm 19 \mathrm{~ms})$, and $\triangle M A P D(12 \pm 9 \mathrm{~ms}$ versus $11 \pm 8 \mathrm{~ms})$.
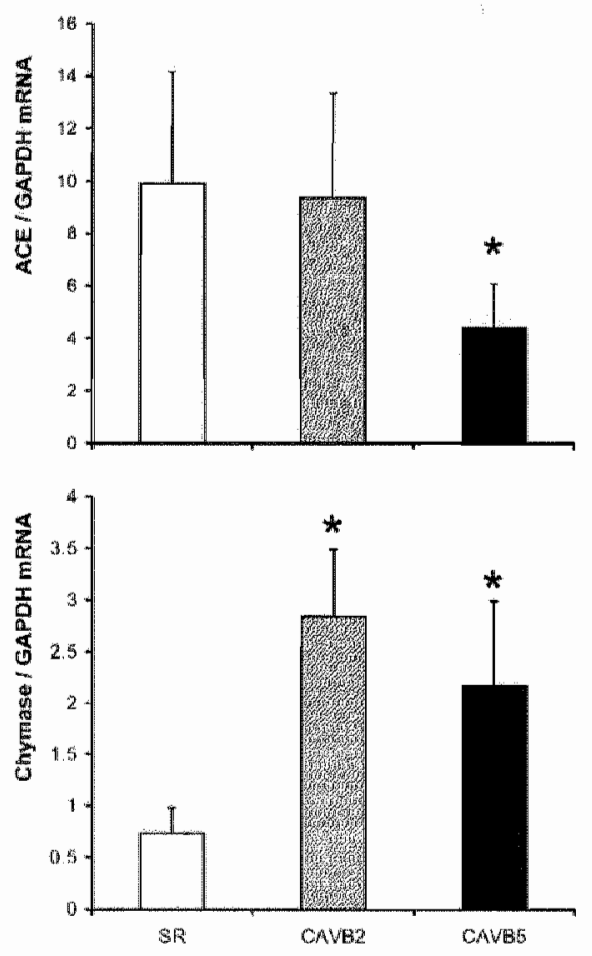

Figure 3. ACE MRNA (upper panell) and Chymase mRNA (lower panel) at SR, C.AVB2 and CAVBS, pelated to GAPDH mRNA ( ${ }^{*}<<0.05$ vs. SR). ACE expression was unaltered at CAVB2 while decreased at CAMBS. Ventricular Chymas expression was increased both at CAVB2 and CAVE5

\subsubsection{AT1-blockade and ventricular remodeling}

Within 2 weeks after creation of AV-block, electrical remodeling occurred in the Irbesartan treated animals. The changes were similar to those seen in the control groups. In table 2, QT, LV MAPD, RV MAPD, $\triangle M A P D$, and VERP during fixed rate pacing (FRP), serially conducted at AAVB and CAVB2, are depicted. All electrophysiological parameters increased significantly at CAVB2. From 2 to 5 weeks AV-block all parameters remained stable, e.g. QTc is shown in figure 5. Thus, Irbesartan did not prevent the occurrence of electrical remodeling. Dofetilide administration resulted in the reproducible induction of TdP in the majority of the dogs: 2 out of 4 at CAVB2l, and 3 out of 5 at CAVB5I. Both the induction and duration 


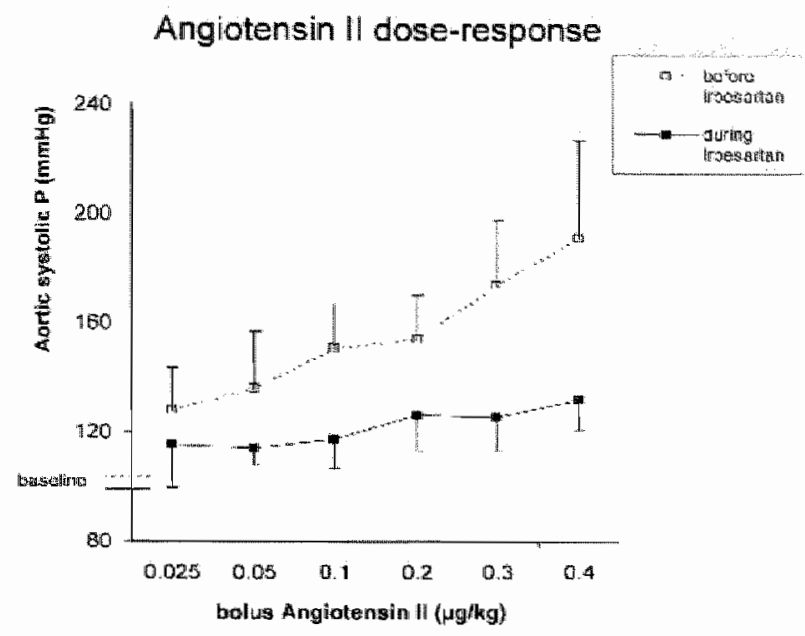

Figure 4. The response of aortic systole pressure $(P)(y$-axis) to infusion of different boluses of angiotensin $1(x-a x i s)$ is shown. Boluses were infused within $30 \mathrm{~s}$, with intervals of 25 min in onder to allow the aortic systolic $P$ to return to its baseline value. Before Irbesartan a higher bolus led to a higher rise in pressure, and after one week oral administration of Irbesartan this response was decreased.

of the TdPs were comparable in the Irbesartan groups, and comparable to the arrhythmias in the control groups. A representative example is shown in figure 6 .

LVSP and LVEDP were unaltered at CAVB2I and CAVB5I when compared to the SR group. The LVSP was $103 \pm 4 \mathrm{mmHg}$ at CAVB2I, $98 \pm 20 \mathrm{mmHg}$ at CAVB5I and $95 \pm 13 \mathrm{mmHg}$ at $S R$, and the LVEDP was $9 \pm 3 \mathrm{mmHg}, 5 \pm 2 \mathrm{mmHg}$ and $8 \pm 3 \mathrm{mmHg}$ respectively. Contractility of the $L V$ had significantly increased at CAVB21 (LV +dP/ dtmax: $2463 \pm 512 \mathrm{mmHg} / \mathrm{s})$, and CAVB5I (2338 $\pm 564 \mathrm{mmHg} / \mathrm{s}$ ) as compared to SR $(1570 \pm 188 \mathrm{mmHg} / \mathrm{s})$. The hemodynamic parameters were comparable to control. None of the Irbesartan treated animals showed signs of congestive heart failure.

Observations concerning the development of cardiac hypertrophy were similar in the Irbesartan groups as compared to control (figure 5). Hypertrophy was present at CAVB5I $(10.7 \pm 1.0 \mathrm{~g} / \mathrm{kg})$ but not at CAVB21 $(8.3 \pm 0.5 \mathrm{~g} / \mathrm{kg})$. A subanalysis revealed that the LV weight-to-body weight ratio at CAVB21 $(4.7 \pm 0.3 \mathrm{~g} / \mathrm{kg})$ was significantly

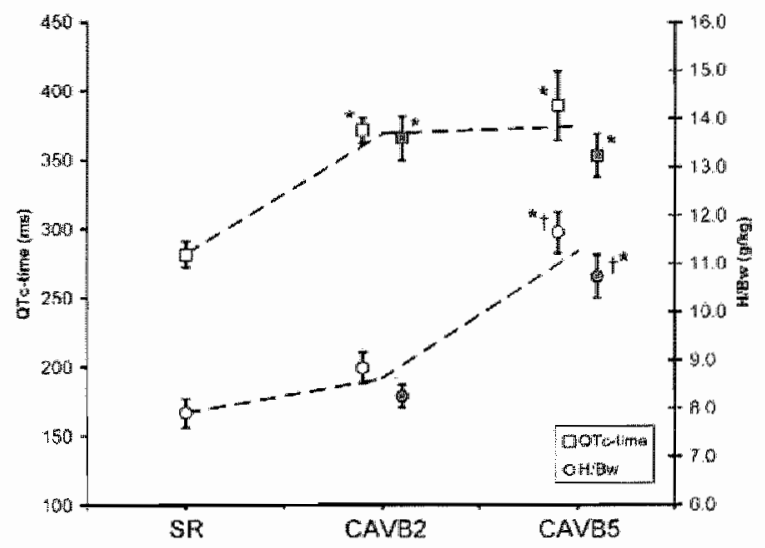

Figure 5. QT (circles) are platted against time: $S R$. CAVB2, and CAVB5. Control groups (white) and Irbesartan groups (gray) are shown in the same picture. The dotted line connects the mean of Irbesartan and control groups. taken together at similar time points merely to emphasize the different time course of changes seen. (*p<0.05 ws $5 \mathbb{R} ;, p<0.05 \mathrm{vs}$ CAVB2). Electrical remodleling, represented

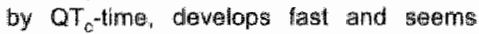
complete at CAVB2 for both control and Irbesartan. Hypertrophy develops more slowly as seen by a significant increase at CAVB5 for both control and Irbesartan groups. 
less than at CAVB5I $(6.1 \pm 0.6 \mathrm{~g} / \mathrm{kg})$. The same was true for the RV weight-to-body weight ratio; $1.8 \pm 0.2 \mathrm{~g} / \mathrm{kg}$ at CAVB2I versus $2.3 \pm 0.4 \mathrm{~g} / \mathrm{kg}$ at CAVB5I.

\subsection{Different time course of electrical remodeling and cardiac hypertrophy}

When plotting the values of the control and Irbesartan groups at similar time points (figure 5), the distinction in temporal behaviour of the two remodeling processes can be appreciated. Electrical remodeling is complete at CAVB2, while cardiac hypertrophy has only developed at CAVB5.

Tabile 2. Electrical remodeling in Irbesartan group. All values in the CAVB2l group were significantly different compared to the AAVBI $(p<0.05)$.

\begin{tabular}{|c|c|c|}
\hline FP $(\mathrm{r}=500 \mathrm{~ms}$ & AMs & $\mathrm{CHV}_{21}$ \\
\hline QT-time & $263 \pm 18$ & $313 \pm 13$ \\
\hline (W NAr & 202 24 & $256-19$ \\
\hline RV MAPD & $208 \pm 22$ & $224 \pm 20$ \\
\hline 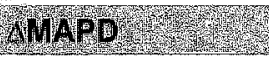 & 1/ & $32+17$ \\
\hline VERP & $164 \pm 9$ & $190 \pm 11$ \\
\hline
\end{tabular}

\section{DISCUSSION}

In the CAVB dog, ventricular electrical remodeling and the arrhythmia-prone condition, i.e. dofetilide-induced TdP, are already present at CAVB2, while the development of cardiac hypertrophy seems to follow a slower time course. Irbesartan, the AT1-blocker, does not prevent ventricular remodeling in this model, regardless of the fact that components of the renin angiotensin system have been implicated in hypertrophy.

\subsection{Temporal dissociation of electrical remodeling from cardiac hypertrophy}

The long-term ( $>5$ weeks) adaptations of the CAVB dog have been the subject of many publications $(4-6,8,9,14,15)$. Electrical remodeling can be characterized by a non-homogeneous lengthening of MAPD (LV>RV) leading to spatial dispersion of repolarization. The incidence of class III antiarrhythmic-induced TdP is high, and the incidence of sudden cardiac death is $10-15 \%$. There is eccentric biventricular hypertrophy, not accompanied by excessive collagen depositions or changes in capillary-fiber ratio. At 5-6 weeks CAVB, mechanical adaptations have led to a hemodynamically compensated state: $\mathrm{LV}$ and $\mathrm{RV}+\mathrm{dP} / \mathrm{dtm}$ ax have increased, cardiac output is maintained, and ventricular EDP is unchanged in comparison to SR. This study is the first one to describe the temporal dissociation of electrical remodeling and related proarrhythmia from cardiac hypertrophy in an in vivo dog model. An increased QT, ventricular MAPD prolongation, spatial dispersion of repolarization, and susceptibility to drug-induced TdP were uniformly present at CAVB2. Cardiac hypertrophy on the other hand developed more slowly: at CAVB2 hypertrophy was 


\section{CAVB2 I}

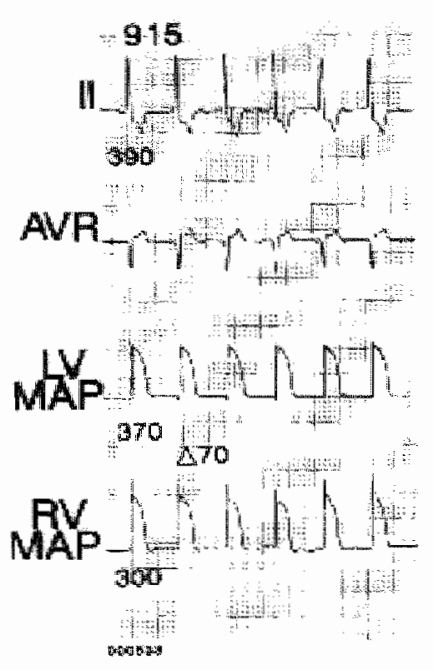

\section{Dofetilide $\left(0.025 \mathrm{mg} / \mathrm{kg} / 5^{3}\right)$}

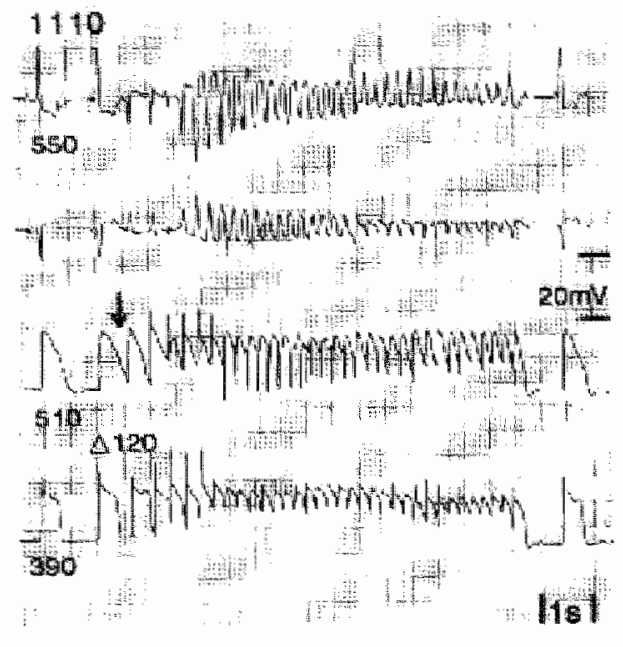

Figure 6. Two surface ECG-leads and LV and RV MAP recordings at a paper speed of $10 \mathrm{~mm} / \mathrm{s}$. When dofetilide was administered at CAVB2 in an Irbesartan treated dog, the QTwtime, LV MAPD, RV MAPD and $\triangle M A P D$ clearly Increased before a self-terminating TdP occurred.

absent in the majority of the dogs, while at CAVB5 it was fully present. LV and RV weights showed comparable results. Lack of synchrony has been indicated in the first days after myocardial infarction in the rat, where downregulation of $\mathrm{K}^{+}$-channel genes and currents was present while no hypertrophy was detectable yet (16). In two papers pharmacological separation of these processes during their developmental phase was reported. In a murine model of pressure overload, cyclosporin A was able to prevent myocyte hypertrophy, while the prolongation of the action potential was only attenuated (17). In aortic-banded rats changes in gene products of $I_{p} I_{10}$ and $\mathrm{I}_{\mathrm{CI}}$ were prevented by treatment with a $\mathrm{Ca}^{2+}$-antagonist, while LV hypertrophy developed (18). However none of these pharmacological studies described the arrhythmogenic consequences of the dissociation. These studies and the present one, where electrical remodeling and hypertrophy develop asynchronously, indicate the presence of different signaling routes. More recently it was suggested that the reduction of ion channel gene products might even be the starting point of hypertrophic signaling (19).

\subsection{No sign of heart failure in the CAVB dog}

Another important finding is that during short-term volume overload, when hypertrophy is not yet present (CAVB2), there are no signs of congestive heart failure: LVEDP is not elevated, $L V+d P / d t$ max is significantly increased, and there are no physicall signs of pump failure. This suggests that during the early time course of mechanical overload mechanisms other than hypertrophy come into play to compensate for 
the increased workload of the heart. Mouse models of pressure overload either transgenic or treated with cyclosporin A, confirm that a preserved cardiac function is not inecessarily accompanied by cardiac hypertrophy $(20,21)$. Whether contractile improvements can be maintained in the long run without the involvement of cardiac hypertrophy is unclear. In this study, where mechanical adaptations and cardiac hypertrophy are both present at CAVB5, hypertrophy may be necessary for the longterm compensation.

\subsection{Lack of effect of Irbesartan}

For several reasons we selected AT1-inhibition: 1) tissue and plasma components of the RAS are (transiently) elevated in the CAVB dog $(4,6), 2)$ Chymase mRNA was elevated at CAVB while ACE-expression was unchanged or even decreased, possibly suggesting a predominance of chymase in tissue angiotensin II production after AV-block, 3) other pathways, like bradykinin, influenced by ACE-inhibitors are left untouched by AT1-blockade, and 4) Irbesartan can be applied effectively at a dosage not influencing blood pressure, thereby preserving hemodynamics. Though the activation of AT1 in the mammalian heart mainly results in the development of myocyte hypertrophy in vitro (22), conflicting data have been published concerning the effect of blockade in vivo. Most prevention studies have focused on the effect of AT1-blockade during pressure overload. For example, in some studies concerning aorta banding in rats, hypertrophy was attenuated, while in others no effect was seen $(18,23,24)$. AT1-blockers failed to prevent cardiac hypertrophy in constrictive pulmonary artery-banded rabbits, cats, and fetal sheep (25-27). Prevention studies in volume overload models are scarce. In rat models of volume overload AT1-blockade attenuated hypertrophy $(28,29)$. Perry et al. described the presence of myocyte hypertrophy after mitral valve regurgitation despite AT1-blockade in the dog (30). In the CAVB dog no prevention of hypertrophy by Irbesartan was seen at CAVB5I as compared to CAVB5. However, a blunted response cannot be ruled out. This all leads us to believe that AT1 may not be the dominant factor in the development of mechanical overload-induced hypertrophy, but that other signaling pathways are of more importance. Moreover, Irbesartan was not able to prevent electrical remodeling in this model. Furthermore, the relation between the presence of electrical remodeling and the susceptibility to dofetilide-induced TdP remained present.

\subsection{Clinical implications}

In clinical studies an increased QT-time and the presence of ventricular arrhythmias has been documented in patients with left ventricular hypertrophy $(1,2)$. A positive correlation between the increase in LV mass and the QT duration has been implicated (2). This experimental study suggests that electrical remodeling and proarrhythmia are likely to precede the presence of hypertrophy.

So far "no clinicall study has addressed temporal aspects of electrical remodeling, proarrhythmia and hypertrophy. We realize that conducting such a study will merely be impossible due to ethical and practical constraints. Therefore the CAVB dog is a very suitable model to study these aspects in detail. 


\section{5 Limitations}

We do not know whether Irbesartan actually reached the AT1 on the membrane of the cardiomyocyte, though we assume this was the case because its vascular counterpart was blocked as checked by angiotensin II dose-response studies. Since we did not measure angiotensin II levels in the cardiac tissue, we have to be careful in relating the changed levels of ACE and chymase mRNA after AV block to the RAS in general. We are aware of the fact that groups are too small in order to compare the incidence of dofetilide-induced TdP between controls and Irbesartan treated dogs, however we want to emphasize that Irbesartan did not influence electrical remodeling. We realize that since $L V$ hemodynamics were only measured during IVR contractility of the LV was as such not fully characterized.

\subsection{Conclusions}

In the complete AV block dog, ventricular hypertrophy is not a prerequisite for electrical remodeling or drug-induced Torsade de Pointes. In the model, the AT1 receptor has no dominant role in the completion of these ventricular remodeling processes.

\section{ACKNOWLEDGEMENTS}

Financial support by the Netherlands Heart Foundation (98.042) is gratefully acknowledged. We thank Dr Ben Jansen for helpful advice, Roel Spätjens for technical assistance, and Dr Dino Nisato for kindly providing Irbesartan. 


\section{REFERENCES}

1. Bikkina $M$, Larson $M G$, Levy $D$. Asymptomatic ventricular arrhythmias and mortality risk in subjects with left ventricular hypertrophy. $\mathrm{J}$ Am Coll Cardiol. $1993 ; 22: 1111-6$.

2. Oikarinen $L$, Nieminen $M S$, Viitasalo $M$, Toívonen $L$, Wachtell $K$, Papademetriou V, Jern S, Dahlof B, Devereux RB, Okin PM. Relation of QT interval and $Q T$ dispersion to echocardiographic left ventricular hypertrophy and geometric pattern in hypertensive patients. The LIFE study. The Losartan Intervention For Endpoint Reduction. J Hypertens. 2001;19:1883-91.

3. Tomaselli GF, Marban E. Electrophysiological remodeling in hypertrophy and heart failure. Cardiovasc Res. 1999;42:270-83.

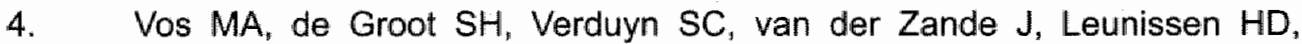
Cleutjens JP, van Bilsen M, Daemen MJ, Schreuder JJ, Allessie MA, Wellens HJ. Enhanced susceptibility for acquired torsade de pointes arrhythmias in the dog with chronic, complete AV block is related to cardiac hypertrophy and electrical remodeling. Circulation. 1998;98:1125-35.

5. Volders PG, Sipido KR, Vos MA, Kulcsar A, Verduyn SC, Wellens HJ. Cellular basis of biventricular hypertrophy and arrhythmogenesis in dogs with chronic complete atrioventricular block and acquired torsade de pointes. Circulation. 1998;98:1136-47.

6. Verduyn SC, Ramakers C, Snoep G, Leunissen JD, Wellens HJ, Vos MA. Time course of structural adaptations in chronic AV block dogs: evidence for differential ventricular remodeling. Am J Physiol Heart Circ Physiol. 2001;280:H288290 .

7. Spinale FG, Holzgrefe HH, Walker JD, Mukherjee R, Kribbs SB, Powell JR, Antonaccio M. Angiotensin II subtype-1 receptor blockade during the development of left ventricular hypertrophy in dogs: effects on ventricular and myocyte function. $J$ Cardiovasc Pharmacol. 1997;30:623-31.

8. Van Opstal JM, Leunissen JD, Wellens HJ, Vos MA. Azimilide and dofetilide produce similar electrophysiological and proarrhythmic effects in a canine model of Torsade de Pointes arrhythmias. Eur J Pharmacol. 2001;412:67-76.

9. De Groot SH, Schoenmakers M, Molenschot MM, Leunissen JD, Wellens $\mathrm{HJ}$, Vos MA. Contractile adaptations preserving cardiac output predispose the hypertrophied canine heart to delayed afterdepolarization-dependent ventricular arrhythmias. Circulation. 2000;102:2145-2151. 
10. Vos MA, Verduyn SC, Wellens HJ. Early afterdepolarizations in the in situ canine heart: mechanistic insights into acquired torsade de pointes arrhythmias. In: Franz MR, editor, Monophasic Action Potentials: Bridging Cell and Bedside, Armonk, NY: Futura Publishing. 2000:553-569.

11. Van de Water A, Verheyen J, Xhonneux R, Reneman RS. An improved method to correct the QT interval of the electrocardiogram for changes in heart rate. J Pharmacol Methods. 1989;22:207-17.

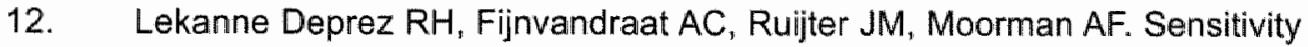
and accuracy of quantitative real-time polymerase chain reaction using SYBR green I depends on cDNA synthesis conditions. Anal Biochem. 2002;307:63-9.

13. Lee YA, Liang CS, Lee MA, Lindpaintner $\mathrm{K}$. Local stress, not systemic factors, regulate gene expression of the cardiac renin-angiotensin system in vivo: a comprehensive study of all its components in the dog. Proc Natl Acad Sci U S A. 1996;93:11035-40.

14. Volders PG, Sipido KR, Vos MA, Spatjens RL, Leunissen JD, Carmeliet E, Wellens $H J$. Downregulation of delayed rectifier $\mathrm{K}(+)$ currents in dogs with chronic complete atrioventricular block and acquired torsades de pointes. Circulation. 1999;100:2455-61.

15. Van Opstal JM, Verduyn SC, Leunissen HD, de Groot SH, Wellens $H J$, Vos MA. Electrophysiological parameters indicative of sudden cardiac death in the dog with chronic complete AV-block. Cardiovasc Res. 2001;50:354-61.

16. Huang B, Qin D, El-Sherif N. Early down-regulation of K+ channel genes and currents in the postinfarction heart. J Cardiovasc Electrophysiol. 2000;11:125261.

17. Wang $Z$, Kutschke W, Richardson KE, Karimi M, Hill JA. Electrical remadeling in pressure-overload cardiac hypertrophy: rale of calcineurin. Circulation. 2001;104:1657-63.

18. Hiramatsu $M$, Furukawa $T$, Sawanobori $T$, Hiraoka $M$. Ion channel remodeling in cardiac hypertrophy is prevented by blood pressure reduction without affecting heart weight increase in rats with abdominal aortic banding. $J$ Cardiovasc Pharmacol. 2002;39:866-74.

19. Kassiri Z, Zobel C, Nguyen TT, Molkentin JD, Backx PH. Reduction of I(to) causes hypertrophy in neonatal rat ventricular myocytes. Circ Res. 2002;90:578-85

20. Hill JA, Karimi M, Kutschke W, Davisson RL, Zimmerman K, Wang Z, Kerber RE, Weiss RM. Cardiac hypertrophy is not a required compensatory response to short- term pressure overload. Circulation. 2000;101:2863-9. 
21. Esposito G, Rapacciuolo A, Naga Prasad SV, Takaoka H, Thomas SA, Koch WJ, Rockman HA. Genetic alterations that inhibit in vivo pressure-overload hypertrophy prevent cardiac dysfunction despite increased wall stress. Circulation. 2002;105:85-92.

22. Paradis $P$, Dali-Youcef N, Paradis FW, Thibault G, Nemer M. Overexpression of angiotensin II type I receptor in cardiomyocytes induces cardiac hypertrophy and remodeling. Proc Natl Acad Sci U S A. 2000;97:931-6.

23. Obayashi $M$, Yano $M$, Kohno $M$, Kobayashi $S$, Tanigawa $T$, Hironaka $K$, Ryouke $T$, Matsuzaki M. Dose-dependent effect of ANG II-receptor antagonist on myocyte remodeling in rat cardiac hypertrophy. Am J Physiol. 1997;273:H1824-31.

24. Baba HA, Iwai $T$, Bauer $M_{2}$ Irlbeck $M$, Schmid KW, Zimmer HG. Differential effects of angiotensin II receptor blockade on pressure- induced left ventricular hypertrophy and fibrosis in rats. J Mol Cell Cardiol. 1999;31:445-55.

25. Rouleau JL, Kapuku G, Pelletier S, Gosselin H, Adam A, Gagnon C, Lambert $\mathrm{C}$, Meloche S. Cardioprotective effects of ramipril and losartan in right ventricular pressure overload in the rabbit: importance of kinins and influence on angiotensin II type 1 receptor signaling pathway. Circulation. 2001;104:939-44.

26. Koide $M$, Carabello BA, Conrad CC, Buckley JM, DeFreyte G, Barnes $M$, Tomanek RJ, Wei CC, Dell'Italia LJ, Cooper Gt, Zile MR. Hypertrophic response to hemodynamic overload: role of load vs. renin- angiotensin system activation. Am J Physiol. 1999;276:H350-8.

27. Segar JL, Scholz TD, Bedell KA, Smith OM, Huss DJ, Guillery EN. Angiotensin AT1 receptor blockade fails to attenuate pressure-overioad cardiac hypertrophy in fetal sheep. Am J Physiol. 1997;273:R1501-8.

28. Ruzicka $M$, Yuan $B$, Harmsen E, Leenen FH. The renin-angiotensin system and volume overload-induced cardiac hypertrophy in rats. Effects of angiotensin converting enzyme inhibitor versus angiotensin $\|$ receptor blocker. Circulation. 1993;87:921-30.

29. Ishiye M, Umemura K, Uematsu T, Nakashima M. Angiotensin AT1 receptormediated attenuation of cardiac hypertrophy due to volume overload: involvement of endothelin. Eur J Pharmacol. 1995;280:11-7.

30. Perry GJ, Wei CC, Hankes GH, Dillon SR, Rynders P, Mukherjee R, Spinale FG, Dell'Italia LJ. Angiotensin II receptor blockade does not improve left ventricular function and remodeling in subacute mitral regurgitation in the dog. $J$ Am Coll Cardiol. 2002;39:1374-9. 


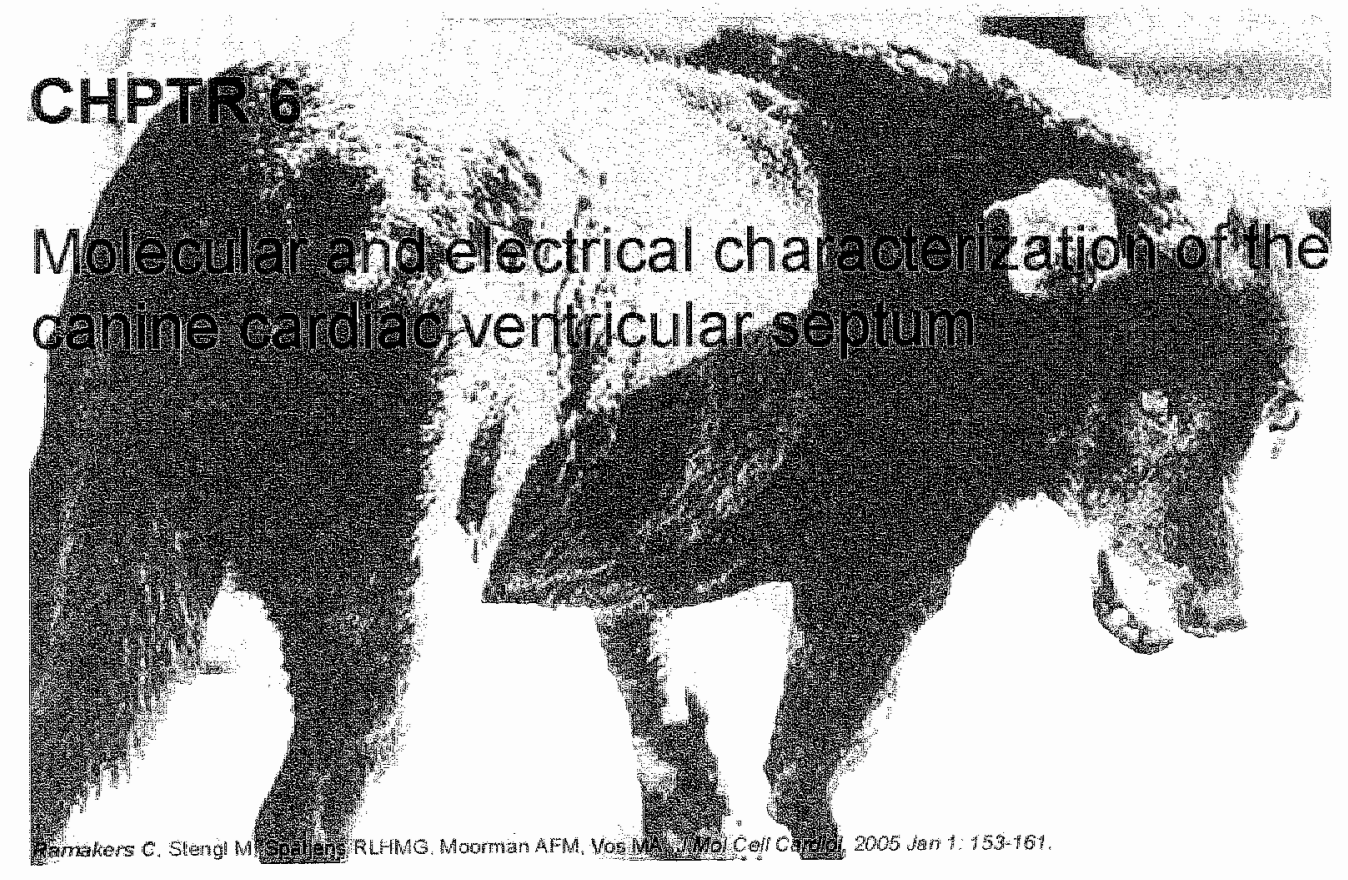




\section{SUMMARY}

Objective: Electrophysiological heterogeneity in the ventricular septum (VS) has been poorly addressed. In this study we investigated the electrophysiological and molecular composition of the VS in control (SR) and chronic complete AV block (CAVB) dogs. In the latter model, we anticipated that the increased inter-ventricular differences in action potential duration (APD; $L V>R V$ ) would accentuate the intrinsic heterogeneous composition of the VS.

Methods and Results: Steady state mRNA levels of ten important cardiac ion channels subunits as well as action potential (AP) characteristics $\left(\mathrm{APD}_{95}\right.$, phase 1 amplitude (P1A), resting membrane potential) were measured in both sides of the VS excluding a small mid-myocardial strip (right: RVS, left: LVS). In SR, differences in steady state mRNA between the two septal layers were observed for KChIP2 ( 5 fold, $P<0.01)$ and $K C N Q 1(\sim 2$ fold,$P<0.05)$ with significantly higher levels of steady state mRNA in the RVS compared to LVS. Correspondingly, shorter APD's and lower P1A's (more spike and dome) were found in RVS, although the AP differences were subtle. This transseptal expression of KChIP2 and KCNQ1 corresponded with the observed differential expression levels in the RV and LV free wall, respectively. Electrical remodelling due to CAVB was also observed in the VS as was shown by $\sim 2$ fold lower levels in KCND3, KCNH2 and KCNQ1 mRNA $(P<0.05)$ in the LVS compared to $\mathrm{SR}$, thereby creating new or eliminating existing transseptal gradients. In parallel to changes in steady state mRNA, CAVB resulted in a loss of the spike and dome morphology and longer $\mathrm{APD}_{95}(P<0.05)$ in the LVS.

Conclusions: Similar to other regions in the cardiac ventricles, the canine VS is molecularly and electrically heterogeneous. In the CAVB dog, this septal heterogeneity becomes accentuated as a result of electrical remodeling. 


\section{INTRODUCTION}

Regional heterogeneity in cardiac action potential (AP) morphology and duration (APD) is an inherent feature of normal, healthy ventricular tissue in mammals. Prominent repolarizing currents contributing to this heterogeneity are the transient outward current $\left(\mathrm{I}_{\mathrm{TO} 1}\right.$ ) and the delayed rectifier currents $\mathrm{I}_{\mathrm{Ks}}$ (slowly activating) and $\mathrm{I}_{\mathrm{kr}}$ (rapidly activating).

in rabbit hearts, $t_{k s}$ and $I_{k s}$ have been described to be heterogeneously distributed from base-to-apex, with $I_{k s}$ being significantly smaller in the apical regions, whereas for $I_{k r}$ the reverse is true (1). For canine hearts, distinct distributions of $I_{\text {TO }}(2,3)$ and $l_{k s}$ (3) currents have been reported between the ventricles, in which both currents were larger in the right ventricle (RV). For the $I_{k s}$ current this is molecularly confirmed by the observation that the mRNA and protein levels of the $\alpha$ subunit of $\mathrm{I}_{\mathrm{Ks}}$, KCNQ1 are significantly higher in the RV of normal dogs (4). In the left ventricular (LV) transmural free wall the $I_{\mathrm{Ks}}$ current density is less prominent in cardiomyocytes from the mid-myocardial region ( $M$ cells) compared to the subepi- and subendocardial regions (5). Furthermore, there is a heterogeneous distribution of the sodium late current $I_{\mathrm{NaL}}$ and the sodium-calcium exchanger $(\mathrm{NCX}) \mathrm{l}_{\mathrm{Na}-\mathrm{Ca}}$, both being larger in the mid-myocardial region $(6,7)$. Finally, in several species including human there is a clear transmural gradient in $\left.\right|_{\text {TO1 }}$ current density increasing from the subendocardial towards the subepicardial side $(8,9)$. Molecularly, this $I_{\text {TO1 }}$ current density corresponds to the steady-state mRNA level of the channel $\beta$ subunit KChIP2 (10), with mRNA $(11,12)$ as well as protein levels $(13)$ being highest on the epicardial side, white the mRNA of the channel a subunit, KCND3, is equally distributed over the LV transmural free wall.

In contrast to the regions described, the ventricular septum (VS) is less well characterized. Sicouri and co-workers demonstrated transmembrane action potential differences across the ventricular septum of the canine heart (14). Based on $I_{\text {To1 }}$ current characteristics in human cardiomyocytes, it has been proposed that the VS is an extension of the LV with myocytes from the LV subepicardium resembling myocytes in the right subendocardial side of the VS (15). However, from a developmental viewpoint, the VS is divided in an LV (LVS) and RV (RVS) part (16). In the adult murine ventricle this theory is supported by the expression pattern of the transcription factor $T b \times 5$, showing exclusive expression in the LV including the LVS but not in the RV and RVS (17). Further support for a divided VS comes from a RVhypertrophy rat model in which the expression of ANF is induced in the RV, as well as the RVS, while no expression of ANF is seen in the LV or the LVS (18). Recently, molecular and electrical characteristics of $\|_{\text {TO1 }}$ in the canine VS were also found to be in line with this theory (13).

In this study, we therefore scrutinized the molecular and electrophysiological composition of the VS in canine ventricles. We not only used VS tissue from control dogs with normal conducted sinus rhythm (SR), but also from dogs with chronic, complete atrio-ventricular block (CAVB) with electrically remodelled hearts. These hearts are characterised by an inhomogeneous lengthening of the APD in 
the ventricles (LV more than RV), and a higher propensity to (drug-induced) early afterdepolarizations, ectopic beats and TdP arrhythmias (19). Based on the interventricular electrical differences present in SR dogs we anticipated that these differences would also be present in the VS. Secondly, because of the spatial nature of electrical remodelling due to CAVB we expected that the augmented differences between the LV and RV would also become more accentuated in the VS.

\section{METHODS}

\subsection{Experimental animals}

The animal experiments were conducted in accordance with the "Dutch Law on Animal Experiments" and were approved by the "Committee for Experiments on Animals" of the Maastricht University, The Netherlands. The procedures for creating CAVB were described before (20). CAVB dogs had an average AVB of $9 \pm 3$ weeks (meantsd).

Table 1. Overvlew of primer sets used for kinetic real-time PCR. The NCBI accession numbers refer to Canis familiaris specific coding sequences.

\begin{tabular}{|c|c|c|c|c|}
\hline \multicolumn{5}{|c|}{ 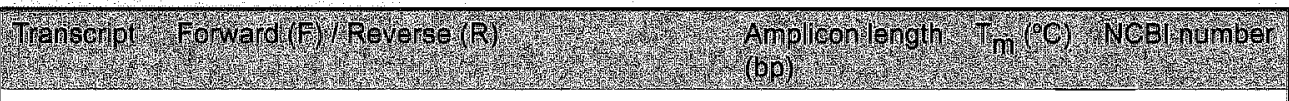 } \\
\hline GAPDH & $\begin{array}{l}\text { F: AGATCCCGCCAACATCAAA } \\
\text { R: ACGATGCCGAAGTGGTCAT }\end{array}$ & 273 & 58 & $A B 038240$ \\
\hline \multicolumn{5}{|c|}{ 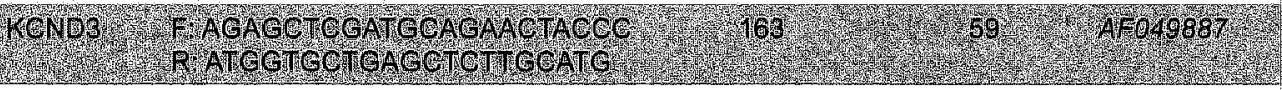 } \\
\hline KChIP2 & $\begin{array}{l}\text { F: CTGGTTTGTCGGTGATTCTTC } \\
\text { R: TTCCTCCTTGGTGATGCAG }\end{array}$ & 101 & 56 & AF458385 \\
\hline 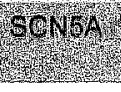 & 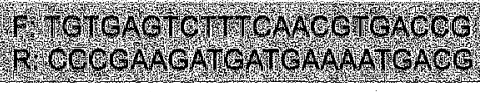 & & & 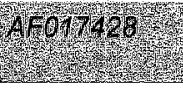 \\
\hline $\operatorname{NCX}$ & $\begin{array}{l}\text { F: TGCCCTCCTGTTTCGATTA } \\
\text { R: CCCAGCCATTCCAGTATTCT }\end{array}$ & 101 & 56 & M57523 \\
\hline \multicolumn{5}{|c|}{ 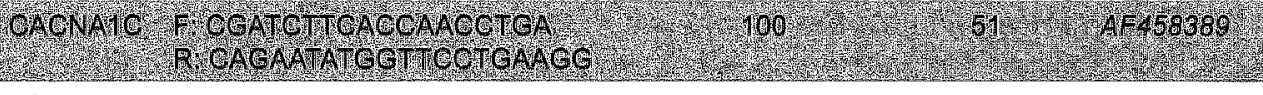 } \\
\hline KCNQ1 & $\begin{array}{l}\text { F: GTCGAGTTTGGCAGCTATGCA } \\
\text { R: CGCAAAGAAGGAGATGGCAA }\end{array}$ & 274 & 60 & Not avallable \\
\hline KENEY & 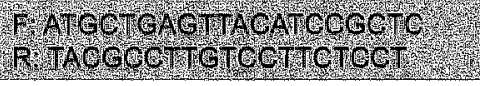 & res & & Neldrailat \\
\hline $\mathrm{KCNH} 2$ & $\begin{array}{l}\text { F: TTTGGCAATGTCTCCCCCA } \\
\text { R: TCGATGCCATTGGTGTAGGACC }\end{array}$ & 257 & 62 & AFO17429 \\
\hline $\mathrm{KOME} 2$ & 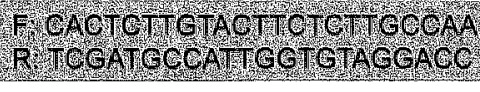 & 列 & & 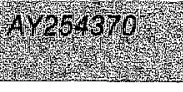 \\
\hline KCNJ2 & $\begin{array}{l}\text { F: ATGGTGGTCTTCCAGTCCA } \\
\text { R: CTCGTTCCTCTTCTTTGGCT }\end{array}$ & 100 & 55 & $A F 277647$ \\
\hline
\end{tabular}




\subsection{Experimental set-up and cell isolation}

Anaesthetized SR ( $n=14$ ) and CAVB dogs $(n=16)$ received 10,000 IU heparin IV on thoracotomy. The hearts were excised and washed in ice-cold cardioplegic solution. In both groups, the septal branch of the left anterior descending coronary artery was cannulated and perfused with collagenase for 30 minutes. Upon washout of the enzyme, the digested septum was divided in five portions: right subendocardial

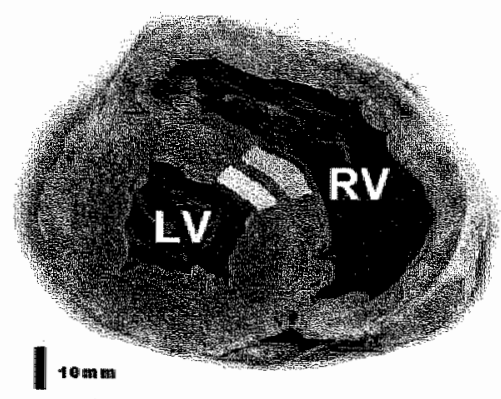

Layers

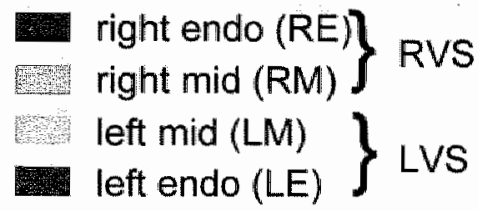

Figure 1. Transwersal wiew of the vemtricle of CAVIB dog showing the four layers (RE+RM: LE+LM) in the VS that were isolated. Inittal expression levels studies in $\mathrm{SR}$ dogs were performed in all 4 layers. Based on similar results in the endocardial and midmyocardial layers on each side, the endocardial and mid-myocardal layers of each side were pooled resulting in right (FVS) and left (LVS) septal tayers.

(RE, $\sim 2 \mathrm{~mm}$ ), right middle ( $R M_{n} \sim 4 \mathrm{~mm}$ ), middle (not used for further experiments), left middle $(L M, \sim 4 \mathrm{~mm})$ and left subendocardial (LE, $\sim 2 \mathrm{~mm}$ ) (figure 1). The individual portions were removed layer-by-layer from the digested area. In our initial expression level experiments in SR dogs we analysed these four layers within the VS (figures 2 and 3 ; panel $B$ and $C$ ). Based on similar results between the subendocardial and mid-myocardial layers on each side, the layers were pooled resulting in LVS (LE+LM) and RVS (RE+RM) layers, which were then used in all other experiments. Cardiomyocytes were imaged by a video camera connected to an inverted microscope (Diaphot300, Nikon) of the set-up. The length and width of each cell were measured on a defined area of the monitor with a $\times 40$ microscopic objective. Cardiomyocyte dimensions were obtained from 3 SR dogs and 4 CAVB dogs in a total of 1512 cells (SR: $n_{\mathrm{LVS}}=324 ; \mathrm{n}_{\mathrm{RVS}}=324$, CAVB: $\mathrm{n}_{\mathrm{LVS}}=432 ; \mathrm{n}_{\mathrm{RVS}}=432$ ).

\subsection{Total RNA isolation / First-strand synthesis}

Two different ways of biopsy collection were used for total RNA isolation. 1) For the LVS and RVS comparison in the VS, cell suspensions (see 2.2) of SR and CAVB (both $n=8$ ) were used; 2) for the overall comparison of LV-VS-RV expression patterns, the ventricle of a SR dog was divided as follows: transseptal (middle part: 
$\sim 10 \mathrm{~mm}$ ) and transmural (anterior free wall, $\mathrm{LV}: \sim 10 \mathrm{~mm}, \sim 8 \mathrm{~mm} \mathrm{RV}$ ) biopsies were cut out and divided through the middle. Each divided part of the biopsies was prepared for cryosectioning (embedded in OCT compound) with the "luminal side" facing up. Upon removal of the endocardial and epicardial layers $(\sim 0.5 \mathrm{~mm}), 4 \mathrm{~mm}$ of tissue was dissected using a cryostat resulting in 6 tissue samples $\left(\mathrm{LV}_{\text {sub-epi" }} \mathrm{LV}_{\text {sub-endo }}\right.$ LVS, RVS, RV sub-endo $_{\text {and }}$ and $\mathrm{R}_{\text {sub-ep }}$ ). Total RNA was isolated using the RNEasy MINI kit (Qiagen/Westburg, Leusden. The Netherlands) according to the manufacturers protocol. DNAse/-digestion was performed after elution of the total RNA from the column. First-strand cDNA was synthesized using $1 \mu \mathrm{g}$ total RNA in combination with an anchored oligo-dT 14 VN primer and was performed as described before (21).

\subsection{Kinetic real-time PCR}

Fluorescence-based kinetic real-time PCR was performed using a LightCycler ${ }^{\mathrm{TM}}$ system (Roche Diagnostics Nederland, Almere, The Netherlands) in combination with the intercalating fluorescent dye SYBR Green I. All 10 amplicons (SCN5A, KCND3, KChIP2, CACNA1C, NCX, KCNQ1, KCNE1, KCNH2, KCNE2, KCNJ2) were quantified using the LinRegPCR method (22) and are expressed relative to the constitutive active GAPDH gene. For an overview of all the primers see table 1. Regarding the use of GAPDH as a housekeeping gene " based on the $1 \mu \mathrm{g}$ total RNA input in the first strand synthesis we found no systematical change in GAPDH mRNA levels due to CAVB when compared to SR.

\subsection{Action potential recordings}

Sharp glass microelectrodes (resistance more than $20 \mathrm{M} \Omega$ ) were filled with $3 \mathrm{M}$ $\mathrm{KCl}$. The standard buffer solution used for the experiments was of the following composition (mM): $\mathrm{NaCl} 145, \mathrm{KCl} 4.0, \mathrm{CaCl}_{2} 1.8, \mathrm{MgCl}_{2}$ 1.0, glucose 11, HEPES $10, \mathrm{pH} 7.4$ with $\mathrm{NaOH}$. AP's were recorded at $37^{\circ} \mathrm{C}$ with a microelectrode amplifier (Axoclamp-2B, Axon Instruments) in a total of 109 cells from 6 SR and 8 CAVB dogs (SR: $n_{\mathrm{LVS}}=20 ; n_{\mathrm{RVS}}=22$, CAVB: $n_{\mathrm{LVS}}=33 ; n_{\mathrm{RVS}}=34$ ) at cycle lengths (CL) of 300,400 , $500,750,1000,2000,3000$, and $4000 \mathrm{~ms}$, digitized and stored for later analysis. Amplitudes were measured as the voltage difference between the resting membrane potentiall and the deepest level of notch (phase 1) and dome (phase 2). The APD was determined at $50 \%\left(\mathrm{APD}_{50}\right)$ and $95 \%$ of repolarization $\left(\mathrm{APD}_{95}\right)$.

\subsection{Statistical analysis}

The data in all figures are expressed as mean \pm sem. Outlier values were detected using the Maximum Normed Residual (MNR) test. Statistical significance was assessed with the Kruskal-Wallis test for non-parametric ANOVA. A level of $P<0.05$ was considered significant. 


\section{RESULTS}

\subsection{Ventricular septum gradients in SR dogs}

\subsubsection{Early repolarization: molecular correlates and phase 1 amplitude (P1A)}

The MRNA levels of the molecular correlate of the inward current $\mathrm{I}_{\mathrm{Na}}$ (SCN5A) were not different (data not shown). For the $\alpha$-subunit of $I_{\text {TO1 }}$ (KCND3), the steady state mRNA levels (figure $2 A$ ) were also not different between the layers, while a $\sim 5$ fold higher level of KChIP2 mRNA (I ${ }_{\text {TO1 }} \beta$-subunit) in the RVS was seen compared to the LVS $(P<0.01$ ) (figure 2B). Between the two septal layers (RVS vs. LVS), the $P 1 A$ (figure $2 \mathrm{C}$, left panel) showed a tendency to be lower in the RVS compared to the LVS, although this did not reach statistical significance. Note that a low P1A can correspond to a high $\mathrm{I}_{\mathrm{TO} 1}$ and/or a low $\|_{\mathrm{Na}}$ current density (figure $2 \mathrm{C}$; inset).

A

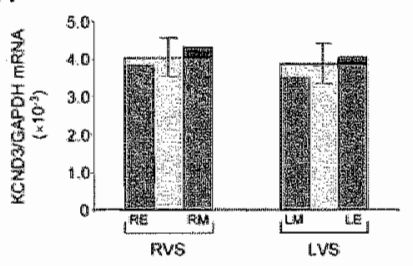

B

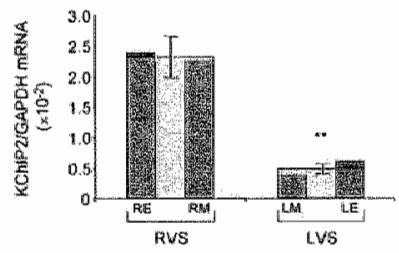

C

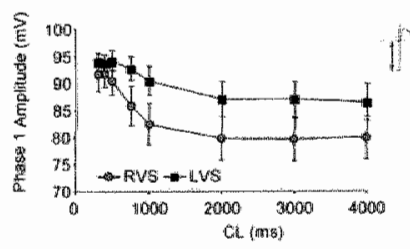

Figure 2. (A) Steady state mRINA levels of the $I_{\text {TDi }} \alpha-$ subunit KCND3 shows an equal distribution in all four layers while the $\beta$-subunit, $K C$ ChIP2 $(B)$ is $\sim 5$ fold higher in RVS (RE=RM) compared to LVS (LE $=\mathbb{L M})\left({ }^{* *}, P<0.01\right)$. (C) Phase 1 amplitude (P1A) in LVS and RVS layers of SR dogs al various cycle lengths. P1A was measured as the voltage difference between the resting membrame potential and the deepest. level of notch (intset). On the right sidte en sximing of Aip reocrding (CLL 2000 mis) in both layars.

\subsubsection{AP plateau and repolarization: molecular correlates and $A P D_{95}$}

Steady state mRNA levels of the NCX were higher in RVS when compared to LVS $(P<0.05$; figure $3 A)$. The mRNA level of KCNQ1 differed between the two septal layers with a $\sim 2$ fold higher expression in the RVS compared to the LVS (figure 3B). The mRNA level of the $\beta$ subunit of $\mathrm{I}_{\mathrm{Ks}}-\mathrm{KCNE} 1$ - was equally distributed (data not shown). Other important molecular correlates of currents contributing to the plateau phase, like the L-type $\mathrm{Ca}^{2+}-I_{\mathrm{Kr}} \alpha$ and $\beta$ subunit, CACNA1C, KCNH2 and KCNE2, respectively, showed no significant difference in steady state mRNA levels between the RVS and LVS (data not shown). No significant difference in $A P D_{95}$ was seen between RVS and LVS at physiological rates. However there were longer APD's in the LVS at higher cycle lengths (LVS $>$ RVS, $P<0.05$ at $C L 3000 \mathrm{~ms}$ ) (figure $3 \mathrm{C}$ ). The resting membrane potential between the two septal layers was not different $(-82.0 \pm-$ 1.4 Vs. $-82.2 \pm-1.6 \mathrm{mV}$ for RVS and LVS, respectively). 
A

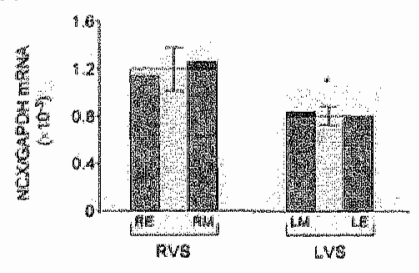

C.

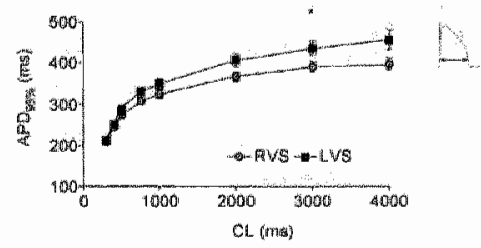

$\mathbf{B}$
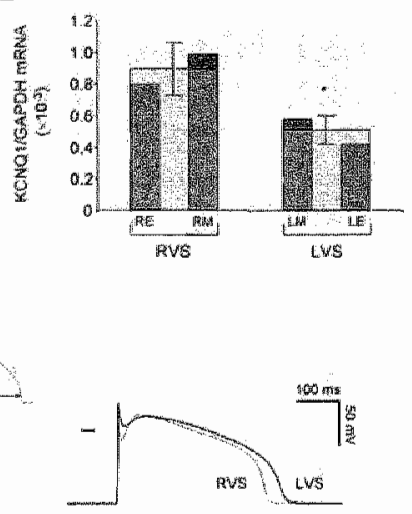

Figure 3. The molecular correlates of $I_{\text {paras }}$ and $l_{\text {Kas }}$ NCX (A) and KCNQ1 (B). respectively, showed a higher mRNA lewel in the RVS (RE=RM) compared to LVS ( $L E=L M)\left(*{ }^{\circ} P<0.05\right)$. (C) $\mathrm{APD}_{95}$ as a function of cycle lengthsi in LVS and RVS of SR dogs.

\subsubsection{Distribution of KChIP2 and KCNQ1 MRNA in different regions of the canine} heart

The steady mRNA levels of KChIP2 (figure 4A) and KCNQ1 (figure 4B) were determined in $\mathrm{RV}_{\text {sub-epi; }}, \mathrm{RV}_{\text {sub-endo }}, \mathrm{RVS}, \mathrm{LVS}, \mathrm{LV}_{\text {sub-endo }}$ and LV $\mathrm{Lub}_{\text {subi }}$ layers of a SR dog. For KChIP2 the mRNA in $L V_{\text {sub-epi }}$ was $\sim 3$ fold higher than in $L V_{\text {sub-endo. }}$. In the VS the difference between LVS and RVS was -5 fold (RVS $>$ LVS). In the LV, the KCNQ1 mRNA did not differ between $L V_{\text {sub-epi }}$ than $L V_{\text {sub-endo }}$ while in the $V S$ there was a small difference in mRNA level between LVS and RVS. In general, the mRNA levels of KChIP2 and KCNQ1 were higher in RV(S) layers than LV(S) layers.

A

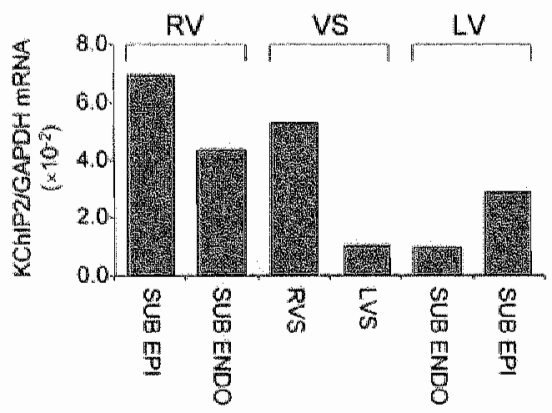

B

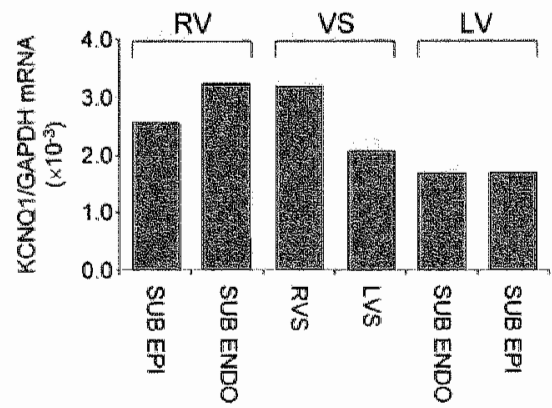

Figure 4. mRNA levels of KChIP2 (A) and KCNQ1 (B) in dissected layers on the subepicardial and - endocardial sides of the LV and FV, and both subendocardial sides (LVS, RVS) of the VS of a SR dog. This dog was considered representative based on the previously quantified KChIP2 (figure 2C) and KCNQ1 (figure 3C) mRNA levels of the LVS and RVS in the SR population $(\mathrm{n}=8$ ). 


\subsection{Augmentation of ventricular septum gradients in CAVB dogs}

The (bi)ventricular hypertrophy due to CAVB was shown by a significant increase the heart weight-to-body weight ratio (10.6 $2.0 \mathrm{vs}$. $8.6 \pm 1.2 \mathrm{~g} / \mathrm{kg})$ and an increase in cell length as well as width in both LVS and RVS compared to SR (table 2).

Table 2. Heart weight-to-body weight ratio (Hw/Bw) and cellular dimensions of VS cells (LVS and RVS) In SR and CAWB dogs.

\begin{tabular}{|c|c|c|c|c|c|}
\hline & Hw/bw $(\mathrm{g} / \mathrm{kg})$ & Length $(\mu \mathrm{m})$ & Width $(\mu \mathrm{m})$ & Length ( $\mu \mathrm{m})$ & Width $(\mu \mathrm{m})$ \\
\hline 8 & 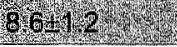 & 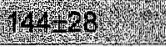 & 297 & & 29. \\
\hline CAVB & $10.6 \pm 2.0$ & $163 \pm 28$ & $34 \pm 8 t$ & $162 \pm 32$ & $34+8^{+}$ \\
\hline
\end{tabular}

\subsubsection{Early repolarization: molecular correlates and phase 1 amplitude (P1A)}

In contrast to SR (figure 2A; figure 5A, dotted columns), the KCND3 mRNA level in CAVB dogs was $\sim 2$ fold lower in LVS compared to RVS $(P<0.05)$. For KChIP2, mRNA levels remained significantly higher in RVS compared to LVS $(P<0.01)$ as was observed in SR (figure 2B; figure 5B, dotted columns).

The mRNA levels of SCN5A were not different between the two layers, as was observed in SR (data not shown). CAVB resulted in a significant difference in P1A between the two septal layers (LVS $>R V S, P<0.05$ at $C L$ 's larger than $1000 \mathrm{~ms}$ ) (figure 5C, left panel).

A

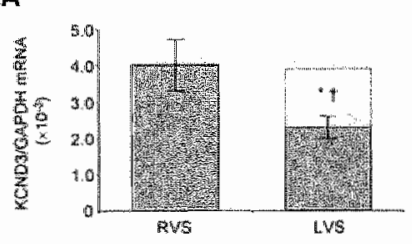

C

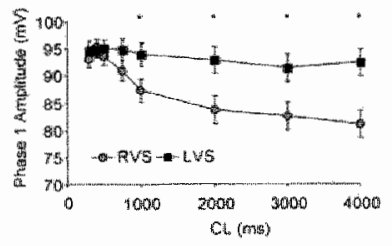

$\mathbf{B}$
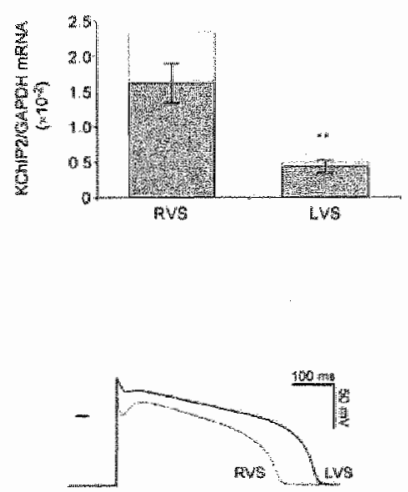

Figure 5. (A) in LVS, steady stalle mRNA lavels of the $I_{\text {To1 }} \alpha$-Subunil KCND3 were lower compared to SR (dotted column), resulting in a significant difference belween RVS and LVS in CAVB ( $t, P<0.05$ vs. LVS SF: *,$P<0.05$ vs. RVS CAVB) (B) For KChIP2, mRNA levels remained significantly higher in RVS compared to LVS (***, $P<0.01)$ as was abserved in $S R$. (C) Phase 1 amplitude (P1A) in LVS and RVS layers of CAVB dogs at various cycle lengths. CAVB resulted in a significant difference in P1A between LVS and $R V S(C L \geq 1000 \mathrm{~ms})$ 
3.2.2 AP plateau and repolarization: molecular correlates and $A P D_{95}$ Compared to SR, there was an overall lower KCNQ1 mRNA level in CAVB (figure 6B, dotted columns). The observed $\sim 2$ fold difference in KCNQ1 mRNA levels between the two septal layers (LVS<RVS) in SR (figure 3B; figure 6B, dotted columns) disappeared. KCNH2 mRNA levels were significantly lower in LVS as compared to RVS $(P<0,05)$ (figure 6A). Compared to $S R$, no changes in mRNA levels for KCNE1, KCNE2, KCNJ2, CACNA1C and NCX were observed (data not shown). in contrast to $S R, C A V B$ resulted in a significant difference in $A P D_{95}$ between LVS and RVS for all measured CL's (LVS>RVS) (Figure 6C). The resting membrane potential between the two septal layers was not different $(-83.4 \pm-0.9$ vs. $-83.0 \pm-1.4$ $\mathrm{mV}$ for LVS and RVS, respectively).

A

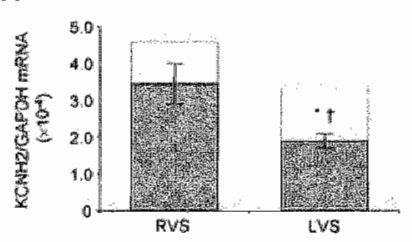

C

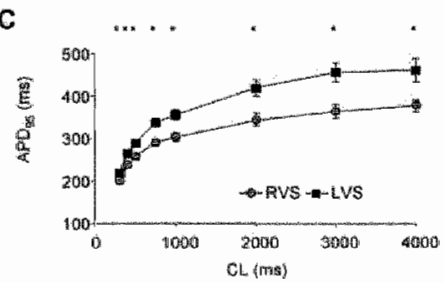

B
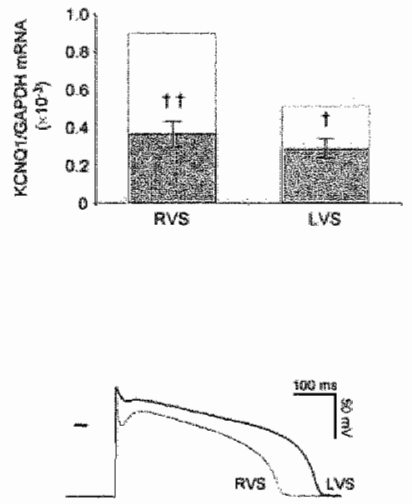

Figure 6. (A) Campared to SR, the molecular correlate of $I_{k s^{\prime}}$ $K C N H 2$, was lower only in the LVS $(\dagger, P<0.05$ ws. LVS SR. dotted columns). This decrease led to a significant difference between LVS and RVS in CANB ( ${ }^{*}, P<0.05$ vs. RVS CAVB). (B) For KCNQ1 the response to CAVB was similar and significant for both layers $(t, P<0.05$ vs. LVS SR: $t T, P<0.01$ ws. RVS $\mathrm{SR}$, dotted columns). (C) $\mathrm{APD}_{95}$ as a function of cycle lengths in LVS and RVS of CAVB dogs. CAVB resulted in a significant difference in $A P D_{6 s}$ between LVS and RVS over the whole range of cycle lenghts.

\section{DISCUSSION}

In the VS of SR dogs, the steady state mRNA levels of KChIP2 and KCNQ1 were higher in RVS as compared to LVS. These differences in mRNA expression were associated with only subtle differences in action potential characteristics. In CAVB dogs, these AP differences become more prominent and were accompanied by a region-specific reduction in mRNA levels of KCND3 (LVS), KCNH2 (LVS), and KCNQ1 (LVS and RVS).

\subsection{Ventricular septum gradients in SR dogs}

In SR dogs, the differences in steady state mRNA levels between the two septal layers were pronounced, as was seen by the significantly higher levels of KChIP2 and KCNQ1 mRNA in RVS compared to LVS (figure 2B; figure 3B). In contrast, the $\mathrm{P} 1 \mathrm{~A}$ and $A \mathrm{AP}_{95}$ only showed subtle differences between the two septall layers, with 
a trend to higher $\mathrm{P} \mathrm{A}^{\prime}$ 's (figure $2 \mathrm{C}$ ) and longer $\mathrm{APD}_{95}$ (figure 3C) in LVS compared to RVS. The larger spike and dome morphology of the RVS is almost certainly related to the $\sim 5$ fold higher levels of KChIP2 mRNA. This relationship has been consistently described in literature by a number of groups (11-13). The discrepancy between the -2 fold difference in KCNQ1 mRNA (figure 3B) and the only marginal difference in the duration of repolarization between the two layers is most probably explained by the fact that $\beta$-adrenergic unstimulated $I_{k s}$ does not contribute to the cellular APD at baseline (23). In addition, the level of NCX MRNA was higher in RVS (figure 3A). A larger $I_{\mathrm{Na} \text {-Ca }}$ current in RVS could counteract the possible $I_{\mathrm{Ks}}$ contribution to the APD and thus diminish the differences in APD between the two septal layers.

\subsection{Augmentation of ventricular septum gradients in CAVB dogs}

The intrinsic electrical differences between the LV and RV become more accentuated in CAVB due to a more pronounced lengthening of the APD in the LV compared to the $R V$, causing an increase in inter-ventricular dispersion ( $\triangle A P D)(19,20,24,25)$. In vitro characterisation of mid-myocardial cells showed an increased cell length (LV and $\mathrm{RV}$ ) (26), a down regulation of the $\mathrm{I}_{\mathrm{Ks}}$ current (LV and RV) (24) and an increase in $\mathrm{I}_{\mathrm{Na}-\mathrm{Ca}}$ current in the LV (27), while $\mathrm{I}_{\mathrm{TO}, 1}, \mathrm{I}_{\mathrm{K} t}, \mathrm{I}_{\mathrm{Kr}}(24)$ and $\mathrm{I}_{\mathrm{Ca}-\mathrm{L}}(27)$ were unchanged. Using multiple endocardial monophasic action potential (MAP) recordings throughout both ventricles in CAVB dogs, including the LV and RV side of the VS, Verduyn and co-workers (28) showed that in wivo the $\triangle A P D$ was very pronounced, and much bigger than the intra-ventricular dispersion $\left(R V_{\text {intra }}=20 \pm 13 \mathrm{~ms} ; L V_{\text {intra }}=1610 \mathrm{~ms} ; \triangle A P D\right.$ $=100 \pm 18 \mathrm{~ms}$ ). Because of this spatial difference in electrical remodelling between the two ventricles we expected increased differences between the two VS layers of CAVB compared to SR dogs.

Indeed, compared to SR we observed a down regulation in KCND3 rather than $\mathrm{KChIP2} \mathrm{mRNA}$ in the LVS. For KCND3 this created a transseptal gradient, whereas the existing difference in KChIP2 mRNA levels was unaltered (figure 5A and B). This decrease in KCND3 mRNA is in line with reported findings that during long term remodelling the KCND3 transcript is subject to transcriptional down-regulation (29, 30). Previously, however, we have shown that in midmyocardial cells in the LV free wall of CAVB dogs, $I_{\text {TO1 }}$ was unaffected (24). The KCND3 mRNA downregulation and decrease in spike and dome morphology in the LVS of CAVB dogs therefore suggests regional heterogeneity in the electrical remodeling process. Of the ion channel subunits that shape the plateau and late repolarization phases of the AP, only $\mathrm{KCNH} 2$ and $\mathrm{KCNQ} 1$ showed a change in steady state mRNA levels (Figure $6 \mathrm{~A}$ and $\mathrm{B}$ ) due to CAVB. For $\mathrm{KCNH} 2$ this created a transseptal gradient, while for KCNQ1 the existing gradient disappeared. Parallel with the changes in steady state mRINA levels, CAVB resulted in significant differences in AP characteristics between the two septal layers (figures $5 \mathrm{C}, 6 \mathrm{C}$ ).

\subsection{Ventricular septum: left ventricular extension or true septum?}

It has been proposed that the VS is an extension of the LV free wall (15). Yet, anatomically, the VS divides the LV from the RV and therefore is as much part of the LV wall as it is of the RV wall (16). Our data on the KChIP2 mRNA levels in SR dogs 
show a significantly higher ( $\sim 5$ fold) mRNA level in RVS than in LVS (figure $2 B$; figure 4A). Such a pattern can be interpreted as being consistent with the pattern in the LV free wall $\left(L V_{\text {sub-epl }}>L V_{\text {sub-endo }}\right)(11,12)$. However, it can also reflect the inter-ventricular difference in $\mathrm{I}_{\text {ro }}$ current density (RV $>L V$ ) (3). Using a comparable dissecting approach as shown in figure 4, Rosati and co-workers (13) confirmed our KChlP2 results in that they showed an overall higher mRNA level in the RV compared to the LV. In support of a divided VS they found that the KChIP2 mRNA levels on the LV and RV endocardial sides corresponded with mRNA levels in the LVS and RVS, respectively. In contrast to KChIP2, the expression pattern of KCNQ1 in the VS of control dogs (RVS>LVS; figure 3B; figure 4B) is only consistent with the definition of the VS being a division between the LV and RV since the pattern: 1) resembles the distribution of the transcript (4) as well as of the $I_{K_{s}}$ current density (24) in the LV and $R V(R V>L V) ; 2$ ) is dissimilar to the LV free wall distribution of $I_{K_{s}}$ with equal current densities on the subepicardial and subendocardial sides (5). Furthermore, the changes in expression levels due to CAVB were more pronounced in LVS than RVS, which is consistent with a more pronounced CAVB-related electrical remodelling in LV (19). Therefore, in our opinion, these data indicate that the VS is not an extension of the LV, but rather shows that there is a mutual contribution of both ventricles to the composition of the septum.

\subsection{Limitations}

The direct correlation between the P1A and $\mathrm{APD}_{95}$ with the steady state mRNA levels of ion channel subunits was not always met. We are aware of the restraints to directly correlate electrophysiological data with steady state mRNA levels. There is a number of possibly interfering parameters between mRNA expression and membrane electrophysiology, such as protein expression, ion channel regulation, interaction of ionic currents. Furthermore, different dogs were used for the electrophystological and molecular experiments. In this study we did not include protein levels of the molecular correlates. Although post-franslational modification is an important (secondary) regulatory mechanism, to our knowledge this has not been reported for the transcripts imvestigated in this study.

Considering the intrinsic difference in wall thickness between the LV and RV free wall, different relative contributions of each ventricular wall to the VS could be suggested. For this possibility we did not correct in our experiments (LVS and RVS portions were of the same thickness), however, exclusion of the middles VS portion from our experiments should prevent such error.

\subsection{Conclusion}

Scrutinizing the VS of SR dogs we show that, like other regions in the ventricles, the VS is molecularly and electrically heterogeneous. In the CAVB dog, this septal heterogeneity becomes accentuated as a result of electrical remodeling. 


\section{ACKNOWLEDGEMENTS}

We would like to thank Dr. Robert Dumaine for providing the canine specific DNA sequences of KCNQ1 and KCNE1. Financial support by the Netherlands Heart Foundation (\#98.042) is gratefully acknowledged.

\section{REFERENCES}

1. Cheng J, Kamiya $K$, Liu W, Tsuji $Y$, Toyama J, Kodama I. Heterogeneous distribution of the two components of delayed rectifier $\mathrm{K}+$ current: a potential mechanism of the proarrhythmic effects of methanesulfonanilideclass III agents. Cardiovasc Res 1999;43(1):135-47.

2. Di Diego JM, Sun $Z Q$, Antzelevitch C. $1($ to $)$ and action potential notch are smaller in left vs. right canine ventricular epicardium. Am J Physiol 1996;271(2 Pt 2):H548-61.

3. Volders PG, Sipido KR, Carmeliet E, Spatjens RL, Wellens HJ, Vos MA. Repolarizing K+ currents ITO1 and IKs are larger in right than left canine ventricular midmyocardium. Circulation 1999;99(2):206-10.

4. Ramakers C, Vos MA, Doevendans PA, Schoenmakers M, Wu YS, Scicchitano S, et al. Coordinated down-regulation of KCNQ1 and KCNE1 expression contributes to reduction of $\mathrm{I}(\mathrm{Ks})$ in canine hypertrophied hearts. Cardiovasc Res 2003;57(2):486-96.

5. Liu DW, Antzelevitch C. Characteristics of the delayed rectifier current (IKr and $(\mathrm{Ks}$ ) in canine ventricular epicardial, midmyocardial, and endocardial myocytes. A weaker IKs contributes to the longer action potential of the $\mathrm{M}$ cell. Circ Res 1995;76(3):351-65.

6. Zygmunt AC, Eddlestone GT, Thomas GP, Nesterenko VV, Antzelevitch C. Larger late sodium conductance in $\mathrm{M}$ cells contributes to electrical heterogeneity in canine ventricle. Am J Physiol Heart Circ Physiol 2001;281(2):H689-97.

7. Zygmunt AC, Goodrow RJ, Antzelevitch C. I(NaCa) contributes to electrical heterogeneity within the canine ventricle. Am J Physiol Heart Circ Physiol 2000;278(5):H1671-8.

8. Furukawa T, Myerburg RJ. Furukawa N, Bassett AL, Kimura S. Differences in transient outward currents of feline endocardial and epicardial myocytes. Circ Res $1990 ; 67(5): 1287-91$. 
9. Liu DW, Gintant GA, Antzelevitch C. Ionic bases for electrophysiological distinctions among epicardial, midmyocardial, and endocardial myocytes from the free wall of the canine left ventricle. Circ Res 1993; 72(3):671-87.

10. Kuo HC, Cheng $C F$, Clark RB, Lin $J J$, Lin JL, Hoshijima M, et al. A defect in the Kv channel-interacting protein 2 (KChIP2) gene leads to a complete loss of I(to) and confers susceptibility to ventricular tachycardia. Cell 2001;107(6):801-13.

11. Rosati B, Pan Z, Lypen S, Wang HS, Cohen I, Dixon JE, et al. Regulation of KChIP2 potassium channel beta subunit gene expression underlies the gradient of transient outward current in canine and human ventricle. J Physiol 2001;533/Pt 1):119-25.

12. Deschenes I, DiSilvestre D, Juang GJ, Wu RC, An WF, Tomaselli GF. Regulation of Kv4.3 current by KChIP2 splice variants: a component of native cardiac I(to)? Circulation 2002;106(4):423-9.

13. Rosati B, Grau F, Rodriguez S, Li H, Nerbonne JM, McKinnon D. Concordant expression of KChIP2 mRNA, protein and transient outward current throughout the canine ventricle. J Physiol 2003;548(Pt 3):815-22.

14. Sicouri S, Fish J, Antzelevitch $C$. Distribution of $M$ cells in the canine ventricle. J Cardiovasc Electrophysiol 1994;5(10):824-37.

15. Konarzewska H, Peeters GA, Sanguinetti MC. Repolarizing $\mathrm{K}+$ currents in nonfailing human hearts. Similarities between right septal subendocardial and left subepicardial ventricular myocytes. Circulation 1995;92(5):1179-87.

16. Netter FH, van Mierop LHS. Formation of cardiac septa. In: Jonkman FF, editor. The CIBA collection of medical illustrations. Summit, New Jersey: CIBA pharmaceutical company; 1969. p. 119-121.

17. Bruneau BG, Logan M, Davis N, Levi T, Tabin CJ, Seidman JG, et al. Chamber-specific cardiac expression of Tbx5 and heart defects in Holt-Oram syndrome. Dev Biol 1999;211(1):100-8.

18. LekanneDeprez RH, van den Hoff MJ, de Boer PA, Ruijter PM, Maas AA, Chamuleau RA, et al. Changing patterns of gene expression in the pulmonary trunkbanded rat heart. J Mol Cell Cardiol 1998;30(9):1877-88.

19. Vos MA, de Groot SH, Verduyn SC, van der Zande J, Leunissen HD, Cleutjens $J P$, et al. Enhanced susceptibility for acquired torsade de pointes arrhythmias in the dog with chronic, complete AV block is related to cardiac hypertrophy and electrical remodeling. Circulation 1998;98(11):1125-35. 
20. Schoenmakers $\mathbb{M}$, Ramakers $C$, van Opstal JM, Leunissen $J D$, Londono C, Vos MA. Asynchronous development of electrical remodeling and cardiac hypertrophy in the complete AV block dog. Cardiovasc Res 2003;59(2):351-9.

21. Lekanne Deprez RH, Fijnvandraat AC, Ruijter JM, Moorman AF. Sensitivity and accuracy of quantitative real-time polymerase chain reaction using SYBR green I depends on cDNA synthesis conditions. Anal Biochem 2002;307(1):63-9.

22. Ramakers C, Ruijter $J_{M}$, Deprez RH, Moorman AF. Assumption-free analysis of quantitative real-time polymerase chain reaction (PCR) data. Neurosci Lett 2003;339(1):62-6.

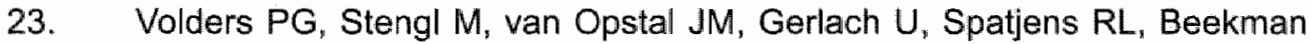
$\mathrm{JD}_{\text {n }}$ et al. Probing the contribution of IKs to canine ventricular repolarization: key role for beta-adrenergic receptor stimulation. Circulation 2003;107(21):2753-60.

24. Volders PG, Sipido KR, Vos MA, Spatjens RL, Leunissen JD, Carmeliet $E$, et al. Downregulation of delayed rectifier $\mathrm{K}(+)$ currents in dogs with chronic complete atrioventricular block and acquired torsades de pointes. Circulation 1999;100(24):2455-61.

25. Verduyn SC, Ramakers C, Snoep G, Leunissen JD, Wellens HJ, Vos MA Time course of structural adaptations in chronic AV block dogs: evidence for differential ventricular remodeling. Am J Physiol Heart Circ Physiol 2001;280(6):H2882-90.

26. Volders PG, Sipido KR, Vos MA, Kulcsar A, Verduyn SC, Wellens HJ. Cellular basis of biventricular hypertrophy and arrhythmogenesis in dogs with chronic complete atrioventricular block and acquired torsade de pointes. Circulation $1998 ; 98(11): 1136-47$.

27. Sipido KR, Volders PG, de Groot $S H$, Verdonck $F$, Van de Werf F, Wellens $\mathrm{HJ}$, et al. Enhanced $\mathrm{Ca}(2+)$ release and $\mathrm{Na} / \mathrm{Ca}$ exchange activity in hypertrophied canine ventricular myocytes: potential link between contractile adaptation and arrhythmogenesis. Circulation 2000;102(17):2137-44.

28. Verduyn SC, Vos MA, van der Zande J, van der Hulst FF, Wellens HJ. Role of interventricular dispersion of repolarization in acquired torsade-de-pointes arrhythmias: reversal by magnesium. Cardiovasc Res 1997;34(3):453-63.

29. Patberg KW, Plotnikov AN, Quamina A, Gainullin RZ, Rybin A, Danilo $P$, Jr., et al. Cardiac memory is associated with decreased levels of the transcriptional factor CREB modulated by angiotensin II and calcium. Circ Res 2003;93(5):472-8. 
30. Kaab S, Dixon J, Duc J, Ashen D, Nabauer M, Beuckelmann DJ, et al. Molecular basis of transient outward potassium current downregulation in human heart failure: a decrease in Kv4.3 mRNA correlates with a reduction in current density. Circulation 1998;98(14):1383-93. 


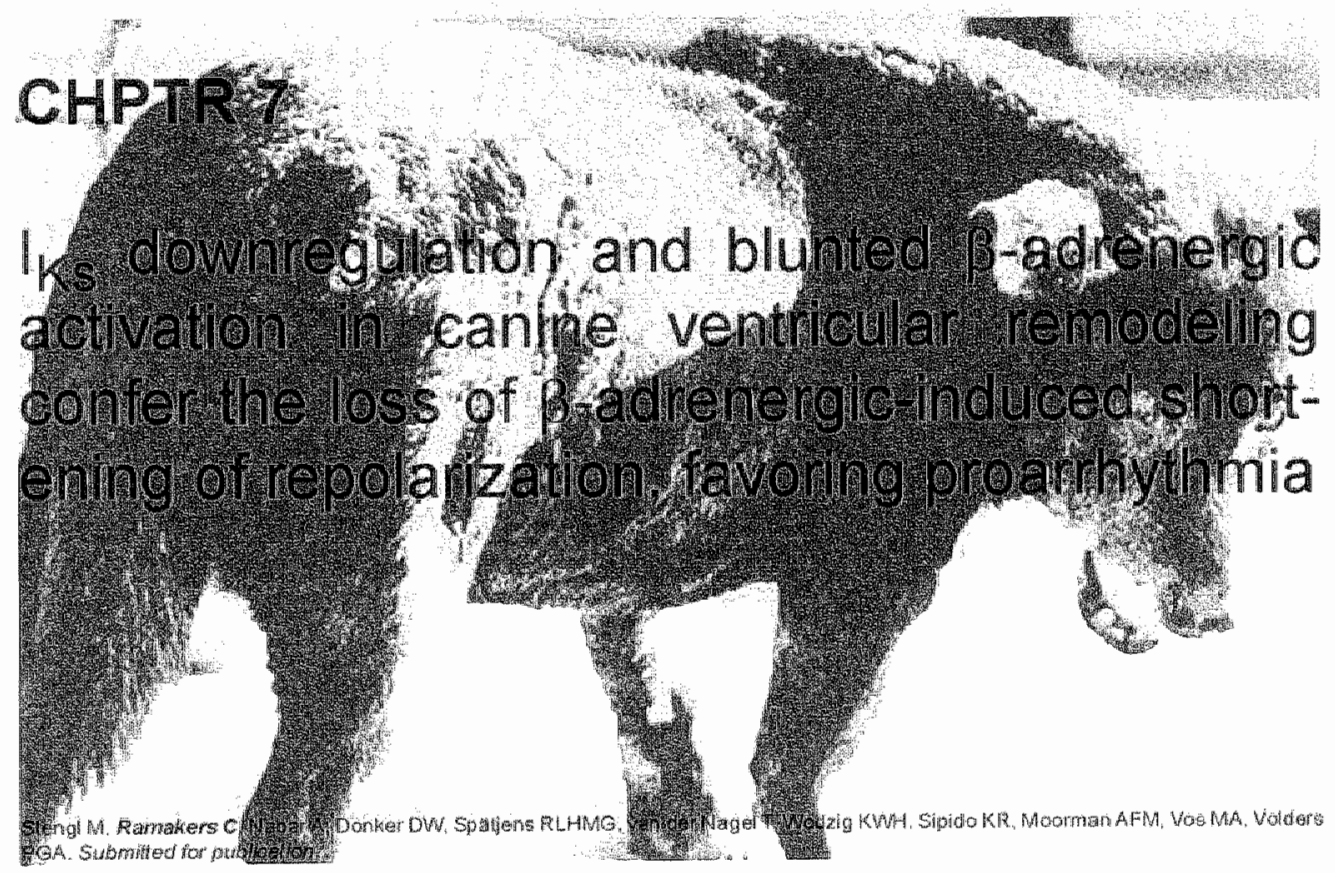




\section{SUMMARY}

Background: Electrical remodeling in cardiac hypertrophy often involves the downregulation of $\mathrm{K}^{+}$currents, including $B$-adrenergic-sensitive $I_{\mathrm{Ks}_{5}}$. In dogs with chronic complete atrioventricular block (AVB) and hypertrophy, decreased $l_{\mathrm{Ks}}$ impairs ventricular repolarization. We examined (1) the molecular basis of $I_{\mathrm{Ks}}$ downregulation from acute to chronic $A V B$ and (2) concomitant changing responses of repolarization to $B$-adrenergic receptor stimulation.

Methods and Results: Serial left-ventricular biopsies were collected from dogs during sinus rhythm (control) and at 3,8 and 30 days of AVB. KCNQ1 mRNA decreased to $58 \pm 13 \%$ after 3 days and further to $42 \pm 9 \%$ at 30 days. $B 1$-Adrenergic receptor mRNA decreased gradually to $63 \pm 8 \%$ at 30 days. In chronic-AVB leftventricular myocytes, $I_{\mathrm{Ks}}$-tail density was reduced: $1.4 \pm 0.3 \mathrm{pA} / \mathrm{pF}$ versus $2.6 \pm 0.4 \mathrm{pA}$ $\mathrm{pF}$ in controls (3-s steps to $50 \mathrm{mV}$ ). B-Adrenergic enhancement of $l_{\mathrm{K}_{\mathrm{s}}}$ was reduced. Isoproterenol shortened action-potential duration $\left(A P D_{95}\right)$ in control cells, while causing heterogeneous responses in chronic $A V B: A D_{95}$ unchanged in 7, decreased in 4 and increased in 2 cells. B-Adrenergic early afterdepolarizations were induced in 4 of 13 chronic-AVB cells, but not in controls. In intact dogs, isoproterenol shortened $\mathrm{QT}_{\mathrm{c}}$ at sinus rhythm (by $-8 \pm 3 \%$ from $295 \mathrm{~ms}$ ), left it unaltered at 3 days AVB $(+1 \pm 3 \%$ from $325 \mathrm{~ms}$ ) and prolonged $\mathrm{QT}$ c at 30 days ( $+6 \pm 3 \%$ from $365 \mathrm{~ms})$.

Conclusions: A profound decrease of $\mathrm{KCNQ} 1 \mathrm{mRNA}$ occurs within days after induction of AVB and is followed by a more gradual decrease of $B 1$-adrenergic receptor mRNA. Downregulation and blunted $B$-adrenergic activation of $I_{\mathrm{Ks}}$ contribute to the loss of $\beta$-adrenergic-induced shortening of ventricular repalarization, favoring proarrhythmia. 


\section{INTRODUCTION}

Electrical remodeling in cardiac hypertrophy often comprises the downregulation of sarcolemmal $\mathrm{K}^{+}$currents, including the delayed-rectifier $\mathrm{K}^{*}$ current $t_{\mathrm{ks}}(1,2) \mathrm{K}$ current downregulation may act to prolong the action-potential duration and enhance excitation-contraction coupling during chronic overload. However "it can confer exaggerated spatial and temporal heterogeneities of ventricular repolarization, rendering the heart more susceptible to deleterious tachyarrhythmia (3).

In the canine model of chronic complete atrioventricular block (AVB) and ventricular hypertrophy, increased spatial $(1,4)$ and temporal dispersion of repolarization (5) predispose to acquired torsades de pointes and sudden cardiac death (6) At the cellular level, $\mathrm{K}^{+}$currents $l_{\mathrm{Ks}}$ and $l_{\mathrm{Kr}}$ are reduced (1), whereas sarcoplasmic reticulum $\mathrm{Ca}^{2+}$ release and $I_{\mathrm{NaCax}}$ are enhanced, especially at slow heart rates (7). An increase in subsarcolemmal $\mathrm{Na}^{+}$concentration underlies the altered $\mathrm{Ca}^{2+}$ handling (8). Previous work has shown that the reduction of $I_{\mathrm{Ks}}$ in chronic AVB can be due to a downregulation of KCNQ1- and KCNE1-gene transcription in the basal and midlateral parts of the left- and right-ventricular wall (9). in the interventricular septum only KNCQ1 mRNA is decreased (10). These findings indicate regional heterogeneity of ion-channel remodeling in the overloaded myocardium, even among $\alpha$ - and $\beta$-channel subunits. The time courses of electromolecular changes remain unclear, especially in the early phase of overload.

Modern insights support the contention that an intact basal $I_{\mathrm{ks}}$ expression plus $\beta$ adrenergic receptor stimulation are both essential for $I_{\mathrm{Ks}}$ to figure in repolarization, at least in the rabbit (11) and the dog (12-14). This suggests that the separate or combined loss of $I_{\mathrm{Ks}}$-channel subunits and $I_{\mathrm{ks}}$-relevant $\beta$-adrenergic-signaling molecules in acquired cardiac pathology carries a risk of repolarization instability and proarrhythmia.

The present study was designed to examine the time course of molecular alterations underlying $I_{\mathrm{Ks}}$ downregulation in the canine left ventricle after AVB induction. We quantified the mRNA expression of KCNQ1 and KCNE1 subunits and $\beta$-adrenergic receptor subtypes in serial myocardial biopsies, and measured catecholamine levels in blood plasma. Concomitant changes of cellular and in-vivo repolarization were closely examined. We hypothesized that the propensity of repolarization to shorten upon B-adrenergic receptor stimulation would be undermined after AVB, favoring proarrhythmia during maintained overload. 


\section{METHODS}

Animal handling was in accordance with the 'Dutch Law on Animal Experimentation' and the 'European Directive for the Protection of Vertebrate Animals Used for Experimental and Other Scientific Purposes (86/609/EU)'. The experiments were approved by the Committee for Experiments on Animals of Maastricht University. Adult mongrel dogs of either gender were used $\left(n_{\text {dogs }}=42\right)$. Premedication consisted of $10 \mathrm{mg}$ oxycodone $\mathrm{HCl}, 1 \mathrm{mg}$ acepromazine maleate and $0.5 \mathrm{mg}$ atropine sulphate i.m. Complete anesthesia was induced by thiopental $(20 \mathrm{mg} / \mathrm{kg}$ i.v. $)$ and maintained by inhalation of halothane $(0.5-1.0 \%)$ and $\mathrm{N}_{2} \mathrm{O}$ and $\mathrm{O}_{2}(2: 1)$. Ampicilline (1000 $\mathrm{mg}$ ) was administered before and after the experiment. For additional analgesia, buprenorphine was given $(0.015 \mathrm{mg} / \mathrm{kg}$ i.m. $)$ after the operation. AVB was induced by radiofrequency catheter ablation of the His bundle $\left(n_{\text {dogs }}=22\right)$.

\subsection{In-Vivo Studies}

In 7 dogs, experiments were performed serially at sinus rhythm and at $0,3,8$ and 30 days of $A V B$, using each dog as its own control. Venous blood samples were collected from these trained animals after minutes of quiescence for determination of plasma catecholamines (see below). Premedication was given as described to achieve conscious sedation, and a standard 6-lead ECG was registered along with a unipolar recording at the chest position corresponding to $V_{4}$. Under these conditions, a short-lasting $\beta$-adrenergic challenge with isoproterenoll ( $1 \mu \mathrm{g} / \mathrm{kg}, \mathrm{i} . \mathrm{v}$.) was given to achieve $>25 \%$ increase in heart rate during sinus or idioventricular rhythm, followed by relaxation. The QT interval was measured and corrected for heart rate by Van-deWater's formula: $\mathrm{QT}_{\mathrm{c}}=\mathrm{QT}-0.087(\mathrm{RR}-1000)(15)$.

Animals were subsequently anesthetized for biopsy sampling. A minimally-invasive procedure was used under closed-chest conditions, allowing fast recovery of the dogs and permitting repetitive sampling at sinus rhythm and 3,8 and 30 days of AVB. Transmyocardial biopsies $(1 \times 1 \times 10 \mathrm{~mm})$ extending from the epicardium to the subendocardium were obtained from the apicolateral region of the left ventricle under fluoroscopic guidance with a commercially-available automated biopsy device (14-G, Acecut, TSK Laboratory, Japan) (16). Histology confirmed minimal injury to the myocardium at the sampling sites. Biopsies were frozen to $-80^{\circ} \mathrm{C}$ in isopentane chilled with liquid nitrogen and then stored until molecular analysis.

\section{2 mRNA Expression Studies}

Total RNA was isolated from the biopsies using the RNEasy MINI kit (Qiagen/ Westburg, Leusden, Netherlands) according to the manufacturer's protocol. DNAse/digestion was performed after elution of the total RNA from the column. First-strand cDNA was synthesized using $1 \mu \mathrm{g}$ total RNA in combination with an anchored oligo$\mathrm{dT}_{14} \mathrm{VN}$ and reverse $18 \mathrm{~S}$ rRNA primer (17). Fluorescence-based kinetic real-time PCR was performed using a LightCycler ${ }^{\mathrm{TM}}$ system (Roche Diagnostics Nederland, Almere, Netherlands) in combination with the intercalating fluorescent dye SYBR Green I. Amplicons (KCNQ1, KCNE1, and $\beta 1$-, $\beta 2$ - and $\beta 3$-adrenergic receptors) 
were quantified using the LinRegPCR method (18) and were expressed relative to the constitutive active 18S rRNA gene. For an overview of the primers used in this study we refer to the Online Text Supplement:

\subsection{Analysis of plasma catecholamines}

Blood samples $(10 \mathrm{~mL})$ were collected into tubes containing lithium heparin as the anticoagulant and transported to the laboratory on ice within $30 \mathrm{~min}$. Samples were centrifuged at $3000 \mathrm{rpm}$ for $10 \mathrm{~min}$ at $4^{\circ} \mathrm{C}$. One hundred $\mathrm{ml}$ of glutathione $\left(95 \mathrm{~g} / \mathrm{L}\right.$ ) was added to $2 \mathrm{~m} \|$ plasma before storage at $-20^{\circ} \mathrm{C}$. For analysis, plasma was mixed with an internal standard (3,4-dihydroxybenzylamine-hydrobromide) followed by liquid-liquid extraction with $99 \% n$-heptane and 1-octanol/acetic acid. After evaporation of the organic phase, $100 \mathrm{ml}$ of the acetic acid layer was injected and analyzed by reversed phase-high performance liquid chromatography with electrochemical detection.

\subsection{Cellular experiments}

Anesthetized sinus-rhythm ( $\mathrm{n}_{\text {dogs }}=20$; controls) and AVB $\left(\mathrm{n}_{\text {cloys }}=22\right)$ dogs received heparin i.v. upon thoracotomy. The hearts were quickly excised and washed in cold cardioplegic solution. The left-anterior-descending coronary artery was cannulated and perfused with $\mathrm{Ca}^{2+}$-free standard-buffer solution. After $\sim 30$ minutes of collagenase perfusion and subsequent washout of the enzyme, a digested part of the apicolateral ventricular wall was dissected and myocytes were isolated from most of the transmural wall except for a $\operatorname{rim}\left({ }^{3} 1.5 \mathrm{~mm}\right)$ of epicardial and endocardial tissue. Myocytes were stored at room temperature in standard-buffer solution and only quiescent rod-shaped cells with clear cross-striations were used for the experiments.

Transmembrane potentials were recorded using high-resistance $(30-60 \mathrm{MW})$ glass microelectrodes filled with $3 \mathrm{~mol} / \mathrm{L} \mathrm{KCl}$. Whole-cell currents were measured using patch pipettes with resistances of 1.0-3.0 MW when filled with internal solution. Experiments were performed at $37 \pm 1^{\circ} \mathrm{C}$. Cell capacitances were $186 \pm 6 \mathrm{pF}\left(\mathrm{n}_{\text {cells }}=54\right)$ in control and $192 \pm 9 \mathrm{pF}\left(\mathrm{n}_{\text {cells }}=36\right.$ ) in AVB cells.

The standard-buffer solution contained (in mmol/L): $\mathrm{NaCl} 145, \mathrm{KCl} 4.0, \mathrm{CaCl}_{2} 1.8$, $\mathrm{MgCl}_{2} 1.0$, glucose 11 , HEPES $10, \mathrm{pH} 7.4$ with $\mathrm{NaOH}$ at $37^{\circ} \mathrm{C}$. In most patch-clamp experiments $\mathrm{KCl}$ was omitted from the external solution to increase $l_{\mathrm{Ks}}$ amplitude and suppress $I_{\mathrm{K} 1}$. Zero external $\left[\mathrm{K}^{+}\right]$increases $I_{\mathrm{Ks}}$ magnitude (in our conditions by $129 \pm 24 \% ; n_{\text {cells }}=12$ ) indirectly through changes in the concentration gradient. This effect is similar in control and AVB cells (1), and the kinetics of $I_{\mathrm{K}, \mathrm{s}}$ activation and deactivation are not influenced (19). The patch-pipette solution contained (in mmol/L): potassium aspartate $125, \mathrm{KCl} 20, \mathrm{MgCl}_{2} 1.0$, MgATP 5, HEPES 5, EGTA $10, \mathrm{pH} 7.2$ with $\mathrm{KOH}$. L-type $\mathrm{Ca}^{2+}$ current was blocked with nifedipine $(5 \mu \mathrm{mol} / \mathrm{L})$. Almokalant was dissolved in the superfusate $(2 \mu \mathrm{mol} / \mathrm{L})$ to block $I_{\mathrm{kr}}$ Isoproterenol was first dissolved in distilled water containing $30-\mu \mathrm{mol} / \mathrm{L}$ ascorbic acid, kept at 5 ${ }^{\circ} \mathrm{C}$ and in the dark until use. HMR1556 $((3 \mathrm{R}, 4 \mathrm{~S})-(+)-\mathrm{N}$-[3-hydroxy-2,2-dimethyl-6(4,4,4-trifluorobutoxy)chroman-4-yl]-N-methylmethanesulfonamide, Aventis Pharma 
Deutschland $\mathrm{GmbH}$, Sanofi-Aventis, Frankfurt am Main, Germany) was used to block $I_{\mathrm{KS}^{*}}$. This compound is highly selective for $I_{\mathrm{Ks}}$ : at a concentration of $500 \mathrm{nmol} / \mathrm{L}$ it blocks the current completely (13), whereas other currents are unaffected (20, 21). HMR1556 was dissolved in dimethyl sulfoxide as $100 \mathrm{mmol} / \mathrm{L}$ stock solution and diluted in the superfusate to achieve a final concentration immediately before experimental application. The final concentrations of dimethyl sulfoxide (maximally $0.1 \%$ ) in the superfusate had no measurable effects on ion currents and action potentials.

\subsection{Statistics}

The data are expressed as mean $\pm S E M$. Data comparisons were made with the Student's $t$ test for unpaired or paired data groups. Serial changes (mRNA expression; QT intervals) were tested using linear-regression analysis and repeatedmeasures ANOVA. In mRNA-expression experiments outlier values were detected using the maximum-mormed residue test. Differences were considered statistically significant if $P<0.05$.

\section{RESULTS}

3.1 Temporal patterns of mRNA expression of $I_{k s}$ subunits and $\beta$-Adrenergic receptors after AVB

mRNA expression of KCNQ1 and KCNE1 subunits was determined in biopsies obtained at sinus rhythm (control) and at 3,8 and 30 days of AVB $\left(n_{\text {dogs }}=7\right)$. KCNQ1 mRNA decreased to $58 \pm 13 \%$ of control $(P<0.05)$ already after 3 days and further down to $42 \pm 9 \%$ at 30 days (Figure 1A). Downregulation of KCNQ1 transcription at chronic AVB matches with previous findings (9). In that study, KCNQ1 protein was reduced by a similar degree (9). In the present study, mRNA expression of KCNE1 did not change after AVB at any of the time points (Figure 1B).

B1-Adrenergic receptor mRNA decreased gradually to $63 \pm 8 \%$ of control $(P<0.05)$ at 30 days (Figure $1 \mathrm{C}$ ). $\beta 2$-Adrenergic receptor mRNA remained unaltered (Figure 1D). Levels of $\beta 3$-adrenergic receptors mRNA were too low to be detected and quantified reliably.

Table. Kinetics of $I_{\text {kis }}$ Actiwation and Deactivation. Activation, depolarizing step from $-50 \mathrm{mV}$ to $+20 \mathrm{mV}$. Deactivation,

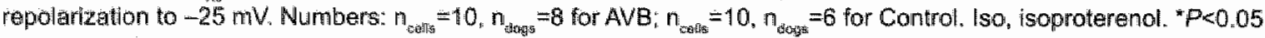
wersus baseline.

\begin{tabular}{|c|c|c|c|c|}
\hline & Activation & Deactivation & Activation & Deactivation \\
\hline Brseling & $511+63$ & 12845 & 50996 & 21 \\
\hline Iso (100 nmol/l) & $412 \pm 53^{\text {d }}$ & $185 \pm 15^{*}$ & $429 \pm 36^{*}$ & $171 \pm 20^{*}$ \\
\hline
\end{tabular}


3.2 Biophysical properties of downregulated $I_{k s}$

Biophysical properties of $J_{K s}$ in myocytes from dogs with chronic AVB ( $n_{\text {cells }}=15$; $n_{\text {dogs }}=7$ ) were compared to controls $\left(n_{\text {cells }}=19 ; n_{\text {dogs }}=12\right)$. Consistent with mRNA downregulation, $l_{\mathrm{Ks}}$ density was significantly smaller in AVB: $1.4 \pm 0.3 \mathrm{pA} / \mathrm{pF}$ versus $2.6 \pm 0.4 \mathrm{pA} / \mathrm{pF}$ in controls $(P<0.05$; tail currents at $-25 \mathrm{mV}$ after $3-\mathrm{s}$ steps to $50 \mathrm{mV}$; Figure 2A). The kinetics of both activation and deactivation of $l_{\mathrm{ks}}$ were not different between AVB and control myocytes (Figure 2B, Table). Voltage dependence of $I_{\mathrm{Ks}}$ activation was also similar in AVB and contro cells (Figure $2 \mathrm{C}$ ). The sensitivity of $I_{\mathrm{Ks}}$ to pharmacological block by HMR1556 remained unchanged in AVB cells with an $1 C_{50}$ of $81 \mathrm{nmol} / \mathrm{L}$ versus $78 \mathrm{nmol} / \mathrm{L}$ in controls (Figure $2 \mathrm{D}$ ).

$l_{\mathrm{Ks}}$ showed a decreased responsiveness to isoproterenol in AVB myocytes. $\mathrm{SC}_{50}$ values were $63 \mathrm{nmol} / \mathrm{L}$ for $A V B$ and $30 \mathrm{nmol} / \mathrm{L}$ for control cells. Maximal stimulation at $300 \mathrm{nmol} / \mathrm{L}$ isoproterenol enhanced $I_{\mathrm{Ks}} 4.0 \pm 0.7$ fold in AVB versus $7.9 \pm 0.7$ fold at control $(P<0.05$; Figure 3$)$. The kinetics of $I_{\mathrm{Ks}}$ were affected similarly by $B$-adrenergic receptor stimulation in AVB and control cells (Table). For voltage steps from -50 $\mathrm{mV}$ to $20 \mathrm{mV}$, halftimes for activation decreased by approximately $100 \mathrm{~ms}$, whereas halftimes for deactivation increased by about $50 \mathrm{~ms}$.

A

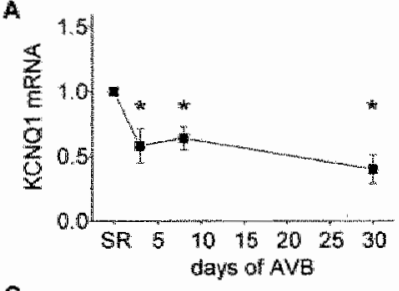

C.

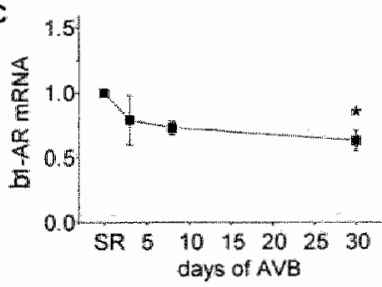

B

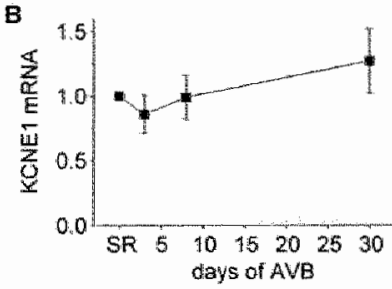

。

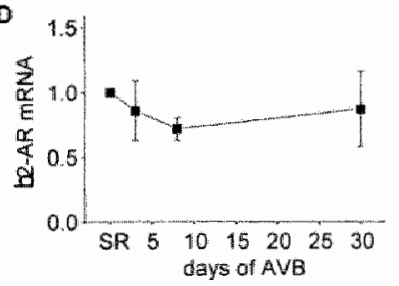

Figure 1. Temporat patterns of MRNA expression of $f_{k s}$ stbunits and $\beta$-adrenergic receptors after ANB. A, KCNO1.B, KCNE1, C, B adrenergic receptor (B1-AR). $D$, B2-adrenergic receptor (B2-AR). Serial transmyocardial biopsies weres obtained at sinus rhythrn and 3,8 and 30 days of AVB. Sere Online Texl Supplement for used primers. " $P<0.05$ versus sinus rimythim (SR).

3.3 Consequences of $I_{k s}$ downregulation for repolarization response to isoproterenol Isoproterenol (100 nmol/L) shortened action-potential duration $\left(A P D_{95}\right)$ significantly in control cells $\left(n_{\text {cells }}=6 ; n_{\text {dogs }}=3\right.$; Figure $4 A$ ). This was mainly due to the stimulation of $I_{\mathrm{Ks}^{*}}$ because block of $I_{\mathrm{Ks}}$ by HMR1556 (500 nmol/L) in the presence of isoproterenol reversed it (13). Heterogeneous responses of repolarization were found in chronic AVB: $A P D_{95}$ remained unchanged in 7, decreased in 4 and increased in 2 myocytes $\left(n_{\text {dogs }}=10 ;\right.$ Figure 4B). Despite the limited ability of AVB cells to shorten APD in response to isoproterenol, $l_{K s}$ still contributed to some degree under these conditions, as evident from the (extra) APD prolongation observed after application of HMR1566 (Figures 4A and 4B). 
Early afterdepolarizations (EADs) were induced in 4 of the 13 chronic-AVB cells with isoproterenol alone, and in 6 of 13 myocytes during isoproterenol plus HMR1556 (Figure 5). EADs developed at short $(500 \mathrm{~ms})$ and long pacing cycle lengths. They were not observed at baseline. In control myocytes, no EADs were observed under any of these conditions (Figure 5).

A

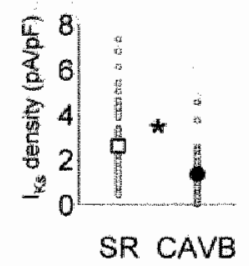

C

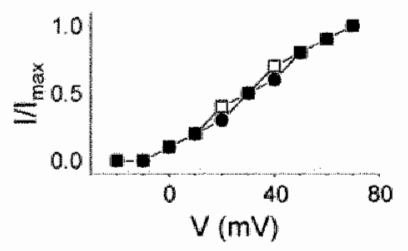

B

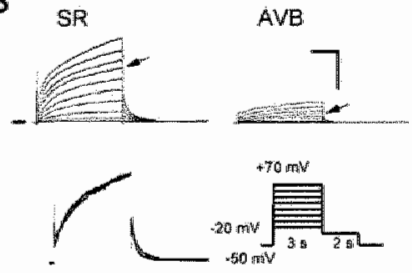

D $\overline{\underline{I}}$

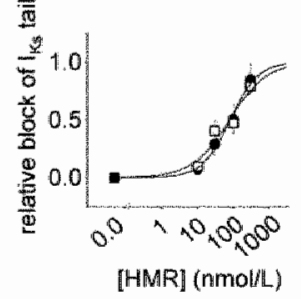

Figure 2. Downregulation of $l_{\mathrm{Ks}}$ in $\mathrm{AVB}$ cells. A, Chronic AVB led to a decrease of $\mathrm{I}_{\mathrm{Ks}}$ density. B, Kinetics of both activation and deactivation of $I_{\mathrm{Kg}}$ were not different between AVB and control myocytes. Upper panels, arrows indicate $I_{\mathrm{KB}}$ traces at depolarizations to $40 \mathrm{mV}$ (SR versus AVB), which were used for comparison of kinetics after artificial equalization of amplitude (in left panel below: see also Table). Vertical bar, 500 pA. Horizontal bar, $1 \mathrm{~s}$. Inset, woltage-clamp protocol. $C_{\text {n }}$ Voltage dependence of $I_{\mathrm{ks}}$ activation was similar in AVB (filled circles) and cantrol cells (open squares). D, Sensitivity of $I_{\text {Ke }}$ to pharmacological block. by HMR1556 remained unchanged in AVB cells (filled circles). *. $P<0.05$.

\subsection{QT responses to isoproterenol in conscious AVB dogs}

To investigate whether repolarization responses to $\beta$-adrenergic receptor stimulation were also altered in vivo, we subjected 6 dogs to short-lasting challenges with isoproterenol (1 $\mathrm{\mu g} / \mathrm{kg}$ i.v.; $>25 \%$ increase of heart rate) at sinus-rhythm control and during idioventricular rhythm at 3,8 and 30 days of AVB.

At baseline during conscious sedation, the heart rate dropped from $128 \pm 12 \mathrm{bpm}$ at sinus rhythm to $41 \pm 4 \mathrm{bpm}$ at 3 days AVB, remaining low thereafter (Figure 6). Baseline QT time (chest lead V4) measured $253 \pm 10 \mathrm{~ms}$ at sinus rhythm and increased thereafter from $371 \pm 12 \mathrm{~ms}$ at 3 days to $414 \pm 7 \mathrm{~ms}$ at 30 days AVB $(P<0.05$ versus 3 days), indicating electrical remodeling (1).

Next we investigated the actions of isoproterenol. Both in sinus and idioventricular rhythm a strong chronotropic effect was noted: heart rates increased from $128 \pm 12$ bpm to $201 \pm 9 \mathrm{bpm}$ (sinus rhythm) and from $41 \pm 4 \mathrm{bpm}$ to $58 \pm 5 \mathrm{bpm}$ ( 3 days AVB), respectively. These chronotropic responses remained similar at the later stages of AVB (Figure 6B). QT-interval measurements were performed at 2 time points during each experiment: 1) when heart rate increased $25 \%$ above the baseline value; 


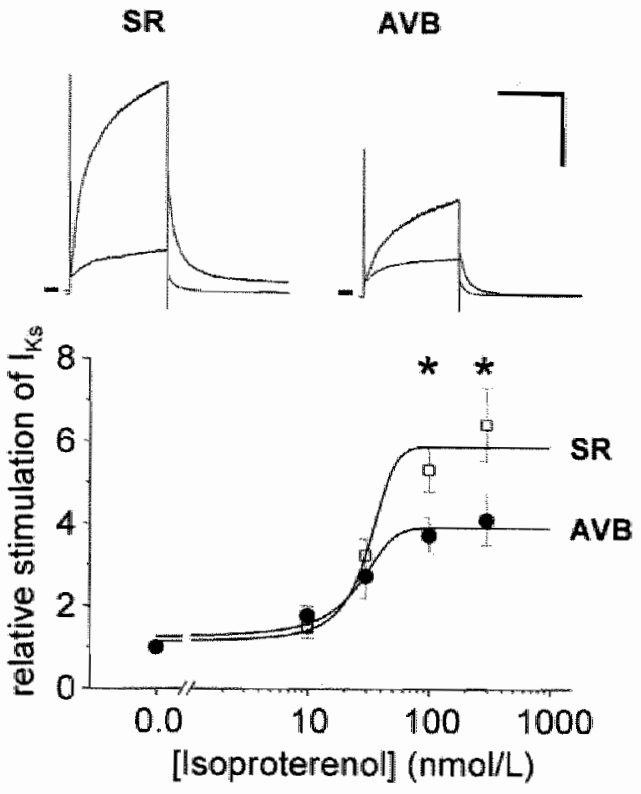

Figure 3. Decreased respionsiveness of $/$ to 10 adremergic stimulation in AVB cells. Upper panal, representative examples of $l_{\text {iss }}$ at baseline and when increased by B-adrenergic stimulation (isoproterenoi, $100 \mathrm{nmol} / \mathrm{L}$ ) in a control (SR) and an AVB cell. Vertical bar, $1 \mathrm{nA}$. Horizontal bar, $2 \mathrm{~s}$. Lower panell, dose dependence of $l_{\mathrm{Ks}}$ stimulation by isoproterenol at control and AVB. ${ }^{*}, P<0.05$.

and 2) during peak chronotropic response. A profound shortening of repolarization accompanied the peak heart-rate increase at sinus rhythm: QT decreased from $253 \pm 10$ to $211 \pm 5 \mathrm{~ms}$ (QT $-17 \% ; P<0.05$ ). At 3 days AVB, QT shortened from $371 \pm 12$ $\mathrm{ms}$ to $347 \pm 6 \mathrm{~ms}$ (heart rate $+25 \%$; QT $-6 \% ; P<0.05$ ) to $324 \pm 4 \mathrm{~ms}$ (peak response; QT $-13 \% ; P<0.05)$. At 30 days AVB, however, QT changes during isoproterenol became much less pronounced despite similar increases in heart rate: QT altered from $414 \pm 7 \mathrm{~ms}$ to $409 \pm 11 \mathrm{~ms}$ (heart rate $+25 \%$; QT $-1 \%$; $P=\mathrm{NS}$ ) to $392 \pm 10 \mathrm{~ms}$ (peak response; QT -5\%; $P<0.05$ ). Individual QT times were often longer than their baseline values (Figure 6). When corrected for heart rate (15), QT was shortened by isoproterenol during sinus rhythm, unchanged at 3 and 8 days AVB, and overtly prolonged in chronic AVB (Figure 6C).

\subsection{Plasma levels of catecholamines}

Plasma levels of dopamine, norepinephrine and epinephrine were measured in venous blood samples at all time points, including the recovery phase after induction of AVB ( 0 days). Measured levels of dopamine ranged from 'not detectable' to 0.32 $\mathrm{nmol} / \mathrm{L}$ under control conditions (median $0.12 \mathrm{nmol} / \mathrm{L}$ ) and did not alter during AVB. Norepinephrine, however, (control concentration $0.87 \pm 0.23 \mathrm{nmol} / \mathrm{L}$ ) increased significantly upon induction of AVB (O days) and peaked at $2.50 \pm 0.56 \mathrm{nmol} / \mathrm{L}$ around 8 days AVB. In the chronic phase of AVB thereafter ( $>8$ days), norepinephrine returned to control levels (Figure 7). Epinephrine showed a similar trend as norepinephrine, but concentrations changes did not reach statistical significance (Figure 7). 
A SR CAVB
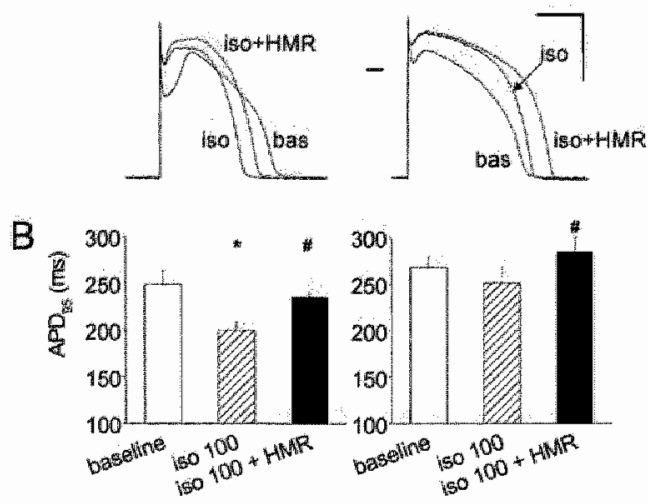

Flgure 4. Effects of $\beta$-adrenergic stimulation on the action potential. Action potentials/APD $D_{s, 5}$ at baseline (bas), in the presence of isoprotereno: (iso; $100 \mathrm{nmol} / \mathrm{L}$ ) and after addition of HMR1556 (500 nmollL) in control (A) and chronic-AVB (B) myocytes. Upper panels, represientative examples. Lower panels, $A P D_{s,}$ values (mean $\#$ SEM) for the different conditions. Vertical bar denotes $50 \mathrm{mV}$. Horizontal bar, $100 \mathrm{~ms}$. " $P<0.05$ versus baseline. \#, $P<0.05$ wersus iso 100 .

\section{DISCUSSION}

The present study demonstrates that a profound decrease of KCNQ1 mRNA occurs within days after induction of AVB in the apicolateral region of the canine left ventricle. It is followed by a more gradual decrease of $B 1$-adrenergic receptor mRNA. The kinetics of downregulated $l_{\mathrm{ks}}$ and its responsiveness to the specific blocker HMR1556 remain unaltered in AVB myocytes. However, B-adrenergic receptor stimulation of $l_{\mathrm{Ks}}$ is decreased. At the level of the cellular action potential these molecular and biophysical characteristics translate to the loss of $B$-adrenergicinduced shortening of repolarization, favoring the occurrence of EADs. In conscious dogs, QT and $Q T_{c}$ responses to $B$-adrenergic challenges confirm the $I_{K s}$-related loss of ventricular repolarization shortening in chronic AVB.

\subsection{Downregulation of $I_{K s}$ and B-Adrenergic Regulation}

Downregulation of $I_{\mathrm{ks}}$ at the chronic stage of AVB has been reported previously in the dog $(1,9)$ and the rabbit $(22)$. Decreases in $I_{K_{s}}$ were also found in other animals models of cardiac hypertrophy and/or failure $(2,23,24)$, and in humans $(25)$. In the
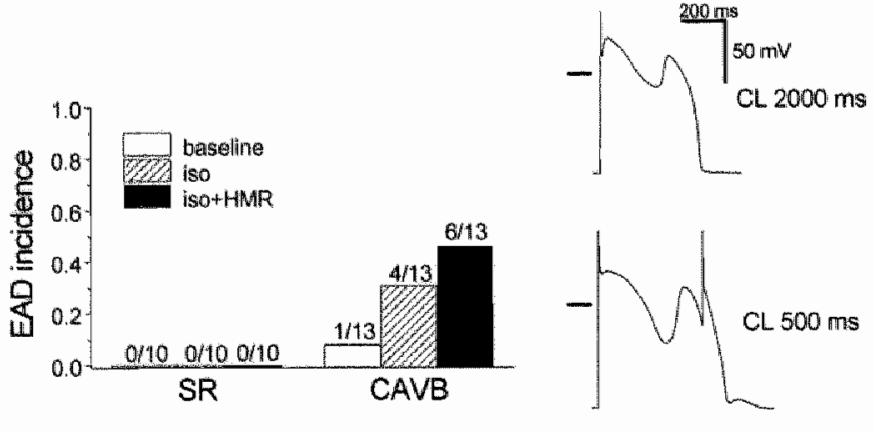

Figure 5. EADs in the presence of $\beta$-adrenergic stimulation in AVB cells. Incidence of EADs at baseline, in the presence of isoproterenal (iso; 100 $\mathrm{nmol} / \mathrm{L})$ and after addition of HMR1556 (500 nmolll) în control (SR) and AVB cells. Right panels, representative action potentials with EADs in the presence of isoproterenol at pacing cycle lengths (CL) of $2000 \mathrm{~ms}$ and $500 \mathrm{~ms}$. 

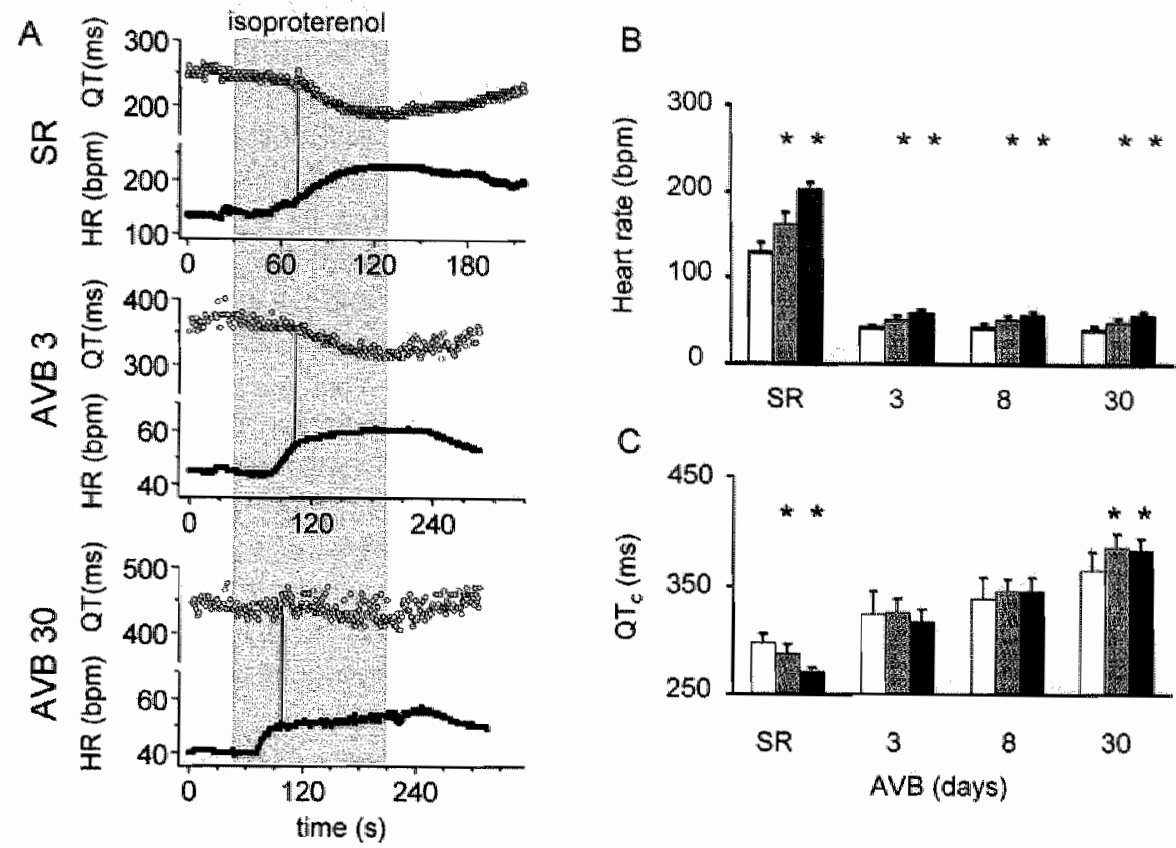

Figure 6. QT responses to isioproterenol in conscious AVB dogs. (A) Heart rates (HR, filled squares) and corresponding QT times (open circles) during infusion of isoproterenoll ( $1 \mu \mathrm{g} / \mathrm{kg}, \mathrm{I}, \mathrm{v}$.) in a representatiwe dag during sinus rhythm (uppen panel), and at 3 days (middle panel) and 30 days of AVB (lower panel). The grey zone indicates the period of isoprotereno: infusion. Vertical lines ind cate the time points of $25 \%$ heart-rate increase. B, Heart-rate responsies to isoproterenol. Empty columns indicate baseline conditions during sinus rhythm (SR) and after $3,8,30$ days of AVB. Hatched columns, $25 \%$ heart-rate increase above baseline. Filled columns, peak responses. C, $\mathrm{QT}_{\mathrm{G}}$ responses to isoproterenol at baseline (empty columns) and during isoproterenol infusion (hatched columns, at $25 \%$ heart-rate increase above baseline; filled columns, during peak responses of heart rate). ", $P<0.05$ versus baseline

present study we closely analyzed the biophysical properties of downregulated $I_{\mathrm{kri}}$ in AVB myocytes. The unaltered kinetics and responsiveness to HMR1556 indicated that reductions in channel numbers, rather than conformational changes, underlie the diminution of this current. Another aspect of $I_{\mathrm{ks}}$ downregulation was the finding, that, in contrast to the reduction of KCNQ1, KCNE1 mRNA did not change. We observed a similar differential response in the canine interventricular septum after chronic AVB (10), whereas reductions of both KCNQ1 and KCNE1 mRNA and protein were found in the basal and midlateral parts of the left- and right-ventricular wall (9). In the latter study (9), mRNA expression was quantified using a combination of Northern biot and quantitative multiplex competitive RT-PCR, whereas in the recent septum study (10) and the present one fluorescence-based kinetic real-time PCR was employed. The latter is a more accurate method (18). To exclude a methodological reason for the apparent discrepancies in KCNE1 results, we redetermined KCNE1 mRNA in tissue from the basal and midlateral left ventricle of normal and chronic-AVB dogs (as in 9) using the fluorescence-based kinetic real-time PCR (as in the present study), 
and found a similar decrease of expression as described previously (9). Based on these data, we consicler regional heterogeneity of $I_{K s}$-subunit remodeling in the left ventricle the most likely explanation for the different results in the 3 studies.

The question arises why the decrease of KCNQ1 did not change the kinetics of $l_{\mathrm{Ks}}$. Wang et al (26) examined the influence of various ratios of KCNQ1: KCNE1 on the current kinetics of the assembled $I_{K s}$ channel. Ratios of $2: 1$ and $1: 1$ resulted in similar current characteristics, and both closely resembled the activation kinetics and voltage dependence of native $I_{\mathrm{Ks}}(26)$. Thus, a unilateral decrease of KCNQ1 of $\sim 50 \%$ (as in AVB) would not be expected to affect the kinetics of native $I_{\mathrm{ks}}$ significantly, in line with the present findings.

Stimulation of $I_{\mathrm{Ks}}$ by $\mathrm{B1}$-adrenergic receptors depends predominantly (if not exclusively) on protein-kinase-A stimulation of KCNQ1 subunits (27). Modulation via 32 -adrenergic receptors has also been suggested, mainly by the finding that cardiac $I_{\mathrm{Ks}}$ density is increased in transgenic mice expressing fusion proteins of $I_{\mathrm{Ks}}$ subunits and human $B 2$ receptors (28). B2-adrenergic signaling could modulate the function of these $I_{\mathrm{Ks}}$ channels even in the absence of exogenous $B$-adrenergic agonists (28). B3-Adrenergic regulation of $I_{\mathrm{Ks}}$ has also been reported, although with

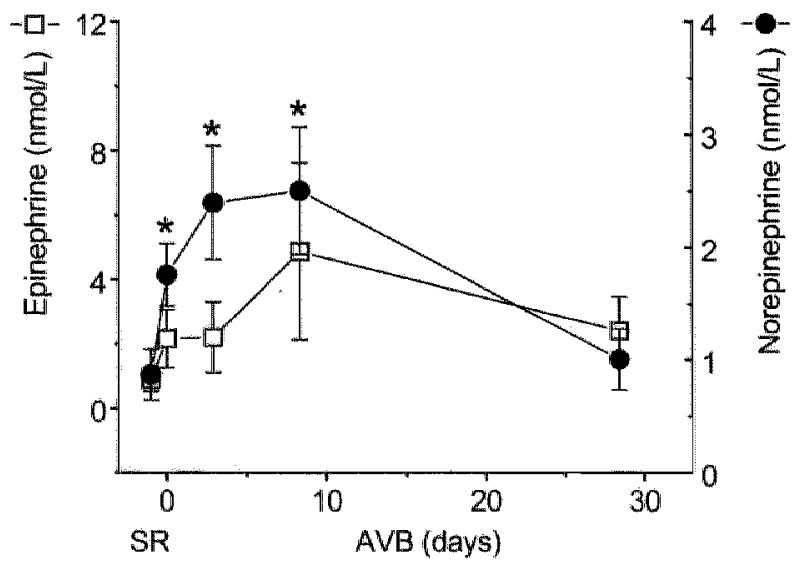

Figure 7. Plasma levels of catecholamines during AVB. Concentrations of epinephrine and norepinephrine in venous blood plasma at sinus rhythm (SR) and 0 , 3,8 and 30 days of $A V B$. * $P<0.05$ versus SR.

different results in different models: B3-receptor stimulation enhanced $I_{\mathrm{ks}}$ in Xenopus oocytes expressing human KvLQT1/MinK channels (29) but inhibited the current in guinea-pig ventricular myocytes (30). From the three receptor subtypes (B1, B2 and B3) examined in the present study, only B1-mRNA expression showed a clear and sustained decrease compatible with the decreased $B$-adrenergic responsiveness of $I_{\mathrm{Ks}}$ in AVB cells. We cannot exclude that, apart from the decreases of KCNQ1 and B1adrenergic receptor expression, other elements of the $I_{\mathrm{Ks}}$-macromolecular signaling complex (31) or $\beta$-adrenergic cascade are also involved in the downregulation of $I_{\mathrm{Ks}}$. 


\subsection{Temporal patterns of remodeling at the molecular and in vivo level: do they} match?

Using a minimally-invasive procedure under closed-chest conditions, we obtained lleft-ventricular transmyocardial biopsies in a serial manner. Thus, follow-up of the transcriptional expression of $l_{\mathrm{Ks}}$-channell subunits and other $l_{\mathrm{Ks}}$-relevant proteins (including B-receptor subtypes) was possible using each dog as its own control, thereby minimizing problems of biological variability. Such problems are often encountered in group comparisons when different animals are used. When we align the patterns of $\mathrm{KCNQ} 1$ and $\mathrm{B1}$-adrenergic downregulation with the altering QT responses in vivo and the changes of plasma norepinephrine, an interesting picture emerges. Considering that $I_{\mathrm{Ks}}$ downregulation is a major determinant of the AVB-induced repolarization prolongation (1), the fast decrease of KCNQ1 mRNA expression (at 3 days; Figure 1) apparently contrasts with the much slower response of QT and QT prolongation by remodeling (after $>8$ days of AVB; Figure 6). However, the contribution of $I_{\mathrm{ks}}$ to repolarization depends critically on $\beta$-adrenergic receptor stimulation (13) and therefore this system must be taken into account when explaining the temporal differences. We find it likely that the early rise of norepinephrine (Figure 7) 'neutralizes' the loss of KCNQ1, effectively maintaining a pseudonormal $I_{\mathrm{Ks}}$ in the first week of AVB. In the period thereafter, the waning of norepinephrine levels and the additional downregulation of $\beta 1$-adrenergic receptors (Figure 1; compare also to ref 32 ) gradually uncovers the QT prolongation. In a similar time-dependent manner, the loss of $\beta$-adrenergic-induced shortening of ventricular repolarization could be explained.

\subsection{Proarrhythmic Consequences of $I_{k s}$ Downregulation}

In control myocytes, $\beta$-adrenergic activation shortened the APD consistently, which indicated that the stimulation of outward currents (mainly $I_{k: s}$ ) prevailed over the stimulation of inward currents (mainly $I_{\text {Cal }}$ ). In chronic-AVB cells, heterogeneous APD responses were observed, likely as the result of $I_{\mathrm{Ks}}$ downregulation in the presence of an unchanged $I_{\text {cat }}$ (7). The reduced $l_{\mathrm{ks}}$ still contributed to repolarization during $\beta-$ adrenergic receptor stimulation, as evident from the (extra) APD prolongation after administration of HMR1566 (Figure 4). Under these conditions (isoproterenol plus HMR 1566) the frequent generation of EADs in chronic-AVB cells, and their absence in control myocytes (Figure 5), strongly suggested that other ionic changes (e.g., enhanced $\mathrm{Na}^{+}-\mathrm{Ca}^{2+}$ exchange) (7) also contributed to the proarrhythmia. Taken together our results indicate that the already labile ventricular repolarization in chronic AVB at baseline is adversely challenged during episodes of intense $\beta$-adrenergic activation. The heterogeneous responses of APD, ranging from limited shortening to overt prolongation in different myocytes, could reflect increased spatial dispersion of repolarization in the midventricular wall. The generation of $\beta$-adrenergic EADs would exaggerate this dispersion of repolarization and also trigger abnormal impulses.

Approximately $10 \%$ of the dogs with chronic AVB die suddenly. In 2 such animals, sudden death occurred during excitement, as witnessed by animal technicians. In 2 other animals, ambulatory electrocardiographic recordings revealed polymorphic 
ventricular tachycardia as the mode of death (6). Tachycardia was immediately preceded by an accelerated idioventricular rhythm and short-coupled ventricular beats from different foci (6). The data suggest a significant contribution of the sympathetic nervous system to the initiation of these arrhythmic events. Given the findings of KCNQ1 downregulation and $\beta$-adrenergic proarrhythmia in this dog model, there is an interesting similarity with the human congenital long-QT 1 syndrome that is due to KCNQ1 loss-of-function mutations. Sympathetic triggers of torsades de pointes, as during exercise and emotion, have long been recognized in such patients (33). In latent carriers of these KCNQ1 mutations, intravenous epinephrine can unmask the abnormal repolarization (34), much like our findings with isoproterenol in dogs with AVB. To our knowledge, this is the first study to describe the usefulness of $\beta$-adrenergic testing in an acquired $I_{\mathrm{Ks}}$ channelopathy.

\subsection{Limitations}

In the present study, we did not determine protein levels of $I_{\mathrm{K} s}$-channel subunits and $\beta$-adrenergic receptors. Instead, we determined their transcriptional and functional expression by measuring $I_{\mathrm{Ks}}$ and its $\beta$-adrenergic stimulation. Previously, mRNA and protein levels correlated well in this model, at least for KCNQ1 and KCNE1 (9). However, it is possible that a delayed protein expression (compared to the mRNA alterations) contributes to the discrepant temporal pattern of KCNQ1 mRNA expression versus the repolarization changes.

Catecholamine levels were determined in peripheral venous plasma. These levels are likely to be higher in the myocardium, especially during pathological conditions (35). In qualitative terms the changes of catecholamine concentrations (notably norepinephrine) in peripheral plasma are expected to be a good reflection of their changes in the heart, with terminal nerve endings as the primary source of release.

\section{ACKNOWLEDGEMENTS}

This work was supported by The Netherlands Organization for Health and Development (ZonMw 906-02-068 to P.G.A.V.), The Netherlands Heart Foundation, (NHS 98.042 to C.R.) and the 'Stichting Hartsvrienden Rescar', Maastricht, Netherlands. Jet D.M. Beekman, Department of Medical Physiology, University Medical Center Utrecht, and Monique M.J. de Jong. Departments of Cardiology and CardioThoracic Surgery, Maastricht provided excellent technical assistance. Michel E.F.H. Pereboom, Department of Clinical Chemistry, Academic Hospital Maastricht, performed the catecholamine analyses. The primers for canine KCNQ1 and KCNE1 genes were kindly provided by Robert Dumaine, PhD, Masonic Medical Research Laboratory, Utica, NY. The authors are grateful to Jos G. Maessen, MD, $\mathrm{PhD}$, Department of CardioThoracic Surgery, Cardiovascular Research Institute Maastricht and Academic Hospital Maastricht for his role in establishing the serialbiopsy technique. 


\section{REFERENCES}

1. Volders PGA, Sipido KR, Vos MA, et al. Downregulation of delayed rectifier $\mathrm{K}^{+}$currents in dogs with chronic complete atrioventricular block and acquired torsades de pointes. Circulation. 1999;100:2455-2461.

2. Tsuji $Y$, Opthof $T$, Kamiya $K$, et al. Pacing-induced heart failure causes a reduction of delayed rectifier potassium currents along with decreases in calcium and transient outward currents in rabbit ventricle. Cardiovasc Res. 2000;48:300309.

3. Tomaselli GF, Zipes DP. What causes sudden death in heart failure? Circ Res. 2004;95:754-763.

4. Kozhevnikov DO, Yamamoto $K$, Robotis $D$, et al. Electrophysiological mechanism of enhanced susceptibility of hypertrophied heart to acquired torsade de pointes arrhythmias: tridimensional mapping of activation and recovery patterns. Circulation. 2002;105:1128-1134.

5. Thomsen MB, Verduyn SC, Stengl M, et al. Increased short-term variability of repolarization predicts d-sotalol-induced torsades de pointes in dogs. Circulation. 2004;11:2453-2459.

6. van Opstal JM, Verduyn SC, Leunissen HDM, et al. Electrophysiological parameters indicative of sudden cardiac death in the dog with chronic complete AVblock. Cardiovasc Res. 2001;50:354-361.

7. Sipido KR, Volders PGA, de Groot SHM, et all. Enhanced $\mathrm{Ca}^{2 *}$ release and $\mathrm{Na} / \mathrm{Ca}$ exchange activity in hypertrophied canine ventricular myocytes: potential link between contractile adaptation and arrhythmogenesis. Circulation. 2000;102:21372144.

8. Verdonck $F$, Volders $P G A$, Vos MA, et al. Increased $\mathrm{Na}^{+}$concentration and altered $\mathrm{Na} / \mathrm{K}$ pump activity in hypertrophied canine ventricular cells. Cardiovasc Res. 2003:57:1035-1043.

9. Ramakers C, Vos MA, Doevendans PA, et al. Coordinated down-regulation of KCNQ1 and KCNE1 expression contributes to reduction of $I_{\mathrm{Ks}}$ in canine hypertrophied hearts. Cardiovasc Res. 2003;57:486-496.

10. Ramakers $C$, Stengl $M_{0}$ Spätjens RLHMG, et al. Molecular and electrical characterization of the canine cardiac ventricular septum. J Mol Cell Cardiol. 2005:in press. 
11. Lei $M$, Cooper PJ, Camelliti $P$, et al. Role of the 293b-sensitive, slowly activating delayed rectifier potassium current, $i_{\mathrm{Ks}^{\prime}}$ in pacemaker activity of rabbit isolated sina-atrial node cells. Cardiovasc Res. 2002;53:68-79.

12. Han W, Wang $Z$, Nattel $S$. Slow delayed rectifier current and repolarization in canine cardiac Purkinje cells. Am J Physiol. 2001;280:H1075-H1080.

13. Volders PGA, Stengl $M$, van Opstal JM, et al. Probing the contribution of $I_{\mathrm{Ks}}$ to canine ventricular repolarization: key role for $B$-adrenergic receptor stimulation. Circulation. 2003;107:2753-2760.

14. Nakashima $H_{1}$ Gerlach $U$, Schmidt $D$, et all. In vivo electrophysiological effects of a selective slow delayed-rectifier potassium channel blocker in anesthetized dogs: potential insights into class III actions. Cardiovasc Res. 2004;61:705-714.

15. Van de Water A, Verheyen J, Xhonneux $R$, et al. An improved method to correct the QT interval of the electrocardiogram for changes in heart rate. J Pharmacol Methods. 1989;22:207-217.

16. Verduyn SC, Jungschleger JGM, Stengl $M$, et al. Electrophysiological and proarrhythmic parameters in transmural canine left-ventricular needle biopsies. Pflügers Arch. 2004;449:115-122.

17. Lekanne Deprez RH, Fijnvandraat $A C$, Ruijter $\mathrm{JM}_{\text {, }}$ et al. Sensitivity and accuracy of quantitative real-time polymerase chain reaction using SYBR green I depends on cDNA synthesis conditions. Anal Biochem. 2002;307:63-69.

18. Ramakers C, Ruijter JM, Lekanne Deprez RH, et al. Assumption-free analysis of quantitative real-time polymerase chain reaction (PCR) data. Neurosci Lett. 2003;339:62-66.

19. Sanguinetti $\mathrm{MC}_{n}$, Jurkiewicz NK. Role of external $\mathrm{Ca}^{2+}$ and $\mathrm{K}^{+}$in gating of cardiac delayed rectifier $\mathrm{K}^{+}$currents. Pflügers Arch. 1992;420:180-186.

20. Gögelein $\mathrm{H}$, Brüggemann $\mathrm{A}$, Gerlach $\mathrm{U}$, et al. Inhibition of $\mathrm{I}_{\mathrm{Ks}}$ channels by HMR 1556. Naunyn-Schmiedeberg's Arch Pharmacol. 2000;362:480-488.

21. Thomas GP, Gerlach U, Antzelevitch C. HMR 1556, a potent and selective blocker of slowly activating delayed rectifier potassium current. J Cardiovasc Pharmacol. 2003;41:140-147.

22. Tsuji $Y$, Opthof $T$, Yasui $K$, et al. Ionic mechanisms of acquired $Q T$ prolongation and torsades de pointes in rabbits with chronic complete atrioventricular block. Circulation. 2002;106:2012-2018. 
23. $X u X, R i a l s ~ S J, W u Y$, et al. Left ventricular hypertrophy decreases slowly but not rapidly activating delayed rectifier potassium currents of epicardial and endocardial myocytes in rabbits. Circulation. 2001;103:1585-1590.

24. Li GR, Lau CP, Ducharme A, et al. Transmural action potential and ionic current remodeling in ventricles of failing canine hearts. Am J Physiol Heart Circ Physiol. 2002;283: $\mathrm{H} 1031-\mathrm{H} 1041$.

25. Li GR, Sun H, Feng J, et al. Ionic mechanisms of the action potential prolongation in failing human ventricular cells. Pacing Clin Electrophysiol. 1998;21:877. Abstract.

26. Wang W, Xia J, Kass RS. MinK-KvLQT1 fusion proteins, evidence for multiple stoichiometries of the assembled $\mathrm{I}_{\text {sK }}$ channel. J Biol Chem. 1998;273:3406934074.

27. Yang $T$, Kanki $H$, Roden DM. Phosphorylation of the $I_{K s}$ channel complex inhibits drug block: novel mechanism underlying variable antiarrhythmic drug actions. Circulation. 2003;108:132-134.

28. Dilly KW, Kurokawa J, Terrenoire $C$, et al. Overexpression of $\beta_{2}$-adrenergic receptors CAMP-dependent protein kinase phosphorylates and modulates slow delayed rectifier potassium channels expressed in murine heart: evidence for receptor/channel co-localization. J Biol Chem. 2004;279:40778-40787.

29. Kathöfer $S$, Zhang $W$, Karle $C$, et al. Functional coupling of human $B_{3}$-adrenoreceptors to the KvLQT1/MinK potassium channel. J Biol Chem. 2000;275:26743-26747.

30. Bosch RF, Schneck $A C$, Kiehn J, et al. $B_{3}$-Adrenergic regulation of an ion channel in the heart-inhibition of the slow delayed rectifier potassium current $I_{K B}$ in guinea pig ventricular myocytes. Cardiovasc Res. 2002;56:393-403.

31. Marx SO, Kurokawa J, Reiken $S$, et al. Requirement of a macromolecular signaling complex for $\beta$ adrenergic receptor modulation of the KCNQ1-KCNE1 potassium channel. Science. 2002;295:496-499.

32. Kiuchi $K$, Shannon RP, Komamura $K$, et al. Myocardial B-adrenergic receptor function during the development of pacing-induced heart failure. I Clin Invest. 1993;91:907-914.

33. Schwartz PJ, Priori SG, Spazzolini C, et al. Genotype-phenotype correlation in the long-QT syndrome: gene-specific triggers for life-threatening arrhythmias. Circulation. 2001;103:89-95. 
34. Shimizu $W$, Noda $T$, Takaki $H$, et al. Epinephrine unmasks latent mutation carriers with LQT'1 form of congenital long-QT syndrome. J Am Coll Cardiol. 2003;41:633-642.

35. Lameris $T W$, de Zeeuw $S$, Alberts $G$, et al. Time course and mechanism of myocardial catecholamine release during transient ischemia in vivo. Circulation. 2000;101:2645-2650. 


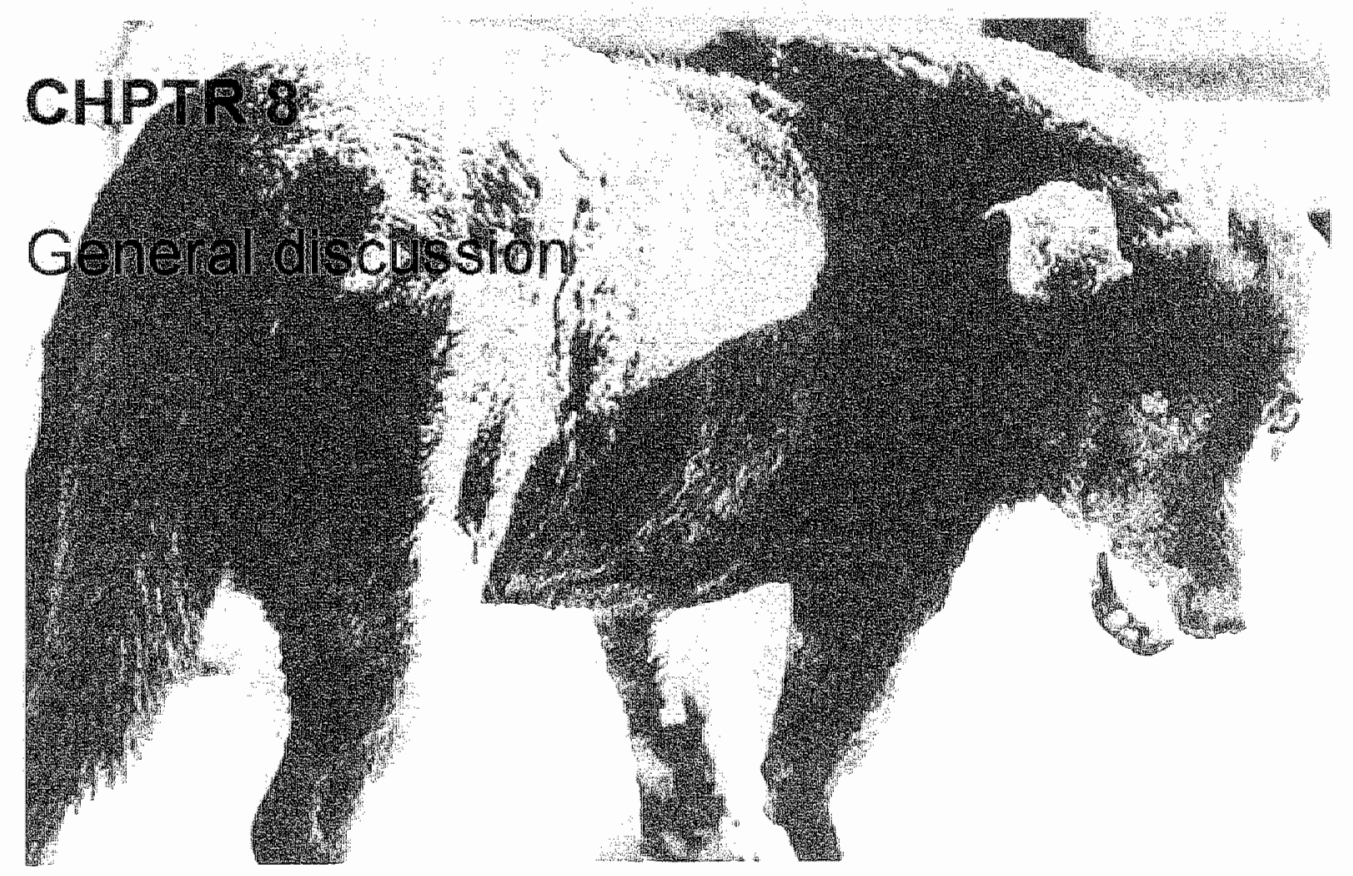




\section{Introduction}

It is a well known fact that spatial differences exist in the electrophysiologic build-up of the normal, healthy ventricular myocardium and that this heterogeneity is subject to change during ventricular remodeling, more specifically electrical remodeling. It is suggested that these changes in spatial heterogeneity (due to genetics and/or environment) are important predisposing factors for the occurrence of ventricular arrhythmias and in some cases sudden cardiac death. Therefore, the focus of this thesis has been to elucidate some of the molecular characteristics of the spatial heterogeneity in remodeled canine hearts compared to normal hearts, and to assess the temporal behavior of these changes in the CAVB dog. By comparing the molecular results with cellular electrophysiological data, an attempt has been made to integrate molecular information towards the function of an intact cell or organ. In order to do so, we developed a new and alternative approach for quantifying mRNA using kinetic real-time RT-PCR.

\section{Kinetic real-time RT-PCR}

Scrutinizing the standard quantification procedure (Chapters 3 and 4 ), we demonstrated that using the recommended standard curve-method can result in severe misinterpretations of steady state mRNA levels. Making use of the raw data output (fluorescence/cycle number) we have developed a new and assumption-free alternative quantification method (LinRegPCR), which we believe is to be preferred

Table 1. Summary of the differences in assumptions, method and statistical analysis between the standard curve and the linear regression method.

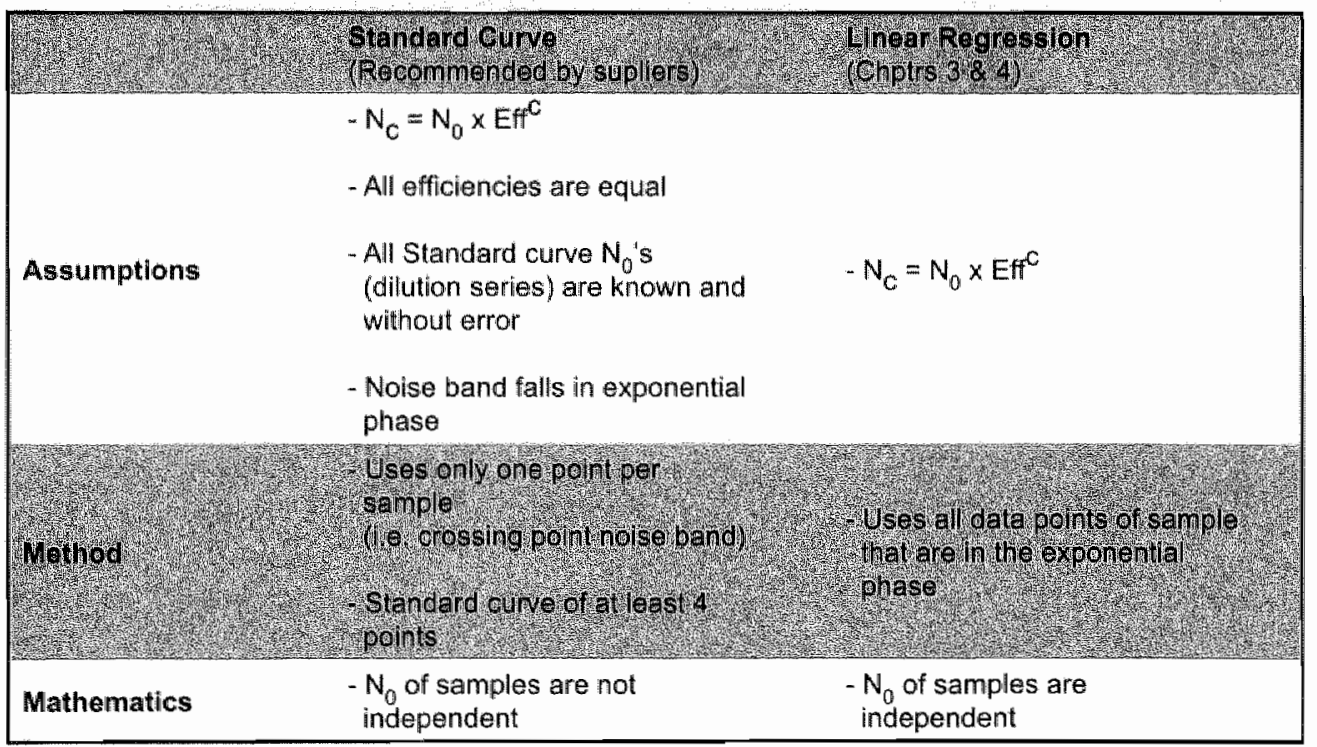


A

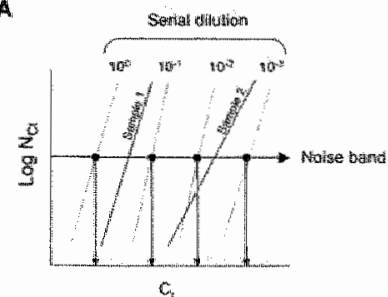

c

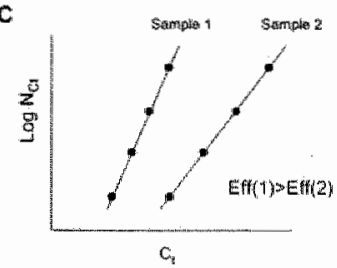

B

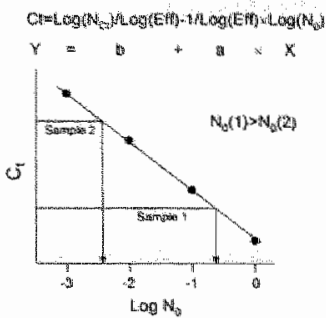

D

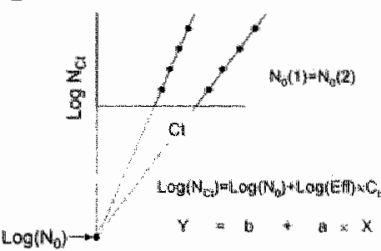

Figure 1. Schematic comparison for quantifying mRNA in kinetic real-time RT-PCR using the standard curve and the linear regression method. $(A, B)$ The standard curve method uses the crossing points of the serial dilutions (dotted lines. $40^{\circ}-10^{-3}$ ) with the noise band yield $C_{1}$ values (cycle numbers), which in combination with the dilutions (known $N_{0}$ values) are used to construct a standard curve. This standard curve is a linear relation between the $C_{1}$ values and the $L_{0} N_{0}$. For unknown samples (sample 1 and 2) similar $C_{\text {, }}$ values are obtained which in turn are used in the standard curve to determine the $N_{0}$ values. (C, D) The linear ragression method makes use of obtained dala points (fluorescence and cycle number) in the truly exponential phase of the PCR (e.g. Log-linear phase). Applying linear regression on these data points results in relative simple first degree relation $(Y=b+a X)$. The " $b$ " variable of each individual sample represents the $Y$-axis intercept $\left(\log \mathrm{N}_{0}\right)$ which can be transformed into an individual $\mathrm{N}_{0}$, value (10way). Note that in the standard curve method no corrections are made for differences in PCR efficiency. This in contrast to the linear regression method.

over the standard curve-method. The motivation for this point-of-view is summarized in table 1 and figure 1. The key-word in both summaries is "assumption", and most importantly: the assumption that all samples analyzed have the same PCR efficiency. We show that when this assumption is not met, quantification using the standard curve-method is unreliable and can not be used!

Based on our alternative approach, a Delphi-based software application has been made available for the calculation of starting concentrations (automatic request via: bioinfo@amc.uva.nl, subject: LinRegPCR). For using this application it is essential that data points (fluorescence and cycle numbers) from experiments are "exportable". It is therefore regrettable that with the introduction of some of the next-generation kinetic real-time PCR machines, this "export" option is going to be canceled as a result of Good Laboratory Practice guidelines. Not only does this reduce the kinetic real-time PCR into a "black box" experiment, there is the potential risk that folddifferences are misinterpreted.

\section{Regulation of ion channel genes}

As already mentioned in Chapter 1, the road from gene to function is bestrewn with multiple regulatory "stops" enabling a cell to react acute and chronically to changes 
In its milieu. Regarding the regulation of ion channels in adult cardiomyocytes, a lot is known about "acute" regulation, e.g. protein phosphorylation. This is in contrast to what is known about the more "chronic" regulation steps ${ }_{\text {" }}$ e.g. gene transcription and mRNA processing (1).

Multiple promoters of ion channels genes and even more putative binding sequences for transcription factors have been "characterized" (i.e. their DNA has been sequenced) in recent years. However, in most cases the actual regulatory potential of these supposed sequences remains to be investigated.

Unfortunately, many scientific contributions in the field of cardiac arrhythmias present mRNA quantification data (e.g. micro-array analysis, RNAse protection assay, kinetic real-time PCR, etc.), claiming that the observed changes are attributed to transcriptional regulation of the transcript. Quantifying mRNA using the above mentioned techniques provides information on the steady state mRNA level of the transcript, this being the net sum of transcription activity and mRNA stability of the transcript of interest. Both mechanisms were shown to be independently involved in the regulation of the KCND3 transcript (2). Treatment of neonatal rat cardiomyocytes with either Angiotensin II (ANG II) or Phenylephrine (both of which are able to induce a strong cardiac hypertrophic response) decreased the steady state mRNA level of KCND3. Interestingly, the ANG II-induced decrease was attributed to an increase in the KCND3 mRNA degradation, while the Phenylephrine-induced decrease was linked to a change in KCND3 promoter activity (2).

The mRNA data presented in this thesis all represent steady state mRNA levels, therefore we cannot distinguish between transcriptional regulation and changes in mRNA degradation rate. It might very well be that both mechanisms are involved in the remodeling process. Based on the transient increase in ANG II-plasma levels (maximal after 1 week AVB, thereafter slowly decreasing to its basal level) (3) there may be an important role for mRNA stability in the "sub-acute" stage of remodeling (acute - 1 week AVB), slowly transitioning to a more dominant role for gene transcription in the chronic AVB situation. Independent on how the transcripts are regulated, chapters 2,5 and 7 show that in CAVB, downregulation of the molecular correlates of ion channels influences the electrophysiological behavior of a cardiomyocyte, in vitro as well as in vivo.

\section{4. $I_{K s}$ Subunit downregulation}

Throughout this thesis the molecular correlates of the slow component of the delayed rectifier current $I_{\mathrm{Ks}^{\prime}}, \mathrm{KCNQ1}$ and $\mathrm{KCNE} 1$, have taken in a central role. The reason for this being that the $\mathrm{I}_{\mathrm{Ks}}$ current is an important contributor to ventricular heterogeneity (4-6), and more importantly, the current density is downregulated in both ventricles as a result of electrical remodeling in our CAVB dog model (7).

Chapter 2 confirms the interventricular difference in $I_{K_{S}}$ current density (RV $>L V$ ) in the normal healthy canine heart (6) by showing that the molecular correlates of the $I_{K s}$ channel KCNQ1 (mRNA and protein) and KCNE1 (protein) are more abundant in 
the RV compared to the LV. In addition both KCNQ1 and KCNE1 mRNA and protein are downregulated as a result of electrical remodeling, confirming the previously reported $\mathrm{I}_{\mathrm{Ks}}$ downregulation in CAVB dogs (7).

Comparing the changes in KCNQ1 and KCNE1 mRNA levels as a result of CAVB in different regions throughout the ventricles it is clear that the use of the adjective "coordinated" in the title of chapter 2 is not as obvious as we would have expected. Although the downregulation of the $\alpha$ subunit is consistent in all regions analyzed, $\beta$ subunit downregulation is only observed in the LV and RV anterior free wall and not in the ventricular septum (Chapter 5) or apical tip of the LV (Chapter 7).

In order to exclude a methodological explanation responsible for this observation, we determined the KCNQ1 and KCNE1 mRNA in the LV anterior free wall using kinetic real-time RT PCR as opposed to the Northern blot and multiplex competitive

Table 2. Overview showing the observed differences in steady state KCNE1 mRNA levels throughout the different chapters in this thesis in combination with the quantification method, tissue sampling and biopsy location.

\begin{tabular}{|c|c|c|c|c|}
\hline P & Chpre & Chpro & chpr 7 & Chptr 8 \\
\hline KCNQ1 MRNA & $\downarrow$ & $\downarrow$ & $\downarrow$ & $\downarrow$ \\
\hline KGNEI HRNA & 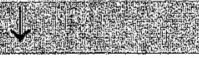 & $=$ & ren & 1 \\
\hline Quantification Method & $\begin{array}{l}\text { Northern blot, } \\
\text { MC PCR }\end{array}$ & Real-time PCR & Real-time PCR & Real-time PCR \\
\hline Tissue samping & $\begin{array}{l}\text { Transulial } \\
\text { homogenates }\end{array}$ & $\begin{array}{l}\text { Gells } \\
\text { hompgenates }\end{array}$ & 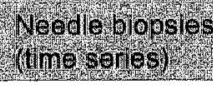 & 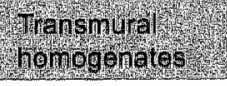 \\
\hline Biopsy location & LV free wall & $\begin{array}{l}\text { Left ventricular } \\
\text { septum }\end{array}$ & LV apex & LV free wall \\
\hline
\end{tabular}

RT-PCR used in chapter 2 . In table 2 we show that irrespective of the quantification technique used (Northern blot and multiplex competitive RT-PCR vs. kinetic realtime RT-PCR), KCNE1 mRNA levels in the anterior LV free wall are downregulated in CAVB dogs compared to control. Therefore we conclude that the discrepancy in KCNE1 mRNA distribution is most probably attributed to the different regions within the ventricles that were analyzed and not a result of different quantification techniques.

Multiple KVLQT1-MinK stoichiometry has been suggested to affect the kinetics of the $I_{\mathrm{Ks}}$ current (8). Based on the KCNE1 molecular data shown in table 2, it might very well be that next to subunit (down)regulation, differences in $I_{K s}$ subunit stoichiometry within different areas of the ventricles might affect the kinetic properties of the current, thereby increasing the heterogeneity in $\mathrm{I}_{\mathrm{K} 3}$ contribution to the ventricular repolarization in CAVB dogs. In view of the proposed role of MinK as a chaperone protein, protecting the KvLQT1 protein from degradation $((9,10)$, regional differences in KCNE1 mRNA might play a role in differences in $I_{K s}$ current density in the various 
regions of the ventricles. In light of this, our results on KCNE1 mRNA heterogeneity implies local control or local differences in the macro-molecular build-up of the $\mathrm{I}_{\mathrm{Ks}}$ ion chaninel.

\section{Local response to electrical remodeling}

Next to KCNQ1 and KCNE1, we also determined the CAVB-induced changes in steady state mRNA levels of other important ion channel subunits in the LV anterior free wall (Figure 2). Comparing these results with the results in chapter 6 (ventricular septum) and chapter 7 (LV apex), it is clear that there exists a large degree of subunit heterogeneity on the level of MRNA in the various regions of the ventricles (Table 3 ). Focusing on the whole LV, the most striking differences are seen between the LV anterior free wall and the left ventricular part of the ventricular septum (LVS). Of all ten quantified transcripts shown in table 3 , six show a differential response to ventricular remodeling in the LV anterior free wall and LVS (SCN5A, KCND3, CACNA1C, KCNE1, KCNH2, KCNJ2). Differences between the LV anterior free wall and the LV apex are less striking, with only the KCNE1 transcript showing a different response. Interestingly, while we were able to detect the KCNE2 transcript $\left(I_{\mathrm{Kr}} \beta\right.$ subunit) in the LVS, we could not detect (ND) the transcript in the LV anterior free wall using kinetic real-time RT-PCR! A possible explanation for this finding is the observation that KCNE2 is mainly expressed in the Purkinje fibers of the conduction system (11). In the LVS, and to a lesser extend the LV apex, the KCNE2 expressing cells of the left bundle branch are relatively well represented, this in contrast to the LV anterior free wall.

The observed heterogeneity in ion channel subunit distribution suggests heterogeneity in ventricular (e.g. electrical) remodeling. However, on the level of

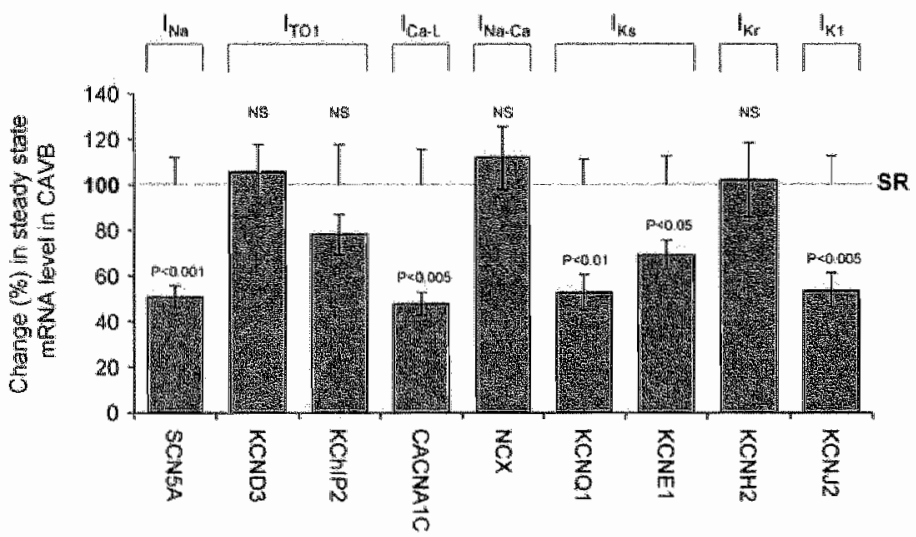

Filgure 2. Quantification overview of the important molecular correlates of ionic currents contributing to the ventricular action potential in the LV anterior free wall. The increase or decrease in steady state mRINA lewels as a result of CAVB is expressed rellative to the SR levels (100\%, dotted line). The average AVB was 65136 days. Significance was tested using a Man-Whitmey non-parametric test for 2 independent samples. 
Table 3. Summary of the changes in the steady state mRNA levels of ion channel subunits as a result of AvB in the different regions within the ventricles. LVS; left ventricular septum. FVS right wentricular septum, ND, not detected.

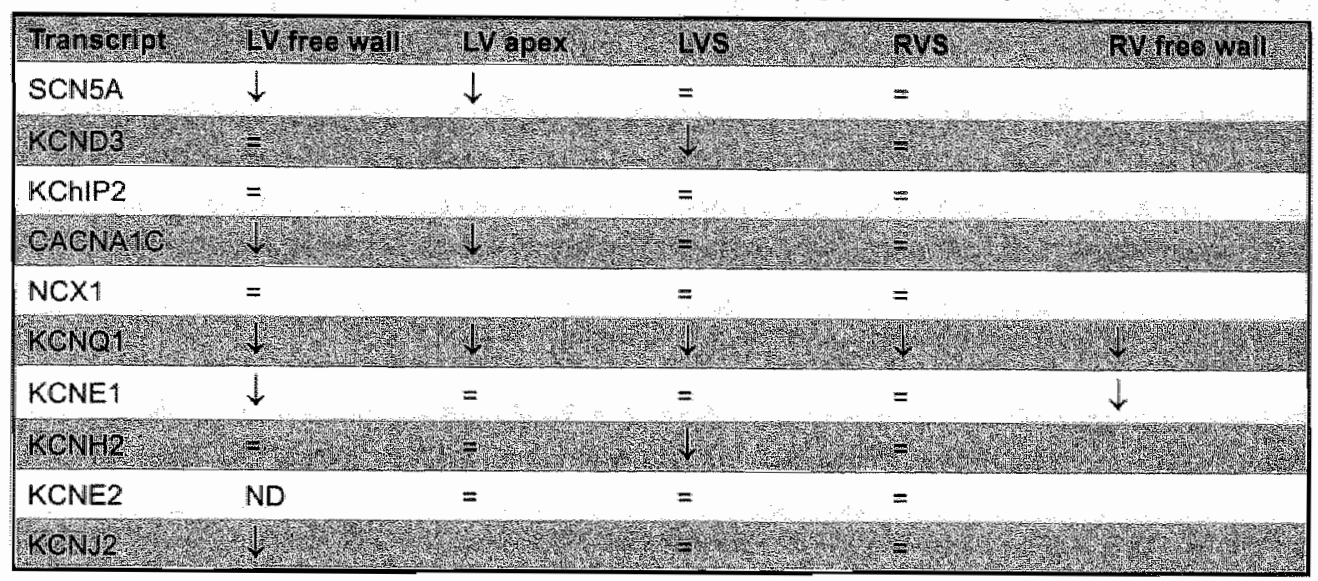

current density changes in CAVB, information on heterogeneity is rather scarce. Up until now, current densities of $I_{\mathrm{Ks}}, I_{\mathrm{Kr}^{\prime \prime}} \mathrm{I}_{\mathrm{TO}}, \mathrm{I}_{\mathrm{K} 1}(7), \mathrm{I}_{\mathrm{Na}-\mathrm{Ca}}$ and $\mathrm{I}_{\mathrm{Ca}-\mathrm{L}}(12)$ have only been measured in midmyocardial cells of the LV and RV anterior free wall, while $I_{\mathrm{Ks}}, I_{\mathrm{Kr}}$ and $I_{\mathrm{TO} 1}$ have been determined in the transmural LV anterior free wall (subepicardial-midmyocardial-subendocardial) (13). In the ventricular septum, only AP characteristics were determined (Chapter 6 ), which at most can be regarded as indicative for changes in (specific) current densities. Therefore, it remains to be investigated whether or not mRNA differences in ion channel subunit distribution within the different areas of the ventricles are also reflected at the level of current density. Although $I_{\mathrm{Ks}}$ (Chapter 2 ) and $I_{\text {TO } 1}(14)$ show perfect linearity between mRNA, protein and channel density, this has not been clarified for other ionic currents. For example in the rat heart, the relative high $\mathrm{KCNH} 2$ mRNA and protein levels do not correlate with the rather small $I_{\mathrm{Kr}}$ current density $(15,16)$. Similar, table 3 shows some inconsistencies regarding determined steady state mRNA levels and previously described current density levels. First, in CAVB dogs, Sipido et al. (12) reported a functional upregulation of the $\mathrm{I}_{\mathrm{Na}-\mathrm{Ca}^{3}}$ whereas the $\mathrm{Ca}^{2+}$ influx through the $I_{\text {cat }}$ was unchanged. On the level of mRNA expression, we show the opposite. For the NCX mRNA levels in the anterior LV free wall we show no change (note that this is in concordance with NCX protein levels (17)), while the level of CACNA1C mRNA ( $\alpha$-subunit of $\mathrm{I}_{\mathrm{Ca}-\mathrm{L}}$ ) was significantly lower in the anterior LV free wall, as well as in the LV apex. Similar, Volders et al. (7) observed no significant change in the current density level of $I_{\mathrm{kg}}$ in CAVB dogs, whereas we show that the molecular correlate $\mathrm{KCNJ} 2$ is significantly lower compared to control dogs.

It is therefore important to note that even when mRNA regulation (e.g. transcriptional regulation and/or mRNA degradation) is the primary regulated process, it will not be the sole influence on current density levels. For example, it might be that transcripts are alternatively spliced or that a regulatory step in the post-translational biosynthetic pathway (e.g. protein trafficking, glycosylation and/or phosphorylation) 
is rate limiting, or that an (unknown) component of the channel in question might be expressed at very low levels or even be missing in the tissue under investigation. Without dismissing the possibility that there might be a discrepancy between mRNA and current density levels, the observed changes in ion channel subunit mRNA heterogeneity due to CAVB are in line with other animal models undergoing cardiac remodeling, including humans $(18,19)$. As in all animal models of overload (i.e. pressure or volume), altered mechanical loading in the CAVB dog is believed to be the primary stimulus initiating the process of ventricular remodeling. Quantifying the mechanical overload in CAVB dogs, diastolic stress, diastolic strain, systolic strain and stroke work were shown to be all significantly increased at the myocardial level (20).

The relation between mechanical stimuli and electrophysiological changes has been investigated since the late 1960's (21). There is an intricate network of cytoskeletal and nucleoskeletal intermediate filaments physically linking the plasma membrane to the nuclear membrane (22) and it has been hypothesized that stretched-induced intermediate filament changes might be able to reconfigure the chromatin structure, thereby permitting the transcription of previously inactive genes (23). Following up on that, Furukawa et al. (24) have shown that the cytoplasmatic domain of the MinK protein (KCNE1) is able to bind with the C-terminal residues of the mechanicalstretch sensor protein Telethonin. Whether the binding of the $I_{\mathrm{Ks}} \beta$ subunit to the mechanical-stretch sensor machinery is able to regulate steady state KCNE1 mRNA levels is unknown, nonetheless it is an inviting hypothesis that regional differences in mechanical overload in CAVB could be held responsible for the heterogeneous expression pattern of KCNE1 and maybe other ion channel subunit mRNAs. This mechanical signal may be different for different regions in the heart (e.g. LVS vs. LV anterior free wall).

\section{Temporal mismatch between structural and electrical remodeling}

The association of ventricular hypertrophy and APD prolongation is a common finding in a number of animal models undergoing ventricular remodeling (25). Like the chicken-and-the-egg paradigm, it is unclear which of the two process instigates the development of the other. The majority of published evidence suggests that hypertrophy is needed for electrical remodeling (26). However, there are studies claiming the opposite (27-29). For example, Kassiri et al. (28) reported that APD prolongation (as a result of specific $\|_{\text {TO1 }}$ channel blockade or dominant negative transgene expression) caused hypertrophy in cultured neonatal rat ventricular myocytes via a $\mathrm{Ca}^{2+} / \mathrm{calcineurin}$ dependent pathway. Similarly, two independent studies showed that in a rat LV myocardial infarction model, electrical remodeling preceded structural remodeling upon left coronary artery ligation $(27,29)$.

On the macroscopic level, all three aspects of the ventricular remodeling in CAVB dogs have a characteristic time course. Structural remodeling gradually progresses until 16 weeks of AVB (17). This in contrast to electrical remodeling, which is already 
completed after 2 weeks of AVB, remaining stable thereafter (16 weeks AVB). Similar to electrical remodeling, contractile remodeling is already completed after 2 weeks of $A V B$, being stable up until 6 weeks of AVB, thereafter slowly declining to its basal level after 10 weeks of AVB (30). In parallel to the above mentioned studies (27-29), we show in chapter 5 that the development of electrical remodeling preceded structural remodeling, suggesting that in CAVB dogs hypertrophy is not a requirement for electrical remodeling. For our CAVB model this is in line with the observation that ventricular pacing is able to regress the structural remodeling while no reverse electrical remodeling is observed (17).

Although Chapter 5 shows that Irbesartan does not prevent structural remodeling, indicating that Angiotensin II Type 1 receptor (AT1)-blockade is not dominantly involved in the development of the structural remodeling process, the dynamic changes in the ACE and Chymase expression pattern as a result of CAVB suggests a switch in the local formation of Angiotensin II (ANG II) from ACE to Chymase (Chapter 5). Increased expression of ACE mRNA is a consistent finding in failing hearts in a number of species, including dogs and humans (31-34). In some studies, this increase in ACE mRNA expression is even accompanied by a decrease in Chymase expression $(32,34)$. In contrast to the above mentioned studies we show a decrease in ACE mRNA and an increase in Chymase mRNA in CAVB dogs. This observation suggests a link between the compensated nature of the ventricular hypertrophy and a switch from ACE to Chymase for the conversion of ANG I in ANG II. In addition to generating ANG II, ACE also catalyzes the degradation of cardioprotective peptide bradykinin, with more favorable kinetics for the hydrolysis of bradykinin than for the formation of ANG II (35). This implies that next to ANG IIformation, another non-ANG II related activity of ACE might be an important factor in the deterioration to heart failure.

\section{Temporal behavior of ion channel subunit mRNA levels upon AVB}

Chapter 5 already showed the temporal mismatch between electrical and structural remodeling in CAVB dogs, with electrical remodeling already completed after 2 weeks of AVB. Following up on this, chapter 7 shows the temporal expression pattern (SR, 3, 8 and 30 days of AVB) of the $I_{K s}$ molecular correlates (KCNQ1 and KCNE1) in combination with the temporal changes in steady state MRNA levels of the $\beta 1$ and $\beta 2$ adrenergic receptors in the LV apex. In imitation of this, Figure 3 shows the steady state mRNA levels of four other ion channel subunits in time: A)

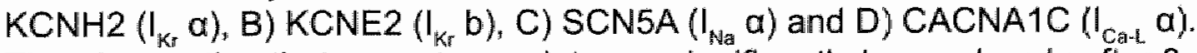

The observation that some transcripts are significantly lower already after 3 days of AVB ( -2 to -3 fold drop in KCNQ1 (Chapter 7 ), KCNH2 and CACNA1C steady state $m \mathbb{R N A}$ levels) suggests that the process of electrical remodeling is initiated quickly upon creation of AVB. B1 adrenergiic receptor (Chapter 7), KCNE2 and SCN5A MRNA levels decreased more gradual, becoming significant after 8 (KCNE2 and SCN5A) or 30 days of AVB ( $\beta 1$ adrenergic receptor). For KCNQ1, CACNA1C and 
SCN5A this lower mRNA level was maintained after 30 days of AVB. Interestingly, upon the initial decrease in steady state mRNA levels, KCNH2 and KCNE2 levels slowly increased, returning to their basal SR level after 30 days of AVB. However, the mechanism behind this $\mathrm{I}_{\mathrm{Kr}}$ subunit "recovery" remains to be investigated.

In conclusion, the results from chapter 7 and figure 3 show that based on the mRNA levels of ion channel subunits, "signs" of electrical remodeling are already present after 3 days of AVB, but based on $Q T_{c}$ and APD values, electrical remodeling is only fully matured after 2 weeks of AVB (Chapter 5 ), remaining stable thereafter.
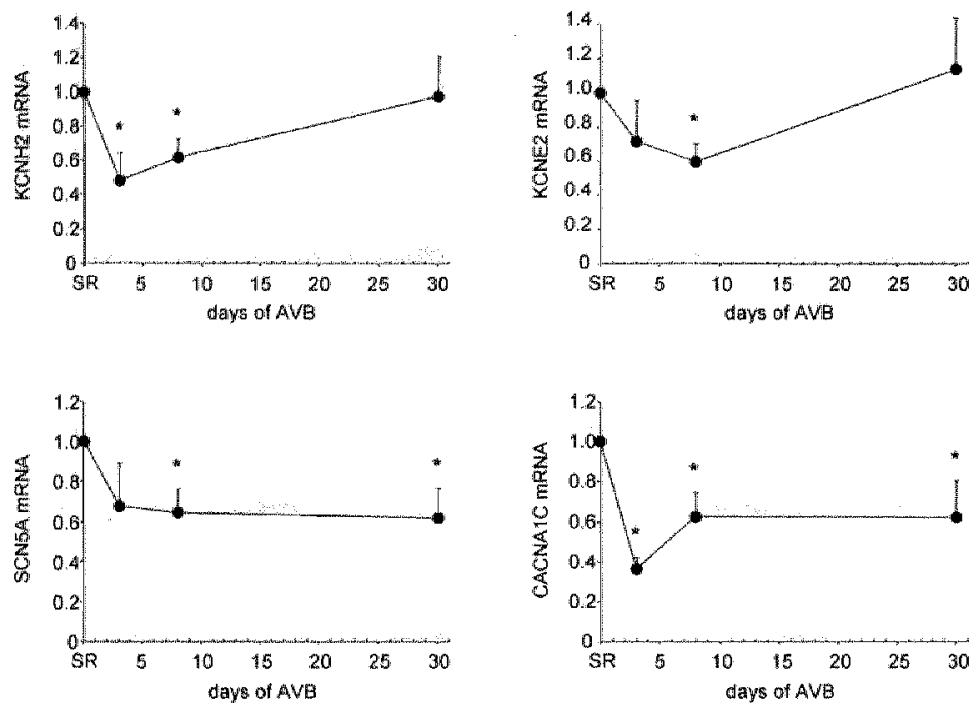

Figure 3. Time course of $\mathrm{mRNA}$ expression of $\mathrm{KCNH2}$ (A), KCNE2 (B), SCN5A

(C) and CACNA1C (D) after induction of AVB (at 3,8 , and 30 days of AVB)." $p<0.05$ vs. SR.

\section{Clinical implications of $\mathrm{I}_{\mathrm{Ks}}$ downregulation}

One of the important findings in this thesis has been the concordant downregulation of the $I_{K s}$ molecular correlates KCNQ1 and the $I_{K s}$ current density due electrical remodelling as a result of AV block. This downregulation of the $I_{K \mathrm{~s}}$ current contributes to a prolongation of the AP and increases the dependence on the $I_{\mathrm{kr}}$ current for late repolarization. The decreased repolarization reserve increases the sensitivity of AP to prolongation due to pharmacological $I_{K_{r}}$ blockade, thereby predisposing dogs to TdP arrhythmias.

In the past there has been a lot of discussion on the relevance of the $I_{\mathrm{Ks}}$ current to the late repolarization of the ventricular AP. However by now it is generally accepted that $I_{K g^{s}}$ in the presence of an in vivo $\beta$ adrenergic stimulus, contributes greatly to the late repolarization of the AP in the intact heart. Additional support for an important role for $I_{K s}$ in ventricular repolarization comes from the congenital Long QT syndrome where the LQT1 and LQT5 subtypes are caused by mutations in the $I_{\mathrm{Ks}} \alpha$-and $\beta$ subunits, respectively. 
Like in all animal models, changes resulting from (electrical) remodelling are indicative for the human situation and it often remains to be seen if results can be extrapolated (this applies in particular to the smaller animal models like mice and rats, and to a lesser extend to larger animal models). In that respect information on ionic current changes in failing human hearts is rather scarce. This is of course mainly attributed to the limited availability of explanted human transplant recipient hearts.

In 1993, Beuckelmann and co-workers (36) reported a decrease in the transient outward current $I_{\text {TO }}$ and the inward rectifier current $I_{\mathrm{K} 1}$ in explanted diseased ventricles, using normal undiseased donor hearts as control. Surprisingly, in their study they only detected a very low level of the delayed rectifier current $I_{k}$, which did not differ between the two groups. More recently in a similar study, the group of Stanley Nattel (37) confirmed the $\mathrm{I}_{\mathrm{TO} 1}$ and $\mathrm{I}_{\mathrm{K} 1}$ current downregulation in diseased human ventricular cells. Converse to the Beuckelmann paper however they also showed a significant decrease in $I_{k s}$ current density.

The results from the latter study (37) are in close agreement with our findings in chapter 2. These combined results further strengthen the correlation between prolonged repolarization (i.e. a substrate for proarrhythmia) and $\mathrm{I}_{\mathrm{Ks}}$ current density downregulation in humans as well as dogs.

\section{Implications for future research}

This thesis has been the start of the molecular characterization of the ventricular, more specifically, electrical remodeling process in CAVB dogs. While large animal models (e.g. dogs) are of great value when trying to extrapolate the on-going (electro)-physiological processes during ventricular remodeling in these models to humans, they are not so obvious as candidates when molecular mechanisms have to be studied. Disadvantages are the inability to create (dog) transgenics, the lack of molecular species-specific tools (e.g. monocional antibodies, BACS, microarrays, etc.) and the limited group sizes (i.e. cost-related and ethical). Having said this, this does not mean that nothing can be done to elucidate some of the deeper mechanisms involved in the electrical remodeling process.

Pharmacological intervention trying to reverse or attenuate the detrimental consequences of chronic cardiac remodeling is of great importance for patient treatment. In that respect the use of (large) animal models is crucial. Over the last decades, the CAVB model has been used to test numerous pharmacological agents on their arrhythmogenic potential or on their potential to reverse electrical remodeling. Up until now, in these trials only (electro)-physiological parameters have been measured. Through the advent of the (fashionable) micro-array approach (which in the near future will also become available for the various tissues in dogs), clues on the underlying molecular mechanisms can be obtained, and ideally pathways can 
be revealed that are involved in the remodeling process. With reproducibility being the Achilles heel of the micro-array technique one has to decide how to approach this. Ideally, isolated cardiomyocytes are used, with the isolated batch being split into an untreated and treated dish. Upon incubation with the pharmacological agent, (electro)-physiological parameters are measured after which the cells are collected for micro-array analysis. However, incubation time in combination with the longevity of the isolated cardiomyocytes will be a problem in this highly in vitro approach. With the in vivo approach, care has to be taken to reduce population heterogeneity to a minimum. In that respect the best way to go is to use dogs with a similar genetic background, ideally using purpose bread dogs from the same litter.

\section{References}

1. Rosati B, McKinnon D. Regulation of ion channel expression. Circ Res 2004;94(7):874-83.

2. Zhang TT, Takimoto $K$, Stewart AF, Zhu C, Levitan ES. Independent regulation of cardiac Kv4.3 potassium channel expression by angiotensin $\mathrm{II}$ and phenylephrine. Circ Res 2001;88(5):476-82.

3. Vos MA, de Groot SH, Verduyn SC, van der Zande J, Leunissen HD, Cleutjens $\mathrm{JP}$, et al. Enhanced susceptibility for acquired torsade de pointes arrhythmias in the dog with chronic, complete AV block is related to cardiac hypertrophy and electrical remodeling. Circulation 1998;98(11):1125-35.

4. Cheng J, Kamiya K, Liu W, Tsuji Y, Toyama J, Kodama I. Heterogeneous distribution of the two components of delayed rectifier $\mathrm{K}+$ current: a potential mechanism of the proarrhythmic effects of methanesulfonanilideclass III agents. Cardiovasc Res 1999;43(1):135-47.

5. Liu DW, Antzelevitch $\mathrm{C}$. Characteristics of the delayed rectifier current (IKr and IKs) in canine ventricular epicardial, midmyocardial, and endocardial myocytes. A weaker IKs contributes to the longer action potential of the $\mathrm{M}$ cell. Circ Res 1995;76(3):351-65.

6. Volders PG, Sipido KR, Carmeliet E, Spatjens RL, Wellens HJ, Vos MA. Repolarizing $\mathrm{K}+$ currents ITO1 and IKs are larger in right than left canine ventricular midmyocardium. Circulation 1999;99(2):206-10.

7. Volders PG, Sipido KR, Vos MA, Spatjens RL, Leunissen JD, Carmeliet $E$, et al. Downregulation of delayed rectifier $\mathrm{K}(+)$ currents in dogs with chronic complete atrioventricular block and acquired torsades de pointes. Circulation 1999;100(24):2455-61. 
8. Wang W, Xia J, Kass RS. MinK-KVLQT1 fusion proteins, evidence for multiple stoichiometries of the assembled IsK channel. J Biol Chem 1998;273(51):34069-74.

9. Barhanin J, Lesage F, Guillemare $E$, Fink M, Lazdunski M, Romey $G$. $\mathrm{K}(\mathrm{V}) \mathrm{LQT1}$ and IsK (minK) proteins associate to form the I(Ks) cardiac potassium current. Nature 1996;384(6604):78-80.

10. Sanguinetti MC, Curran ME, Zou A, Shen J, Spector PS, Atkinson DL, al. Coassembly of $\mathrm{K}(\mathrm{V}) \mathrm{LQT} 1$ and minK (IsK) proteins to form cardiac I(Ks) potassium channel. Nature 1996;384(6604):80-3.

11. Pourrier M, Zicha S, Ehrlich J, Han W, Nattel S. Canine ventricular KCNE2 expression resides predominantly in Purkinje fibers. Circ Res 2003:93(3):189.91.

12. Sipido KR, Volders $P G$, de Groot $S H$, Verdonck $F$, Van de Werf F, Wellens $\mathrm{HJ}$, et al. Enhanced $\mathrm{Ca}(2+)$ release and $\mathrm{Na} / \mathrm{Ca}$ exchange activity in hypertrophied canine ventricular myocytes: potential link between contractile adaptation and arrhythmogenesis. Circulation 2000;102(17):2137-44.

13. Thomas GP, Vos MA, Antzelevitch C. The Effect of Volume Overioad Hypertrophy on Transmural Distribution of the Delayed Rectifer (Kr and $\mathrm{Ks}$ ) and Transient Outward (Ito) Currents in the Heart. PACE 2001;24(11):597.

14. Rosati B, Grau F, Rodriguez S, Li H, Nerbonne JM, McKinnon D. Concordant expression of KChIP2 mRNA, protein and transient outward current throughout the canine ventricle. J Physiol 2003;548(Pt 3):815-22.

15. Pond AL, Scheve BK, Benedict AT, Petrecca K, Van Wagoner DR, Shrier A, et al. Expression of distinct ERG proteins in rat, mouse, and human heart. Relation to functional $\|(\mathrm{Kr})$ channels. J Biol Chem 2000;275(8):5997 6006.

16. Wymore RS, Gintant GA, Wymore RT, Dixon JE, McKinnon D, Cohen IS. Tissue and species distribution of mRNA for the IKr-like K+ channel, erg. Circ Res $1997 ; 80(2): 261-8$.

17. Peschar M. Reverse remodeling in bradycardia induced volume overload: the role of optimizing the pacing site. PhD Thesis 2003.

18. Gomez AM, Benitah JP, Henzel D, Vinet A, Lorente P, Delgado C. Modulation of electrical heterogeneity by compensated hypertrophy in rat left ventricle. Am J Physiol 1997;272(3 Pt 2):H1078-86.

19. Nerbonne JM, Guo W. Heterogeneous expression of voltage-gated potassium channels in the heart: roles in normal excitation and arrhythmias. I Cardiovasc Electrophysiol 2002;13(4):406-9. 
20. Donker DW, Volders PGA, Borgers M, Vos MA, Arts T. Increases of systolic fiber strain and end-diastolic fiber stress are the primary local mechanical changes in chronic heart block. Eur Heart J 2004:25:555.

21. Lab MJ. Mechanoelectric feedback (transduction) in heart: concepts and implications. Cardiovasc Res 1996;32(1):3-14.

22. Miller $M K_{n}$ Granzier $H$, Ehler $E$, Gregorio $C C$. The sensitive giant: the role of titin-based stretch sensing complexes in the heart. Trends Cell Biol 2004;14(3):11926.

23. Bloom S, Lockard VG, Bloom M. Intermediate filament-mediated stretchinduced changes in chromatin: a hypothesis for growth initiation in cardiac myocytes. $\mathrm{J}$ Mol Cell Cardiol 1996;28(10):2123-7.

24. Furukawa $T$, Ono $Y$, Tsuchiya $H$, Katayama $Y$, Bang $M L$, Labeit $D$, et al. Specific interaction of the potassium channel beta-subunit minK with the sarcomeric protein T-cap suggests a T-tubule-myofibril linking system. J Mol Biol 2001;313(4):775-84.

25. Tomaselli GF, Marban E. Electrophysiological remodeling in hypertrophy and heart failure. Cardiovasc Res 1999;42(2):270-83.

26. Swynghedauw B. Molecular mechanisms of myocardial remodeling. Physiol Rev 1999;79(1):215-62.

27. Huang $B$, Qin D, El-Sherif $N$. Early down-regulation of $K+$ channel genes and currents in the postinfarction heart. J Cardiovasc Electrophysiol 2000;11(11):125261.

28. Kassiri Z, Zobel C, Nguyen TT, Molkentin JD, Backx PH. Reduction of I(to) causes hypertrophy in neonatal rat ventricular myocytes. Circ Res 2002;90(5):57885.

29. Perrier E, Kerfant BG, Lalevee N, Bideaux P, Rossier MF, Richard S, et al. Mineralocorticoid receptor antagonism prevents the electrical remodeling that precedes cellular hypertrophy after myocardial infarction. Circulation 2004;110(7):776-83.

30. Schoenmakers M. Ventricular remodeling and arrhythmogenisis in the canine heart: focus on prevention. PhD Thesis 2004.

31. Barlucchi $L$, Leri $A$, Dostal DE, Fiordaliso F, Tada $H$, Hintze $T H$, et all. Canine ventricular myocytes possess a renin-angiotensin system that is upregulated with heart failure. Circ Res 2001;88(3):298-304. 
32. Lee $\mathrm{YA}_{*}$, Liang $\mathrm{CS}$, Lee MA, Lindpaintner $\mathrm{K}$. Local stress, not systemic factors, regulate gene expression of the cardiac renin-angiotensin system in vivo: a comprehensive study of all its components in the dog. Proc Natl Acad Sci U S A 1996;93(20):11035-40.

33. Studer R, Reinecke $H$, Muller $B$, Holtz J, Just $H$, Drexler $H$. Increased angiotensin-l converting enzyme gene expression in the failing human heart. Quantification by competitive RNA polymerase chain reaction. J Clin Invest 1994;94(1):301-10.

34. Su X, Wei CC, Machida N, Bishop SP, Hankes $G_{H}$, Dillon RA, et al. Differential expression of angiotensin-converting enzyme and chymase in dogs with chronic mitral regurgitation. J Mol Cell Cardiol 1999;31(5):1033-45.

35. Margolius HS. Kallikreins and kinins. Molecular characteristics and cellular and tissue responses. Diabetes 1996;45 Suppl 1:S14-9.

36. Beuckelmann DJ, Nabauer M, Erdmann E. Alteration of $\mathrm{K}+$ currents in isolated human ventricular myocytes from patients with terminal heart failure. Circ Res 1993;73(2):379-385.

37. Li GR, Sun H, Feng J, Nattel S. Ionic mechanisms of the action potential prolongation in failing human and ventricular cells. PACE 1998b; $21: 877$

38. Ramakers $C$, de Lange FJ, Soufan A, van der Wal S, Derksen $P$, Koopman T, Postma A, Hoogaars W, Horsthuis T, van den Berg G, de Rooy L, Bezzina C, van Engelshoven R, Fijnvandraat $A$, Wakker $V$, Koehorst R, Cassini $S$, Thomsen $M$, Schoenmakers $M$, Kruithof $B$, de Julio $M$, Antoons $G$, van der Weele $P, B o o g e r d ~ K J$, Houweling $A$, Laghetto $L$, van Paassen $H$. Working as a PhD student in Maastricht and Amsterdam: from medical science to outstanding social events. Dutch Proc for Belgium Ambulance Personal 2005; 4(5):1-480. 



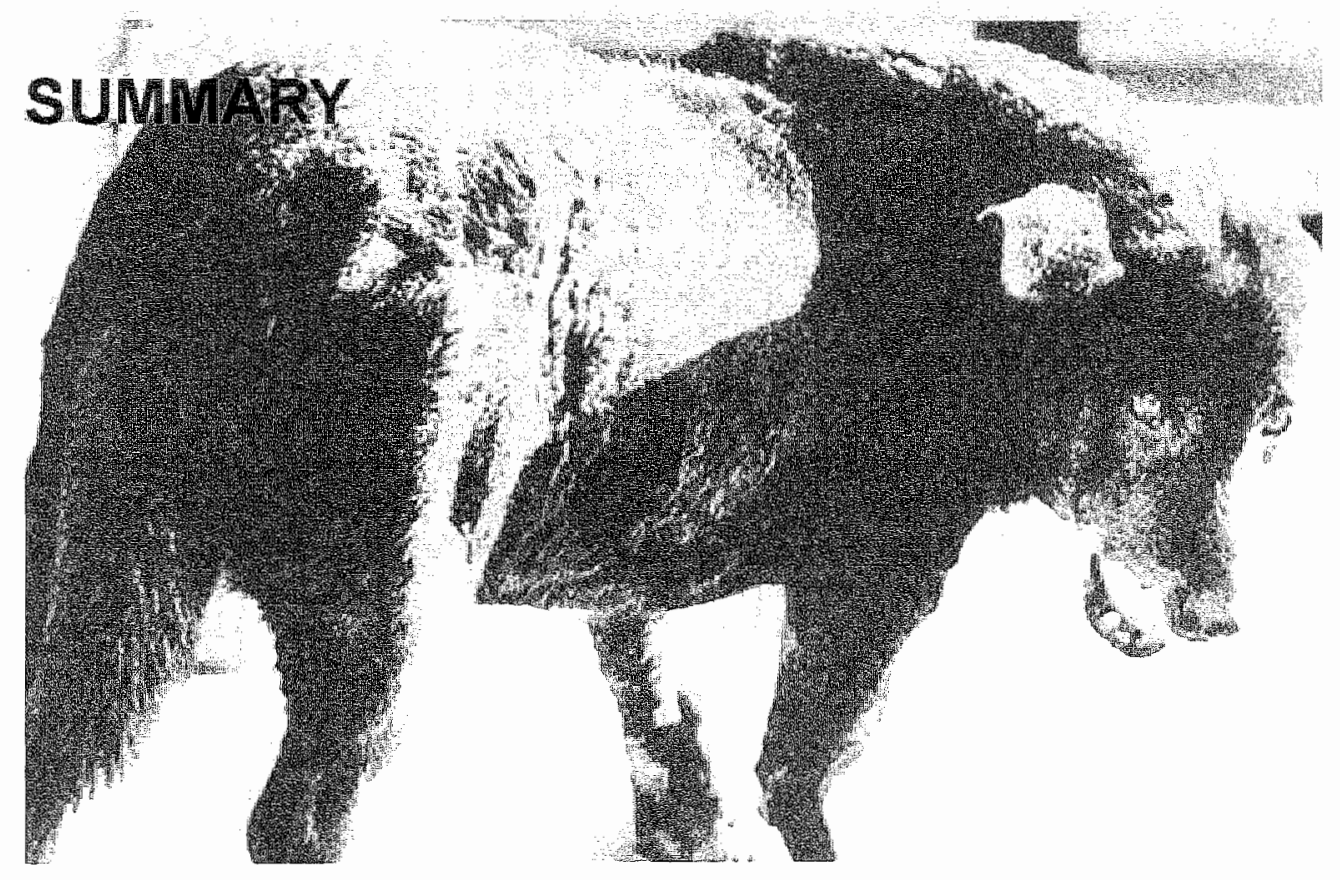


The "intrinsic" electrical heterogeneity of cardiomyocytes within the normal healthy heart is essential for a proper and optimal function of the heart. It is therefore not surprising that changes in this "heterogeneity" can be very deleterious for the overall function of the heart. In this context cardiac arrhythmias are often considered to be the final event leading to sudden cardiac death, independent of the cause of impairment. Next to beat-to-beat variation, the prolongation of the QT time seen on an electro-cardiogram is an important "indicator" for the possible occurrence of an arrhythmic event, like Torsade de Pointes. This prolongation can be caused by changes in the density of ion channels in the cell membrane of cardiomyocytes. This process of electrophysiological change is commonly referred to as electrical remodeling.

The use of large animal models with changed cardiac electrical phenotypes similar to the ones seen in the human population is essential to get more insight in the cellular mechanisms underlying the process of electrical remodeling. In this context the canine model with chronic complete atrio-ventricular block (CAVB) has proven to be of great value. While in the last decades this model has been extensively studied on the level of in vivo and in vitro (electro)-physiology, the molecular characterization of the remodeling process is not well described. This thesis is the first, hopefully in a series of many, to touch upon some of the molecular aspects of the CAVB-induced electrical remodeling process.

With chapter 1 being the general introduction to the subject, the electrical heterogeneity of the various regions within the heart are discussed in relation to the differences in action potential morphology. Next, the molecular correlates of all important ion channel subunits involved in shaping the ventricular action potential are covered with a link to the congenital and acquired long QT syndrome (LQTS). The CAVB dog is introduced as an animal model undergoing ventricular remodeling. Special attention is given to the process of electrical remodeling and the inhomogeneous lengthening of the AP duration. Finally, chapter 1 ends with the theoretical backgrounds of two PCR based quantification methods used in the following chapters: competitive multiplex RT-PCR and kinetic real-time RT-PCR.

Throughout the chapters different approaches to quantify mRNA are used. While chapter 2 uses a combination of Northern blotting and competitive multiplex RT$P C R$, the results presented in chapters 5 through 8 make use of the more reliable kinetic real-time RT-PCR approach. Because it is the prime directive for any scientist to fully understand a technique before using it, we scrutinized the mathematics behind the recommended approach of quantification in kinetic real-time RT-PCR. In doing so we found that the most basic assumption on which this so-called "standard curve" approach relies (i.e. all samples analyzed have the same PCR efficiency). is not always met, thereby resulting in possible misinterpretations of mRNA levels. Therefore, in chapters 3 and $\mathbf{4}$ we introduce a new and assumption-free method for quantifying mRNA in kinetic real-time RT-PCR without using a standard curve. Our approach makes use of the exponential mathematics in the early phases of the PCR. Through simple linearization of this exponential relation and linear regression on the 
log-linear data points the $y$-axis intercept (representing the begin concentration of the amplicon of interest) is calculated.

In light of the ventricular heterogeneity, interventricular ( $L V$ vs. RV) differences have been reported for $\mathrm{I}_{\mathrm{KS}}$ and $\mathrm{I}_{\text {TO, }}$, both showing larger current densities in cells originating from the midmyocardium of the RV compared to cells from the LV midmyocardium. On the molecular level, chapter 2 shows that this difference is explained by higher steady state mRNA and protein levels of KCNQ1 and KCNE1 in the RV for $\|_{K s}$ (Chapter 2) and a higher KChIP2 mRNA level in the RV for IO1 (Chapter 6).

With a clear link between the previously reported decrease in $I_{k s}$ current density and AP prolongation, Chapter 2 also demonstrates that the reported $50 \%$ downregulation of the $I_{K_{s}}$ current finds it regulatory origin in lower steady state mRNA levels of the $I_{K s}$ channel subunits KCNQ1 and KCNE1, indicating either regulation of gene transcription, a change in mRNA stability or both. Furthermore, we speculate on an additional translational regulatory step, since there is a discrepancy between downregulated $\mathrm{mRNA}$ and protein levels.

Chapter 6 covers the molecular and electrical heterogeneity in the (under exposed) ventricular septum of SR as well CAVB dogs. Scrutinizing the VS of SR dogs we show that, like other regions in the ventricles, the VS is molecularly and electrically heterogeneous. Furthermore, in the CAVB dog this septal heterogeneity becomes accentuated as a result of electrical remodeling. Finally, chapter 6 speculates on the ventricular septum being composed out of parts with characteristics form both ventricles.

Next to electrical remodeling, CAVB also results in a biventricular hypertrophy (structural remodeling). In contrast to the generally accepted idea that hypertrophy is needed for electrical remodeling, we show in chapter 5 that both processes develop asynchronously and that structural remodeling is not a prerequisite for electrical remodeling. Furthermore chapter 5 indicates that the blockade of the AT1 receptor by Irbesartan has no dominant role in the completion of the ventricular remodeling processes.

It is a well known fact that $I_{\mathrm{Ks}}$ depends heavily on adrenergic stimulation. Chapter 7 discusses the time dependency of the concordant downregulation of KCNQ1, KCNE1 and $\mathrm{I}_{\mathrm{Ks}}$ in combination with changes in plasma level catecholamines (epinephrine, norepinephrine) and mRNA levels of the $\beta$-adrenergic receptors 1, 2 and 3 upon creation of AVB. The acute downregulation of the KCNQ1 mRNA (aiready after 3 days of AVB) contrasts the only gradual increase in QT upon AVB. This discrepancy is explained by the fact that norepinephrine levels are transiently elevated (between acute $A V B$ and 10 days of $A V B$ ) thereby maintaining a "pseudonormal" $I_{\mathrm{Ks}}$ current level. Combined, these results indirectly confirm the strong dependence of the $I_{\mathrm{Ks}}$ current on $\beta$-adrenergic stimulation. Only after the waning of norepinephrine levels (>10 days AVB) and the additional gradual downregulation of $\beta 1$-adrenergic receptors the $\mathrm{QT}_{G}$ finally becomes prolonged, thereby predisposing CAVB dogs to TdP arrhythmias.

Finally, in chapter 8 the temporal and spatial aspects of the process of ventricular remodeling in CAVB dogs which have been the basis of this thesis are discussed in broader perspective. In conclusion we can say that the (molecular) process of 
electrical remodeling is very dynamic. Not only are there interesting temporal aspects (e.g. chapter 5: electrical vs. structural remodeling; chapter 7, figure 1: the acute vs. more gradual decrease in KCNQ1 and $\beta 1$-adrenergic receptor mRNA, respectively), the changed spatial heterogeneity (chapter 8 , table 3 ) also raises questions. 


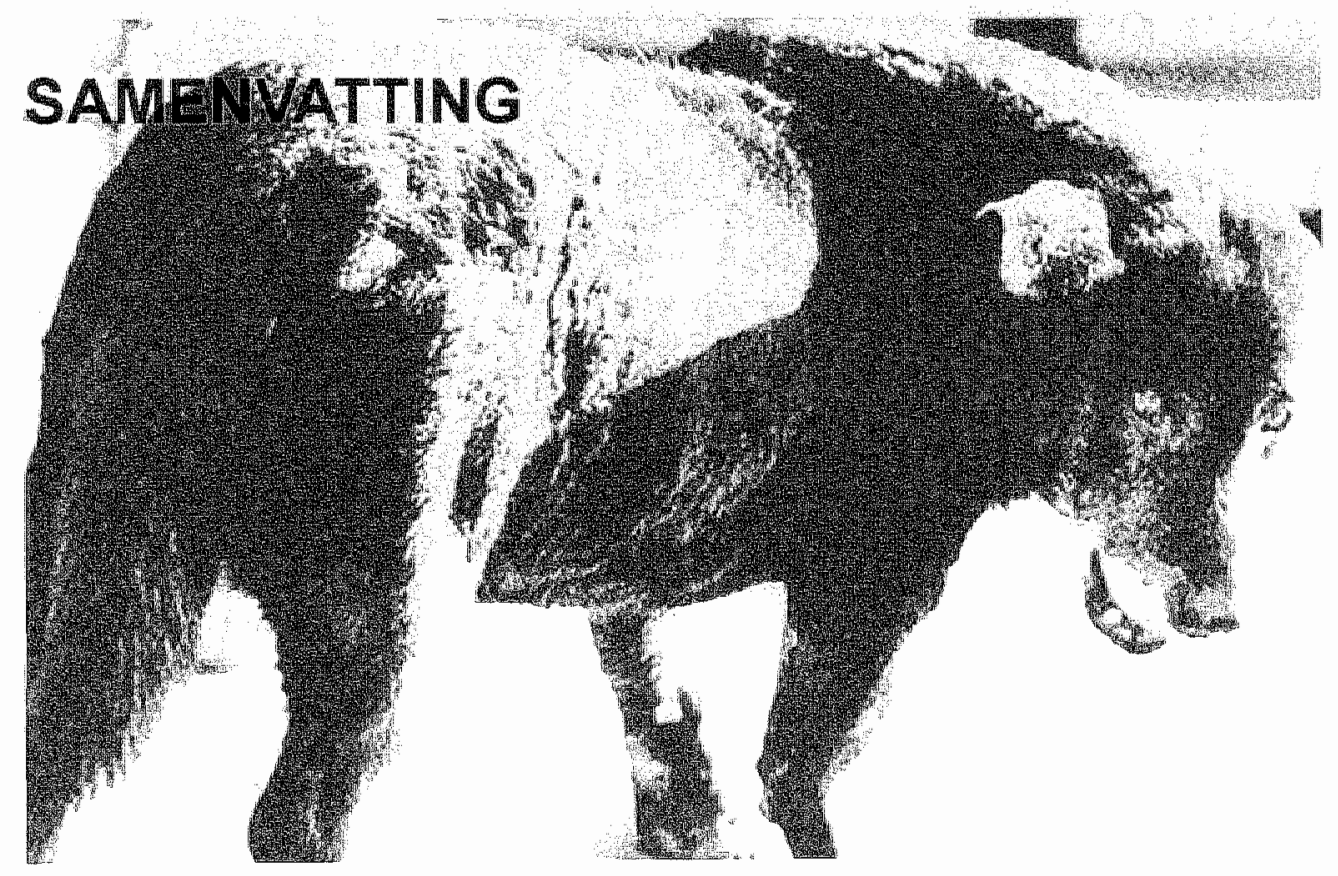


Elektrische heterogeniteit in de verschillende soorten hartspiercellen is essentieel voor het optimaal functioneren van het gezonde hart. Het is daarom dan ook niet verbazingwekkend dat veranderingen in deze heterogeniteit kunnen leiden tot hartfalen. In de context van hartfalen worden hartritmestoornissen vaak beschouwd als het eindpunt van een chronisch proces dat uiteindelijk kan leiden tot plotse hartdood. Een belangrijke indicator voor het mogelijk optreden van hartritmestoornissen die door de cardioloog kan worden afgelezen op een elektrocardiogram is een verlengde QT tijd. Deze QT tijd verlenging kan o.a. worden veroorzaakt door een verandering van het aantal ionkanalen (ionkanaaldensiteit) in de celmembraan van een hartspiercel. Het proces dat ten grondslag ligt aan deze verandering wordt ook wel elektrische remodelering genoemd.

Om een beter inzicht te krijgen in de remodeleringsprocessen zoals die zich voordoen in patiënten met hartklachten wordt vaak gebruik gemaakt van grote proefdiermodellen, zoals varkens, geiten of honden. Een voorbeeld hiervan is de hond met een chronische compleet atrio-ventriculair blok (CAVB). Terwijl de elektro-fysiologische processen in dit model de afgelopen decennia uitvoerig zijn beschreven, is de moleculair biologische beschrijving van het remodeleringsproces zwaar onderbelicht gebleven. Dit proefschrift is daarom ook een eerste stap, hopelijk in een serie van velen, die de moleculair biologische veranderingen van de CAVBgeïnduceerde remodelering beschrijft.

Hoofdstuk 1 begint als "zovele hoofdstukken 1" met een algemene introductie. Verschillen in actiepotentiaalmorfologie en -duur in de verschillende regio"s van het hart worden in de context van elektrische heterogeniteit geplaatst. Vervolgens worden de moleculaire componenten van ionkanalen die betrokken zijn bij de ventrikulaire actiepotentiaal behandeld en wordt er een link gelegd met de aangeboren (congenitale) en verworven vormen van het lange QT syndroom (LQTS). De CAVB hond wordt geïntroduceerd als een proefdiermodel waarbij ventriculaire remodelering kan worden bestudeerd. Binnen dit model wordt in hoofdstuk 1 speciale aandlacht besteed aan thet proces van elektrische remodelering en de niet-homogene verlenging van de actiepotentiaalduur. Ook worden in het kader van het bepalen van MRNA expressie niveaus de achtergronden van twee op PCR gebaseerde mRNA kwantificatie methoden besproken: de competitieve multiplex RT-PCR methode en de kinetische real-time RT-PCR methode.

In de verschillende hoofdstukken worden verschillende methodes gebruikt voor het kwantificeren van mRNA niveaus. In hoofdstuk 2 wordt een combinatie van Northern blotting en competitieve multiplex RT-PCR gebruikt, terwijl in de hoofdstukken 5, 6, 7 en 8 de nieuwe en meer betrouwbare kinetische real-time RT-PCR methode wordt gebruikt. Omdat het van essentieel belang is dat een onderzoeker een methode weet te doorgronden alvorens deze te gebruiken, worden in hoofdstukken 3 en $\mathbf{4}$ de theoretische en wiskundige aspecten van de kinetische real-time RT-PCR methode belicht. Een belangrijk aspect bij de aanbevolen kwantificatie methode met behulp van een zogenaamde standaard curve is de aanname dat de efficiëntie van de PCR voor ieder monster dat wordt geanalyseerd gelijk is. Deze aanname is echter niet 
altijd valide en kan dientengevolge leiden tot een grove onder- of overschatting van de mRNA niveaus. Om de "gelijke efficiëntie" aanname te omzeillen wordt in hoofdstuk 3 en 4 een nieuwe methode besproken voor het kwantificeren van kinetische real-time RT-PCR data. Deze zogenaamde "lineaire regressie" methode maakt het mogelijk om met de ruwe data output van ieder afzonderlijk monster de mRNA niveaus te bepalen zonder gebruik te maken van de standaard curve.

Interventriculaire heterogeniteit (LV vs. RV) is al beschreven op het niveau van de $I_{K s}$ en $I_{T O 1}$ stromen. Vergeleken met de linker kamer is de dichtheid van beide stromen groter in cellen van de mid-myocardiale regio van de rechter kamer. Voor de $I_{\mathrm{Ks}}$ stroom wordt in hoofdstuk 2 de moleculaire basis van dit interventriculaire beschreven in dat de moleculaire componenten KCNQ1 en KCNE1 van het $I_{K s}$ kanaal beide meer tot expressie komen in de rechter kamer. Voor de $I_{\text {TO1 }}$ stroom wordt in hoofdstuk 6 een hogere expressie in de rechter kamer voor de $\mathrm{I}_{\text {To1 }} \beta$ component KChIP2 beschreven.

Naast de concordantie in $I_{\mathrm{Ks}}$ expressie (mRNA - eiwit - stroom) met betrekking tot de interventriculaire verschillen in controle honden wordt in hoofdstuk 2 ook de $50 \% I_{\mathrm{Ks}}$ stroom afname ten gevolge van elektrische remodelering in CAVB honden verklaart: zowel KCNQ1 als KCNE1 laten een afname in expressie zien waardoor er een afname in kanaaldensiteit ontstaat.

Hoofdstuk 6 gaat verder met ventriculaire heterogeniteit en beschrijft de moleculaire en elektrische heterogeniteit in het ventriculaire septum. Net zoals in ander gebieden in de hartkamers is er ook een "intrinsieke" heterogeniteit in het ventrikulaire septum van controle honden. In CAVB honden wordt deze heterogeniteit versterkt onder invloed van elektrische remodelering. Hoofdstuk 6 eindigt door te speculeren over de opmaak van net ventrikulaire septum. In tegenstelling tot wat in het verleden is beschreven wijzen de resultaten uit hoofdstuk $6 \mathrm{er}$ op dat het septum bestaat uit twee delen: een deel met rechter kamer eigenschappen en een deel met linker kamer eigenschappen.

Naast elektrische remodelering wordt de CAVB hond ook gekenmerkt door een hypertrofie van beide kamers (biventrikulaire hypertrofie t.g.v. structurele remodelering). In tegenstelling tot het algemeen geaccepteerde beeld dat hypertrofie een vereiste is voor het optreden van elektrische remodelering, laat hoofdstuk 5 zien dat beide processen zich asynchroon ontwikkelen. Terwijl elektrische remodelering reeds na twee weken is voltooid, duurt het 5 weken voordat de hypertrofie ten volste is ontwikkeld. Verder laat hoofdstuk 5 zien dat het blokkeren van de angiotensine II receptor type 1 met behulp van Irbesartan geen invloed heeft de voltooiing van het ventrikulaire remodelering proces.

Het is alom bekent dat de $I_{\mathrm{Ks}}$ stroom sterk afhankelijk is van adrenerge stimulatie. In hoofdstuk 7 wordt de tijdsafhankelijkheid van KCNQ1, KCNE1, I ${ }_{\mathrm{Ks}}$ stroom afname en $\mathrm{QT}_{\mathrm{c}}$ tijd toename besproken in relatie tot de veranderingen in bloedplasma epinefrine, norepinefrine spiegels en mRNA niveaus van $\beta$-adrenerge receptoren 1,2 en 3 na AVB. De acute afname van KCNQ1 mRNA (na 3 dagen AVB) staat in contrast met de maar geleidelijke toename in $Q T_{c}$ tijd na AVB. Deze discrepantie wordt verklaart door het feit dat de norepinefrine plasmaspiegel tijdelijk is verhoogt (tussen acuut en 10 dagen AVB) waardoor een pseudonormaal $I_{\mathrm{Ks}}$ stroom niveau 
wordt gehandhaafd. De $Q T_{c}$ tijd begint pas te verlengen wanneer de norepinefrine spiegel weer zakt naar zijn normale niveau in combinatie met een graduele afname in $\beta 1$-adrenerge receptoren.

Tot slot worden in hoofdstuk 8 worden de temporele en spatiele aspecten van elektrische remodelering in CAVB honden die de basis vormen van dit proefschrift in een breder verband bediscussieerd. Concluderend kunnen we stellen dat de (moleculair) biologische processen die gepaard gaan met elektrische remodelering erg dynamisch zijn. Naast de interessante temporele bevindingen (bijv. hoofdstuk 5: elektrische vs. structurele remodelering; hoofdstuk 7, figuur 1: acute vs. graduele afname in KCNQ1 en $\beta 1$-adrenerge receptor, respectievelijk), zijn de moleculaire veranderingen in spatiele heterogeniteit op zijn zachtst gezegd verassend. Met name de discrepanties tussen de linker kant van het ventrikulaire septum en de linker kamer vrije wand (hoofdstuk 8, tabel 3 ) nodigen uit tot verder onderzoek. 


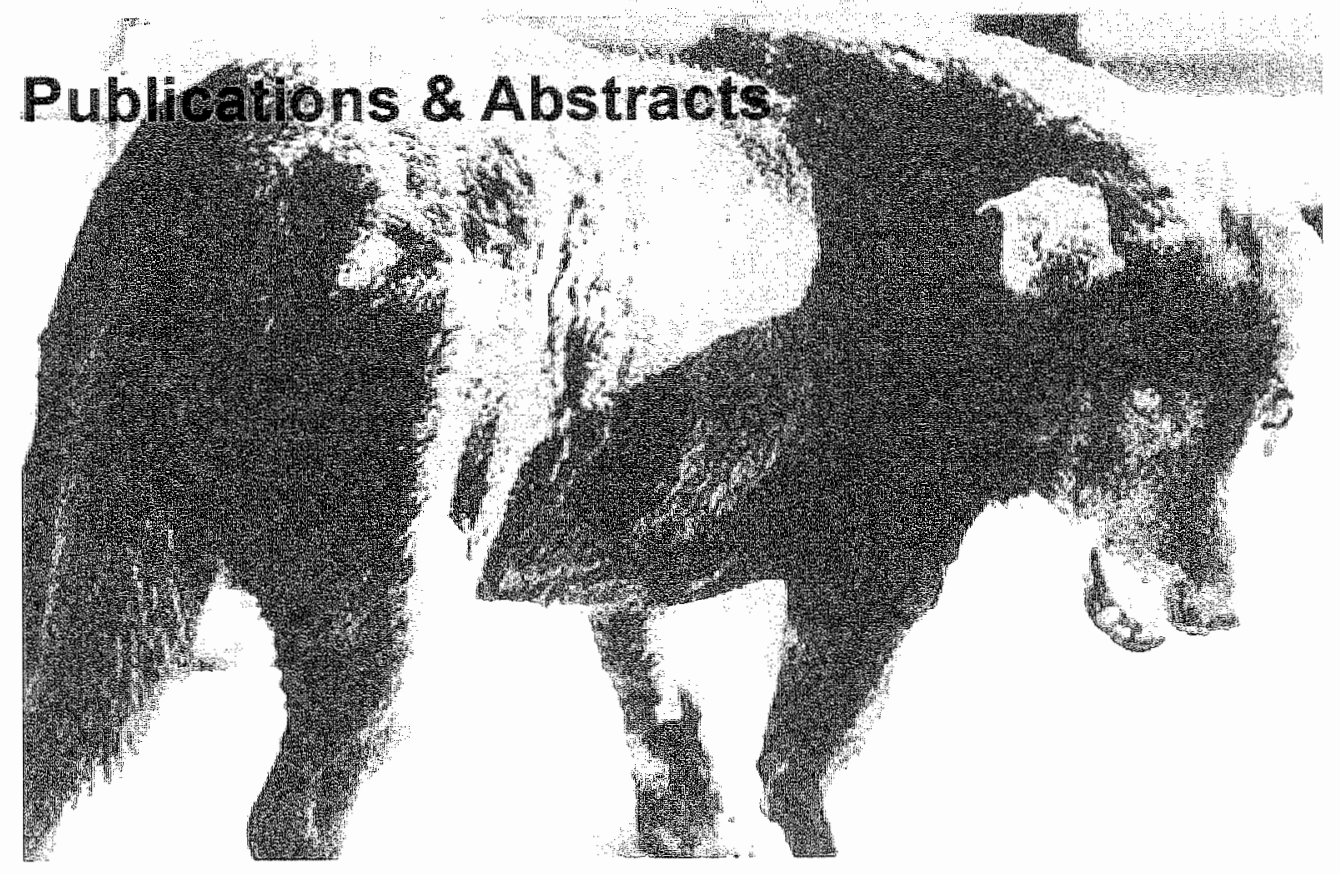




\section{PUBLICATIONS}

Verduyn SC, Ramakers C, Snoep G, Leunissen JD, Wellens HJ, Vos MA. Time course of structural adaptations in chronic AV block dogs: evidence for differential ventricular remodeling.

Am J Physiol Heart Circ Physiol, 2001 Jun; 280 (6): H2882-2890.

Ramakers C, Vos MA, Doevendans PA, Schoenmakers M, Wu YS, Scicchitano S, lodice A, Thomas GP, Antzelevitch C, Dumaine R. Coordinated down-regulation of KCNQ1 and KCNE1 expression contributes to reduction of $\mathrm{l}(\mathrm{Ks})$ in canine hypertrophied hearts.

Cardiovasc Res. 2003 Feb; 57 (2): 486-496.

Ramakers C, Ruijter JM, Deprez RH, Moorman AFM. Assumption-free analysis of quantitative real-time polymerase chain reaction (PCR) data.

Neurosci Lett. 2003 Mar 13; 339 (1): 62-66.

Schoenmakers M, Ramakers C, van Opstal JM, Leunissen JD, Londono C, Vos MA. Asynchronous development of electrical remodeling and cardiac hypertrophy in the complete AV block dog.

Cardiovasc Res. 2003 Aug 1; 59 (2): 351-359.

Ramakers C, Timmer D, Bakker O, Lekanne Deprez RH, Ruijter JM, Moorman AFM. Quantification of mRNA using linear regression of Log-linear PCR data-points as an alternative for the standard curve approach.

In: Rapid Cycle Real Time PCR - Methods and Applications: Quantification. 2004 Dec: Eds: Wittwer C, Hahn M, Kaul K. Springer-Verlag Berlin and Heidelberg.

Ramakers C, Stengl M, Spätjens RLHMG, Moorman AFM, Vos MA. Molecular and electrical characterization of the canine cardiac ventricular septum.

J Mol Cell Cardiol. 2005 Jan 1: 153-161.

Stengl M, Ramakers C, Nabar A, Donker DW, Spätjens RLHMG, van der Nagel T, Wodzig KWH, Sipido KR, Moorman AFM, Vos MA, Volders PGA. I Ko $_{\mathrm{s}}$ Downregulation and Blunted B-Adrenergic Activation in Canine Ventricular Remodeling Confer the Loss of B-Adrenergic-Induced Shortening of Repolarization, Favoring Proarrhythmia.

Submitted for publication. 


\section{ABSTRACTS}

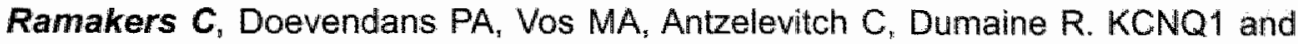
KCNE1 expression is reduced in dogs with chronic AV block.

Biophysical Society. New Orleans, January 2000.

Ramakers C, Dumaine R, Doevendans PA, Antzelevitch C, Vos MA. Both KCNQ1 and $\mathrm{KCNE} 1$ expression is reduced in dogs with chronic AV block.

European Society of Cardiology. Amsterdam, August 2000.

Vos MA, van Opstal JM, Verduyn SC, Leunissen JD, Ramakers C, Doevendans $P$, Dumaine R, Antzelevitch C, Volders $P_{n}$ Sipido K. Electrophysiological and molecular aspects of drug induced Torsade de Pointes (TdP).

World conference on clinical pharmacology and therapeutics. Florence, July 2000: 27.

Ramakers C, Vos MA, Doevendans PA, Schoenmakers M, Wu YS, Scicchitano S, lodice A, Thomas GA, Antzelevitch C, Dumaine R. Downregulation of KCNQ1 and KCNE1 contributes to reduction of IKs in canine hypertrophied hearts.

Molecular pathology of cardiac arrhythmias, Keystone Symposium. Santa Fe, January 2003.

Stengl M, Ramakers $C$, Nabar A, Donker DW, Vos MA, Volders PG. IKs downregulation in canine ventricular hypertrophy confers the loss of $B$-adrenergicinduced shortening of repolarization, favoring proarrhythmia (abstract).

American Heart Association. Circulation. 2004; 110 (suppl III): III-319-1II-320.

Ramakers C, Stengl M, Spätjens RLHMG, Moorman AFM, Vos MA. Molecular and electrical composition of the canine cardiac ventricular septum.

Netherlands Heart Journal, Volume 12, Supplement 3, December 2004 



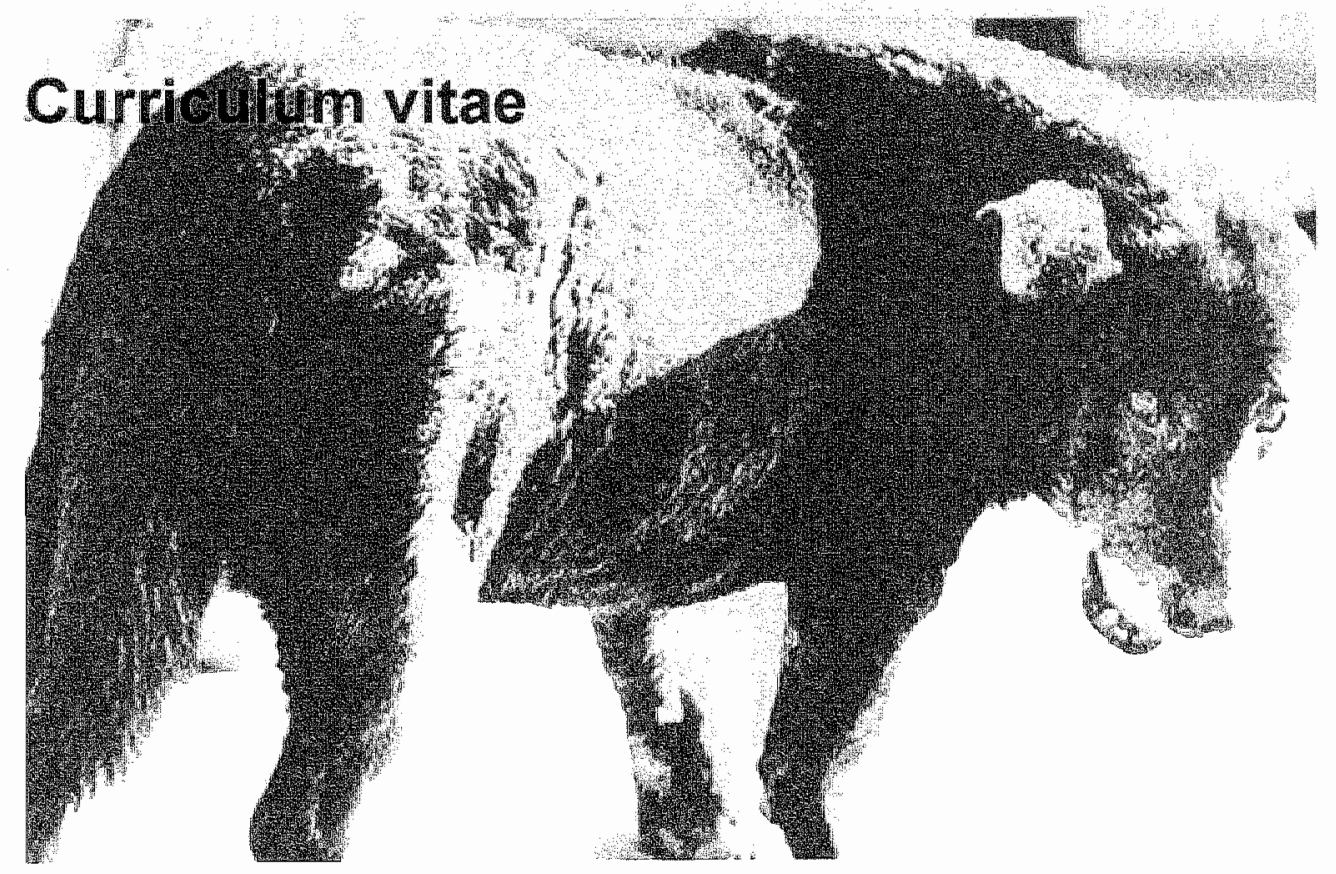


Christian Ramakers werd geboren op 20 april 1973 te Maastricht als zoon van Anita Leenders en Andre Ramakers. Na een mislukte CITO toets op de lagere school ging hij met lood in zijn schoenen naar de Christelijke MAVO Maria Imaculata te Maastricht alwaar hij in 1989 zijn diploma behaalde. Na 3 jaar te hebben doorgebracht op de Middelbare Laboratorium School te Sittard vond de 18 jarige Christian het tijd om het ouderlijke huis te verlaten en op avontuur te gaan naar Arnhem, met als resultaat dat hij in 1996 zijn HBO diploma Laboratoriumtechniek behaalde aan de Internationale Agrarische Hogeschool Larenstein te Velp. Nog steeds niet uitgestudeerd schreef hij zich in voor de opleiding Biologie aan de toenmalige Katholieke Universiteit Nijmegen. Zijn wetenschapsstage bracht hij deels door in het Masonic Medical Research Laboratory te Utica, New York, waar hij de basis legde voor zijn eerste wetenschappelijke publicatie. Na het behalen van zijn examen Medische Biologie in 1999 begon Christian in februari 2000 aan zijn promotieonderzoek, beschreven in dit proefschrift, bij de afdeling Cardiologie van de Universiteit Maastricht. Bij dit onderzoek werd hij begeleid door Prof. Dr. Marc Vos en Prof. Dr. Antoon Moorman. Het onderzoek werd voor een groot deel uitgevoerd bij de afdeling Anatomie en Embryologie in het Academische Medisch Centrum van de Universiteit van Amsterdam. Sinds december 2004 werkt hij als postdoc bij de afdeling Medische Fysiologie van het UMC Utrecht. 


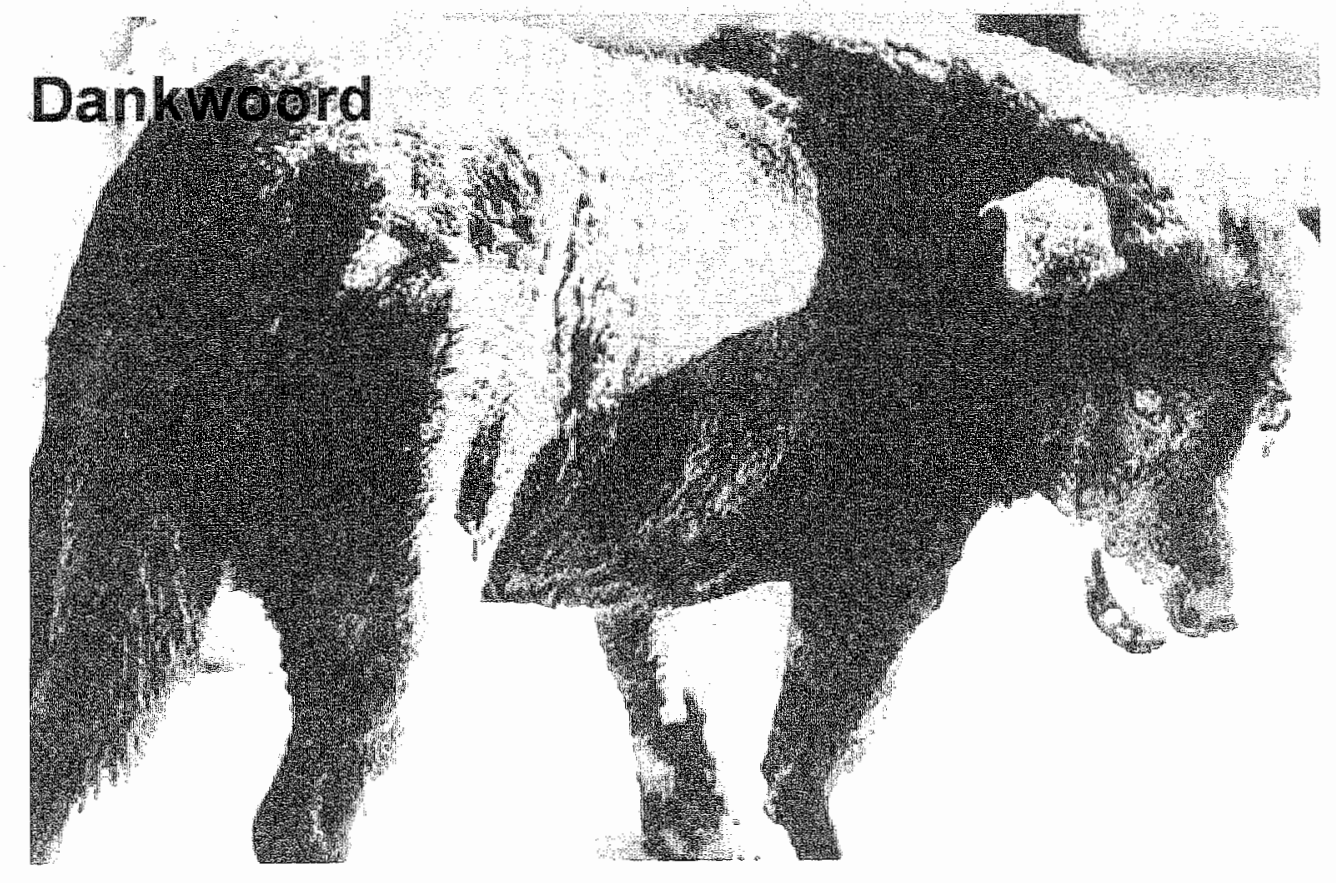


In tegenstelling tot vele andere proefschriften wordt dit een kort dankwoord. Ik ben namelijk de mening aangedaan dat het beter is om iedereen in zijn algemeenheid te bedanken en daardoor niemand te vergeten dan iedereen persoonlijk te bedanken met de kans liemand te vergeten. Dus bij deze: ledereen wordt bedankt! Uiteraard ontkom ik er niet aan om een paar mensen wel persoonlijk te bedanken...

Prof. Dr. M.A. Vos, beste Marc, als mijn primaire "broodheer" en eindverantwoordelijke ben jij natuurlijk als eerste aan de beurt. Ondanks het feit dat ik mijn tijd voor een groot deel in Amsterdam heb doorgebracht ben je er toch in geslaagd mij op zo'n manier te begeleiden dat dit boekje redelijk tot goed gevuld is met artikelen. Jouw min of meer "financiële onafhankelijkheid" in dit basale vakgebied is vrijwel uniek en zeker bewonderenswaardig. Hierdoor creëer je niet alleen een grote paraplu waaronder AlO's "hun eigen ding" mogen doen, je stimuleert ze ook tot het nemen van hun eigen verantwoordelijkheden. Ik wens je veel succes toe met je nieuwe uitdaging, en als je ooit in het "stijve, doch correcte" gebied boven de grote rivieren een een Belgische bierbrouwerij wil beginnen, kun je me altijd bellen. Bedankt! Prof. Dr. A.F.M. Moorman, beste Antoon, ook jij hebt een serieuze bijdrage geleverd aan het tot stand komen van dit proefschrift. Jouw "open-deur-policy" heb ik altijd kunnen waarderen en je was nooit te beroerd om "effe snel" (sorry simane) wat resultaten door te nemen. De wijze waarop je de afdeling Anatomie \& Embryologie leidt verdient heel veel respect en ik kan oprecht zeggen dat ik nog nooit op zo'n goed gestructureerd, gezellig en professioneel (ok, niet altijd helemaal professioneel) lab heb gewerkt (alleen die ochtendbesprekingen en progress reports om half negen vond ik niks!!!!).

Ook wil ik de leden van de beoordelingscommissie, Prof. Daemen, Prof. Crijns, Prof. de Bakker, Prof. Doevendans en Prof. Allessie, bedanken voor hun bereid heid om het manuscript kritisch door te lezen en tijdens de verdediging te opponeren.

Mijn paranimfen, Frederik - Brezthian Frodsj- de Lange en Alexandre -Aas Deus ex mandinaal-Soufan wil ik bedanken voor hun voor hun excellente vouwkunsten (folding 500 invitations is a biatch) en de organisatie rondom mijn promotie.

Als laatste wil ik natuurlijk mijn ouders bedanken voor de steun die ik, eigenlijk al sinds mijn geboorte ;-), heb gekregen. Papa en Mama, wij weten als niemand anders dat moeilijke tijden komen en gaan (relativeren is een must!) en het feit dat ik dit proefschrift aan Eric opdraag zegt voor ons drieen al genoeg..... 